\title{
AN INVESTIGATION OF INTERCULTURAL TEACHING AND LEARNING IN TERTIARY EFL CLASSROOMS IN VIETNAM
}

By

Ho Si Thang Kiet

\begin{abstract}
A thesis
submitted to the Victoria University of Wellington in fulfilment of the requirements for the degree of Doctor of Philosophy in Applied Linguistics
\end{abstract}

Victoria University of Wellington 


\section{ACKNOWLEDGEMENTS}

First and foremost, I would like to express my profound gratitude to my supervisors, Dr. Jonathan Newton and Prof. Janet Holmes, for their invaluable guidance, insightful feedback, continuous support and encouragement for my thesis, especially during the difficult moments on my Ph.D. journey. Without my supervisors, I would not have been able to complete this study.

My sincere thanks go to the School of Linguistics and Applied Language Studies for providing me with a friendly and professional research environment. I would like to thank all the staff of the School, particularly Associate Professor Paul Warren, Dr. John Macalister, Dr. Peter Gu, Dr. Jean Parkinson, Dr. Elaine Vine, Dr. Alastair Ker, Dr. Angela Joe, Bernie Hambleton, Sarah Dunstan and Anna Adams for their support.

My deep appreciation goes to Dr. Alvino Fantini for sending me his updated Assessment of Intercultural Competence Form for my study. I am also grateful to Dr. Dalice Sim, Dr. Dennis Dawson, and Dr. Dinh Quang Khieu for their statistics assistance. I thank Claudia Finkbeiner, Kirsten Reid and Deborah Laurs for their helpful advice. I also thank all the Vietnamese teachers and students participating in my study for their valuable data. My special thanks go to Dr. Patrick Coelho and Dr. Parrill Stribling for their proofreading of my thesis.

I would like to thank NZAID for awarding me a scholarship to do my Ph.D. study for three and a half years in New Zealand. I wish to thank Bridget Nankivell, Inge De Leeuw, and Julia Harrison from NZAID for their kind assistance. I also thank the Faculty of Humanities and Social Sciences for awarding me research grants to conduct fieldwork in my home country and present papers at many conferences in New Zealand.

I am also grateful to Dr. Averil Coxhead and Dr. David Hirsh for their great support for the publication of a part of my study in the University of Sydney Papers in TESOL.

Finally, I thank all my colleagues in the Ph.D. group and especially my friends Lorry, Richard, Tim, Hai, Liza, Natalia, Le, Khieu, Bao Trang, Patrick and Doan Ha for their friendship and kindness. I also thank my family in Vietnam for their love. 


\begin{abstract}
Intercultural competence has become an important goal of foreign language education in response to the need for learners to function effectively in an increasingly multicultural world. Language and culture are seen as interwoven and inseparable components and therefore learning a foreign language inevitably means learning about other ways of being and behaving. Many foreign language programmes around the world, particularly in North America, Europe, Australia and New Zealand, have adopted an intercultural pedagogy which seeks to integrate into the language teaching experience opportunities for developing intercultural competence for language learners. This study investigates intercultural teaching and learning in tertiary EFL classrooms in Vietnam, a context in which intercultural approaches to language teaching and learning have not been widely considered.

The study consisted of three phases. The first phase involved a curriculum review in which I critically evaluated the extent to which culture and culture learning are represented in the curriculum frameworks for tertiary EFL programmes and in the national education policy on foreign language education in Vietnam. The findings showed that the importance of culture and culture learning is not emphasised, and the designation of culture to separate culture courses establishes a separate status, construct and treatment of culture and culture learning in the EFL programmes.

In the second phase of the study, I analysed the perceptions of fourteen Vietnamese EFL teachers and two hundred Vietnamese EFL students on culture in language teaching and learning, and their classroom practices. The findings indicated that the teachers' beliefs about culture teaching revealed a predictable priority for teaching language rather than culture. Their culture teaching practices were greatly influenced by their perceptions and beliefs regarding culture in language teaching. The students also treated culture as a subordinate priority in language learning. Overall, they found culture learning beneficial for their language learning and supported the teachability of language and culture in EFL classes. Both the teachers and students identified a number of constraints that restricted their opportunities and motivation to engage in teaching and learning culture.
\end{abstract}

The third phase of the study involved an empirical study investigating the effect of adopting an intercultural stance in English speaking lessons on the 
development of the learners' intercultural competence. Over a nine-week teaching period, eighteen English speaking lessons (90 minutes / lesson / week) for two equivalent, intact classes (seventy-one students) were observed. For one class, the lessons were adapted to reflect the principles of intercultural language learning. For the other, no changes were made. The results showed that the intercultural competence of learners in the intercultural class increased by significantly more than that of learners in the standard class. In particular, the students in the intercultural class were able to better articulate ethnorelative awareness and attitudes towards their home culture and the target culture. The findings also showed that the reflective journal was an effective tool to assess learners' process of acquiring intercultural competence, particularly affective capacities that are not easy to evaluate by other means.

Overall, the study provided evidence for the feasibility of intercultural teaching and learning in tertiary EFL classrooms in the Vietnamese context. It also showed that intercultural teaching and learning cultivated learners' affective capacities which are often overlooked in the EFL classroom. It is hoped that the study can inform the work of curriculum designers, education policy-makers as well as EFL teachers and students for the implementation of intercultural language teaching and learning in Vietnam and elsewhere. 


\section{TABLE OF CONTENTS}

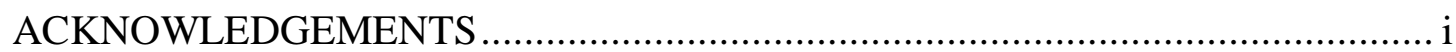

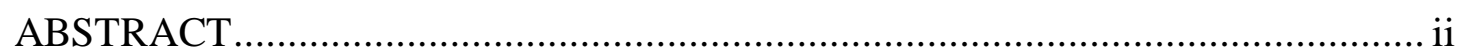

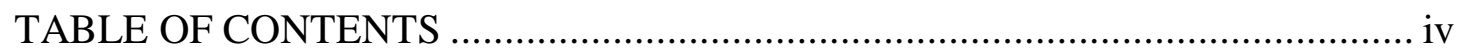

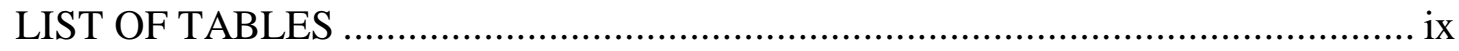

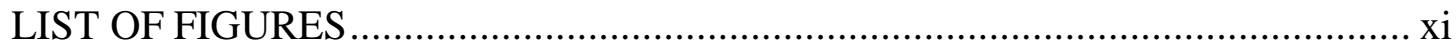

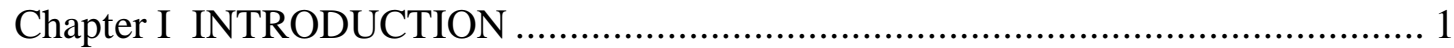

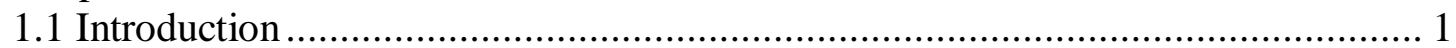

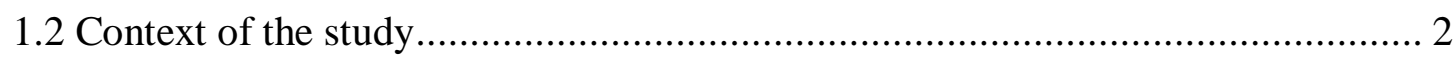

1.2.1 Confucianism and education in Vietnam ............................................... 2

1.2.2 The status of culture teaching and learning in Vietnamese EFL education..... 3

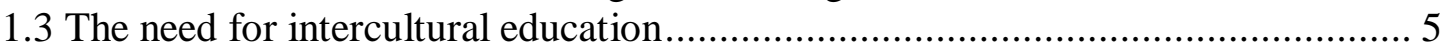

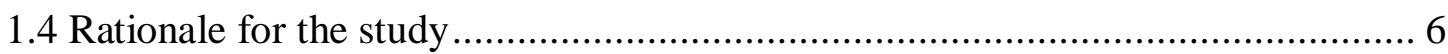

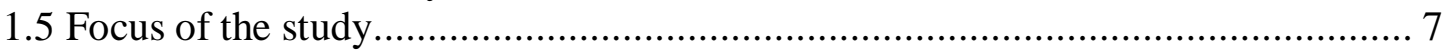

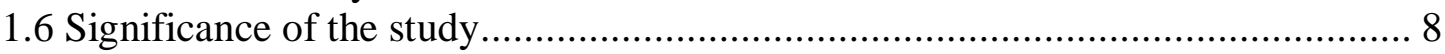

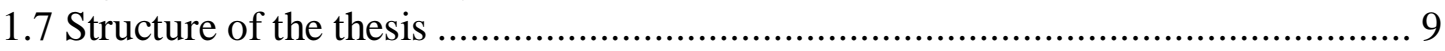

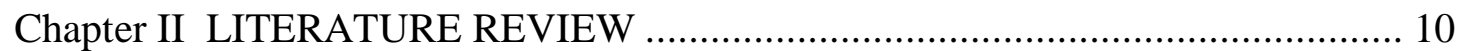

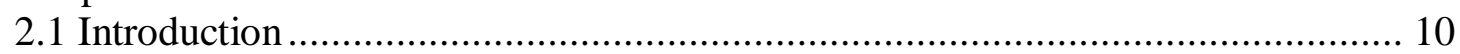

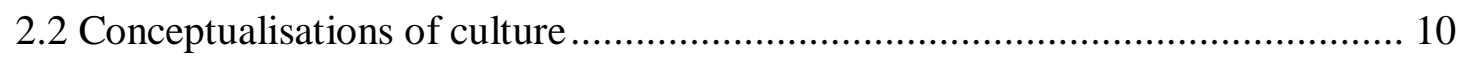

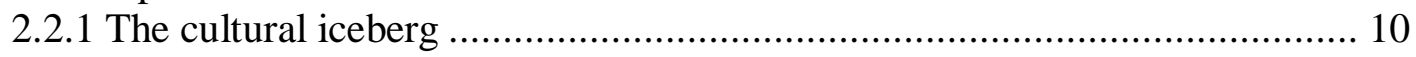

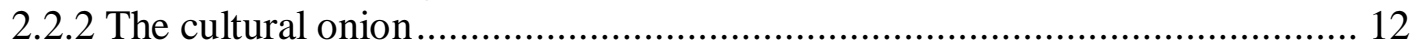

2.2.3 Culture as a fact fulfilled, a future competence and an encounter in an open

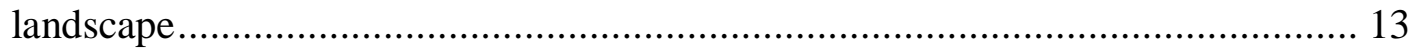

2.2.4 Culture in relation to community, communication and individual............... 13

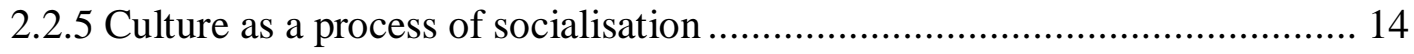

2.2.6 Modernist and post-modernist concepts of culture................................. 15

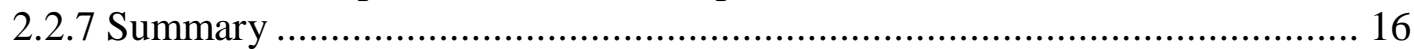

2.3 The relationship between language and culture ........................................... 17

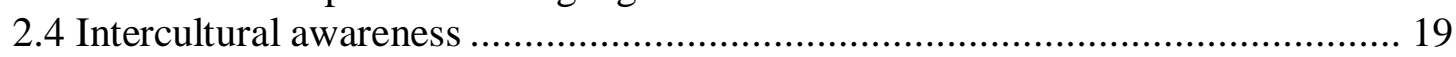

2.5 The concept of intercultural competence .................................................... 21

2.6 Conceptual models of intercultural competence ............................................ 24

2.6.1. Bennett's (1993) Developmental Model of Intercultural Sensitivity .......... 25

2.6.2 Byram's (1997) model of intercultural competence .................................. 26

2.6.3 Fantini's (2000) model of intercultural communicative competence ........... 29

2.6.4 Liddicoat's (2002) model of intercultural competence acquisition............... 30

2.6.5 Deardorff's (2004) model of intercultural competence ............................. 32

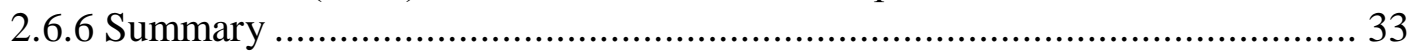

2.7 Culture teaching and learning in foreign language education............................ 34

2.7.1 Approaches to culture in foreign language education ............................. 34

2.7.2 Research on culture teaching and learning in European and Western contexts

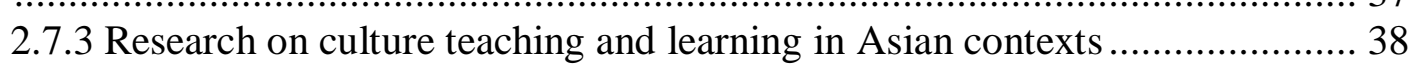

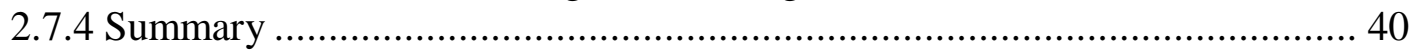

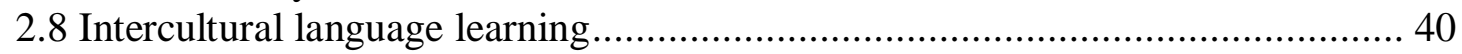

2.8.1 Definition of intercultural language learning ......................................... 40

2.8.2 Process of intercultural language learning .......................................... 41 


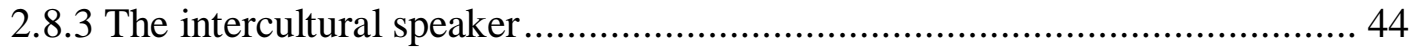

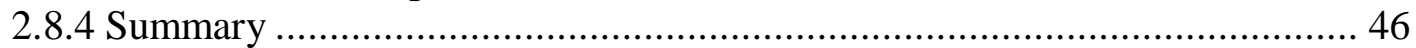

2.9 Principles for intercultural language teaching and learning ........................... 46

2.9.1 Principles for intercultural language teaching ........................................ 46

2.9.2 Principles for intercultural language learning .................................... 49

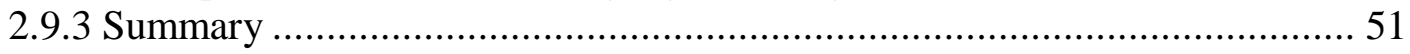

2.10 International trends in the practice of intercultural language learning .............. 52

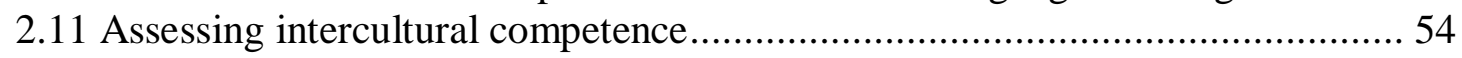

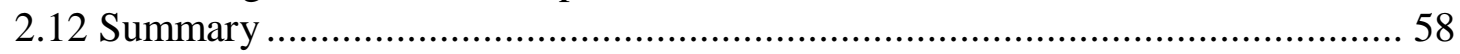

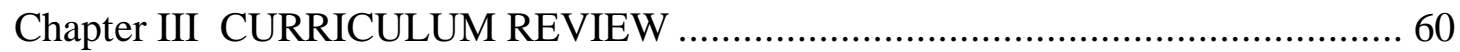

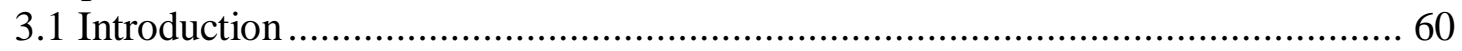

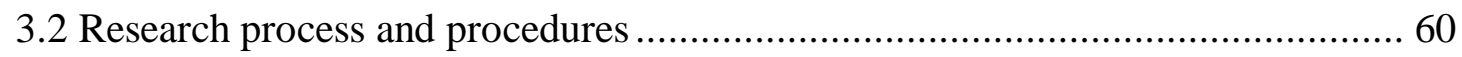

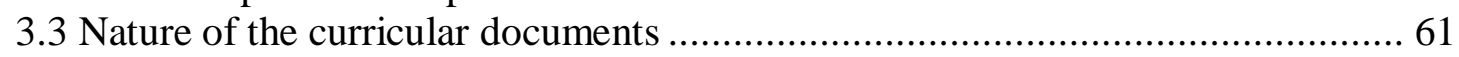

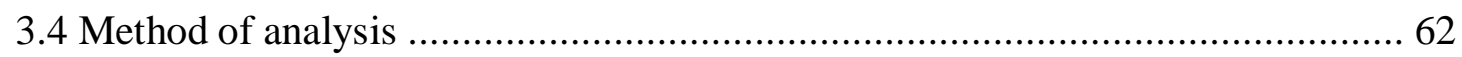

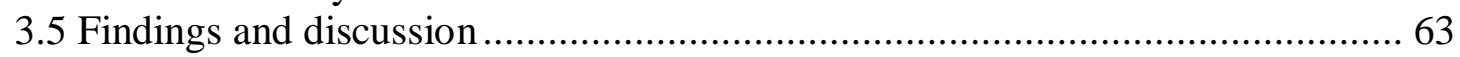

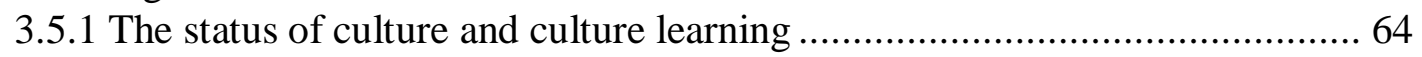

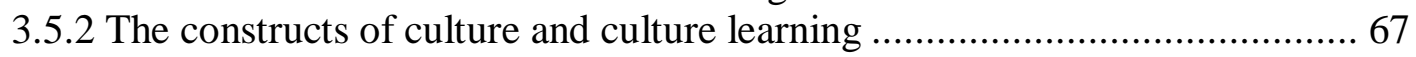

3.5.3 The treatment of culture and culture learning ...................................... 70

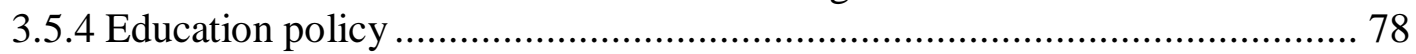

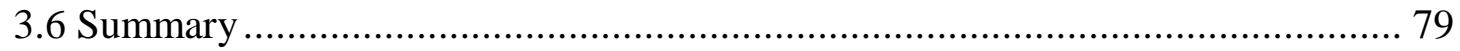

Chapter IV METHODOLOGY FOR AN ANALYTICAL STUDY OF TEACHERS

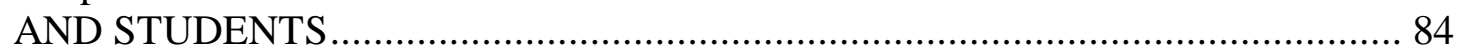

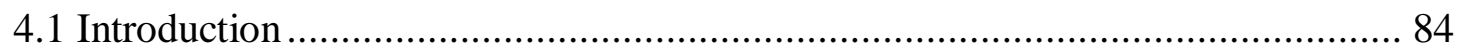

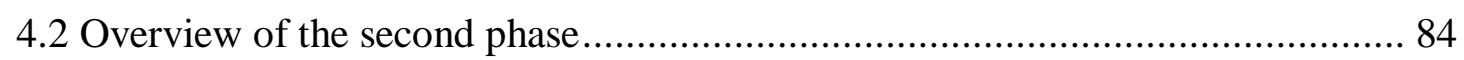

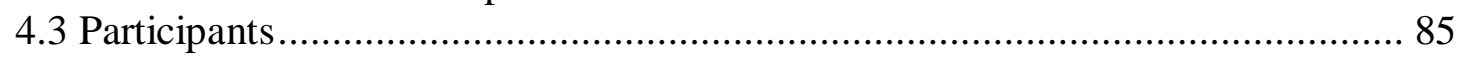

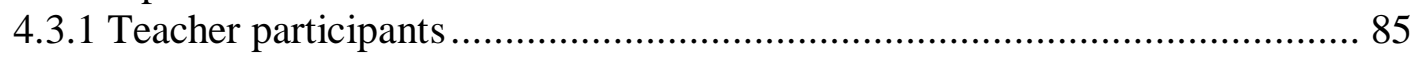

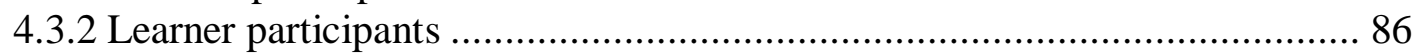

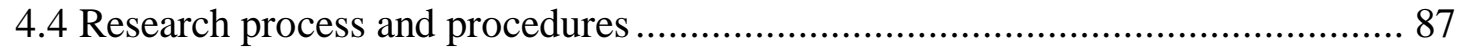

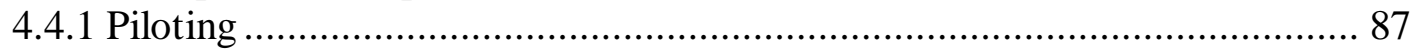

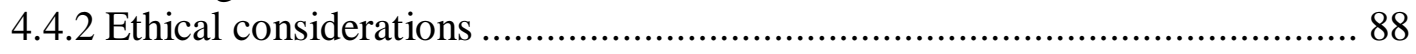

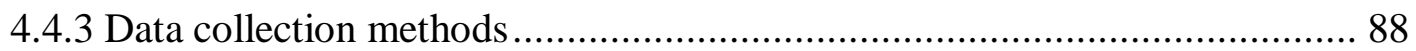

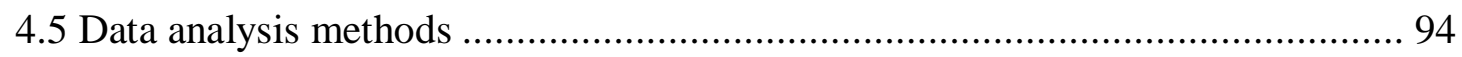

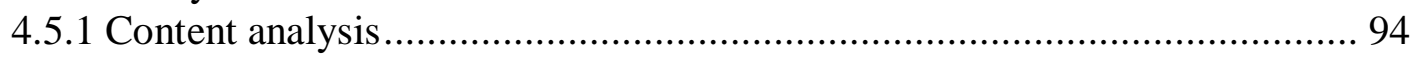

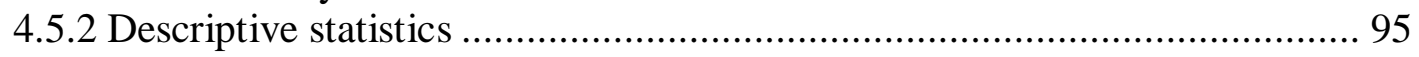

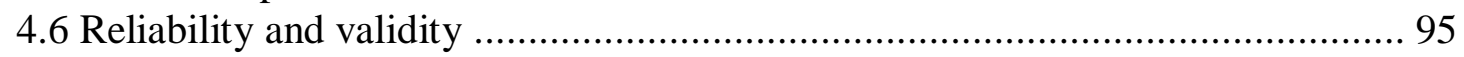

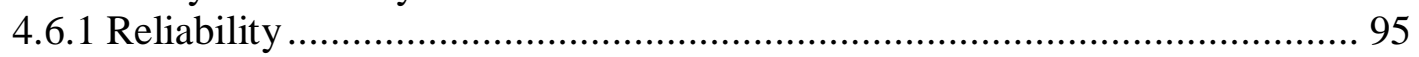

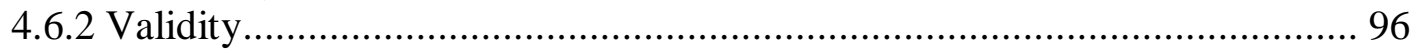

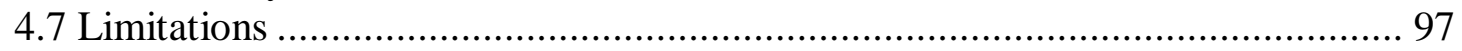

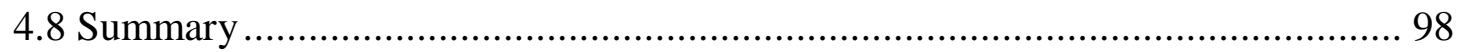

Chapter V TEACHER PERCEPTIONS AND CULTURE TEACHING

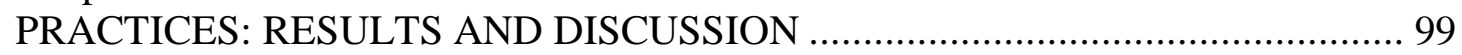

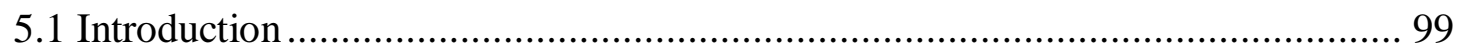

5.2 Teachers' perceptions and beliefs concerning culture in language teaching ........ 99

5.2.1 Definitions of culture ...................................................................... 100

5.2.2 Awareness of the relationship between language and culture .....................103

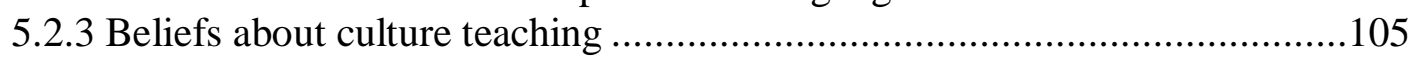

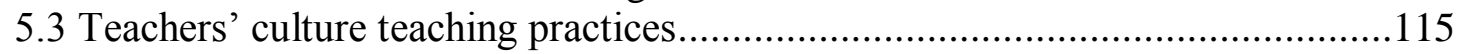


5.3.1 Teachers' culture teaching approaches .....................................................115

5.3.2 Teachers' self-evaluation of culture teaching approaches .........................121

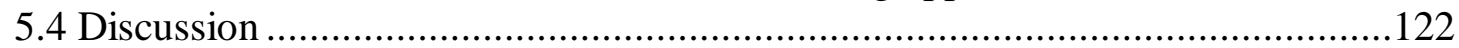

5.4.1 Culture defined as social structures and speech acts ..............................122

5.4.2 Facts-oriented approach as culture teaching practice .............................122

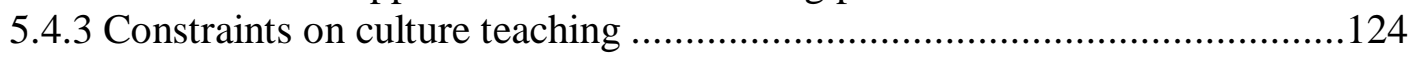

5.4.4 Potential for adopting intercultural language teaching ............................126

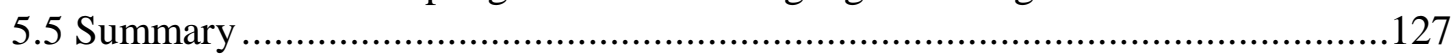

Chapter VI STUDENT PRIORITIES AND PERCEPTIONS OF CULTURE

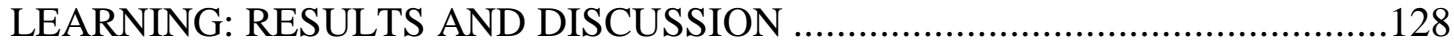

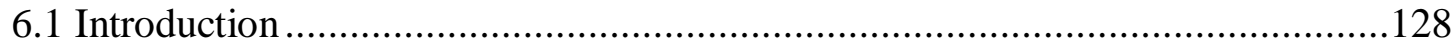

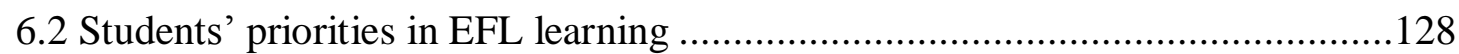

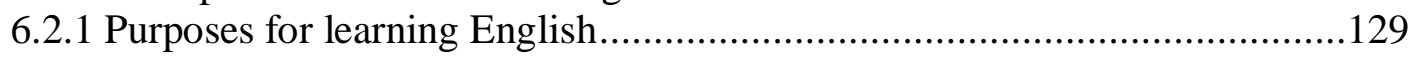

6.2.2 Preferences for linguistic and cultural contents....................................130

6.2.3 Preferred topics in language learning ............................................... 131

6.3 Students' perceptions of culture and language learning .................................133

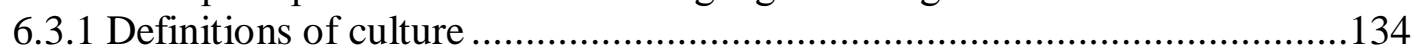

6.3.2 Awareness of the relationship between language and culture.....................135

6.3.3 Beliefs about culture in language learning .............................................136

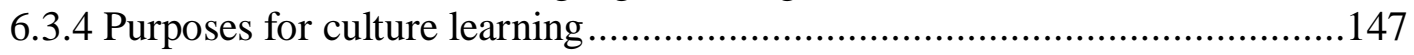

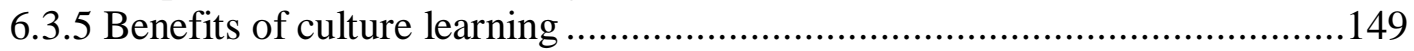

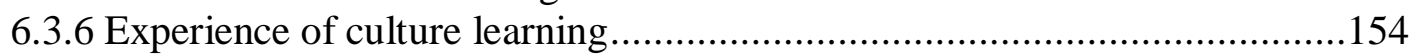

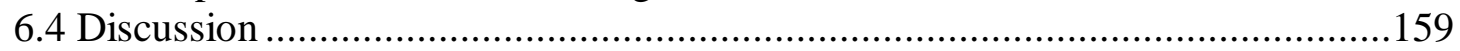

6.4.1 Culture as a subordinate priority in language learning .............................159

6.4.2 Culture defined as social structures ......................................................160

6.4.3 Behavioural capacities as the ultimate purpose for culture learning ............161

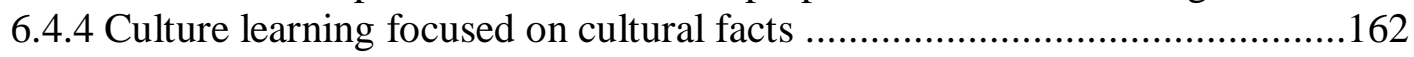

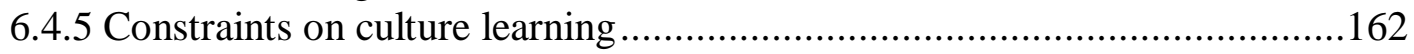

6.4.6 Potential for adopting intercultural language learning .............................164

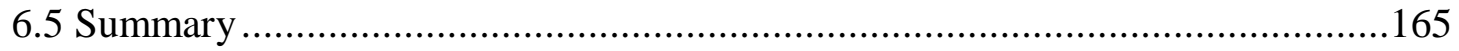

\section{Chapter VII METHODOLOGY FOR THE INTERCULTURAL INTERVENTION}

(166

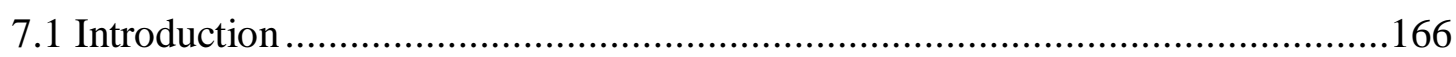

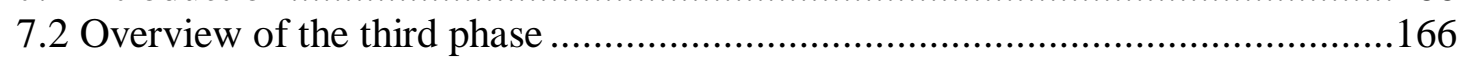

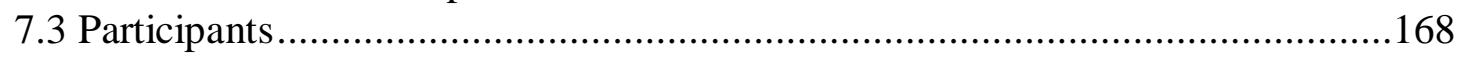

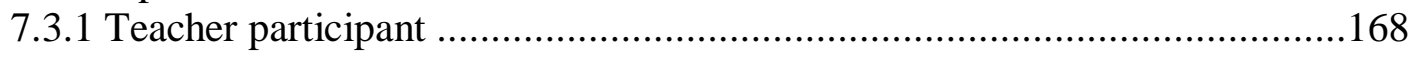

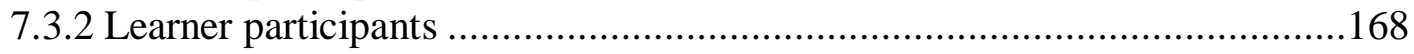

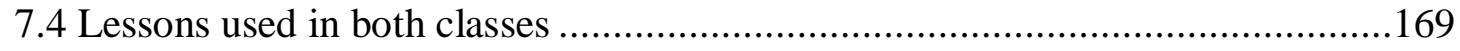

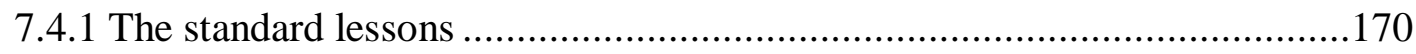

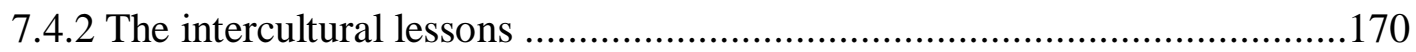

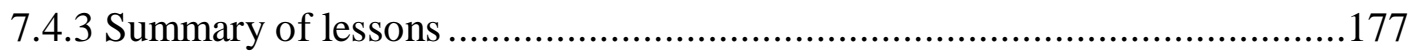

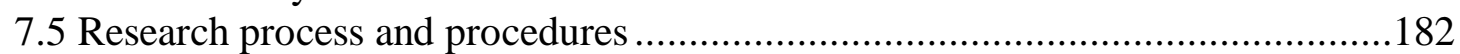

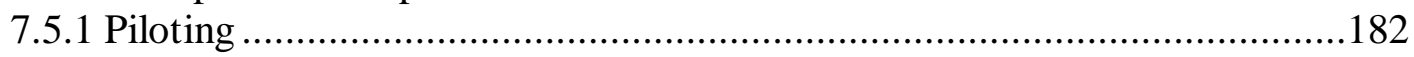

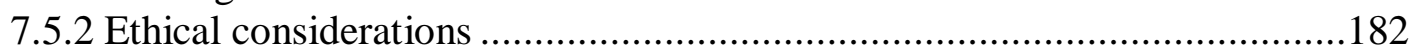

7.5.3 Principles for selecting the Standard and Intercultural classes ...................183

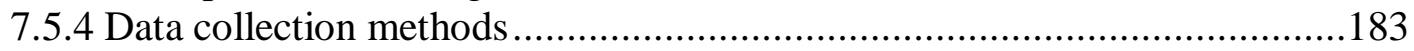

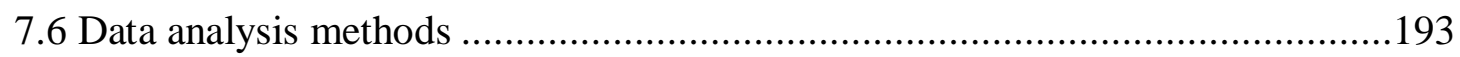

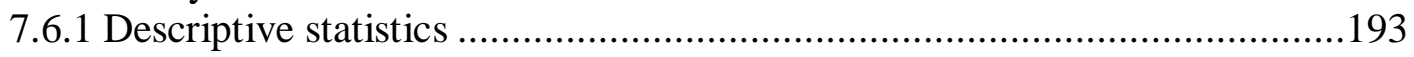




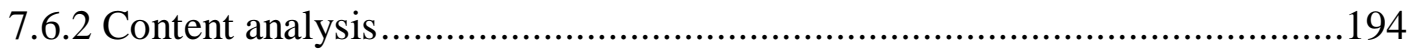

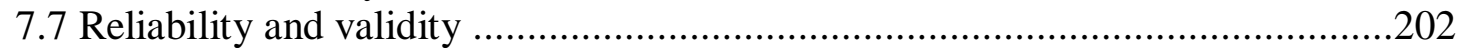

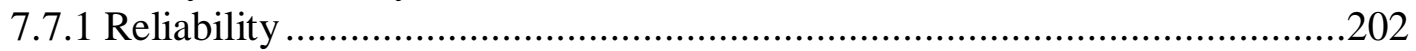

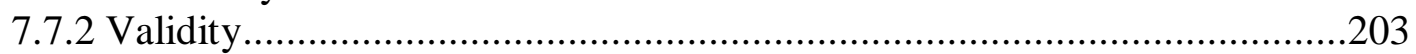

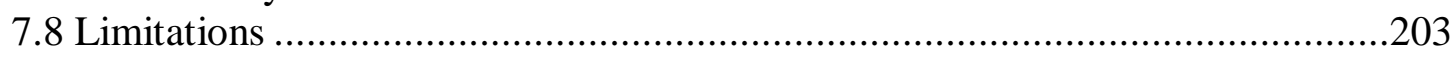

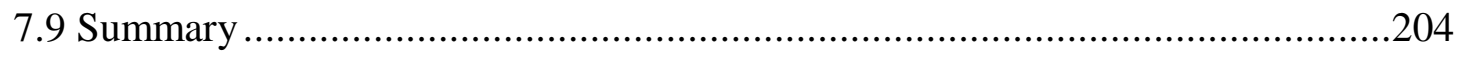

Chapter VIII THE INTERCULTURAL INTERVENTION: RESULTS AND

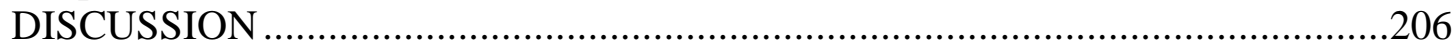

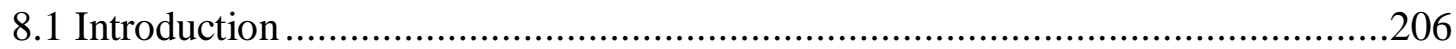

8.2 Development of the learners' intercultural competence .................................206

8.3 Nature of the learners' intercultural competence development .......................216

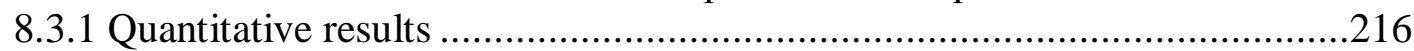

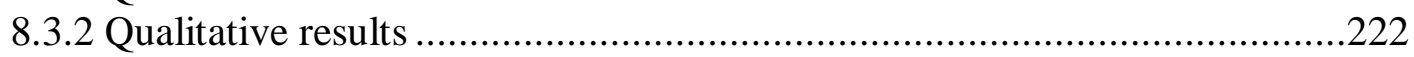

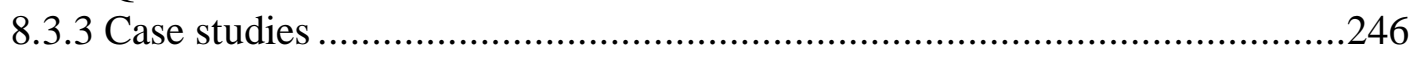

8.4 Students' experience of intercultural language learning .................................264

8.4.1 Quantitative results: self-evaluation questionnaire.................................264

8.4.2 Qualitative results: interviews and journals ........................................266

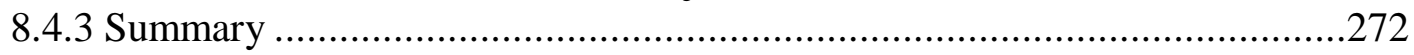

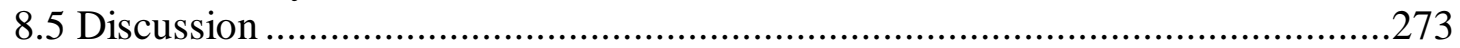

8.5.1 A proposed model of intercultural awareness ..........................................273

8.5.2 A proposed model of intercultural attitudes .........................................2.275

8.5.3 Dimensions of the learners' developing intercultural competence .............277

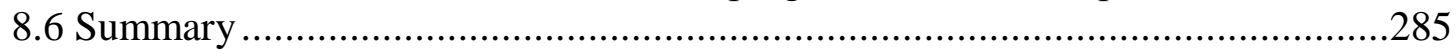

Chapter IX CONCLUSIONS AND IMPLICATIONS …...................................28

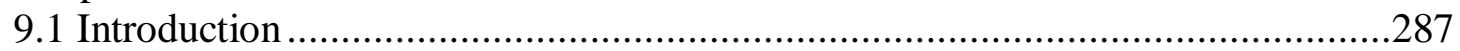

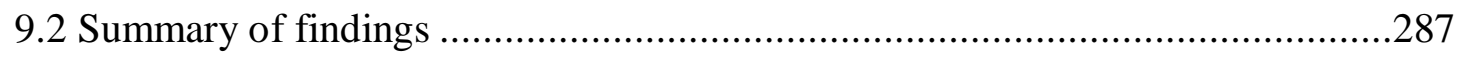

9.2.1 Curriculum review ...................................................................28

9.2.2 Teachers' and students' perceptions and classroom practices ....................289

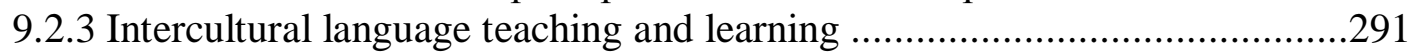

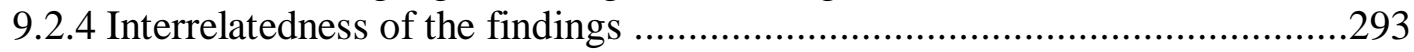

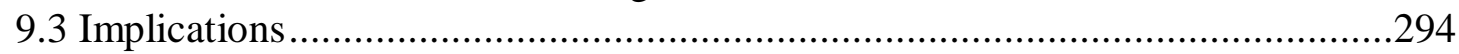

9.3.1 Implications for curriculum designers ..............................................294

9.3.2 Implications for education policy makers .............................................295

9.3.3 Implications for intercultural language teaching and learning .....................296

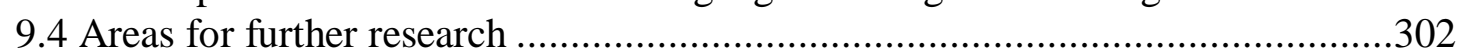

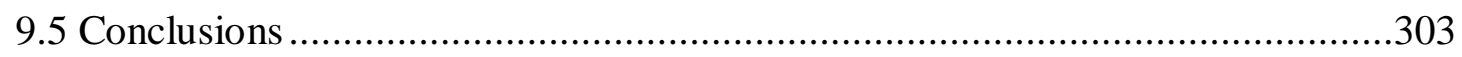

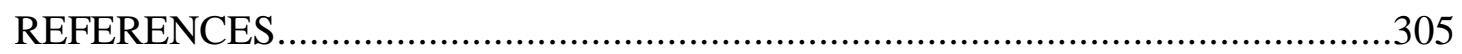

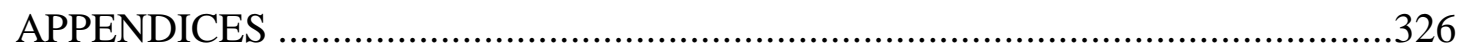

Appendix 1: Evidence of culture and culture learning in the curricular documents (Phase 1)

Appendix 2: Approval of Human Ethics Committee

Appendix 3: Information sheet for teacher participants (Phase 2)

Appendix 4: Information sheet for student participants (Phase 2)

Appendix 5: Consent forms for teacher and student participants

Appendix 6: Summary of classroom observations (Phase 2) 
Appendix 7: Teacher interviews (Phase 2)

Appendix 8: Student questionnaire

Appendix 9: Student focus-group interviews (Phase 2)

Appendix 10: Summary of Categories and Coding for qualitative data of the questionnaire

Appendix 11: Summary of Categories and Coding for teacher interviews

Appendix 12: Summary of Categories and Coding for student focus-group interviews (Phase 2)

Appendix 13: Description of a sample lesson (Phase 3)

Appendix 14: Information sheet for teacher participant (Phase 3)

Appendix 15: Information sheet for student participants (Phase 3)

Appendix 16: Research schedules

Appendix 17: Intercultural Competence Inventory

Appendix 18: Reflective Journal

Appendix 19: Self-evaluation questionnaire

Appendix 20: Student focus-group interviews (Phase 3)

Appendix 21: Extract samples of learners' reflective journals

Appendix 22: Quantitative coding of students' journal entries 


\section{LIST OF TABLES}

Table 2.1: Conceptualisations of culture ............................... 16

Table 2.2: Alternative terms for Intercultural Communicative Competence .... 23

Table 2.3: Summary of conceptual models of intercultural competence ........ 33

Table 2.4: Assessment tools for intercultural competence .................... 56

Table 3.1: Summary of evidence of culture and culture learning in curriculum frameworks............................................. 80

Table 4.1: Demographic information of teacher participants................ 85

Table 4.2: Demographic information of learner participants in the

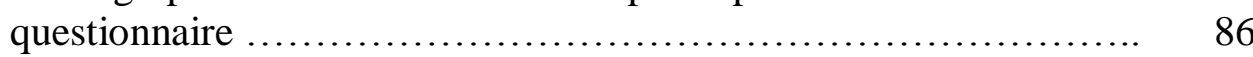

Table 4.3: Demographic information of learner participants in focus-group interviews

Table 4.4: Characteristics of classroom observations ....................... 90

Table 4.5: Classroom observation scheme.................................. 90

Table 4.6: Summary of the questionnaire ................................ 92

Table 4.7: Summary of data collection methods.......................... 94

Table 5.1: Teachers' definitions of culture ................................ 100

Table 5.2: Summary of classroom observations............................. 116

Table 6.1: Students' purposes for learning English ......................... 129

Table 6.2: Students' preferences in language learning ...................... 130

Table 6.3: Students' preferred topics in language learning ................... 132

Table 6.4: Students' beliefs about aspects of culture learning ................. 146

Table 6.5: Factor loadings for students' purposes for culture learning .......... 148

Table 6.6: Students' purposes for culture learning ......................... 148

Table 6.7: Students' rating of the benefits of culture learning................. 149

Table 6.8: Students' opinions about the teachability of language and culture ... 150

Table 6.9: Students' opinions about the benefits of culture learning........ 151

Table 6.10: Students' culture learning activities in the classroom.............. 155

Table 6.11: Students' culture learning activities beyond the classroom ......... 157

Table 7.1: Scheme of quasi-experimental design........................... 167

Table 7.2: Demographic information of learner participants.................. 169

Table 7.3: Differences between the two classes in lesson design.............. 178

Table 7.4: Summary of the lesson content in the two classes ................. 179

Table 7.5: Reliability analysis of the pre-test in the Standard class............ 185

Table 7.6: The learner journal corpus.................................... 188

Table 7.7: Principles for case study selection............................. 190

Table 7.8: Summary of self-evaluation questionnaire........................ 192

Table 7.9: Summary of data collection methods........................... 193

Table 7.10: Coding system for data analysis............................... 196

Table 7.11: Examples of units of analysis ................................ 198

Table 7.12: Confusion matrix .......................................... 201

Table 7.13: Confusion matrix in independent coding ....................... 201

Table 7.14: Confusion matrix in coding with consensus...................... 202

Table 8.1: Pre-test and post-test for intercultural knowledge.................. 207

Table 8.2: Pre-test and post-test for intercultural attitudes.................... 208

Table 8.3: Pre-test and post-test for intercultural skills...................... 209

Table 8.4: Pre-test and post-test for intercultural awareness................. 210 
Table 8.5: Independent-samples t-tests for pre-test and post-test in the two classes................................................... 211

Table 8.6: Independent-samples t-tests for intercultural gains in the two classes 214

Table 8.7: Correlation among the IC components in the post-test ............ 215

Table 8.8: Independent and dependent variables.......................... 217

Table 8.9: Results of the RMLR model................................ 218

Table 8.10: Parameter estimates of the RMLR model ..................... 218

Table 8.11: Differences in students' intercultural demonstration between the two classes............................................. 220

Table 8.12: Independent t-tests for students' experience of intercultural

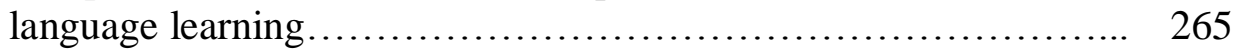




\section{LIST OF FIGURES}

Figure 2.1: The cultural iceberg ...................................... 11

Figure 2.2: The cultural onion ...................................... 12

Figure 2.3: Culture: community, communication and individual .............. 14

Figure 2.4: Points of articulation between culture and language ............... 18

Figure 2.5: Developmental Model of Intercultural Sensitivity................ 25

Figure 2.6: Elements of intercultural competence ......................... 27

Figure 2.7: Byram's (1997) model of intercultural communicative competence. 29

Figure 2.8: Fantini's (2000) model of intercultural communicative competence $\quad 30$

Figure 2.9: A path for developing intercultural competence .................. 30

Figure 2.10: Progression in developing intercultures ........................ 31

Figure 2.11: Process model of intercultural competence ................... 32

Figure 2.12: Widening the learner's picture of culture ..................... 42

Figure 2.13: Different stages of intercultural learning ..................... 43

Figure 2.14: Interaction among perspectives, practices and products.......... 52

Figure 2.15: The assessment cycle ........................................ 57

Figure 3.1: Relationship among the documents .......................... 61

Figure 8.1: Development of learners' intercultural knowledge in the two classes 212

Figure 8.2: Development of learners' intercultural attitudes in the two classes... 212

Figure 8.3: Development of learners' intercultural skills in the two classes...... 212

Figure 8.4: Development of learners' intercultural awareness in the two classes. 213

Figure 8.5: Intercultural gains in the two classes.......................... 214

Figure 8.6: A proposed model of intercultural awareness ................... 274

Figure 8.7: A proposed model of intercultural attitudes...................... 276 


\section{Chapter I \\ INTRODUCTION}

\subsection{Introduction}

For centuries, Chinese and French used to be the main foreign languages taught at schools in Vietnam. In the 1950s, although English language teaching became more popular after the French withdrawal in 1954, it still did not gain an important status in education. Due to Vietnam's close relations with the former USSR and China at that time, Russian and Chinese became the main foreign languages taught at schools. Only with the establishment of Vietnam's open-door policy vis-à-vis the outside world in 1986 did EFL education in Vietnam get more attention. Since the 1990s, EFL teaching has spread widely and become more important as it plays a key role in the country's development in economics, technology and education. Since Vietnam became a full and official member of the World Trade Organization (WTO) in 2007, the teaching and learning of English has become more significant than ever. EFL teaching has boomed, and English has become prevalent at all levels of national education from primary to secondary schools and universities in Vietnam. English has even become a crucial requirement in employment in many institutions all over the country.

This growth in demand for English reflects changes in our world which increasingly looks like a 'global village' where intercultural contacts between people from different cultural backgrounds are part of everyday life for many people. The possibilities for intercultural communication have become greater than ever and their benefits are visible in the foreign language classroom (Vogt, 2006). Learning a foreign language is not only about learning its vocabulary and linguistic system, but also about studying the culture integrated in it. Language and culture are interwoven and cannot be separated (e.g., Agar, 1994; Kramsch, 1998). It is, therefore, impossible to learn a foreign language without engaging with its culture. Intercultural

competence has become an important goal of foreign language teaching and learning that emphasizes the interdependence of language and culture and the importance of intercultural understanding (e.g., Crozet and Liddicoat, 2000; Liddicoat, Papademetre, Scarino and Kohler, 2003). In the country's international integration, Vietnamese EFL 
students have more opportunities to learn English and communicate with people from other cultures. It is important for them to develop intercultural competence in foreign language education in order to study and work in a multicultural world. This research project investigates intercultural teaching and learning in tertiary EFL classrooms in Vietnam, a context in which intercultural approaches have not yet been widely considered.

\subsection{Context of the study}

This section briefly describes the influence of Confucianism on education in Vietnam, and the status of and need for culture teaching and learning in Vietnamese EFL education.

\subsubsection{Confucianism and education in Vietnam}

Confucianism has had a profound influence on Vietnamese education. Confucianism has "put great emphasis on moral education, particularly highlighting the moral role of the [Vietnamese] teacher and the learner" (Phan, 2008, p.7). Thus, the aim of education in Vietnam is to help learners to become good citizens in terms of not only knowledge but also morality (ibid.). A well-known saying in Vietnamese culture is 'Tiên học lễ, hậu học văn' ('First learn how to behave, then learn the subject') (Kramsch and Sullivan, 1996, p.206). This old Confucian style reinforces traditional views of teaching and learning. The teacher is honoured, respected and has the role of enlightening students and making learning occur (Nguyen, 2002). The teacher is not only an 'expert knower of the language', but also a 'mentor' and a 'moral leader' (Kramsch and Sullivan, 1996, p.206). Other proverbs about this moral role of the teacher include, 'Không thầy đố mày làm nên' ('Without teachers, one can't do anything'), and 'Nhất tụ vi su, bán tụ vi su' ('He who teaches you one word is a teacher, he who teaches you half a word is also a teacher') (Breach, 2004, p.32). With the reform of the national education system, a great number of Vietnamese teachers have been trained and encouraged to use communicative language teaching (CLT) methods. They have attempted to integrate the new teaching methodology from the West into the traditional teaching practices. However, Pham (2005) argues that adopting CLT principles challenges the basic Vietnamese educational values, and so 
teachers usually experience a conflict between two teaching approaches in practice: teaching grammar or teaching communication. Some teachers even bear two different identities as a teacher of English and a Vietnamese teacher (Phan, 2004) to adapt to the new situation.

\subsubsection{The status of culture teaching and learning in Vietnamese EFL education}

Recently, the importance of culture teaching and learning has been highlighted in the foreign language classroom in Vietnam (Dinh, 2005; Pham, 2001). According to Dinh (2005), a mastery of the linguistic system of a foreign language is not sufficient for learners to understand the culture embedded in the target language. Dinh argues that foreign language teaching needs to help learners become better integrated into a large society and get used to cultural diversity, willingness to communicate and empathy. Pham (2001) also stresses the importance of cultural competence in intercultural communication as it can help speakers accurately express their intentions and understand the information perceived as well as avoid misunderstandings that may lead to communication breakdown. Pham argues that the efficacy of language use in communication would be much reduced if teachers are only concerned about developing learners' skills based on the linguistic system of the foreign language.

Although the importance of culture teaching has been stated in the foreign language classroom, the issue of intercultural language learning is still very new to many Vietnamese EFL teachers and students. The lack of attention to intercultural language learning may be due to two main reasons. First, students are not given opportunities to recognize the interculturality in daily life. When the country is geared towards multilateral and diversified international relations, however, there is an urgent need for foreign language learners to develop intercultural competence to be successful not only in communication with people from other cultures but also in a multicultural environment at the workplace.

Second, the neglect of intercultural language learning in Vietnam lies in the design of EFL curricula and practices of language learning in the classroom. It can be observed that culture has a very modest place in the EFL curricula. The Ministry of Education and Training (MOET) has control over two-thirds of the tertiary curriculum, which reduces the flexibility of the entire curriculum. In addition, the curriculum is usually linguistics-based and exam-oriented, and consequently culture 
tends to be treated as a peripheral goal in language courses. Based on observations and direct interviews with both language teachers and learners, Dinh (2005) states two main reasons for the neglect of culture teaching in the foreign language classroom in Vietnam. The first reason is that many language learners still believe that the mastery of vocabulary and grammatical rules will help them learn a foreign language well. Therefore, all social rules that affect the use of language in communication are usually neglected. The second reason is that the focus on the testing of vocabulary, grammar and translation has relegated culture to a subordinate status. Phan (2004) also states that many Vietnamese teachers of English are not aware of the socio-cultural dimension of foreign language education, which leads to the neglect of culture teaching and learning in the EFL classroom.

With a linguistic focus in language learning, culture courses, i.e., British and American culture courses ${ }^{1}$, are more likely to become the only source that provides students with cultural knowledge about the target language culture. Although students can develop their cultural knowledge of the target language country in these courses, this receptive aspect of cultural competence is not sufficient (Lessard-Clouston, 1997). In addition, this kind of culture learning tends to deal with transmission of cultural facts. Tseng (2002) believes that culture should be learnt in a process rather than through a collection of facts.

When English is used among people from different cultural backgrounds, intercultural competence becomes essential. In many cases, misunderstanding in cross-cultural communication occurs due to cultural differences even if both interlocutors have good communicative competence (Pham, 2001). Intercultural competence, therefore, becomes an indispensible competency for foreign language learners to be successful in intercultural communication. In order that Vietnamese EFL learners can meet their learning needs for intercultural encounters, EFL education in Vietnam should consider the importance of developing intercultural competence in language learning. In a study on EFL teaching in Vietnam, Kramsch and Sullivan (1996) suggest that intercultural communication should be integrated to prepare "learners to be both global and local speakers of English and to feel at home in both international and national culture" (p. 211).

\footnotetext{
${ }^{1}$ British and American culture courses are taught in the third year for English language majors to provide knowledge about the geography, history and institutions of the United Kingdom and the United States of America.
} 


\subsection{The need for intercultural education}

In our multicultural world, together with globalisation, education for international understanding has become an integral part of school education in many societies. New concepts like 'intercultural education', 'intercultural understanding' or 'interculturalism' have become prevalent. The term 'intercultural education' was first introduced in the USA to describe educational programmes for the integration of different ethnic groups in North America (Doye, 1999). In a multicultural country, intercultural education aims at integrating different cultures, whereas in a monocultural country intercultural education is mainly concerned with the education of citizens towards internationalism and multiculturalism (Kaikkonen, 2001). Both aims of intercultural education are applicable for Vietnam. There is a great need for Vietnamese EFL students to learn English to communicative with people from other Asian countries and the world to meet the needs of the country's international integration. However, intercultural competence is not just about better communication in English. It is also about developing a deeper sensitivity to difference and diversity in Vietnam given its rich and complex multiethnic make-up ${ }^{2}$. This can be a strong impetus for Vietnam to move towards intercultural language teaching and learning.

Kaikkonen (2001) mentions various reasons for intercultural learning. First, it concerns understanding and strengthening a person's own cultural identity. Awareness of one's own identity is the foundation for intercultural learning. Second, our world today reflects a multicultural reality where there are different trends for intercultural collaboration and integrative aspirations. Especially, the opening of boundaries between the East and the West has made intercultural understanding and learning more important than ever. Third, abundant intercultural encounters are prevalent in our daily life. Tourism, youth exchanges, studying and working abroad, trade, diplomacy or mobility of people around the world have led to an increased demand for intercultural learning. Fourth, a variety of social phenomena such as racism, ethnocentrism, xenophobia, extremism, nationalism, stereotypes, prejudices, discrimination, refugees, or immigration have increased the need for intercultural education so as to enhance cultural understanding between people from different backgrounds. Finally, global problems such as changes in the environment, pollution,

\footnotetext{
${ }^{2}$ There are 54 ethnic groups in Vietnam although one ethnic group, the Kinh group, make up 85.7\% of the population (Wikipedia).
} 
growth of population, wars or unequal distribution of resources have also underlined the need for intercultural learning. All of these reasons for intercultural education are relevant and important for Vietnam.

With such a great need for intercultural education ${ }^{3}$, foreign language education plays a central role in intercultural understanding as it mediates the interpretation and construction of meanings among people from different language and cultural backgrounds (Scarino and Crichton, 2007). Intercultural language learning is, therefore, promoted as a way to encourage learners' tolerance, respect and empathy towards other peoples and cultures, foster their mutual and reciprocal willingness to negotiate meanings across languages and cultures and prepare them for life in a multicultural world.

\subsection{Rationale for the study}

I conducted this research with three main reasons as mentioned below.

The first reason came from my own language teaching experience. I have taught both language skills and culture courses at the university in Vietnam. Particularly, I designed a British culture course which moved beyond accumulated cultural facts for students to learn and instead engaged them in more interactive and exploratory culture learning. For example, I engaged them in role-playing and theatre performances about different aspects of the target culture. My students were motivated to learn about culture in this way. I have also had a lot of intercultural experiences from my studies in France, Australia and New Zealand and my visit to America to share with my students. Therefore, I conducted this research with an attempt to adopt an intercultural perspective for my own language teaching.

The second reason was concerned with the current EFL education in Vietnam. So far, communicative language teaching has been applied in EFL classes, but there is still a strong focus on aspects of language, such as grammar and vocabulary, rather than on the cultural dimension of language learning. To my knowledge, no empirical studies on intercultural language learning have been conducted in the Vietnamese EFL classroom. I wanted to fill this gap by conducting this research to investigate the

\footnotetext{
${ }^{3}$ Ideally, intercultural education would be realised across the curriculum (Byram and Fleming, 1998). However, the teachers and students focused on in this study were English language majors and so intercultural education must fall on the EFL curriculum.
} 
evidence of culture in the Vietnamese tertiary EFL sector and the feasibility for implementing intercultural teaching and learning in tertiary EFL classrooms in Vietnam.

The third reason was concerned with the country's international integration that requires Vietnamese students to study and work in a multilingual and multicultural world. To do this, they need to be both linguistically and interculturally competent. I conducted this research to meet this demanding expectation of the country.

The study, therefore, aimed to provide EFL teachers and students with insight into the intercultural dimension of foreign language education and promote intercultural language teaching and learning in the EFL classroom. It also aimed to prepare students to successfully engage in intercultural communication and fulfil the needs of the country in the development of its international relations with many other countries in a multilingual and multicultural environment.

\subsection{Focus of the study}

The study was motivated by the following overarching question:

To what extent is intercultural teaching and learning feasible in the Vietnamese tertiary EFL sector?

This question was investigated in three phases. The first and second phases involved an analytical study which looked for evidence of culture in the Vietnamese EFL sector through a curriculum review of the tertiary EFL programmes (RQ1) and in the perceptions of the teachers and students and their classroom practices (RQs 2 and 3). The third phase involved an empirical study which investigated intercultural learning in an intervention study (RQs 4, 5 and 6). The research addresses six research questions (RQ):

RQ1: To what extent is culture in language teaching and learning evident in the curriculum frameworks for tertiary EFL programmes in Vietnam?

RQ2: How is culture in language teaching evident in the perceptions and classroom practices of Vietnamese EFL teachers? 
RQ3: How is culture in language learning evident in the priorities and perceptions of Vietnamese EFL students?

RQ4: To what extent did the intercultural competence of students in the intercultural class develop compared to that of students in the standard class?

RQ5: What was the nature of the development of intercultural competence of students in the two classes?

RQ6: How did the students of the intercultural class perceive intercultural language learning?

These research questions are presented in full in subsequent chapters. Research question 1 is addressed in chapter III, research questions 2 and 3 in chapters IV, V, and VI, and research question 4, 5, 6 in chapters VII and VIII.

\subsection{Significance of the study}

The study has the following potential outcomes:

(a) It provides evidence for the feasibility and benefits of intercultural language learning in the Vietnamese EFL context where such an approach had not been widely considered;

(b) It may enhance Vietnamese EFL teachers' awareness of teaching culture as an integral component of language teaching and develop intercultural perspectives that may have an impact on their syllabus design and language teaching methodology. This may also contribute to their professional development as a component of a long-term plan in foreign language teaching;

(c) It may help Vietnamese EFL students perceive the importance of culture in language learning and develop intercultural competence alongside language proficiency for effective intercultural communication;

(d) It may help direct the attention of education policy makers and curriculum designers to the advantages of redefining the objectives of foreign language education towards the goals of intercultural language learning. This may help contribute to improved efficacy in foreign language education. 


\subsection{Structure of the thesis}

The thesis consists of nine chapters that are structured as follows:

Chapter I describes the context in which the study was conducted as well as the rationale, research questions and the significance of the study.

Chapter II reviews the literature and the theoretical frameworks on which the study is based.

Chapter III presents the curriculum review for the tertiary EFL programmes in Vietnam.

Chapter IV outlines the methodology of an analytical study of the perceptions of teachers and students on culture in language teaching and learning and their classroom practices.

Chapter V reports the results and discussion of the teachers' perceptions of culture in language teaching and their culture teaching practices.

Chapter VI reports the results and discussion of the students' priorities in EFL learning and their perceptions of culture learning.

Chapter VII outlines the methodology of the intercultural intervention.

Chapter VIII reports the results and discussion of the effect of adopting an intercultural stance on the development of the learners' intercultural competence.

Chapter IX draws the conclusions of the study and presents its contributions, implications, as well as outlining directions for future research.

In the next chapter, I will review the literature which provides the theoretical framework for this study. 


\section{Chapter II \\ LITERATURE REVIEW}

\subsection{Introduction}

This chapter reviews the literature on the conceptualisations of culture, the relationship between language and culture, conceptual models of intercultural competence, approaches to culture in foreign language education, intercultural language learning, and assessment of intercultural competence. These provide the theoretical framework for the present study.

\subsection{Conceptualisations of culture}

Culture is a highly complex phenomenon. Due to its complexity, many researchers from different disciplines have tried to formulate definitions of culture which reflect their perspectives on culture. There were more than two hundred definitions of culture in the early 1950s (Kroeber and Kluckhohn, 1952). Culture is described as the "glue that binds a group of people together" (Brown, 1994, p.163) or it is defined as "the software of the mind" (Hofstede, 1997, p.4). From my reading of the literature, six conceptualisations of culture stood out. This is necessarily a selective list, but these conceptualisations nevertheless capture a range of different ways that culture has been viewed in the scholarly literature drawn on in intercultural language learning over the past three decades.

\subsubsection{The cultural iceberg}

Weaver (1993) uses the metaphor of a cultural iceberg to refer to the concept of culture. Weaver argues that when one enters another culture, it is somewhat like a collision between two icebergs. Using the 'iceberg analogy' of culture, Weaver wants to show that a large proportion of our own culturally-shaped perceptions are invisible and mostly unconsciously applied in our everyday interactions. Weaver's concept of culture can be described as follows: 
Culture can be likened to an iceberg-only 10 percent of the whole is seen above the surface of the water. It is the 90 percent of the iceberg that is hidden beneath the surface of the water that most concerns the ship's captain who must navigate the water. Like an iceberg, the most meaningful (and potentially dangerous) part of culture is the invisible or subjective part that is continually operating on the unconscious level to shape our perceptions and our responses to these perceptions. It is this aspect of culture that leads to the most intercultural misunderstandings (Cushner, McClelland, and Safford, 1996, p.50).

Hanley (1999) also describes Weaver's cultural iceberg in two main parts: the surface culture and the deep culture (Figure 2.1).

FIFURE 2.1

The Cultural Iceberg (Weaver, 1993)

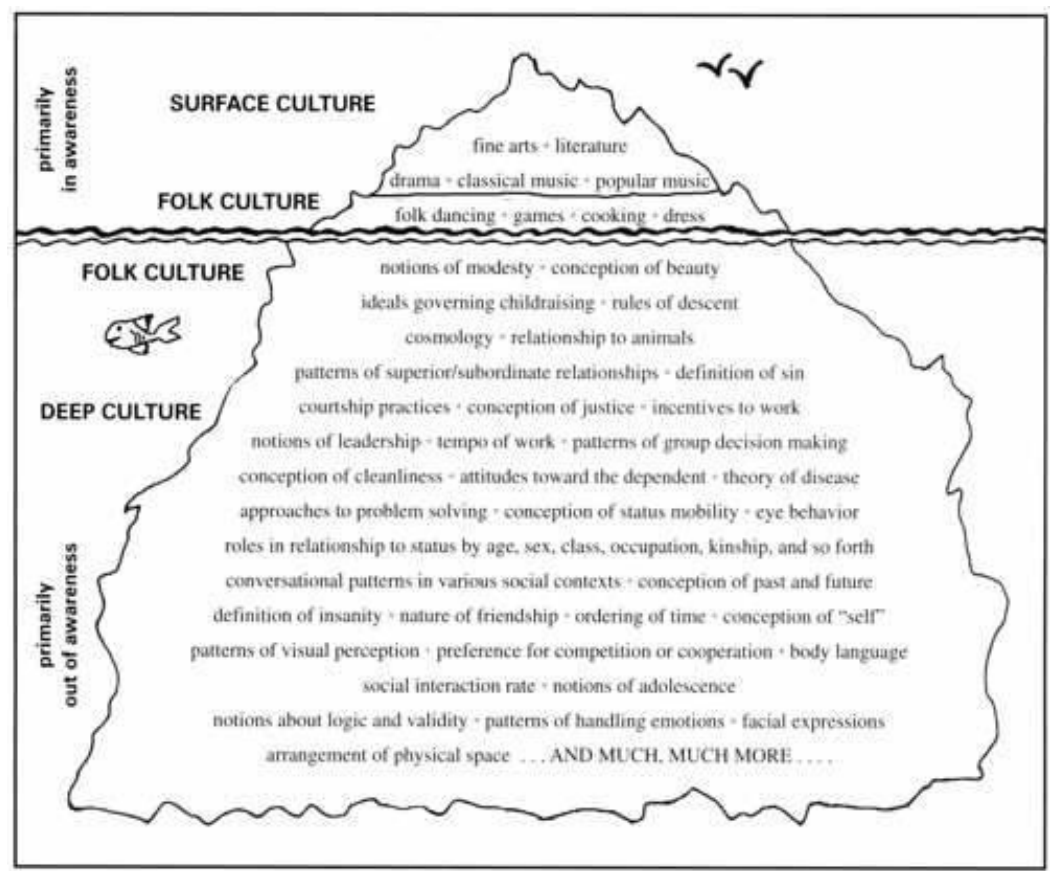

(Source: Hanley, 1999)

The surface culture, i.e., the part 'above the water', is visible and includes elements of folk culture such as fine arts, folk dancing, dress, cooking, etc. The deep culture, i.e., the part 'under the water' or the out-of-awareness part of culture, is invisible and includes elements like concept of justice, eye behaviour, concept of self, approaches to problem solving, etc. Ogbu (1988) states that "cultural tasks vary from culture to culture because different populations have worked out different solutions to common problems in life, such as how to make a living, reproduce, maintain order within their 
border, defend themselves against outsiders, and so on" (p. 13). From the image of Weaver's cultural iceberg, Hanley argues that it is necessary to move beyond the tip of the cultural iceberg towards the submerged part in order to develop cultural competence.

\subsubsection{The cultural onion}

Trompenaars and Hampden-Turner (1998) visualize the concept of culture using the image of the cultural onion (Figure 2.2). The cultural onion consists of three layers. On the outside of the onion is the explicit layer of culture or explicit products of culture which are the "observable reality of the language, food, buildings, houses, monuments, agriculture, shrines, markets, fashions and art" (Trompenaars and Hampden-Turner, 1998, p.21). The middle layer of the cultural onion comprises norms and values. Norms are the "mutual sense a group has of what is 'right' or 'wrong"” (ibid, pp.21-22), whereas values "reflect a cultural group's definition of good or bad and serve as criteria to choose between alternatives" (Shaules, 2007, p.57). The core of the cultural onion is described as basic assumptions about existence. Shaules states that these underlying or deep assumptions behind the norms and values are highly abstract and function at deeper levels of the self. As Shaules argues, "[i]t is the challenge of dealing with these hidden differences in norms and values and assumptions that constitute...[a] deep culture learning challenge" (p.59).

FIGURE 2.2

Cultural onion (Trompenaars and Hampden-Turner, 1998)

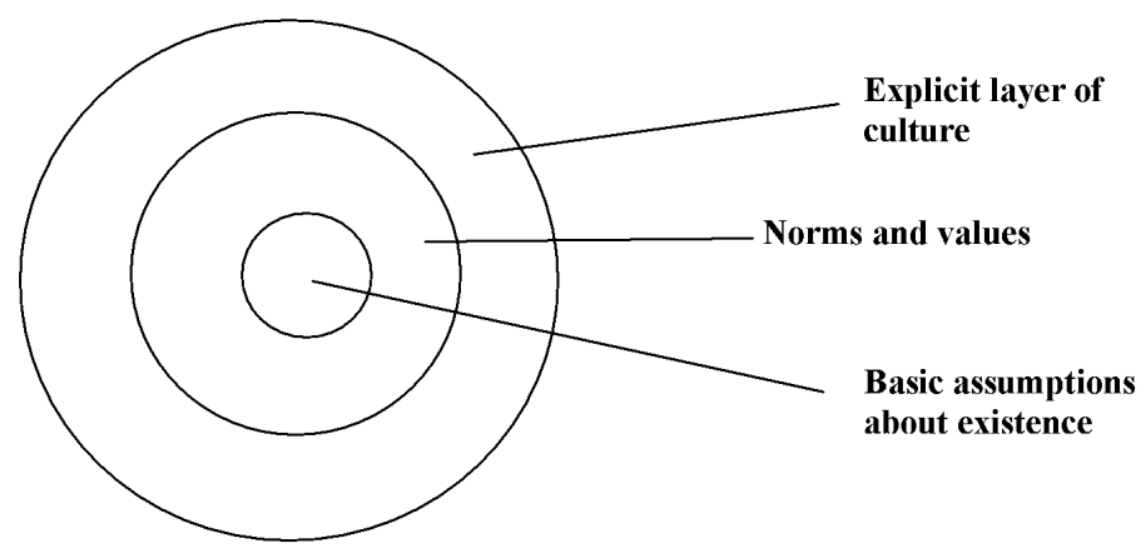




\subsubsection{Culture as a fact fulfilled, a future competence and an encounter in an open landscape}

Tornberg (2000, cited in Larzén-Östermark, 2009) conceptualises culture into three different concepts: culture as a fact fulfilled, culture as a future competence and culture as an encounter in an open landscape. The first concept refers to culture as nationally defined with cultural differences that exist between nations. The second concept points to culture as an ability to be learnt and practiced for successful future encounters with people from other cultures. The third concept of culture refers to a unique, open-ended, face-to-face encounter in the space between the self and the other where learners have to find a balance between their own identity and solidarity towards the other. Tornberg problematises the generalisation of national cultural traits with one language. He views culture as an ongoing process that is present in all encounters between people at a personal level.

\subsubsection{Culture in relation to community, communication and individual}

Kaikkonen (2001) defines culture in relation to community, communication and the individual as shown in Figure 2.3. According to Kaikkonen, the concept of culture should be approached from two angles: the social perspective and the communicative perspective. The former seeks an explanation for cultural phenomena in the order of society based on values, appreciations, cultural standards, role expectations, rules, etc. The latter emphasizes the individual's action through interactions with others within the community in learning the fundamentals of culture such as language, behavioural routines and communication rituals. Kaikkonen argues that there would be no culture without the three interactive components, i.e., the individual, communication and the community. From this point of view, culture is defined as follows:

Culture is a common agreement between the members of a community on the values, norms, rules, role expectations and meanings which guide the behaviour and communication of the members. Furthermore, it includes the deeds and products which result from the interaction between the members (Kaikkonen, 2001, p.81). 
FIGURE 2.3

Culture: community, communication and individual (Kaikkonen, 2001, p.80)

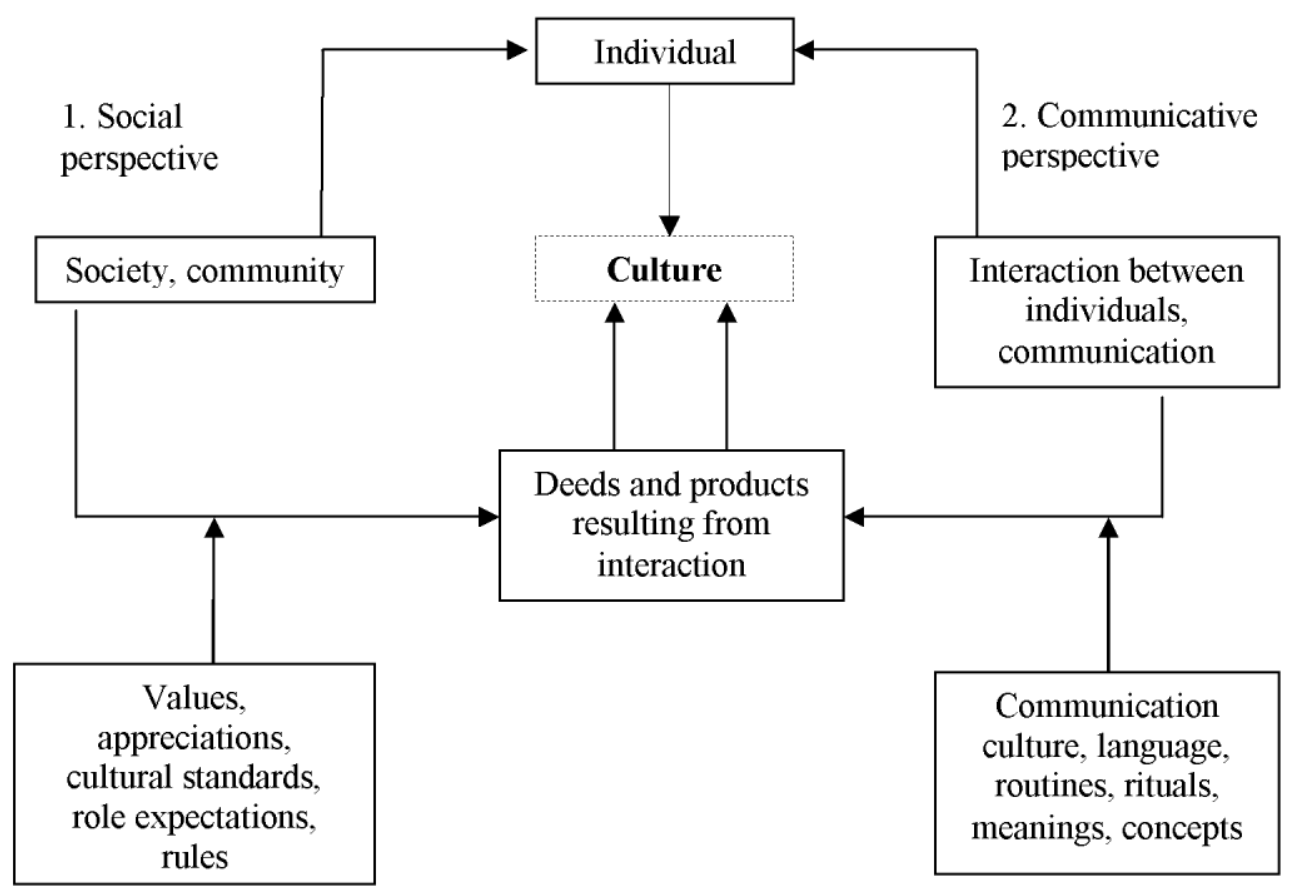

\subsubsection{Culture as a process of socialisation}

Liddicoat et al. (2003) conceptualise the concept of culture in relation to the process of socialisation. They emphasize the outcome of successful communication with a knowledge of and engagement with the cultural system on the establishment of shared concepts, meanings and worldviews. For them, the transmission of cultural systems to members of a cultural group is done through the process of socialisation which is not necessarily overt, and language has the primary role in the transmission of cultural knowledge. They also argue that cultural variants with time, place, social group, age group, etc. are privileged over others by the dominant cultural group in a society. From this conceptualisation, culture is defined as

...a complex system of concepts, attitudes, values, beliefs, conventions, behaviours, practices, rituals and lifestyles of the people who make up a cultural group, as well as the artefacts they produce and the institutions they create (Liddicoat et al., 2003, p.45). 


\subsubsection{Modernist and post-modernist concepts of culture}

Kramsch (2006) classifies culture in language study into two main perspectives: the modernist perspective and the post-modernist perspective. The modernist perspective associates culture with humanistic and sociolinguistic concepts. The humanistic concept of culture refers to a general knowledge of literature, arts, music, institutions, literary and philosophical achievements. It is also called 'big C' culture (Doye, 1999). Culture in this concept is traditionally taught with standard national languages and the study of the literature has a heavy emphasis in the curriculum for foreign language majors. The $1980 \mathrm{~s}$ witnessed a 'communicative turn' with the emerging communicative language teaching approach, and consequently the humanistic concept gave way to the sociolinguistic one with a focus on communication and interaction in social contexts. The sociolinguistic concept associates culture with "the native speakers' ways of behaving, eating, talking, dwelling, their customs, their beliefs and values" (Kramsch, 2006, p.13). It is also known as 'little c' culture or 'small cultures' (Holliday, 1999). This concept of culture is similar to Brislin's definition:

Culture is widely shared ideals, values, formation and uses of categories, assumptions about life, and goal-directed activities that become unconsciously or sub-consciously accepted as "right" and "correct" by people who identify themselves as members of a society (Brislin, 1990, p.11).

The sociolinguistic concept of culture led researchers in the 1980s to adopt a strong focus on cross-cultural pragmatics and the sociolinguistic appropriateness of language use in authentic cultural contexts. In the foreign language classroom, culture was more likely to be a tourist snapshot about getting things done in the target country. However, culture in this concept was seen as monolithic with the equation of one language to one national culture. Kramsch (2006) argues that this conception is problematic as the concept of culture has become "politicized and embroiled in the controversies associated with the politics of ethnic identity, religious affiliation and moral values" (p.12).

Kramsch's post-modern perspective of culture is classified into culture as Discourse and culture as identity. Culture as Discourse with a capital ' $D$ ' refers to the "ways of using language, or thinking, feeling, believing, valuing, and of acting that 
can be used to identify oneself as a member of a socially meaningful group or social network" (Gee, 1999, p.143). This concept of culture is similar to the "membership in a discourse community that shares a common social space and history, and common imaginings" (Kramsch, 1998, p.10). Kramsch shows that the concept of culture as Discourse with a closer link between language and culture implies the embeddedness of every utterance in asymmetrical relations of power between interlocutors, and the constant renegotiation of meaning through language. When culture is placed in Discourse, the individual's membership in a culture is linked to his or her social and political identity. It is this shift from culture to identity that gives learners "agency and a sense of power" (Kramsch, 2006, p.17).

\subsubsection{Summary}

A summary of the various conceptualisations of culture in the literature is given in Table 2.1.

TABLE 2.1

Conceptualisations of culture

\begin{tabular}{cll}
\hline No. & Concepts of culture & \multicolumn{1}{c}{ Descriptions } \\
\hline 1. & Cultural iceberg (Weaver, 1993) & Visible and invisible parts of culture \\
& & \\
\hline 2. & Cultural onion (Trompenaars and Hampden- & $\bullet$ explicit products of culture \\
& Turner, 1998) & $\bullet$ norms and values \\
& & $\bullet$ basic assumptions about existence \\
\hline 3. & Culture as a fact fulfilled, a future competence & $\bullet$ culture as nationally defined \\
& and an encounter in an open landscape & $\bullet$ culture as an ability to be learnt \\
& (Tornberg, 2000) & $\bullet$ culture as an ongoing process at a \\
& & personal level \\
\hline 4. & Culture in relation to community, communication & $\bullet$ cultural phenomena in the social order \\
& and the individual (Kaikkonen, 2001) & $\bullet$ interaction between individuals \\
& & \\
\hline 5. & Culture as a process of socialisation (Liddicoat $e t$ & Cultural system of a cultural group \\
& al., 2003) & \\
\hline 6. & Modernist and post-modernist concepts of culture & $\bullet$ humanistic and sociolinguistic concepts \\
& (Kramsch, 2006) & $\bullet$ culture as Discourse and culture as \\
& & identity \\
\hline & &
\end{tabular}


From these concepts of culture, it can be seen that the cultural iceberg of Weaver and the cultural onion of Trompenaars and Hampden-Turner are similar in that culture is conceptualised with underlying or deep assumptions which are usually invisible and highly abstract. These hidden cultural values function at deeper levels of the self during the process of cultural learning. Kaikkonen's concept of culture in relation to community, communication and individual is similar to Kramsch's sociolinguistic concept and the one of culture as Discourse when these concepts highlight the importance of the interaction between the individual and the community in social contexts. Both Tornberg and Kramsch problematise the generalisation of national cultural traits with one language. Kramsch's concept of culture as identity matches with the one of Tornberg as an encounter in an open landscape in that the issue of identity is important for learners to negotiate with 'the other'. Liddicoat et al. highlight the process of socialisation as the concept of culture. The teacher and student perceptions of culture in language teaching and learning in the second phase of the study will be analysed in light of these conceptualisations of culture.

The concept of culture in language learning is being re-evaluated. This reevaluation tends to deal with the hybridity of culture that has been recognized by many contemporary cultural theorists (e.g., Byram, 1997; Kramsch, 1993; Tornberg, 2004). Hybridity can be seen as a deliberate crossing of borders, whereby alien items are taken into one's own language and culture (Bhabha, 1994). Tornberg (2004) highlights the "hybrid, multi-vocally contested practices of narrative and negotiation between and beyond cultural borders" (p.134). This hybridity and plurality of culture underpins the foundation for intercultural approaches to language learning in modern language teaching (Byram, 1997; Kramsch, 1993).

\subsection{The relationship between language and culture}

Language and culture have an extremely complex relationship. As Agar (1994) states, "culture is in language and language is loaded in culture" (p.28). This means that language is an integral part of culture and also an expression of culture. Kramsch (1998) also mentions that language expresses, embodies and symbolizes cultural reality. Mitchell and Myles (2004) argue that language and culture are acquired together with each supporting the development of the other. Liddicoat et al. (2003) also claim that language and culture interact with each other in a way that culture 
connects to all levels of language use and structures, i.e., there is no level of language which is independent of culture (Figure 2.4). The inextricable and interdependent relationship between language and culture is reflected through different terms such as linguaculture (Friedrich, 1989), language-and-culture (Liddicoat et al., 2003), languaculture (Risager, 2005), culturelanguage (Papademetre and Scarino, 2006) or culture-in-language (Carr, 2007). This relationship can be expressed through cultural denotations and connotations in semantics (Byram, 1989), cultural norms in communication (Kramsch, 1993) and the social construction of culture through language (Kramsch, 1995).

FIGURE 2.4

Points of articulation between culture and language (Liddicoat et al., 2003, p.9)

\begin{tabular}{|c|c|c|c|c|}
\hline Culture & & & & Language \\
\hline $\begin{array}{c}\text { world } \\
\text { knowledge }\end{array}$ & $\begin{array}{c}\text { spoken/written } \\
\text { genres }\end{array}$ & $\begin{array}{l}\text { pragmatic } \\
\text { norms }\end{array}$ & $\begin{array}{l}\text { norms of } \\
\text { interaction }\end{array}$ & $\begin{array}{c}\text { grammar/lexicon/ } \\
\text { prosody } \\
\text { pronunciation/ } \\
\text { kinesics }\end{array}$ \\
\hline $\begin{array}{l}\text { Culture in } \\
\text { context }\end{array}$ & $\begin{array}{l}\text { Culture in general } \\
\text { text structure }\end{array}$ & $\begin{array}{c}\text { Culture within } \\
\text { utterances }\end{array}$ & $\begin{array}{l}\text { Culture in the } \\
\text { organisation and } \\
\text { selection of units of } \\
\text { language }\end{array}$ & $\begin{array}{c}\text { Culture in linguistic } \\
\text { and paralinguistic } \\
\text { structures }\end{array}$ \\
\hline
\end{tabular}

Kramsch (1995) distinguishes three types of links between language and culture through the history of language teaching: universal, national and local links. She argues that the universal links between language and culture are effectively captured in literature. These links can draw on the universal canon of world literatures ${ }^{4}$ to ensure "a certain cosmopolitan, at first religious, then aesthetic, view of the world, that various speakers of various languages could share across social and national boundaries" (Kramsch, 1995, p.86). The national links between language and culture convey a national perspective in which language teaching was separated from the

\footnotetext{
${ }^{4}$ Kramsch includes in this canon the 'great works' of world literatures such as the Holy Scriptures or Cicero's oratories.
} 
teaching of literature and the teaching of culture. Subjects like French 'civilisation', German 'Landeskunde', or English 'culture' were therefore taught separately from language learning. Kramsch argues that this separation has caused language teaching to lose sight of the mediating role of language in the social construction of culture and made culture become a fifth skill after speaking, listening, reading and writing. The local links between language and culture place a focus on the pragmatic functions and notions expressed through language in everyday life.

Risager (1996, cited in Larzén, 2005) also distinguishes between three different perspectives on the relationship between language and culture. The first perspective is about the embeddedness of culture in the pragmatics and semantics of language. This perspective reflects the traditional way of culture teaching from a linguistic viewpoint. Risager argues that the linguistic competence may function well and does not necessarily contain the pragmatic and semantic features of native speech. The second perspective sees culture as the macro context of language usage. Language is spoken in different contexts as a first language, a second language or a foreign language. Whenever language is transferred into a new cultural context, language and culture will be reunited in that new context. The third perspective is concerned with culture as the thematic content of language teaching in which there is no given connection between the language use and the spoken and written content.

To summarise, language and culture have an inextricable and interdependent relationship which is expressed through the way they interact with each other. Language has the mediating role that socially constructs culture. This can be recognised in language teaching. The extent of the teacher and student awareness of the relationship between language and culture will be analysed in the second phase of the study. The relationship between language and culture is made meaningful in language learning as "the person who learns language without learning culture risks becoming a fluent fool" (Bennett, Bennett and Allen, 2003, p.237). The interaction between language and culture highlights the importance of intercultural awareness that is described in the next section.

\subsection{Intercultural awareness}

As language and culture are interdependent and inseparable, cultural awareness in language learning becomes essential for language learners. A variety of scholars 
propose different perspectives about cultural awareness. Tomalin and Stempleski (1993) define cultural awareness as "sensitivity to the impact of culturally-induced behaviour on language use and communication" (p.5). They propose three important qualities of cultural awareness: awareness of one's own culturally-induced behaviour, awareness of others' culturally-induced behaviour and the ability to explain one's cultural perspective. Jones (1995) refers to cultural awareness as an exploration of 'otherness'. The term 'otherness' refers to the foreignness of the target language culture that learners need to relate to in foreign language learning. 'Relating to otherness' is considered the essence of intercultural communication as this implies that "both learners' first and target cultures be put under scrutiny in the language class so as to make visible the differences which can potentially prevent the two cultures from relating successfully" (Crozet and Liddicoat, 2000, p.3). Jones (1995) argues that cultural awareness develops with learners who move from examining their own lifestyles and language to an examination of the attitudes, values and conventions of others. Tomalin and Masuhara (2004) also distinguish between cultural knowledge and cultural awareness. Cultural knowledge is defined as "information about the characteristics of our own and other people's cultures" (p.6), and cultural awareness refers to "perceptions of our own and other people's cultures" (ibid). While cultural information is often static, out of date and stereotypical, cultural awareness is dynamic, multi-dimensional and interactive. Tomalin and Masuhara state that cultural awareness can be gained through experiences of the other culture either directly from visiting the culture or indirectly via movies, music, literature and other artefacts (ibid).

However, Rantz and Horan (2005) argue that the concept of 'cultural awareness' does not reflect the complex and dynamic definition of culture as it isolates the target culture in a neutral or objective perspective. They refer to the concept of 'intercultural awareness' that places cultures in relation to each other. This relativism of cultures not only implies one's insight into the target culture and one's self discovery in the process of discovering the other culture but also the importance of moving beyond the surface behaviours and artefacts to the underlying beliefs and values. Such movement implies 'a move from 'ethnocentrism' to 'ethnorelativism', the ability to 'decentre', to see things from someone else's perspective, to develop 'empathy' as well as an awareness of the intercultural process of change of both 
individuals and societies arising out of the dynamics of encounters between them" (Rantz and Horan, 2005, p.211).

In addition, arguing that the ideal outcomes of cultural awareness are not fully managed by most learners, Shaules (2007) offers a more comprehensive account of intercultural awareness with an emphasis on cultural relativism. Cultural relativism means "understanding the limits of one's cultural perspective and appreciating the cultural perspective of others" (p.85). According to Shaules, intercultural understanding is necessary to mitigate potential conflict that may be created from cultural differences. Shaules also states that the deep cultural learning process usually involves both positive and negative reactions to cultural differences as a natural part of the learning process. He suggests that learners' negative reactions to intercultural experiences need to be dealt with in more depth to reflect the deep cultural learning process.

Thus, the concept of intercultural awareness rather than that of cultural awareness reflects the complex and dynamic definition of culture. Intercultural awareness posits cultures in relation to each other. This awareness of cultural relativism will help learners move away from their own cultural perspectives so as to see things from the others' perspective, and thus develop intercultural understanding in the deep cultural learning process. This is related to the concept of intercultural competence described in the next section.

\subsection{The concept of intercultural competence}

Language education has gone through different periods in which its aims have been developed from linguistic competence to communicative competence and intercultural competence. Post-World War-II, Chomsky's (1965) view on the acquisition of linguistic competence was considered an important goal in language learning. Language learners were expected to know about a language by learning the linguistic system, i.e., its grammatical structures, vocabulary and pronunciation. With this view, teachers tended to ignore or even deny the importance of the socio-cultural context in language acquisition.

The emergence of pragmatics in the 1960s and 1970s with an emphasis on the performance of speech acts made language teachers realize that learners cannot communicate effectively with only well-structured sentences. The grammatical 
structures were replaced by lists of language functions. The term 'communicative competence' was first introduced by Hymes in the early 1970s to describe several systems of rules underlying communicative behaviour. In the 'communicative turn' in language education in the early 1980s in the USA and in the mid 1980s in Europe (Canale and Swain, 1980), communicative competence prevailed as the main goal for language learners to learn how to use language appropriately in different situations. The concept of communicative competence was then reconsidered and revised over years with a strong focus on pragmatics (Celce-Murcia, 2007) or enlarged with six competences for language learners to acquire, namely linguistic competence, sociolinguistic competence, discursive competence, strategic competence, social competence and sociocultural competence (Van Ek, 1986).

However, the concept of communicative competence has been criticised by many scholars. It tends to place an emphasis on speech acts and discourse competence rather than cultural competence (Byram, 1997). As Crozet and Liddicoat (2000) argue, "[a] learner who knows some of the language but none of the culture risks being fluent but socially incompetent in any attempt to communicate with native speakers" (p.14). Saville-Troike (1989) also argues that communicative competence must include the notion of cultural competence as the culture of the target language often differs greatly from that of the first language. In a communicative approach, only cultural aspects of the target language are taken into account, while the learner's own culture is left in a peripheral position or even completely ignored (Alptekin, 2002). Crozet and Liddicoat (1999) argue that communicative language teaching did not lead to intercultural understanding, tolerance and harmony between different cultures as it did not fully recognize the links between language and culture.

As the norms of a native speaker are no longer suitable for a foreign language learner, the concept of communicative competence is probably not the most appropriate approach in foreign language teaching. The concept of intercultural competence' (IC) or 'intercultural communicative competence' (ICC) (Byram, 1997) has resulted from the refocusing of the goal of language education with culture at the core as opposed to a narrower focus on linguistic or communicative competence. The use of the term 'intercultural' reflects the view that EFL learners have to gain insight into both their own culture and the foreign culture, as well as be aware of the intercultural encounters that occur in communication situations in the foreign language (Kramsch, 1993). There are many alternative terms that have been used to 
describe this complex concept (Table 2.2). What all these terms account for is the ability to step beyond one's own culture and deal with other people from linguistically and culturally diverse backgrounds (Sinicrope, Norris and Watanabe, 2007).

TABLE 2.2

Alternative terms for intercultural communicative competence

(Sinicrope, Norris and Watanabe, 2007, p.3)

$\begin{array}{lll}\text { transcultural communication } & \text { international communication } & \text { ethnorelativity } \\ \text { cross-cultural communication } & \text { intercultural interaction } & \text { biculturalism } \\ \text { cross-cultural awareness } & \text { intercultural sensitivity } & \text { multiculturalism } \\ \text { global competitive intelligence } & \text { intercultural cooperation } & \text { pluralingualism } \\ \text { global competence } & \text { cultural sensitivity } & \\ \text { cross-cultural adaptation } & \text { cultural competence } & \\ \text { international competence } & \text { effective inter-group communication }\end{array}$

There are different definitions of intercultural competence given by different authors. The conceptualisation of intercultural competence mainly deals with learners' ability to communicate and interact across cultures. For example, Byram (1997) defines intercultural competence as "the ability to communicate and interact across cultural boundaries" (p.7). Paige (2004) refers to intercultural competence as "one's ability to interact and communicate effectively with persons from other cultures and in culturally diverse settings" (p.79). Deardorff (2006) cites her own study (Deardorff, 2004) which provides a top-rated definition of intercultural competence from 23 intercultural scholars: "the ability to communicate effectively and appropriately in intercultural situations based on one's intercultural knowledge, skills and attitudes" (Deardorff, 2004, p.194). Effectiveness is the ability to achieve desired personal outcomes (Wiseman, 2002), while appropriateness is achieved when the communicators meet the expectations and demands of the situation (Straub, 2007, cited in Hiller, 2010).

Apart from the ability to communicate and interact across cultures, the issue of cultural identity in learners' intercultural competence is also taken into account. Kim (2009) defines identity as "an individual's global self-identity that is constituted by both personal and social dimensions" (p.54). In this sense, the term cultural identity 
refers to the group dimension of identity (Kim, 2009). Phan (2008) argues that "identity is constructed, multiple, hybrid and dynamic, but it gives one a sense of belonging" (p.64). Taken the issue of identity into account, Byram, Gribkova and Starkey (2002) define intercultural competence as the "ability to ensure a shared understanding by people of different social identities, and [the] ability to interact with people as complex human beings with multiple identities and their own individuality" (Byram, Gribkova and Starkey, 2002, p.10).

Most importantly, intercultural competence emphasizes learners' mediation between different cultures. According to Risager (1998), intercultural competence is the ability that allows foreign language learners to "function as mediators between their home culture and the target culture and to use the target language as contact language with people who use this language as first language" (p.244). The ability to mediate between cultures enables learners to look at themselves from an 'external' perspective, analyze and adapt their own behaviours, values and beliefs (Byram and Zarate, 1997). It is in this mediation across cultures that self-reflection becomes an important ability. Crozet and Liddicoat (1999) argue that intercultural competence "makes learning a foreign language more than learning skills as it involves a lot of self-reflection where both thoughts and feelings play a part in negotiating meaningful resolution between potential linguacultural clashes" (pp.121-122).

To sum up, the concept of intercultural competence resulted from the refocusing of the goal of language education with culture at the core. Linguistic competence and communicative competence have proven insufficient to prepare learners for study or work in a multicultural setting where intercultural encounters usually occur. Due to its complexity, the concept of intercultural competence has been defined in a range of ways, but it mainly emphasises the ability to communicate effectively and appropriately in intercultural situations and the ability to mediate between languages and cultures.

\subsection{Conceptual models of intercultural competence}

There are many models of intercultural competence that have been conceptualised in the literature. Five important models are described below in chronological order. 


\subsubsection{Bennett's (1993) Developmental Model of Intercultural Sensitivity}

Bennett (1993) proposes the Developmental Model of Intercultural Sensitivity (DMIS) for the acquisition of intercultural competence over a continuum from ethnocentric stages to ethnorelative stages (Figure 2.5). The model assumes that a person develops his or her competence in intercultural relations as the experience of cultural differences becomes more complex (Vogt, 2006).

FIGURE 2.5

Developmental Model of Intercultural Sensitivity (Bennett, 1993)

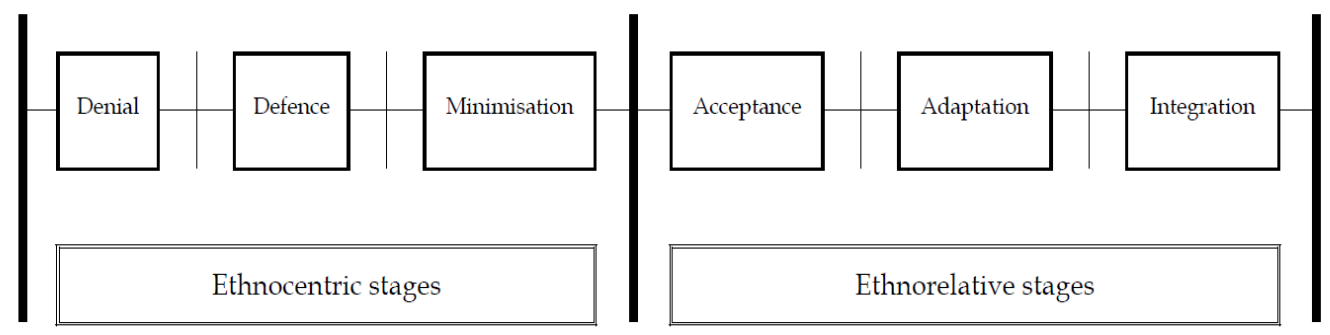

On the continuum of the ethnocentric stages, learners move along from Denial to Defence and Minimization. At the sub-stage of Denial, cultural differences are regarded as an inferior form of one's own cultural experience and learners may not be informed or aware of other cultures or the influence of their own culture on their viewpoints. At the second sub-stage of Defence, learners are likely to divide the world into $u$ s and them and consider their culture superior to others. At the third sub-stage of Minimization, cultural differences are acknowledged, but still treated as unimportant and therefore learners tend to lack cultural self-awareness.

On the continuum of ethnorelative stages, learners move along from Acceptance to Adaptation and Integration. At the sub-stage of Acceptance, learners manifest a respect for difference and identify cultural differences that operate in a wide range of human interactions. At the sub-stage of Adaptation, learners have the ability to shift their cultural frames of reference, that is, they start with an awareness of their own culture and try to look at the world from the other culture's perspective. This shift of perspective helps develop their intercultural empathy. At the last stage of Ethnorelativism, Integration, learners no longer see their self at the center, but rather on the margins of the combination of cultures, and their cultural identity becomes more fluid. Bennett et al. (2003) argue that Integration is not necessarily better than 
Adaptation. So a radical reconstruction of identity is not essential; but what is more important is empathy for one's interlocutor (Liddicoat et al., 2003).

The DMIS has many critics. Liddicoat et al. (2003) argue that this model suggests a linear development of IC, which may not be the case. They state that interculturality and language are loosely connected in the model and there is no clear indication of the place of language and language teaching. Scarino (2009) also argues that the linear progression of the model does not accord with the complexity of the development of intercultural sensitivity and that the model does not recognize the contextualization or specificity of tasks in the development of intercultural competence. Although the model is also linked with language development through novice, intermediate and advanced levels (Bennett et al., 2003), it is still problematic as it assumes that language learners have no prior exposure to issues of intercultural communication and that language proficiency is very closely tied to cultural sensitivity (Liddicoat et al., 2003).

\subsubsection{Byram's (1997) model of intercultural competence}

Byram (1997) develops a model of IC that consists of five savoirs to be acquired by language learners (Figure 2.6). The five savoirs include knowledge, attitudes, skills of interpreting and relating, skills of discovery and interaction and critical cultural awareness. They are defined as follows:

1. Savoirs (knowledge): of social groups and their products and practices in one's own and in one's interlocutor's country, and of the general processes of societal and individual interaction.

2. Savoir être (attitudes): curiosity and openness, readiness to suspend disbelief about other cultures and belief about one's own.

3. Savoir comprendre (skills of interpreting and relating): ability to interpret a document or event from another culture, to explain it and relate it to documents or events from one's own.

4. Savoir apprendre/faire (skills of discovery and interaction): the ability to acquire new knowledge of a culture and cultural practices and the ability to operate knowledge, attitudes and skills under the constraints of real-time communication and interaction. 
5. Savoir s'engager (critical cultural awareness/political education): an ability to evaluate critically, and on the basis of explicit criteria, perspectives, practices and products in one's own and other cultures and countries.

FIGURE 2.6

Elements of intercultural competence (Byram, 1997, p.34)

\begin{tabular}{|c|c|c|}
\hline & $\begin{array}{c}\text { Skills } \\
\text { Interpret and relate } \\
\text { (savoir comprendre) }\end{array}$ & $\begin{array}{c}\text { Attitudes } \\
\text { Relativising self } \\
\text { Valuing other } \\
\text { (savoir être) }\end{array}$ \\
\hline $\begin{array}{c}\text { Knowledge } \\
\text { of self and other; } \\
\text { of interaction: individual and } \\
\text { societal } \\
\text { (savoirs) }\end{array}$ & $\begin{array}{c}\text { Education } \\
\text { Political education } \\
\text { Critical cultural awareness } \\
\text { (savoir s'engager) }\end{array}$ & $\begin{array}{c}\text { Skills } \\
\text { Discover and/or interact } \\
\text { (savoir apprendre/faire) }\end{array}$ \\
\hline
\end{tabular}

These five savoirs can be classified into affective capacities, behaviour and cognitive capacities that an interculturally competent learner needs to display (Byram, 2006, pp.22-26):

(1) Attitudes/Affective capacities

- Acknowledgement of the identities of others

- Respect for otherness

- Tolerance for ambiguity

- Empathy

(2) Behaviour

- Flexibility

- Communicative awareness

(3) Cognitive capacities

- Knowledge

- Knowledge discovery

- Interpreting and relating

- Critical cultural awareness 
Byram argues that the cognitive, affective and behaviour components of ICC are interdependent and the relationship between attitudes and knowledge is not the simple cause and effect often assumed, but quite complex. As Fleming (2003) states, "overemphasis on knowledge may have little impact on the transformation of attitudes" (p.88). Although the cognitive element is often considered to be essential for empathetic understanding, mere exposure to acquisition of the linguistic competence is not sufficient for the development of openness towards other cultures (Byram, Morgan et al., 1994).

Byram (1997) develops a comprehensive model of Intercultural Communicative Competence that consists of not only intercultural competence but also linguistic competence, sociolinguistic competence and discourse competence (Figure 2.7). For Byram, Intercultural Competence (IC) concerns the individual's ability to interact in their own language with people from another country and culture based on their knowledge, attitudes and skills in intercultural communication. Intercultural Communicative Competence (ICC), on the other hand, concerns the individual's ability to interact with people from another country and culture in a foreign language by acting as a mediator between people of different cultural origins. Individuals with ICC therefore draw upon their knowledge of another culture that is linked to their language competence with appropriate language use, their awareness of language connotations, meanings and values and skills for acquiring new languages and cultural understandings. In spite of this distinction, the notions of IC and ICC are usually used interchangeably by many scholars. From the components of ICC, it can be said that linguistic competence is no longer the only purpose of foreign language teaching and learning and therefore the incorporation of culture into the lesson content becomes indispensable (Dinh, 2005). As Byram wants to present a general framework that could be used in different locations of learning including the classroom, field work and independent learning are also taken into consideration in his comprehensive model of ICC. Although Byram shows that the dimensions of ICC are both interrelated and separate, there is a lack of clarity about the level of integration in the model (Scarino, 2009). Also, the framework does not clearly show the process an individual learner goes through to reach deeper levels of intercultural understanding (Shaules, 2007). 
FIGURE 2.7

Byram's (1997) model of intercultural communicative competence (p.73)

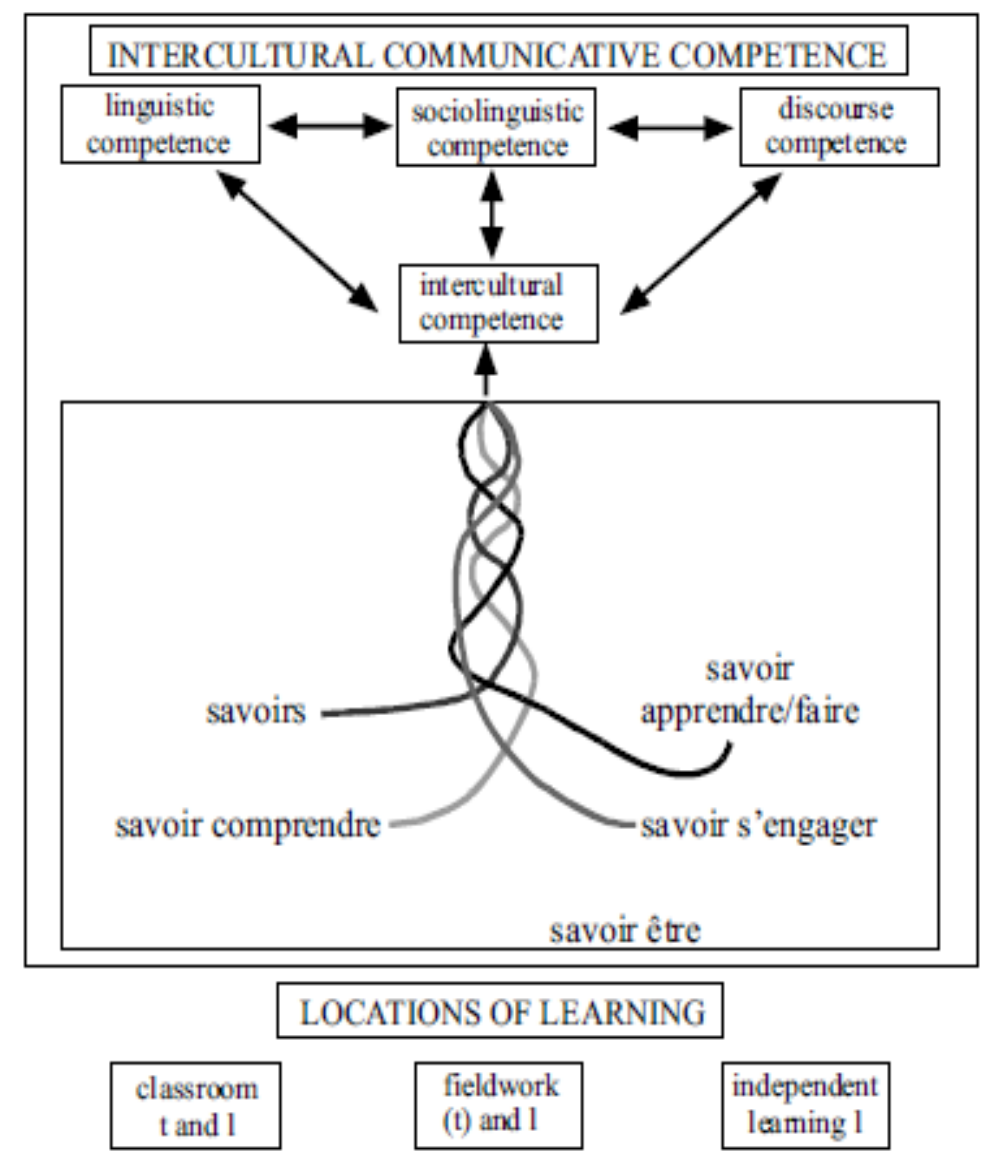

\subsubsection{Fantini's (2000) model of intercultural communicative competence}

Fantini (2000) also constructs a model of intercultural communicative competence that consists of four elements: awareness, attitudes, skills, knowledge (Figure 2.8). Fantini argues that awareness of self and others is the most powerful dimension of the quartet A+ASK and is therefore seen as the keystone on which effective and appropriate interaction depends. Having an influence on other dimensions of the quartet, awareness is located at the centre. Fantini (2005) argues that there is no consensus about what ICC means. He defines ICC briefly as "the complex of abilities needed to perform effectively and appropriately when interacting with those who are linguistically and culturally different from oneself" (Fantini, 2005, p.1). In Fantini's words, effectiveness refers to one's own view of one's performance in the second language-culture (i.e., an "etic" or outsider's view of the host culture), whereas 
appropriateness refers to how one's performance is perceived by one's hosts (i.e., an “emic" or insider's view).

FIGURE 2.8

Fantini's (2000) model of intercultural communicative competence (p.28)

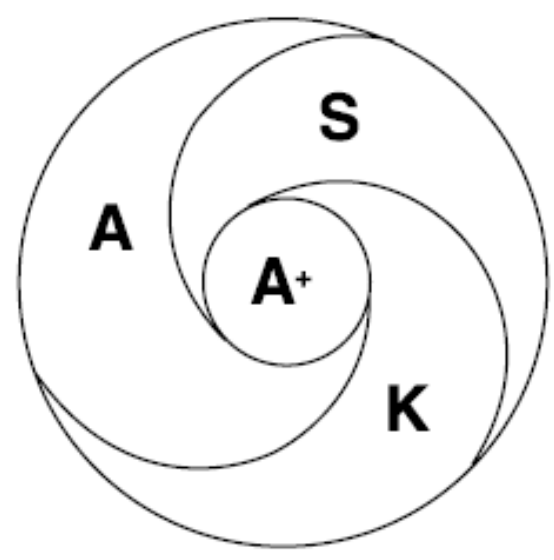

\subsubsection{Liddicoat's (2002) model of intercultural competence acquisition}

Liddicoat (2002) proposes a model of intercultural competence acquisition in a nonlinear, cyclical process (Figure 2.9). Learners start acquiring culture through language with new elements of input that are then noticed for reflection and experimentation. The noticing is an important stage for learners to reflect on the nature of the difference and modify their practices to accommodate the new input. This leads to output in the language with a modified set of norms which itself provides opportunities for new noticing. This new noticing is then ready for learners to have further reflections on their new output, which puts them in a continuous cycle of acquisition of culture.

FIGURE 2.9

A path for developing intercultural competence (Liddicoat, 2002)

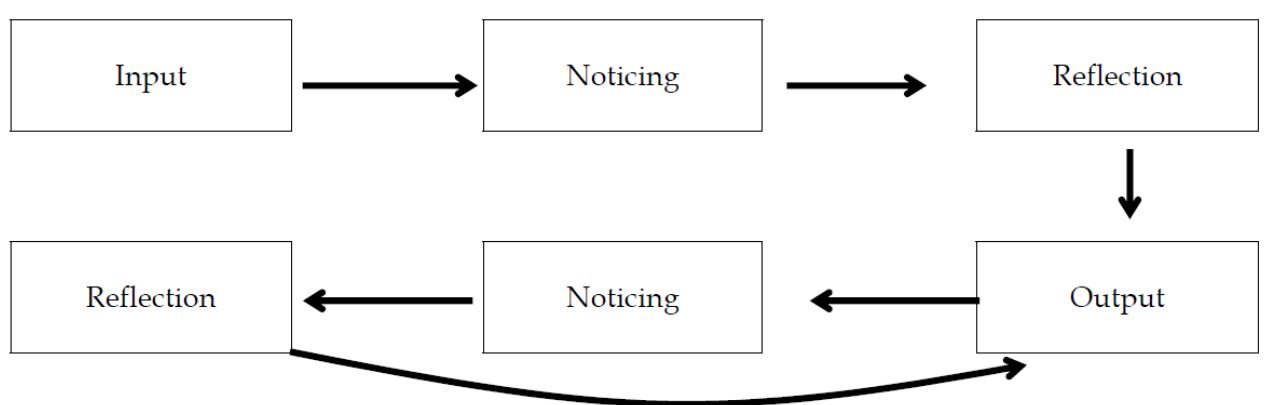


Liddicoat (2002) further argues that learners develop their process of cultural acquisition through an approximate system of practices that consists of a set of intercultural practices or intercultures (Figure 2.10). Liddicoat states that these intercultures are learners' accommodations to their noticing and reflection on the input, which may contain rules identical to those of their first culture, rules derived from the target culture and rules that belong to neither culture. Liddicoat et al. (2003) argue that the progression in developing intercultures is not linear or staged as learners may adopt an uncomfortable practice that makes them move to a more comfortable position. This means that "the end-point of cultural development is not the L2 cultural practices, but rather an intermediate intercultural 'third place' developed between the L1 and L2 sets of practices" (Liddicoat et al., 2003, p.21). Consequently, evidence of less 'native-like' practices may be the result of ongoing intercultural development or progression in learning (ibid). This implies that a foreign language learner does not need to assume the role of a native speaker, but that of an intercultural speaker.

FIGURE 2.10

Progression in developing intercultures (Liddicoat, 2002)

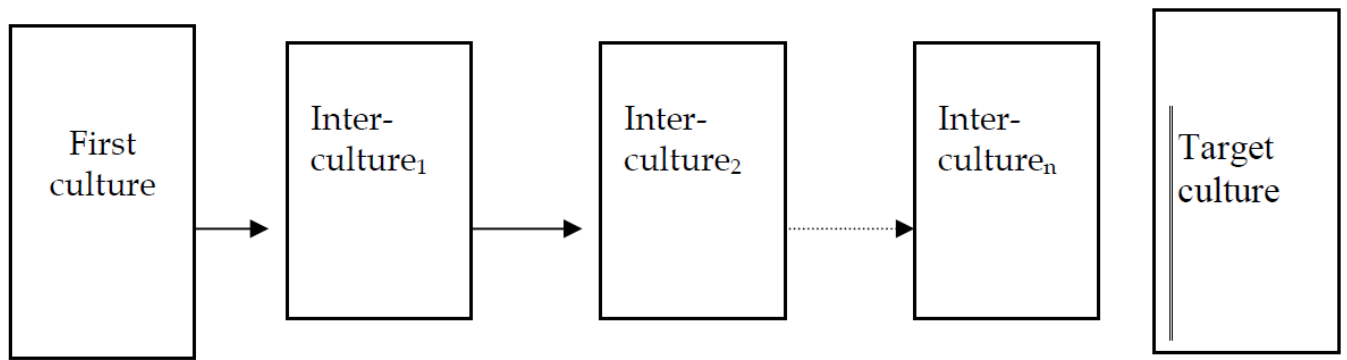

However, Newton and Shearn (2010a) argue that this model has a number of limitations. First, the model does not acknowledge the relationship between the target culture and the intercultures. Second, the model starts with a monocultural learner which is often not the case particularly in multicultural societies where learners come to the language classroom with a variety of pluralistic cultural and linguistic backgrounds. Third, the movement away from the first culture in the model does not reflect "a cultural win-win situation" (Finkbeiner, 2007, p.7) of intercultural language learning. 


\subsubsection{Deardorff's (2004) model of intercultural competence}

Deardorff (2006) cites her own study (Deardorff, 2004) which develops a process model of intercultural competence (Figure 2.11) as a student outcome of internationalisation. This model conceptualises the dynamic and ongoing process of acquiring intercultural competence. As one never achieves ultimate intercultural competence, the process of acquiring this competency is crucial.

FIGURE 2.11

Process model of intercultural competence (Deardorff, 2006, p.256)

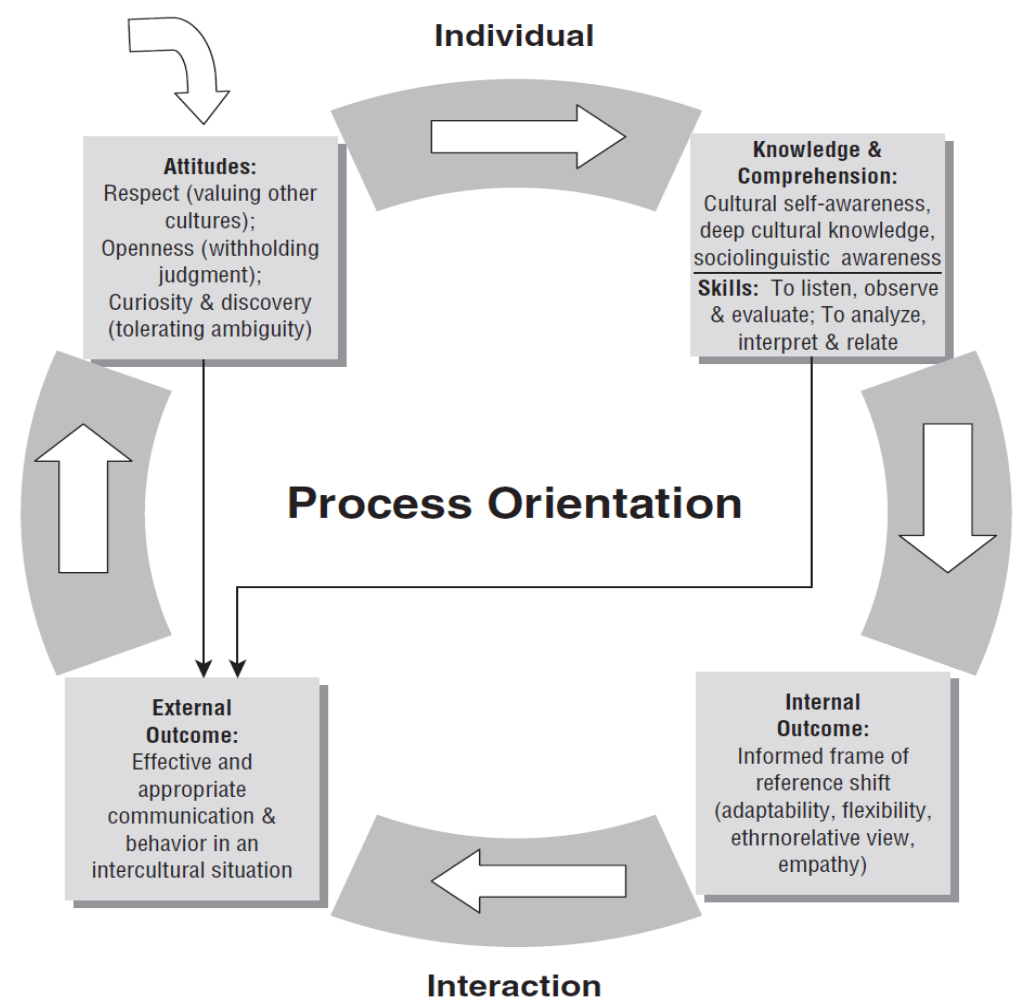

The model shows the movement from the personal level to the interpersonal level. The personal level starts with the learner's pre-requisite attitudes of respect, openness, curiosity and discovery, followed by the acquisition of knowledge and specific skills. This level leads to the internal outcome that involves the informed frame of reference shift such as adaptability, flexibility, empathy and ethnorelative views. The interpersonal level is achieved through intercultural interaction, which leads to the desired external outcome in which learners behave and communicate effectively and appropriately in intercultural situations. This external outcome will lead to attitudes of 
respect, openness, curiosity and discovery in a cyclical framework. This indicates that the role of the attitudinal element is considered the most critical in this model as it can be the starting point and also the outcome. Deardorff (2008) believes this model has a Western bias as it was derived from the opinions of intercultural experts who were predominant from the United States.

\subsubsection{Summary}

The major models of intercultural competence are summarised in Table 2.3.

TABLE 2.3

\section{Summary of conceptual models of intercultural competence}

\begin{tabular}{|c|c|c|}
\hline No. & Model of IC & Constructs \\
\hline 1. & $\begin{array}{l}\text { Bennet's (1993) Developmental } \\
\text { Model of Intercultural } \\
\text { Sensitivity (DMIS) }\end{array}$ & $\begin{array}{l}\text { - Ethnocentric stages: Denial, Defence, Minimization } \\
\text { - Ethnorelative stages: Acceptance, Adaptation, } \\
\text { Integration }\end{array}$ \\
\hline 2. & $\begin{array}{l}\text { Byram's (1997) model of } \\
\text { intercultural competence }\end{array}$ & $\begin{array}{l}\text { - Intercultural competence: Knowledge, Attitudes, Skills of } \\
\text { discovery and interaction, Skills of interpreting and } \\
\text { interaction, Critical cultural awareness } \\
\text { - Intercultural communicative competence: Linguistic } \\
\text { competence, sociolinguistic competence, discourse } \\
\text { competence, intercultural competence }\end{array}$ \\
\hline 3. & $\begin{array}{l}\text { Fantini's (2000) model of } \\
\text { intercultural communicative } \\
\text { competence }\end{array}$ & $\begin{array}{l}\text { - Knowledge } \\
\text { - Attitudes } \\
\text { - Skills } \\
\text { - Awareness }\end{array}$ \\
\hline 4. & $\begin{array}{l}\text { Liddicoat's (2002) model of } \\
\text { intercultural competence } \\
\text { acquisition }\end{array}$ & $\begin{array}{l}\text { - Input } \\
\text { - Noticing } \\
\text { - Reflection } \\
\text { - Output } \\
\text { - Intercultures }\end{array}$ \\
\hline 5. & $\begin{array}{l}\text { Deardorff's (2004) process } \\
\text { model of intercultural } \\
\text { competence }\end{array}$ & $\begin{array}{l}\text { - Attitudes } \\
\text { - Knowledge and comprehension } \\
\text { - Internal outcome (e.g., empathy and ethnorelative views) } \\
\text { - External outcome (effective and appropriate } \\
\text { communication and behaviour) }\end{array}$ \\
\hline
\end{tabular}


Among these conceptual models of intercultural competence, while the ones of Byram and Fantini involve knowledge, skills, attitudes and awareness as the four core components of this competency, the other models focus on the process of acquiring intercultural competence. Although Byram's model is the most comprehensive as it could be used in different contexts, there is a lack of clarity about the process of developing learners' intercultural understanding. The models of Bennett and Liddicoat show the acquisition of intercultural competence through different stages, but still have limitations in terms of linearity. Deardorff's model reflects a more dynamic and ongoing process of acquiring intercultural competence. The strengths of these models should be explored while their limitations need to be taken into consideration in language practice. The review of these conceptual models of intercultural competence will shed light on the nature of the development of intercultural competence of the students in the third phase of the study.

\subsection{Culture teaching and learning in foreign language education}

This section reviews approaches to culture in foreign language education and previous studies on culture teaching and learning in the classroom in different contexts around the world.

\subsubsection{Approaches to culture in foreign language education}

Culture in language teaching has undergone many changes, each of which can be seen as a reconceptualisation of culture and the role of culture in language teaching (Crozet, Liddicoat and Lo Bianco, 1999). Through the history of culture pedagogy, Liddicoat et al. (2003, pp.5-7) identify four broad approaches to culture in foreign language teaching and learning. These approaches are not strictly time bound and are often contiguous although, as Liddicoat et al. note, the culture as societal norms approach emerged in the 1980s and the culture as practice approach in the 1990s.

High culture: This is the traditional way of teaching culture that focuses on an established canon of literature. Cultural competence is measured through the breadth of reading and knowledge about the literature. The relationship between language and culture in its broad sense is quite tenuous due to the minimal language use for 
communication with native speakers. This approach to culture minimizes the use of language for communication with native speakers and sees culture residing primarily in the text itself.

Area studies: This approach to culture focuses on knowledge about a country which is often presented as background knowledge for language learning. The learner is described as a "knower of cultural information" (Liddicoat, 2004, p.55). Culture competence is particularly viewed through the depth of knowledge of the history, geography and institutions of the target language country. The culture pedagogy in this period was mainly content-oriented (Risager, 2007). Culture was usually taught separately from language learning on courses such as Landeskunde (in Germany), civilisation (in France) and civilita (in Italy) (Byram, 1989; Kramsch, 1993). Culture in this approach is something to be observed with the learner constructed as an external observer of culture rather than as an internal practitioner (Liddicoat, 2004). Language and culture have a loose connection as language is mainly used for events, institutions, people and places.

Culture as societal norms: This approach, which resulted from the work of anthropologists in the 1980s, views culture as the practices and values that typify them. Everyday behaviours of members of speech communities are viewed as grounded in the national culture (Kramsch, 2006). Cultural competence is measured by one's knowledge about things that a cultural group is likely to do and understanding of cultural values by certain ways of acting or beliefs. This view of cultural competence is problematic as the learner observes and interprets an interlocutor's language and actions from another cultural paradigm. As Risager (2007) argues, the relationship between language and culture in this approach is described as a marriage, which presupposes a distinct dichotomy between language and culture. As in high culture and area studies approaches, the view of culture in this approach is considered static and homogeneous and easily leads to a possibility of the stereotyping of the target culture (Liddicoat, 2006).

Culture as practice: This approach views culture as sets of practices or the lived experience of the individual (Geertz, 1983). This 'cultural turn' as a breakthrough in language pedagogy in the 1990s provided a foundation for intercultural language 
learning (Risager, 2007). According to Risager, this period was characterised by internationalisation with a marked increase in overseas student exchanges and school trips, which made the teaching of culture become more oriented towards experienced culture and personal culture encounters. In the culture as practice approach, the learners' cultural competence is shown in the ability to interact in the target culture in informed ways. In other words, culture is seen as an "interactionally constructed product" (Liddicoat, 2004, p.57). This approach to culture advocates a critical foreign language pedagogy that examines the culturally constructed nature of the self and the other and creates hybridity (Liddicoat, 2004). It also engages language learners in developing an intercultural perspective in which their own culture and the target culture are involved. With such a perspective, learners are able to reach an intercultural position where they continuously develop intercultural communicative skills during the process of language learning.

From these four broad approaches to culture, Liddicoat et al. (2003) distinguish two main views of culture: the static view and the dynamic view. The static view of culture assumes that culture contains factual knowledge or cultural artefacts to be observed and learned about. Teaching therefore focuses on topics such as the history, customs, institutions, arts, literature and geography of a country (Liddicoat et al., 2003). This view of culture does not clearly link language and culture (Liddicoat, 2001) and simply consists of "information to be transmitted" (Crawford and McLaren, 2003, p.33). The static view of culture, therefore, does not study culture as a process in which the learner will eventually engage (Liddicoat, 2002).

The dynamic view of culture, on the other hand, contrasts with the static one and is emphasized in intercultural language learning. This view of culture requires learners to actively engage in culture learning, rather than merely learn about the target culture in a passive way. They are encouraged to view cultural facts as situated in time and space and variable across time, regions, classes and generations (Crawford and McLaren, 2003). This view of culture also requires learners to have knowledge of their own culture and an understanding of their own culturally-shaped behaviours. The culture as practice approach is regarded as a dynamic view of culture as teachers can help learners decentre from their own culture (Byram, 1989; Kramsch, 1993) with sorts of exposure to the target culture and the skills and knowledge they need to achieve decentring (Liddicoat et al., 2003). Chambers (2004) attaches the dynamic 
view of culture to the intercultural perspective that takes the dynamic process of change in culture into account, both at social and individual levels. The culture as practice approach to culture with a dynamic view of culture will be adopted in the intercultural lessons in the empirical study.

\subsubsection{Research on culture teaching and learning in European and Western contexts}

The foreign language classroom can be seen as a kind of microcosm of the real world where languages and cultures come into contact with one another (Coperias Aguilar, 2009). Culture teaching in the EFL classroom can be dealt with from two broad perspectives: teaching culture as information and teaching culture as process (Wright, 2000). Teaching culture as information involves the cultural information that the instructor imparts to students through culture learning devices such as culture capsules, culture clusters, culture incidents and assimilators and culture mini-dramas (Lange, 1998). However, an emphasis on culture as a dynamic set of practices or the lived experience of individuals (Geertz, 1983) leads to greater emphasis on experience and perceptions of culture as a process. Allen (1985) argues that awareness and appreciation of another culture are achieved through students' ongoing discovery process. Culture learning as a process provides students with opportunities to explore different cultural aspects, reflect on their cultural explorations and create their own relational meanings between their own culture and the target culture (Kramsch, 1993).

A large number of previous international research studies have investigated how foreign language teachers perceive culture in language teaching in different contexts. Byram and Risager's (1999) study with 212 English teachers in Britain and 653 Danish teachers in Denmark showed that there was a concentration of national culture and little attention paid to aspects of culture beyond those in textbooks. Although Danish teachers tended to have a deeper and more flexible understanding of the concept of culture than the British, very few teachers thought that the cultural dimension of foreign language teaching was more important than the linguistic one. Sercu's (2001) survey of 135 teachers of English, French and German in Belgium showed that culture was viewed by the teachers within a traditional paradigm with no reference to promoting intercultural communicative competence (cited in Larzén, 2005). 
In Spain, Castro, Sercu and Mendez Garcia (2004) conducted a study in which Spanish secondary school EFL teachers supported the new culture and language teaching objectives in the curriculum even while they were conflicted by needing to prioritise culture teaching in language teaching. This study was a part of a large-scale study conducted by Sercu et al. (2005) in seven countries (Belgium, Bulgaria, Greece, Mexico, Poland, Spain and Sweden) that divided foreign language teachers based on two distinct profiles: the favourably disposed teachers, who were willing to teach intercultural competence, and the unfavourably disposed teachers, who were reluctant to do so. In spite of the teachers' willingness to interculturalise foreign language teaching, traditional information-transfer pedagogy was still prevalent among the teachers in the seven countries. The shortcoming of this information-rich type of culture teaching is that it frequently develops stereotypical images and gives learners no personal strategies for reflection (Liddicoat, 2006).

In the USA, Klein's (2004) study of high school language teachers found that culture teaching was separated from language instruction. Klein states that the maximization of the teachers' language production keeps culture learning at a surface level and may interfere with the achievement of their cultural goals. Diaz-Greenberg and Nevin (2003) investigated how three student teachers distinguished between the 'Five Cs approach' (Communication, Cultures, Connections, Comparisons and Communities) proposed by the National Standards and the 'Four Fs approach' (Food, Fashion, Festivals and Folklore). The study showed that the student teachers could teach culture with the 'Five Cs approach' although their textbooks may present the 'Four Fs approach'. It concluded that the cultural background of teachers may affect their perceptions as well as presentation of the cultural norms of the target culture.

\subsubsection{Research on culture teaching and learning in Asian contexts}

The majority of theories and scholarship in intercultural language learning is Western and potentially Eurocentric. Kim (2010) argues that there has been an unchallenged predominance of American scholarship in shaping the development of intercultural communication in Asia. However, she states that the current state of research reflects "a healthy transformation from uncritical presentations of research in Western traditions to reflective applications of such research to Asian cultural contexts" (Kim, 2010, p.176). 
The status of culture in EFL education has recently been given more emphasis in Asian countries. In Thailand, for example, the National Education Curriculum in 2002 has incorporated culture into the curriculum based on four strands: culture, communication, connection and community (the 4Cs) (Baker, 2008). Based on the increasingly intercultural nature of English use and teaching in Thailand, Baker states that there are many opportunities to develop cultural awareness in the context of Thai EFL classroom.

In Korea, Jon (2009) investigated the interculturality in higher education as student intercultural learning and development through a domestically based international programme. Jon shows that the international students had a strong impact on Korean students' intercultural learning experiences. The Korean students became more aware of cultural differences and intercultural perspectives as personal intercultural change and had both positive and negative experiences in their interaction with international students and faculty.

In China, intercultural awareness in foreign language teaching and learning has also received more attention since the beginning of this century. Newton and Shearn (2010a) mention that the reform in English education in China in 2006 adopted cultural awareness as one of the five objectives of English teaching and learning through the test framework of New Standards for English Course ${ }^{5}$. Yu and Chang (2009) investigated Chinese learners' intercultural communicative competence and found that the English teaching in China tended to focus more on cultural knowledge but less on developing learners' communication awareness and communicative competence. $\mathrm{Yu}$ and Change concluded that there was still much room for Chinese learners to improve their intercultural attitudes towards foreign cultures. Wang and Coleman (2009) conducted a survey of Internet-mediated intercultural foreign language education in China and found that the traditional teaching of linguistic and cultural knowledge was still widely valued and influential and the implementation of an ICC-oriented pedagogy was largely impeded by technical, pedagogical and practical constraints.

In spite of this emerging emphasis on culture in the curriculum and an effort to incorporate interculturality into EFL education in Asian countries, culture teaching and learning practices still have a peripheral status. For example, in Taiwan, most

\footnotetext{
${ }^{5} \mathrm{http}: / /$ www.100875.com.cn/newsdetail.cfm?iCntno=9961.
} 
EFL teachers were not confident enough about their skills and knowledge for culture teaching and some of them were even skeptical about the necessity and significance of teaching culture in their language classrooms (Tsou, 2005). In addition, there was also a lack of guidelines for culture teaching and empirical research on culture learning, which made teachers less willing to teach culture in the classroom (ibid). These shortcomings suggest that there is still room for developing the intercultural strand of language teaching in Asian contexts.

\subsubsection{Summary}

The history of culture pedagogy has witnessed four broad approaches to culture in foreign language teaching and learning, which involve high culture, area studies, culture as societal norms and culture as practice. Among these four approaches, only the culture as practice approach engages language learners in developing an intercultural perspective in which their own culture and the target culture are involved. This approach to culture is regarded as a dynamic view of culture within language teaching and learning as it can help language learners to decentre from their own culture and reach an intercultural position where they can continuously develop intercultural communicative skills in the process of language learning. However, previous research studies show that the intercultural dimension of language teaching is still underestimated in Western contexts. In Asian contexts, culture teaching and learning in practices also have a peripheral status. The culture as practice approach corresponds to the intercultural approach to language learning that is described in the next section.

\subsection{Intercultural language learning}

This section will define intercultural language learning and describe its process.

\subsubsection{Definition of intercultural language learning}

Since the 1990s, based on the deeper understanding of the interdependence between language and culture, intercultural language teaching has emerged as a new approach to language teaching that teaches culture as an integrated part of language (Crozet and Liddicoat, 2000). This approach implies "an acknowledgement and understanding of 
the links between language and culture as well as an understanding of how communication works across cultures" (Crozet and Liddicoat, 2000, p.1). According to Liddicoat et al. (2003), language and culture are placed at the centre of the learning process as these elements are fundamentally interrelated. Intercultural language learning (IcLL) is defined as follows:

Intercultural language learning involves developing with learners an understanding of their own language(s) and culture(s) in relation to an additional language and culture. It is a dialogue that allows for reaching a common ground for negotiation to take place, and where variable points of view are recognised, mediated, and accepted (Liddicoat et al., 2003, p.46).

Liddicoat et al. (2003) set up the goals of IcLL at both global and individual levels. At the global level, language learners develop an understanding and valuing of all languages and cultures, an understanding and valuing of their own language(s) and culture(s) and their target language(s) and culture(s) as well as intercultural sensitivity as an ongoing goal and are able to mediate between languages and cultures. At the individual level, language learners are able to communicate interculturally using multiple perspectives to understand and create meaning, i.e., to become an intercultural language user. In this sense, learners' intercultural space and identity are emphasised in their dynamic engagement in intercultural interactions.

Kaikkonen (2001) mentions some qualities that language learners need to develop in IcLL. According to Kaikkonen, "[t]he ability to be sensitive to both familiar and foreign phenomena, the ability for empathy, seeing things from the others' points of view and to share feelings with others are essential for intercultural foreign language learning” (p.101). Other important qualities include respect for diversity and tolerance. As Kaikkonen states, "tolerance is a matter of growing out of the narrowness of one's own social behaviour, growing out of the belief that the behaviours that are typical of one's own national or cultural group are somehow better or more natural than the behaviours of others" (p.101). These essential qualities can be acquired through the process of intercultural language learning.

\subsubsection{Process of intercultural language learning}

In IcLL, language learners go through a complicated process. Kaikkonen (2001) argues that in this process the learner's picture of culture grows wider as the learner 
constantly acquires new information about the foreign culture and language as well as consciousness of the special features of their own culture and language (Figure 2.12). This "multidimensional learning process" (Kaikkonen, 2001, p.90, italics in the original) provides language learners with opportunities to connect new knowledge of the target culture with their previous experiences and knowledge. As Kaikkonen mentions, individuals interpret the surrounding reality in different ways even though they belong to the same community. Therefore, the starting point in foreign language education is from one's own previous knowledge, experience, beliefs and ideas:

We are shaped by our culturally influenced perceptions about people (attitudes to and roles of children, old people, men and women, equality, social class, etc.); by our conceptions of knowledge, language, communication and interaction; our ways of living, residing, eating, drinking, getting dressed, moving around, etc.; by our national and social traditions; and by ideas connected with race, nation, tribe and so on (Kaikkonen, 2001, p.75).

\section{FIGURE 2.12}

Widening the learner's picture of culture (Kaikkonen, 2001, p.86)

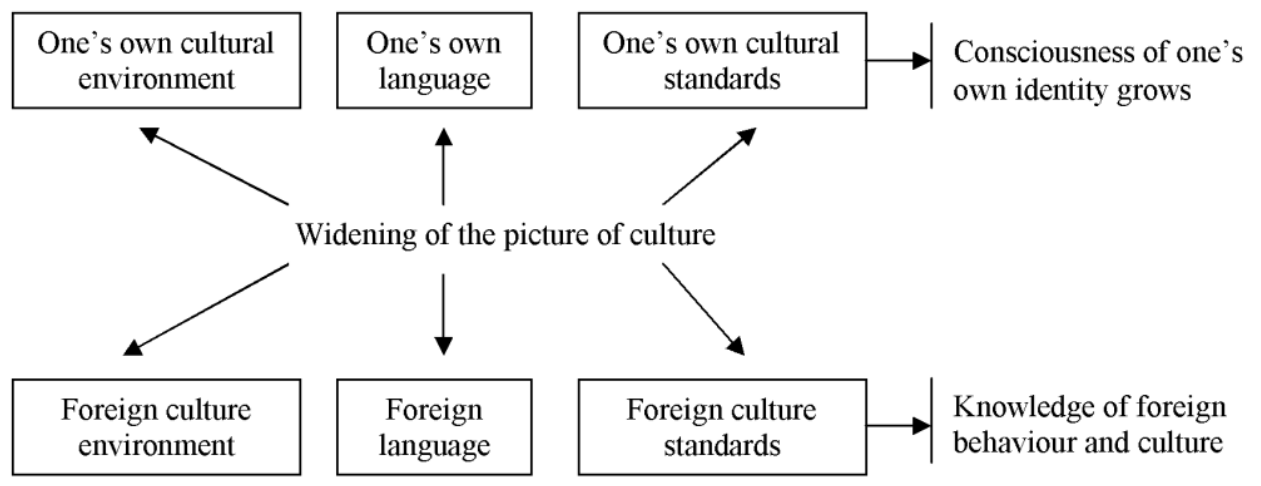

Kaikkonen (1997) argues that the language learner needs to go through four stages of interculturally oriented language learning (Figure 2.13). Firstly, the learner needs to be sensitised to foreign phenomena. Secondly, the learner observes the foreign culture and its phenomena and compares his/her observations with those of his/her own culture. Thirdly, the learner gets information about the foreign language and its cultural standards and compares with those of his/her own language and culture. Finally, new meanings get shaped and built on the basis of the first three stages, which eventually leads to successful communication and interaction with members of 
the foreign culture. From these four stages of IcLL, it can be seen that observations and cultural comparisons are very important stages for learners to reflect upon and build new meanings and concepts from which they can successfully interact with members of the foreign culture.

FIGURE 2.13

Different stages of intercultural learning (Kaikkonen, 1997, p.49)

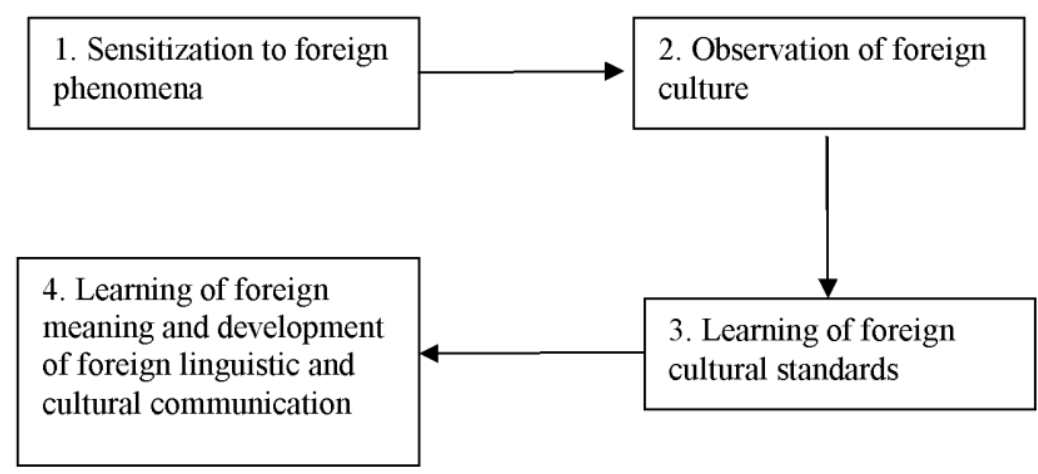

Kaikkonen (2001) also uses the metaphor of the protective shell of the native language and culture that learners have to grow out of to learn about the target culture. As Liddicoat (2004) states, the intercultural approach puts the focus on the teaching of the self in relation to the other and the other in relation to the self. This means that learners have to shift from the familiar in their own culture to the unfamiliar or the foreignness in the target culture. This process is called de-familiarization in which learners take an 'alien perspective' to distance themselves from what has been taken for granted (Stevens, 2003). It is by relativising one's self and the other that learners engage in a process in which they infer, compare, interpret, discuss and negotiate meanings (Liddicoat et al., 2003). In other words, they are able to decentre from their cultural positioning and view their practices from an external perspective as well as develop both insider and outsider perspectives on the target culture (Liddicoat, 2004).

In this process of decentring, the learner tries to find a negotiated interactional space between cultures or the "third place" (Kramsch, 1993, p.236). This concept originates in Bhabha's (1992) description of a 'third space' that "revalues the ideological bases of division and difference" (p.58). The third place refers to a location between the home and target cultures where one's own and the other's behaviours are grounded in a particular cultural context (O'Dowd, 2003). It is a "common ground for negotiation to take place and where variable points of view are 
recognised, mediated and accepted" (Liddicoat et al., 2003, p.46). Kramsch (1993) also uses the image of "being on the fence" for language learners who need to locate themselves in a place that "grows in the interstices between the cultures the learner grew up with and new cultures he or she is being introduced to" (p.236). It is in this unbounded and dynamic place that language learners can bridge the gap between cultural differences and achieve their personal and communicative goals (Crozet and Liddicoat, 2000).

\subsubsection{The intercultural speaker}

The spread of English as an international language all over the world has led to the question of its ownership. English is no longer a property of English-speaking countries. Graddol (2006) suggests that Global English or English as a lingua franca may eventually replace EFL as the goal of language teaching. From this perspective, the ultimate goal of foreign language learning is not native speaker-level competence. This means that the movement towards the target culture does not imply that language learners have to develop native speaker-like abilities. Lange and Paige (2003) argue that learners "should be helped to understand the native speaker's communicative intentions but should not be expected to behave in a native-like manner" (p.xii). Fantini (2005) states that the intercultural experience allows but does not demand native-like behaviour as individual choices are both complex and personal.

In fact, native speaker-level communicative competence is an unrealistic goal for most language learners. This goal assumes that they have to ignore their own social and cultural identities and adopt a new sociocultural identity (Byram, 1997; Kramsch, 1997, 2006). Peltokorpi and Schneider (2009) state that "very 'native' behaviour could create confusion and uncertainty among the locals, and thus make communication more difficult" (p.291). Peltokorpi and Schneider cite a study of Dahl and Habert (1986) which shows that a lot of Japanese people increased their uncertainty and confusion when they were confronted by a foreigner who spoke fluent Japanese and acted exactly like a Japanese as they could not categorize him or her as either Japanese or foreign. The aim of IcLL is that learners need to understand their own identity in relation to others and develop openness to diversity, willingness to engage with others and move away from ethnocentrism in identity construction (Bennett et al., 2003; Kramsch, 1993). 
Instead of trying to attain native-speaker competence, foreign language learners need to constantly refine their position as an intercultural communicator between their existing, familiar cultural practices and the ones experienced from the learning of the target language (Kramsch, 1993). They need to take a step back to critically evaluate both their own beliefs and values and those of target culture members. By doing this, the intercultural learner is

....able to see relationships between different cultures - both internal and external to a society - and is able to mediate, that is interpret each in terms of the other, either for themselves or for other people. It is also someone who has critical or analytical understanding of (parts of) their own and other cultures - someone who is conscious of their own perspective, of the way in which their thinking is culturally determined, rather than believing that their understanding and perspective is natural (Byram, 2000, p.10).

In other words, they become 'intercultural speakers' who are able to "mediate/interpret the values, beliefs and behaviours (the 'cultures') of themselves and of others and to 'stand on the bridge' or indeed 'be the bridge' between people of different languages and cultures" (Byram, 2006, p.12). This means that the learner has to go through a 'hybridisation process' (House, 2007) in their mediation between cultures. This is the 'third place' that the learner needs to attain.

Kramsch (1993) argues that the intercultural speaker with his or her linguistic competence in combination with knowledge and understanding of other cultures can act as a mediator between cultures. This ability to mediate between cultures is identified as one of the main aims of intercultural language teaching and is defined as "being able to take an external perspective on oneself as one interacts with others and to analyze and, where desirable, adapt one's behaviour and underlying values and beliefs" (Byram, 2006, p.4). Byram argues that the act of mediation between cultures distinguishes the 'intercultural' from the 'bicultural' as the latter does not intrinsically involve this act. However, the demands on the intercultural speaker become great with an emphasis within intercultural competence on learner autonomy and lifelong learning as language learners not only have to mediate between cultures in a certain context but also in all kinds of situations that may be unfamiliar to them. 


\subsubsection{Summary}

Intercultural language learning is an approach to language teaching based on a deep understanding of the interdependence of the relationship between language and culture. In intercultural language learning, learners need to develop an understanding and valuing of their own language and culture as well as the target language and culture and be able to mediate among languages and cultures. To develop this ability, learners have to go through different stages of a complicated intercultural process in order to successfully communicate and interact with members of other cultures. The following section examines a variety of principles to be applied for intercultural language teaching and learning.

\subsection{Principles for intercultural language teaching and learning}

This section reviews the principles for intercultural language teaching and learning which can be used as guidelines for an interculturally informed pedagogy.

\subsubsection{Principles for intercultural language teaching}

Newton and Shearn (2010b) propose six principles for intercultural communicative language teaching (iCLT) (pp.63-76). These principles are briefly reviewed below.

\section{Principle 1: iCLT integrates language and culture from the beginning}

This principle highlights the interdependent and inextricable relationship between language and culture (see section 2.3 in this chapter). Kramsch (1993) refers to the cultural act performed in our speech, while Carr (2007) uses the term 'culture-inlanguage' for the relationship between these two components. Liddicoat (2008) also emphasises the dynamic interplay of culture with language in communication:

Every message a human being communicates through language is communicated in a cultural context. Cultures shape the ways language is structured and the ways in which language is used. A language learner who has learnt only the grammar and vocabulary of a language is, therefore, not well equipped to communicate in that language (p.278). 
Culture becomes an important part of the teaching of all the language macroskills (Crozet and Liddicoat, 2000). Learners need to learn both language and culture 'from the beginning', i.e., the earliest stages of language learning. As Liddicoat et al. (2003) argue, delaying cultural input could open up space for false or uninformed cultural learning as a result of a lack of awareness of difference. Liddicoat (2008) points out the consequences that result from such delay of cultural input in language learning:

Language is not learnt in a cultural vacuum which can be filled in later; rather, learners create their own cultural assumptions as they learn. An absence of input about culture does not leave a vacant cultural space. Rather, it fosters a cultural space which is filled by uninformed and analysed assumptions based on assumptions and understandings from the learners' first culture (p.279).

\section{Principle 2: iCLT engages learners in genuine social interaction}

Newton and Shearn (2010b) state that learners experience culture through the ways of communication as well as the oral and written content. As they point out, "interaction is not simply a tool for developing fluency; it provides opportunities for learners to confront their culturally constructed worlds and cultural assumptions, and so to learn more about themselves" (p.66). Learners also engage in social interaction by actively constructing knowledge through their interpretation and interrogation of cultural input (Crichton, Paige, Papademetre and Scarino, 2004). Opportunities for language learners to engage in interaction with not only native speakers of the target language but also with other cultural informants are valuable in order to enhance the process of acquiring interculturality.

Principle 3: iCLT encourages and develops an exploratory and reflective approach to culture and culture-in language

The principle implies that cultural acquisition involves much more than the acquisition of only facts. Factual approaches to culture teaching used by any program of teaching culture are of limited benefit for learners (Liddicoat et al., 2003). As Ingram and O’Neil (2001) argue, “knowledge alone leaves learners ensconced in their own culture looking out at the other culture and observing its differences (often 
judgementally) - rather like walking through a museum" (p.14). iCLT encourages and develops exploratory learning which is seen as "a process of discovery that allows learners to develop their individual conceptualisations of culture and to decentre from their taken-for-granted cultural world" (Newton and Shearn, 2010b, p.68). In this type of learning, learners are encouraged to see cultural information as subjective and dynamic (Byram, 1997), actively construct knowledge and critically evaluate aspects of the target culture from their experience and reflection.

\section{Principle 4: iCLT fosters explicit comparisons and connections between languages and cultures}

Cultural comparison is a fundamental process of intercultural language learning in which learners explore a new culture and a new language while making connections with their own culture and language (Liddicoat et al., 2003). This cultural awareness aims to enhance an "inner sense of the equality of cultures, an increased understanding of [one's] own and other's people's cultures, and a positive interest in how cultures both connect and differ" (Tomlinson, 2001). By making comparisons and connections between languages and cultures, learners can achieve insights into the self and others (Byram, 2006, Kramsch, 2006). Newton and Shearn (2010b) suggest that a reflective, interpretative comparison which draws on the learner's current knowledge and the new knowledge they are acquiring should be encouraged to make iCLT more effective.

\section{Principle 5: iCLT acknowledges and responds appropriately to diverse learners and learning contexts}

This principle highlights the importance of recognising and embracing diversity of learners in iCLT. Research on teaching for diverse learners and culturally responsive teaching highlights the effectiveness of instructional practices, particularly in multicultural classes (Newton and Shearn, 2010b). Teachers are encouraged to appreciate and respect different cultures that learners bring into the classroom as well as cultivate learners' motivation as diversity is reflected in a range of motivational dispositions (ibid). 
Principle 6: iCLT emphasises intercultural communicative competence rather than native-speaker competence

This principle emphasises intercultural communicative competence rather than the native-speaker competence. Native-speaker competence is no longer a realistic goal in language learning as it is an impossible target for most language learners (Kramsch, 1997, 2006) and an undesirable assimilationist goal that separates learners from their own culture and makes them adopt a new sociocultural identity (Byram, 1997). As Byram (2003) argues, no native speaker is an authority on their culture, nor a perfect linguistic model, and thus it will be inappropriate to use the native speaker as models for cultural competence. Therefore, exploring the target culture through various cultural informants helps learners avoid generalising any individual interpretation as a representative description of the whole target culture. Newton and Shearn (2010b) suggest that language learners should be encouraged to critically analyse their observations in native-speaker interactions and make informed choices about appropriate behaviour. A shift from native-speaker competence to intercultural competence broadens the goals of language teaching instruction to enable learners to become both linguistically and interculturally competent in communication across language and cultural boundaries.

\subsubsection{Principles for intercultural language learning}

In order to promote effective intercultural language learning, Liddicoat et al. (2003, pp.47-51) propose a set of five principles for IcLL as guidelines for curriculum design and classroom interaction as follows:

Active construction: Learning involves the purposeful and active construction of knowledge within a sociocultural context of use. Learners explore language and culture through active engagement and develop a personal and intercultural space with multiple dimensions. To do this, learners need to be provided with a range of tasks in which they can use the language purposefully through interaction with people, texts and technologies. They are encouraged to develop personal ways to deal with linguistic and cultural difference as well as to explore the culturally conditioned nature of human behaviour. Teachers need to engage students in interaction with 
peers and others through tasks that stimulate their interest, improve recognition, increase critical thinking about language and culture, and develop skills of formulating questions, observing, discovering, discussing and experimenting.

Making connections: Learning is based on learners' previous knowledge and requires challenges to their initial conceptions. Learners compare languages and cultures, draw connections and build the relevant bridges between home and target language and culture based on their existing knowledge of language and culture against new input. This comparison exposes them to challenges that lead to new insights through which they make connections, reorganise and extend their existing framework of knowledge. To do this, learners need to develop ways to re-think their initial conceptions and transform their knowledge and identity as well as develop a growing understanding of the interdependence of language and culture. Teachers can provide learners with scaffolding through interactive questioning, instruction, resources, and technologies. Teachers also need to encourage students to observe, predict, compare, explain, integrate and inquire through interaction and connections across texts and contexts.

Social interaction: Learning is social and interactive. Learners communicate about linguistic and cultural differences and similarities across linguistic and cultural boundaries where they engage with new conceptual systems through language. To do this, learners need to engage in social interaction, which is central to communication, in which they work towards reciprocal relationships, directly explore different cultures, conceptual systems, sets of values, linguistic and cultural boundaries, and see their own and others' cultures in a comparative light. Teachers need to encourage all learners' social involvement by valuing and promoting their discussion, thinking, inquiry and experimentation. They also need to guide conversation to include learners' views, judgments, rationale, as well as draw upon their multiple ideas, knowledge, beliefs, values and behaviours.

Reflection: Learning involves becoming aware of the processes underlying thinking, knowing, and learning through conscious awareness and reflection. Learners reflect critically and constructively on linguistic and cultural differences and similarities as well as on their own intercultural behaviour. They also articulate the multiple dimensions of their own intercultural space and identity. To do this, learners need to 
reflect critically on language and culture, develop the ability to reflect on and engage with difference or ways of modifying behaviour. They also need to monitor their own production and its effects on others, as well as develop a metalanguage for discussing the relationship between language and culture. Teachers need to promote learners' reflection on linguistic and cultural concepts, and discuss goals, processes, and judgments with them. They also need to foster the development of learners' intercultural sensitivity and intercultural space by engaging them with other cultures while their primary culture is still maintained.

Responsibility: Learning depends on learners' attitudes and disposition towards learning. Learners are responsible for contributing to successful communication across languages and cultures and for developing an intercultural perspective. To do this, learners need to show willingness to interact with people with diverse languages and from different cultures. They need to develop awareness of the validity of diverse value and conceptual systems, recognise the need to decentre from their own cultural perspective and understand the naturalness of multiple perspectives. Teachers need to support the setting of learners' personal goals and foster their engagement with differences, awareness of generalisations and co-operative learning. They also need to encourage learners' self-monitoring and self-assessment and demonstrate understanding through personal attitudes and behaviours.

\subsubsection{Summary}

Intercultural language teaching and learning involve a set of fundamental principles which can be used as guidelines for curriculum design and classroom interaction and for enhancing the effectiveness of language teaching and learning. There are similarities between Liddicoat et al.'s principles and those of Newton and Shearn. Both focus on the importance of making connections between languages and cultures, learners' participation in social interactions and reflections on their intercultural experience in IcLL. Newton and Shearn's principles are concerned with the teachinglearning nexus whereas those of Liddicoat et al. deal with the learning process. For this reason, the Newton and Shearn's principles of intercultural language teaching will be used for the analysis of the evidence of culture in the curriculum review, whereas those of Liddicoat et al. will be adopted in the empirical study. 


\subsection{International trends in the practice of intercultural language learning}

Intercultural language learning has become an important focus of language education. There have been several projects on IcLL, particularly in North America, Europe, Australia and New Zealand.

In North America, the National Standards in Foreign Language Education Project (Standards for Foreign Language Learning, 1996) is a framework for second language learning that places "culture learning at the forefront of language instruction" (Phillips, 2003, p.162). Culture is one of the Five Cs alongside Communication, Connections, Comparisons, and Communities. An interaction among perspectives, practices and products (Figure 2.14) is emphasised in the National Standards. The two standards for Culture indicate that "students demonstrate an understanding of the relationship between the practices and perspectives of the cultures studies" and "students demonstrate an understanding of the relationship between the products and perspectives of the cultures studies" (ibid, p.164). Understanding perspectives about meanings, attitudes, values and ideas of cultures studies is, therefore, the ultimate goal of foreign language learning as perspectives are the common thread in the two standards for culture learning (ibid).

\section{FIGURE 2.14}

Interaction among perspectives, practices and products

(Standards for Foreign Language Learning, 1996, p.43, cited in Phillips, 2003, p.165)

\section{PERSPECTIVES}

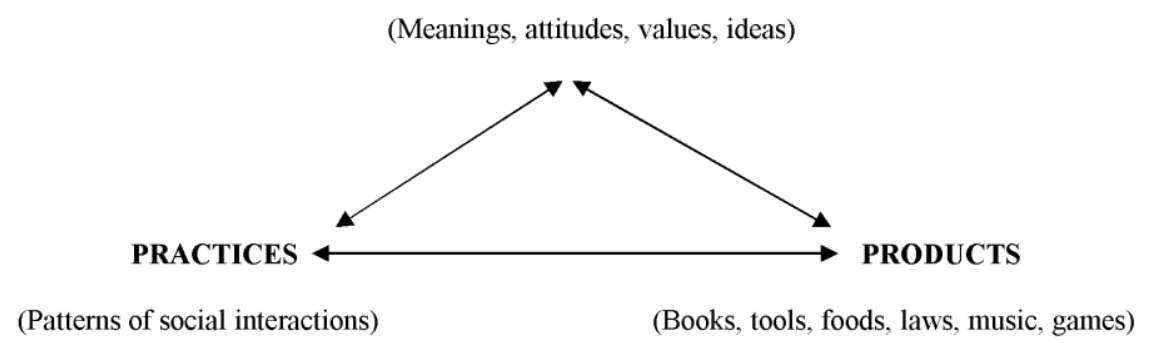

In Europe, the Common European Framework of Reference for Languages (CEFR) (Council of Europe, 2001) is a common basis for language syllabuses, curriculum guidelines and assessment across Europe. The CEFR identifies the knowledge and skills required for language learners to reach each of the six levels of communicative 
proficiency. These levels are based on the acquisition of general and communicative language competences. The emphasis on culture is one of the main purposes of the CEFR that helps language learners to become plurilingual and develop interculturality (Council of Europe, 2001). With linguistic and cultural competences, language learners are able to develop "an enhanced capacity for further language learning and greater openness to new cultural experiences" as well as "mediate, through interpretation and translation, between speakers of the two languages" (Council of Europe, 2001, p.43). The CEFR has been developed from the European experience of language teaching. Some European countries such as Germany, the Netherlands or the United Kingdom have adopted a broader approach to intercultural language teaching and learning. For example in Germany, intercultural learning and education are a general requirement in the teaching of any subject at any level of schooling and across the curriculum in the entire country (Newton and Shearn, 2010a). Based on his research in England and Denmark, Byram (2006) emphasises that it is important to involve both linguistic and cultural competences in language teaching for both instrumental and educational reasons. Gohard-Radenkovic, Lussier, Penz and Zarate (2004) also claim that "the teaching/learning of modern languages...intensif[ies] the openness to other cultures and the contact with otherness in the development of positive cultural representations associated with xenophile attitudes" (p.53).

In Australia, the Asian Languages Professional Learning Project (ALPLP) (Asia Foundation Education, 2004) supports the teaching of Asian languages in primary and secondary schools through the development and delivery of an innovative professional learning programme focusing on intercultural language learning and links across the curriculum. The ALPLP has helped teachers to implement intercultural language learning more systematically in the languages classroom in Australia. Following the success of the ALPLP, the Intercultural Language Teaching and Learning in Practice (ILTLP) (University of South Australia, 2007) was further developed in Australia with the key focus areas of long-term planning and developing assessment processes and ways of describing outcomes of intercultural language learning. The ILTLP has helped teachers increase their knowledge and understanding of intercultural language teaching and learning and how to integrate them into classroom practices and assessment. 
In New Zealand, the New Zealand Curriculum (2007) emphasizes that learning a new language helps students to "acquire knowledge, skills and attitudes that equip them for living in a world of diverse peoples, languages, and cultures" (Ministry of Education, 2007, p.24). The Cultural Knowledge strand in the Learning Languages area, which is given an equal status with that of Language, focuses on the interrelationship between culture and language and on culture learning in which students are required to compare and contrast different beliefs and cultural practices of their own and the target culture in order to understand more about themselves and become more understanding of others. Newton, Yates, Shearn and Nowitzki (2010) propose a new direction for languages teaching in New Zealand with an evidencebased framework of six principles for guiding effective intercultural communicative language teaching in New Zealand schools. Newton et al. (2010) argue that a shift towards interculturality in languages teaching will provide learners with opportunities to develop their understanding and ability to effectively cope with the growing diversity of languages and cultures in New Zealand. The Teacher Professional Development in Languages (TPDL) programme implemented in New Zealand in 2007 and 2008 also aimed to help language teachers in Years 7-10 to improve their teaching language proficiency, increase their knowledge of the languages curriculum and increase their understanding of second language teaching methodology (Harvey, Conway, Richards and Roskvist, 2010, p.2).

To sum up, there have been important international trends in the practices of intercultural language learning, particularly in North America, Europe, Australia and New Zealand. The international trends of intercultural language learning continue to spread at a global level. The International Federation of Language Teacher Associations ${ }^{6}$ states that its first aim is "to promote the teaching and learning of living languages in order to facilitate and improve communication, understanding, cooperation and friendly relations between all peoples of the world" (cited in Newton and Shearn, 2010a, p.15).

\subsection{Assessing intercultural competence}

Assessing intercultural competence is not an easy task as it is an ever-developing competence that never ends and it also requires learners' willingness and acceptance

\footnotetext{
${ }^{6}$ http://www.fiplv.org/
} 
of other perspectives while challenging their own values and beliefs (Coperias Aguilar, 2009). The assessment of ICC is therefore probably the most difficult task for language teachers. This is the reason why it has been long neglected as "such assessment is not possible, or not reliable or valid enough to be used when learners are to be given certification of their abilities" (Byram, 1997, p.6). Schulz (2007) highlights some key problems in the assessment of intercultural competence in tertiary foreign language programmes:

Despite a vast body of literature devoted to the teaching of culture, however, there is no agreement on how culture can or should be defined operationally in the context of foreign language learning in terms of concrete instructional objectives, and there is even less consensus on whether or how it should be formally assessed. Indeed, despite all the claims about the importance of cultural content and culture learning in the language classroom, the profession has no tradition of assessing cultural understanding in the context of language instruction, either at the precollegiate or collegiate level (p.10).

Nevertheless, there have been many attempts to assess ICC by using a variety of indirect or direct assessment tools or a combination of them (Sinicrope et al., 2007) (Table 2.4). For example, course-embedded assessments (e.g., essays, mid-terms and finals, projects, portfolios) and program-specific questionnaires, self-assessments and interviews are commonly used methods for assessing the intercultural competence outcomes in some college foreign language programs across the United States (ibid). Sinicrope et al. claim that while the indirect assessments tools that consist mostly of self-reports or surveys may have potential theoretical and methodological drawbacks, direct assessment tools can provide "more detailed, nuanced and individualised accounts" (p.28) that can avoid the limitations in the indirect assessment approaches.

Sinicrope et al. argue that a combination of direct and indirect assessment methods, or a blended approach to assessing intercultural competence, may provide more comprehensive accounts of intercultural phenomena. For example, this blended approach in Fantini (2006) and Straffon (2003) revealed more layers and nuances in the growth of intercultural competence than the use of indirect assessment approaches alone. Sinicrope et al. suggest that educators should consider whether a combination of indirect and direct assessment methods will result in a more comprehensive 
development of intercultural competence in their foreign language or study abroad programmes. In addition, Schultz (2007) argues that traditional methods of assessment do not lend themselves to evaluating culture learning and therefore alternative forms of assessment, such as self-assessment, reflective journals, diaries or portfolios are needed.

TABLE 2.4

Assessment tools for intercultural competence (Sinicrope et al., 2007)

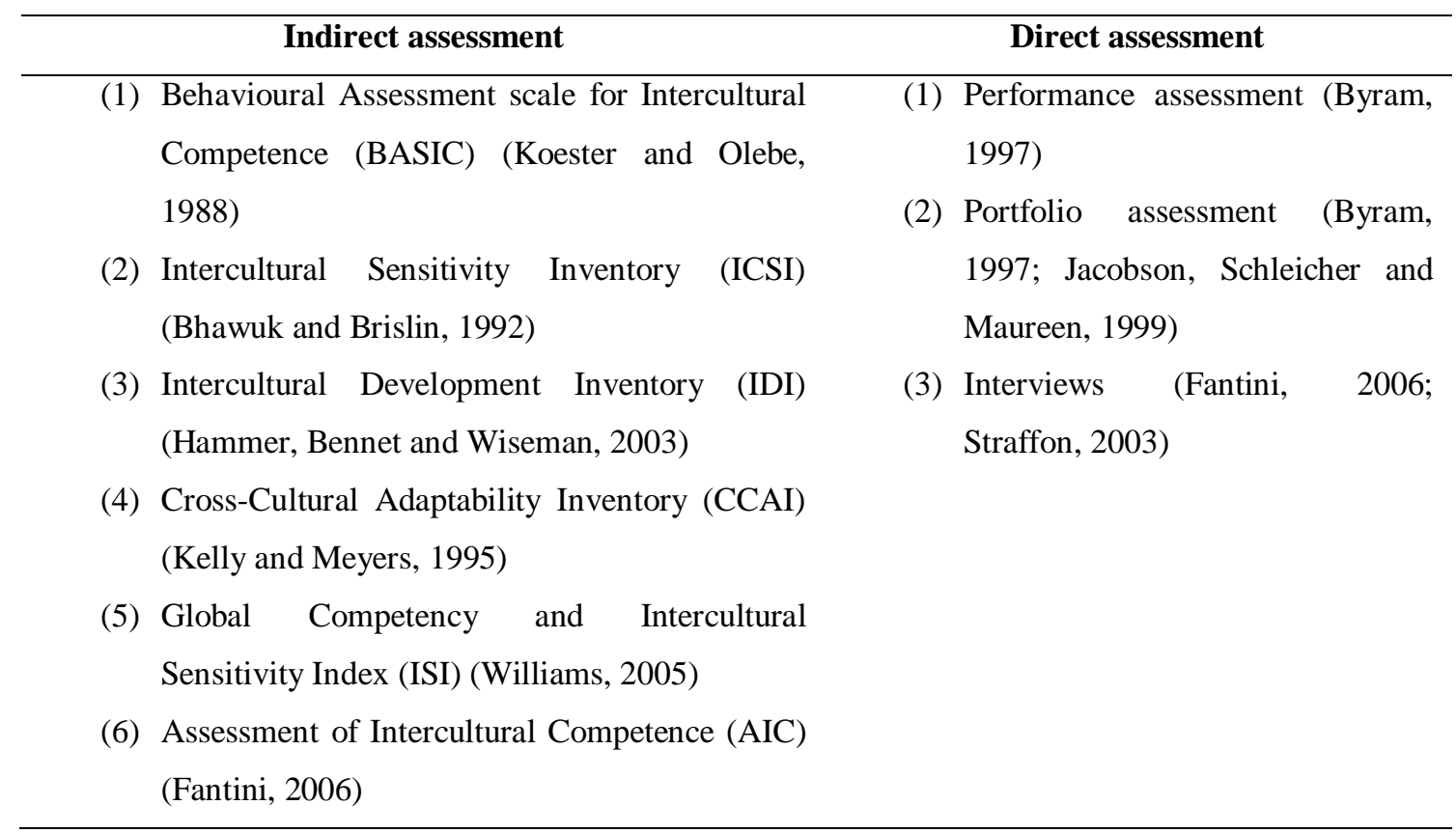

On the other hand, Scarino (2009) is more concerned about the assessment of intercultural competence in relation to students' performances. According to Scarino, assessment tools like cultural awareness tests (Byram, Morgan et al., 1994), or attitudinal tests (Cadd, 1994), do not capture students' participation in communication and their reflective analysis of instances of communication across cultures. Scarino argues that students have dual roles in language learning. As participant users of the target language, they use language to communicate and experience ways of making meanings between languages and cultures. As learners/analysers of the target language, they critically reflect on the exchange of meanings from different points of views and on their own values and those of others. Assessing intercultural competence, in Scarino's argument, should involve “assessing students' performances 
in experiencing and analysing communication, a dual process that requires moving between the students' own languages and cultures and the language and culture being learned" (p.69). Scarino proposes that assessing intercultural competence should follow a cycle that involves four interrelated processes: conceptualising, eliciting, judging and validating (Figure 2.15).

FIGURE 2.15

The assessment cycle (Scarino, 2009, p.70)

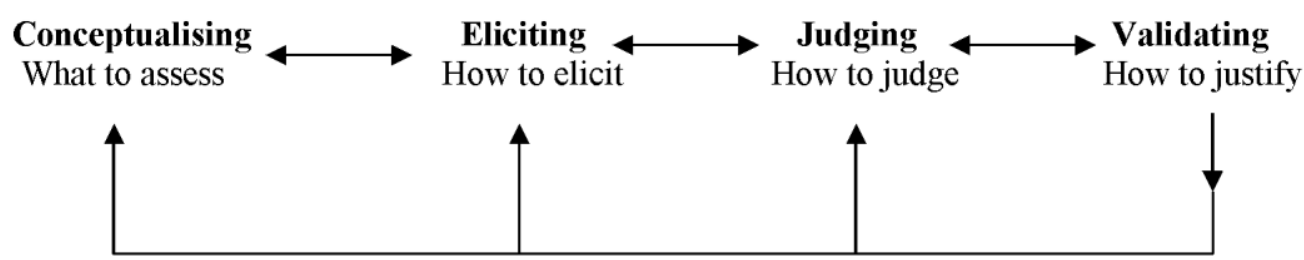

In this assessment cycle, it is almost impossible to assess the whole of intercultural competence. Deardorff (2008) recommends that specific aspects of intercultural competences need to be prioritised for assessment based on the overall mission or purpose of a course or a programme, and that measurable objectives need to be stated in relation to each of these prioritised aspects of intercultural competence. She proposes the setting up of measurable objectives through the acronym SMART: Specific (what, why, how), Measurable, Action-oriented, Realistic and Time delineated. In addition, Deardorff also emphasises the integration of assessment tools/methods on an ongoing basis with the use of more direct and qualitative measures such as journals or blogs and e-portfolio assessment. She concludes that the assessment of intercultural competence is ultimately about learning and that the groundwork needs to be in place for meaningful intercultural communicative assessment.

To sum up, assessing intercultural competence is a difficult task due to its complexity. Because of the shortcomings of indirect methods, more direct and qualitative measures are proposed for the assessment. However, a combination of both indirect and direct methods as a blended approach can be considered in order to provide a more comprehensive picture of learners' intercultural growth. For this purpose, the empirical study will adopt both indirect and direct methods to investigate the students' development of intercultural competence in language learning. The 
assessment of intercultural competence needs to focus on students' performances on an ongoing basis. Researchers also argue that it is important to prioritise specific goals and measurable objectives depending on the purpose of a course or a programme to assess this complex competency. Therefore, intercultural awareness and attitudes will be prioritised as the main goals of the intercultural lessons in the empirical study.

\subsection{Summary}

This chapter has reviewed a range of relevant literature as the basis for developing a theoretical framework for the present study. Among different conceptualisations of culture, the hidden cultural values functioning at deeper levels in the cultural iceberg and the cultural onion are important for language learners to make visible in culture learning. The importance of the interaction between the individual and the community in social contexts and the issue of identity is also highlighted. The concept of culture in language learning is being re-evaluated to deal with the hybridity and plurality of culture that underpins the foundation for intercultural language learning. The inextricable and interdependent relationship between language and culture can be made meaningful in foreign language teaching and learning.

Moreover, intercultural competence has become an important goal of language education as linguistic competence and communicative competence have proved insufficient to prepare learners for study or work in a multicultural setting. As the reviewed models of intercultural competence have their strengths and limitations, it would be ideal to have a comprehensive, dynamic and ongoing process model of acquiring intercultural competence in foreign language learning. Assessing intercultural competence is a difficult task due to its complexity. A combination of both indirect and direct methods for assessment is therefore suggested to provide a more comprehensive picture of learners' intercultural competence growth.

In spite of the increasing trends in the practice of IcLL in the world, IcLL has not been widely considered in Asian contexts; even this approach to culture learning may be completely new to many Vietnamese EFL teachers and students. Vietnamese learners have been more familiar with learning grammar, vocabulary and translation. Although they are also concerned with developing communication skills, these skills tend to deal with language use rather than with the cultural dimensions of language learning. When learning about culture, learners are more likely to acquire only 
cultural knowledge about the target culture, rather than developing an understanding about the target language and culture in relation to their own language and culture, let alone their reflections on cultural differences between L1 and L2 cultures. Because of these reasons, IcLL may take more time for Vietnamese learners to get familiar with. Nevertheless, given the diversity of ethnic groups in Vietnam as well as the needs of Vietnamese learners to communicate with Asian countries and the world, IcLL can potentially help Vietnamese learners to fulfil their goals. This study was conducted to investigate the feasibility of intercultural teaching and learning in tertiary EFL classrooms in Vietnam to meet the needs of Vietnamese learners of English.

In the next chapter, I will review the curricular frameworks for Vietnamese tertiary EFL programmes regarding the status, construct and treatment of culture and culture learning in these documents. 


\section{Chapter III \\ CURRICULUM REVIEW}

\subsection{Introduction}

This chapter presents the first phase of this study that involves a review of the curriculum frameworks for tertiary EFL programmes and the national education policy on foreign language education in Vietnam. The curriculum review examines the nature and extent of the elaboration of culture and culture learning in the documents in order to identify the potential for developing intercultural language learning in tertiary EFL programmes. The review also aims to provide a reference point for Vietnamese EFL teachers to reflect on their culture teaching practices. The curriculum review addresses the following research question (RQ):

RQ1: To what extent is culture in language teaching and learning evident in the curriculum frameworks for tertiary EFL programmes in Vietnam?

\subsection{Research process and procedures}

The curriculum review focuses on the four following documents:

(1) The Vietnamese Higher Education National Curriculum Frameworks of English (Ministry of Education and Training, 2004) (the NCE).

(2) The curriculum framework for the Bachelor of Arts in English for Translation and Interpretation degree programme (2008) at a Vietnamese university (the ETI major).

(3) The curriculum framework for the Bachelor of Arts in English for Tourism degree programme (2008) at a Vietnamese university (the ETO major).

(4) A national education policy on foreign language education in Vietnam regarding the project "Teaching and learning foreign languages in the national education system in the period of 2008-2020" (Government of the Socialist Republic of Vietnam, 2008). 
The documents were requested directly from a Vietnamese university and were the officially endorsed versions. The NCE (2004), prescribed by the Ministry of Education and Training (MOET), is used as the curriculum guideline for all tertiary EFL programmes in Vietnam. The relationship among the documents is shown in Figure 3.1.

\section{FIGURE 3.1}

Relationship among the documents

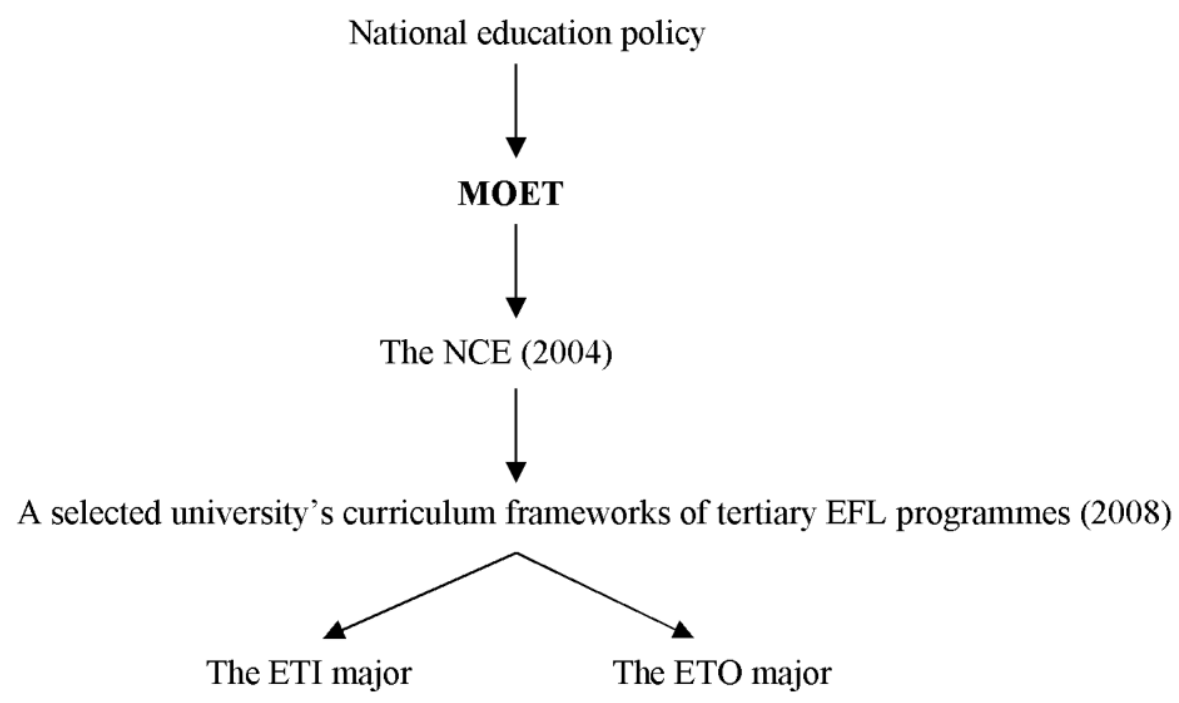

\subsection{Nature of the curricular documents}

The NCE (2004) consists of four parts: training objectives, knowledge requirements and training timeframe, descriptions of compulsory courses, and instructions for designing specific English majors.

The ETI and ETO majors (2008) adopt the NCE training objectives and compulsory courses (general education and professional education courses) and also include some other professional education courses. The curriculum frameworks of the two English majors conform to a similar structure: training standards and a detailed curriculum framework. The training standards consist of guidelines for enrolment, graduation, staff and facilities standards. Although these training standards consist of learners' knowledge, skills, attitudes and behaviours, the standards of knowledge and skills are related to language learning, whereas those of attitudes and behaviours are more likely to deal with learners' moral qualities. The detailed curriculum framework 
consists of twelve parts: training objectives, training timeframe, knowledge requirements, enrolment, training processes and graduation conditions, marking scale, programme content (list of courses), teaching schedule, course descriptions, teaching staff, facilities, and instructions for programme implementation. A large part of the training standards is repeated in the training objectives of the two majors.

\subsection{Method of analysis}

The curriculum review uses a framework for analysis developed by Liddicoat et al. (2003, pp.33-34) to review languages curriculum in each state and territory in Australia. This framework was chosen as it is based on an extensive, up-to-date review of international scholarship in the field of intercultural language learning. Liddicoat et al.'s framework identifies three dimensions of culture and culture learning for analysis:

(1) The status of culture and culture learning (as seen in the presence of explicit reference to culture, position within the document and stated importance).

(2) The constructs of culture and culture learning, i.e., "how does this learning relate to how language learning overall is conceived?" (ibid., p.33).

(3) The treatment of culture and culture learning, i.e., "how do the documents deal with/represent this learning?" (ibid.)

Five out of six principles of intercultural communicative language teaching and learning (iCLT) proposed by Newton and Shearn $(2010 \mathrm{~b})^{7}$ are used to guide the curricular analysis. They are as follows:

Principle 1: iCLT integrates language and culture from the beginning

Principle 2: iCLT engages learners in genuine social interaction

Principle 3: iCLT encourages and develops an exploratory and reflective approach to culture and culture-in language

Principle 4: iCLT fosters explicit comparisons and connections between languages and cultures

\footnotetext{
${ }^{7}$ The principle iCLT acknowledges and responds appropriately to diverse learners and learning contexts is omitted in this curriculum review due to the homogeneousness of the Vietnamese EFL classes in this study.
} 
Principle 5: iCLT emphasises intercultural communicative competence rather than native-speaker competence

These principles mostly address the treatment of culture and culture learning, and so are discussed in relation to this. They are used to examine the extent to which culture and culture learning are present in the curriculum frameworks. The process of the curricular analysis involved the following steps:

(a) Reading the whole content of the NCE and the two English majors to have a general idea about how EFL teaching and learning are represented in the documents and identify any similarities and differences across the documents.

(b) Doing a close analysis of the documents: looking for clues in the documents that may reveal any evidence of culture and culture learning.

(c) Selecting and translating the relevant parts of the documents that are related to culture and culture learning into English.

(d) Synthesising the findings of the analysis into the curriculum review under the three dimensions of culture and culture learning in accordance with the five principles of iCLT.

\subsection{Findings and discussion}

The findings regarding the evidence of culture and culture learning in the NCE (2004) and the two English majors (2008) (Appendix 1) are presented under three headings: Status, Constructs and Treatment of culture and culture learning. The discussion of the findings makes reference to these documents, drawing examples and quotes to highlight and support the findings. At the end of the analysis in each heading, evaluative comments are presented to discuss the evidence of culture and culture learning in the curricular documents. The national education policy on foreign language education in Vietnam is finally analysed to provide insight into the directions of the national education system for foreign language teaching and learning. 


\subsubsection{The status of culture and culture learning}

This section discusses the status of culture and culture learning as reflected in the presence of explicit reference to culture, the positioning within the document and the stated importance of culture learning in the NCE and the two English majors.

The NCE (2004)

Culture and culture learning are stated in the specific training objectives of the NCE. Within its four specific training objectives, two objectives explicitly deal with culture and culture learning:

Objective 1: Providing learners with broad knowledge of the English language, British and American culture, societies and literature.

Objective 4: Equipping students with active learning skills for self-study in order to continue to enhance knowledge and practical language skills, initially developing critical thinking and scientific research capacity about issues of language, literature or culture-civilization of English-speaking countries.

(Training objectives, the NCE, 2004, p.1)

Culture learning is also explicitly stated in two general education courses, culture courses and literature courses. In the Introduction to Linguistics course, culture learning is stated through the relationship between languages and cultures. In the Foundation of Vietnamese culture course, culture learning is stated through general theories and approaches to culture and the learners' home culture. In culture courses, culture learning is stated in the study of British and American culture. In British and American literature courses, culture learning is stated through the cultural values of literary works.

In addition, culture learning is implicitly stated in language skills courses through a system of topics related to daily life (e.g., society, science, culture, economy, and environment). In the remainder of the NCE, the main focus is on language. The importance of culture and culture learning is not stated. 


\section{The English majors}

The two English majors adopt the NCE specific training objectives for their general training objectives. These majors explicitly address culture and culture learning in two general education courses, British and American culture courses, and British and American literature courses in the same way as the NCE does.

In the ETI major, culture learning is also stated in the training standards. Within two knowledge standards, one explicitly involves culture learning:

Knowledge standard 1: Graduates of English for Translation and Interpretation are equipped with general knowledge about Marxism-Leninism, Ho Chi Minh thoughts, and general education knowledge as foundation knowledge for the English programme; basic knowledge about aspects of the English language (phonetics, vocabulary, grammar), culture, literature, civilization of the mainstream Englishspeaking countries such as the UK and the USA, and basic knowledge and skills of translation and interpretation (Training standards, the ETI, 2008, p.1).

Culture learning is explicitly stated in one professional education course, the Interpretation 2, in which learners are encouraged to discover cultural similarities and differences. In addition, culture learning is implicitly stated through developing the skills of translating sociocultural reports in the specific training objectives of the ETI major. Culture learning is also implicitly stated in some professional education courses. For example, in the Reading 1 course, students learn a variety of topics related to education, family, customs and manners, festivals. In the Translation 1 and Translation 2 courses, students develop the skills of translating basic documents and texts related to cultural topics, cultural forms, traditions, and customs. In the Literary Translation course, students learn semantics style, pragmatics related to cultural elements, customs and manners.

Like the ETI major, culture learning in the ETO major is also stated in its training standards. Within its sixteen knowledge standards, culture and culture learning are explicitly stated in two:

Knowledge Standard 11: Having general knowledge of Vietnamese culture or English-speaking cultures such as the UK or the USA... 
Knowledge Standard 16: Having deep knowledge of Vietnamese culture including knowledge of Vietnamese foods or Champa culture.

(Training standards, the ETO, 2008, pp. 29-30)

Culture learning is also stated in the specific training objectives of the major. Within its six objectives, one explicitly involves culture and culture learning:

Objective 1: Graduates of English for Tourism are equipped with general knowledge about Marxism-Leninism, Ho Chi Minh thoughts, and general education knowledge as foundation knowledge for the English programme; basic knowledge about aspects of the English language (phonetics, vocabulary, grammar), culture, literature, civilization of the mainstream English-speaking countries such as the UK and the USA, and basic professional knowledge of tourism (Training objectives of the ETO major, 2008, p.32).

Culture learning is explicitly stated in one professional education course, the Consumerism behaviour in Tourism, which aims to provide learners with knowledge about

...personal psychology, beliefs, values, customs and manners that may have an impact on people in tourism consumerism... (Consumerism behaviour in Tourism, the ETI, 2008, p.49).

Three other courses have an emphasis on the learners' home culture (C1) including Champa culture (core culture course), Vietnamese foods and Vietnamese costumes (selective courses). In the rest of the ETO major, culture learning is implicitly stated in one language skills course, the Reading 1 , in which students learn a variety of topics related to education, family, customs and manners, festivals.

In the remainder of the two English majors, the main focus is on language and the importance of culture and culture learning is not stated.

\section{Evaluative comments}

(i) Culture and culture learning are mainly visible in the training objectives and/or training standards and culture courses in the NCE and the English majors. The 
main reference to culture learning in relation to culture courses establishes a separate status of culture and culture learning in the curriculum frameworks.

(ii) The importance of culture and culture learning is not stated in the NCE and the English majors. Instead, the documents adopt an instrumental orientation to EFL that provides learners with knowledge of the English language to prepare them for work in areas that use English without an emphasis on intercultural communication.

(iii) $\mathrm{C} 1$ knowledge is emphasised as professional education knowledge in the ETO major. This emphasis aims to provide learners of the ETO major with additional knowledge about their own culture in order to work in tourism areas. In the ETI, however, C1 knowledge is only considered as general education knowledge. A focus on this type of knowledge could provide a basis for learners to engage in intercultural language learning.

\subsubsection{The constructs of culture and culture learning}

This section examines the ways in which culture and culture learning are constructed in the NCE and the two English majors, focusing on the relationship to the construct of language learning, the degree and nature of integration of language and culture and the relationship to the wider curriculum.

The NCE (2004)

Language learning is constructed in the NCE using two kinds of compulsory knowledge:

(a) General education knowledge

(b) Professional education knowledge

General education knowledge involves political education and foundation courses which are taught in the learners' first language. These foundation courses provide a basis for learners to learn a foreign language. Professional education knowledge involves specialised English courses which are designed for specific English majors. 
Based on this relationship to the construct of language learning, culture and culture learning are structured in the NCE in three main strands:

(a) as a foundation knowledge strand with general education courses;

(b) as a separate culture strand with culture courses;

(c) as a linguistic strand with language courses.

Regarding the degree and nature of integration of language and culture, there is no explicit recognition of such integration in the framework. Only one general education course, the Introduction to Linguistics, explicitly deals with the relationship between languages and cultures in its objectives. This course provides learners with

...basic knowledge about the nature of human languages, the relationship between languages and cultures, languages and critical thinking, general knowledge about phonetics, grammar, vocabulary, semantics, and pragmatics for understanding a specific language (Vietnamese or the target language)...(Introduction to Linguistics, the NCE, 2004, p.4).

As a separate culture strand, culture is constructed as knowledge about a particular culture, i.e., British or American culture, in the training objectives of the NCE:

Objective 1: Providing learners with broad knowledge of the English language, British and American culture, societies and literature (Training objectives, the NCE, 2004, p.1).

In relationship to the wider curriculum, the NCE makes reference to connections between a language learning area and a wider curriculum in three ways:

(a) Professional education knowledge can be designed for specialised Single Majors of English such as English for Education, English for Translation and Interpretation, English language, English culture, English literature or developed towards a second major to form a major of English for Specific Purposes.

(b) Majors-Minors can be formed on the selection of courses belonging to a second training programme apart from English (e.g., Russian, French, Business 
Administration, International Relations, International business, Vietnam studies) to extend learners' professional ability and working areas after graduation.

(c) Double-Majors are formed with an equal combination of knowledge in the first and the second majors.

\section{The English majors}

The two English majors adopt the three main strands of the NCE in the construct of culture and culture learning as mentioned above as these three main strands consist of the compulsory courses required by the NCE. In addition, culture and culture learning in the ETO major are also constructed with a focus on the learner's home culture (C1) as mentioned in section 3.5.1. The relationship to the wider curriculum is not stated in the two English majors.

\section{Evaluative comments}

(i) There is little recognition of the relationship between language and culture in the frameworks, except in a single objective of one general education course. This indicates that language and culture are not constructed in an integrated way in language learning.

(ii) Culture is constructed as knowledge about a particular culture, i.e., British culture or American culture, which corresponds to the areas studies approach to culture in foreign language education (Liddicoat et al., 2003). With this construct of culture, the learner is structured as an external observer of culture rather than as an internal practitioner (Liddicoat, 2004). A separate culture strand with culture courses suggests a separate construct of culture and culture learning in the curriculum frameworks.

(iii) The construct of culture and culture learning vis-à-vis the learner's $\mathrm{C} 1$ in professional education courses of the ETO major indicates an instrumental orientation to work in tourism areas. However, explicit $\mathrm{C} 1$ learning provides a foundation for students to engage in intercultural language learning.

(iv) In relationship to the wider curriculum, single majors of English may take advantage of the cultural dimension of the target language to develop cultural awareness for learners. The relationship between majors-minors with other 
languages such as Russian or French may also develop learners' awareness of the relationship between languages and cultures across these languages.

\subsubsection{The treatment of culture and culture learning}

This section discusses the extent to which culture and culture learning are treated in the NCE and the two English majors according to Newton and Shearn's (2010b) five principles of intercultural language teaching and learning applied in this curriculum review.

\section{Principle 1: iCLT integrates language and culture from the beginning}

This principle emphasises the importance of teaching and learning language and culture as interdependent components. The term 'from the beginning' refers to the early start of this task. In this curriculum review, it refers to the teaching and learning of language and culture at the beginning of the tertiary EFL programmes.

In the NCE and the English majors, the general education courses, i.e., Introduction to Linguistics, Comparative Linguistics, Foundation of Vietnamese culture, Vietnamese language, are taught at the beginning of the EFL programmes in order to provide a foundation for learners to learn a foreign language and compare languages. Culture in language skills courses is implicitly taught at the beginning of language learning through daily life topics. However, British and American culture courses are taught in the third year of study.

\section{Evaluative comments}

(i) The general education courses taught at the beginning of language learning aim to provide learners with a foundation for language comparisons only. However, the focus of some of these courses on the learners' first language (L1) and home culture (C1) may help them develop cultural self-awareness at the beginning of language learning as a basis to engage in intercultural language learning.

(ii) The cultural dimension of daily life topics in language skills courses provides a starting point for developing learners' cultural awareness in the first year of their 
degree studies. This is important as Kramsch (1993) claims that culture teaching should be started early in order that learners can adopt different views of cultural phenomena.

(iii) The teaching of British and American culture courses in the third year of study suggests a separate treatment of culture and culture learning in the frameworks.

\section{Principle 2: iCLT engages learners in genuine social interaction}

This principle emphasises the importance of learners' engagement in social interaction in order to draw attention to intercultural dimensions of communication in a foreign language.

The NCE (2004)

The NCE considers the development of communication skills in one of its specific training objectives for EFL learners:

Objective 2: Training and developing communication skills in English at a relatively high fluency in social and professional communication situations (Training objectives, the NCE, 2004, p.1).

In the objective mentioned above, the development of communication skills for intercultural communication is not explicitly stated.

\section{The English majors}

The ETI major also develops learners' communication and problem-solving skills in its training objectives. Within its ten specific training objectives, communication and problem-solving skills in English are presented in two:

Objective 2: Having the skills of communicating fluently in English in social and professional communication situations. 
Objective 3: Having the skills of solving problems in translation and interpretation of documents from English-Vietnamese and vice versa.

(Training objectives, the ETI, 2008, p.5)

The communication and problem-solving skills mentioned in the objectives above are not necessarily the intercultural skills that students need for communication with people from other cultural backgrounds.

Similarly, the ETO major also aims to develop communication and problemsolving skills for students in its specific training objectives. Within its six specific training objectives, communication and problem-solving skills are presented in two:

Objective 2: Having the skills of communicating fluently in English in social and professional communication situations.

Objective 6: Having the skills of solving problems related to professions of tour guides, receptionists and tour managers.

(Training objectives, the ETO, 2008, p.33)

These communication and problem-solving skills are not necessarily the intercultural skills that students need for their professions in tourism.

\section{Evaluative comments}

(i) The emphasis on communication skills in the training objectives of the NCE and the English majors establishes an important basis for the practice of iCLT. However, the extent to which communication is used to achieve intercultural outcomes is not stated in these objectives. Opportunities for attending to intercultural dimensions in communication practice should be encouraged in the curriculum frameworks to engage learners in intercultural language learning.

(ii) The problem-solving skills in the English majors should be developed into intercultural skills for learners to acquire to solve problems in intercultural interactions. 
Principle 3: iCLT encourages and develops an exploratory and reflective approach to culture and culture-in-language

This principle emphasises learners' exploration of and reflections on visible and invisible parts of culture in language learning.

The NCE (2004)

As mentioned in section 3.5.2, culture is constructed as knowledge about a particular culture. Therefore, the culture courses require learners to develop the knowledge about that specific culture rather than engage them in the process of discovery for conceptualising culture (Newton and Shearn, 2010b). For example, the objectives of the British culture course are to

...develop learners' knowledge about the country and British people, the system of values, customs, society, religion, and the systems of politics and economy of the United Kingdom as a foundation to apply in the acquisition of the English language and intercultural communication (British culture, the NCE, 2004, p.8).

The American culture course also has similar objectives in developing learners' knowledge about the USA and American people. In the remainder of the NCE, the exploratory approach to culture and culture learning is not mentioned.

The reflective approach to culture is stated only in the British-American literature course which aims to develop learners' ability to

...perceive and evaluate the good and the fineness of British-American literature, the social and cultural values of literary works...(British-American literature, the NCE, 2004, p.7).

In the remainder of the NCE, the reflective approach to culture is not mentioned. 


\section{The English majors}

The instantiation of the British and American culture courses in the two English majors is consistent with the NCE. The exploratory approach to culture and culture learning is not mentioned in the two English majors. The reflective approach tends to be related to language learning only. For example, the Speaking 3 course in the ETI major requires learners to

...listen to others' opinions and perspectives...and critically evaluate others' perspectives with a positive attitude and respect (Speaking 3, the ETI, 2008, p.18).

The objective above does not explicitly state that such reflections are applied for culture learning. In the remainder of the two English majors, there is no reference to the reflective approach to culture and culture learning.

\section{Evaluative comments}

(i) The NCE and the two English majors require learners to develop only knowledge about a particular culture in culture courses rather than provide them with opportunities to engage in an exploratory and reflective approach to culture. Intercultural language learning requires learners to engage in the process of discovery and exploring the visible and invisible parts of culture.

(ii) The reflective approach to culture learning is stated only in the literature courses. Such an approach could be usefully emphasised so that learners can develop critical cultural awareness which is crucial for acquiring intercultural competence. As this approach is not stated in the remainder of the NCE and the two English majors, it could be developed in the curriculum so as to engage learners in critical reflections on the cultural dimension of language learning.

\section{Principle 4: iCLT fosters explicit comparisons and connections between languages and cultures}

This principle emphasises the value of comparisons and connections between languages and cultures that enables learners to enhance awareness of similarities and 
differences between their own language and culture and the target language and culture for intercultural language learning.

\section{The NCE (2004)}

The NCE tends to foster explicit comparisons and connections between languages rather than between languages and cultures in general education courses. For example, the Introduction to Linguistics course provides learners with general linguistic knowledge to

...understand a specific language (Vietnamese or the target language) and use it as a basis for language comparisons (Introduction to Linguistics, the NCE, 2004, p.4).

The Comparative Linguistics course provides:

... a theoretical tool to compare the learners' mother tongue with a foreign language for a deeper understanding about the two languages and specific strategies for language comparisons (Comparative Linguistics, the NCE, 2004, p.5).

The Vietnamese language course provides:

...basic and updated knowledge about the Vietnamese language to be used as a basis for language comparisons (Vietnamese language, the NCE, 2004, p.5).

In addition, explicit comparisons and connections between the learners' home culture and the target culture are fostered in one general education course and the British and American culture courses. For example, the Foundation of Vietnamese culture course focuses on general theories and approaches to culture as well as the learners' home culture as a foundation to learn a foreign language. This course aims to provide learners with

...general theories of culture, perspectives and approaches to culture in general and Vietnamese culture in particular. Through cultural elements of space and time, students will develop an understanding about the Vietnamese cultural character. The 
course also develops in learners a national cultural spirit through the study and contact with the target language culture (Foundation of Vietnamese culture, the NCE, 2004, p.4).

The objectives of the culture courses also allow learners to make connections between their own culture and the target culture. For example, the British culture course (as well as the American culture course) enables learners to develop:

...skills of comparing and relating [the target culture] to the national culture

[Vietnamese culture] and civilization (British culture, the NCE, 2004, p. 8).

\section{The English majors}

The instantiation of general education courses in the English majors is consistent with the NCE. Apart from those courses, the Vietnamese writing and the Vietnamese Speaking and Presentation courses are additionally provided in the two English majors as general education courses. These two courses aim to help learners understand different ways of writing and speaking in their first language, which may be useful for them to compare with the target language they are learning.

The two English majors adopt the British and American culture courses from the NCE to develop learners' skills of comparisons and connections between the target culture and their home culture. In addition, in the ETI major, the Interpretation 2 course also develops learners' ability to

...compare languages and find out cultural similarities and differences and appropriate styles for each specific context...(Interpretation 2, the ETI, 2008, p.21).

In the ETO major, on the other hand, the learners' national culture $(\mathrm{C} 1)$ gets the focus. The Champa culture course provides learners with knowledge of history of the establishment of the Champa kingdom and its cultural achievements as a specific cultural feature in Central Vietnam. The two selective courses on Vietnamese foods and Vietnamese costumes provide learners with knowledge of typical Vietnamese foods and a variety of Vietnamese costumes of different ethnicities. However, there is 
no recognition of comparisons and connections of this $\mathrm{C} 1$ knowledge to the target language culture $(\mathrm{C} 2)$ in the objectives of these courses.

\section{Evaluative comments}

(i) The general education courses tend to foster explicit comparisons and connections for language comparisons rather than between languages and cultures. However, learners may develop cultural awareness about differences between their first language and the target language by engaging in this process.

(ii) The Foundation of Vietnamese culture course is important because it provides learners with knowledge about general theories of culture, perspectives and approaches to culture, and the learners' own culture, which is essential for the practice of intercultural language learning. By fostering learners' cultural selfawareness, this course provides a foundation for learning about another culture.

(iii) The culture courses that focus on the learners' national culture in the ETO major aim to provide learners with basic cultural knowledge of their home culture for their jobs as tour guides. These courses may become even more useful if they also encourage learners to compare and connect this $\mathrm{C} 1$ knowledge with the target language culture for intercultural language learning.

\section{Principle 5: iCLT emphasises intercultural communicative competence rather than native-speaker competence.}

This principle emphasises the learners' ability to communicate across cultural boundaries rather than use the target language like a native speaker.

As mentioned in principle 2, communication skills are stated in the training objectives of the NCE and the two English majors. These communicative skills emphasise the native-speaker standards of language proficiency rather than intercultural communicative competence. Only the objective of one language skills course in the NCE states that learners are enabled to:

...communicate effectively with native English speakers and English-speaking foreigners in most common communication situations...(English 1, the NCE, 2004, p.9, emphasis added). 
Another language skills course in the NCE also seeks to enable learners to

...apply appropriate communicative strategies in different communication situations (English 2, the NCE, 2004, p.10, emphasis added).

There is no reference to intercultural communicative competence in the remainder of the NCE and the two English majors.

\section{Evaluative comments}

Both the NCE and the two English majors prioritise the native-speaker standards of language proficiency rather than intercultural communicative competence. Only the objectives of two language skills courses in the NCE deal with communicative effectiveness and appropriateness in different communication situations. Interculturally-informed communicative competence should be integrated in the curriculum in order to develop an intercultural sensitivity for learners to engage in interactions with people from other cultural backgrounds.

\subsubsection{Education policy}

The analysis of the national education policy on foreign language education in Vietnam (2008) shows no reference to culture teaching and learning. However, it contains some views on foreign language teaching and learning that are worth discussing.

Since the country joined the WTO in 2007, it has been moving to a new era of international integration. Consequently, the teaching and learning of foreign languages in Vietnam is going through some considerable improvement in terms of content and quality. The project 'Teaching and learning foreign languages in the national education system in the period of 2008-2020' sets up specific objectives of foreign languages education in Vietnam for the next decade:

...By 2020, the majority of Vietnamese graduates from professional high schools, junior colleges and universities will be able to use a foreign language independently, feel confident in communication, study and work in an integrated, multilingual, and multicultural environment; turn foreign languages into a strength of Vietnamese 
people to serve the country's cause of industrialisation and modernisation (Government of the Socialist Republic of Vietnam, 2008, p.1, my translation).

As can be seen from the objectives above, Vietnamese learners of foreign languages are supposed to study and work in "an integrated, multilingual and multicultural environment". However, the importance of culture learning is not stated although learners are likely to engage in intercultural interactions in such an environment.

In addition, the education policy states the foreign language proficiency level that Vietnamese EFL learners have to achieve. It sets the levels of language proficiency required for foreign language education in Vietnam according to the six criteria in the Common European Framework of References (CEFR) (Council of Europe, 2001). For example, the levels of language proficiency for foreign language learners at junior colleges and universities in Vietnam are equal to levels 4 and 5 respectively in the CEFR. This framework is used as a basis for designing materials, teaching syllabi and building assessment criteria for each level of study and training in foreign language education in Vietnam. The adoption of the CEFR shows an effort of education policy makers in providing a qualified foreign language education based on international standards for Vietnamese EFL learners. However, while one of the main purposes of the CEFR is to help language learners become plurilingual and develop interculturality (Council of Europe, 2001), the Vietnamese education policy only focuses on the acquisition of linguistic competence based on the criteria of the CEFR. In other words, it emphasises the native-speaker standard of language proficiency rather than the development of learners' intercultural competence in foreign language education. The objectives of interculturality in the CEFR should be integrated into the Vietnamese EFL education policy in order to better prepare learners for study and work in an integrated, multilingual, and multicultural environment.

\subsection{Summary}

This curriculum review involves the analysis and critical evaluation of three curricular documents and a document on the national education policy on foreign language education that shape Vietnamese tertiary EFL programmes. The findings indicate that the status, construct and treatment of culture and culture learning in the two English 
majors are greatly dependent on those in the National Curriculum. The findings are summarised in Table 3.1.

TABLE 3.1

Summary of evidence of culture and culture learning in curriculum frameworks

\begin{tabular}{|c|c|c|c|}
\hline Dimension & NCE & ETI & ETO \\
\hline \multirow{6}{*}{ Status } & $\begin{array}{l}\text { - Explicit culture and culture } \\
\text { learning in specific training } \\
\text { objectives. }\end{array}$ & $\begin{array}{l}\text { - Explicit culture and } \\
\text { culture } \quad \text { learning in } \\
\text { training standards and } \\
\text { general } \\
\text { objectives. }\end{array}$ & $\begin{array}{l}\text { Explicit culture and } \\
\text { culture learning in training } \\
\text { standards and specific } \\
\text { training objectives. }\end{array}$ \\
\hline & $\begin{array}{l}\text { - Explicit culture and culture } \\
\text { learning in some general } \\
\text { education courses and } \\
\text { culture courses. }\end{array}$ & $\begin{array}{l}\text { - Explicit culture and } \\
\text { culture learning in some } \\
\text { general education } \\
\text { courses, culture courses } \\
\text { and one professional } \\
\text { education course. }\end{array}$ & $\begin{array}{l}\text { - Explicit culture and } \\
\text { culture learning in some } \\
\text { general education courses, } \\
\text { culture courses and one } \\
\text { professional education } \\
\text { course. }\end{array}$ \\
\hline & $\begin{array}{l}\text { - Separate status of culture } \\
\text { and culture learning in } \\
\text { culture courses. }\end{array}$ & $\begin{array}{l}\text { - Separate status of } \\
\text { culture and culture } \\
\text { learning in culture } \\
\text { courses. }\end{array}$ & $\begin{array}{l}\text { - Separate status of culture } \\
\text { and culture learning in } \\
\text { culture courses. }\end{array}$ \\
\hline & $\begin{array}{l}\text { - Importance of culture and } \\
\text { culture learning not stated. }\end{array}$ & $\begin{array}{l}\text { - Importance of culture } \\
\text { and culture learning not } \\
\text { stated. }\end{array}$ & $\begin{array}{l}\text { - Importance of culture and } \\
\text { culture learning not stated. }\end{array}$ \\
\hline & $\begin{array}{l}\text { - Implicit culture learning in } \\
\text { language skills courses. }\end{array}$ & $\begin{array}{l}\text { - Implicit culture } \\
\text { learning in specific } \\
\text { training objectives and } \\
\text { some professional } \\
\text { education courses. }\end{array}$ & $\begin{array}{l}\text { - Implicit culture learning in } \\
\text { some specific training } \\
\text { objectives and one } \\
\text { professional education } \\
\text { course. }\end{array}$ \\
\hline & & & $\begin{array}{l}\text { - Emphasis of } \mathrm{Cl} \\
\text { knowledge in professional } \\
\text { education courses. }\end{array}$ \\
\hline Construct & $\begin{array}{l}\text { - Three main strands of } \\
\text { culture and culture learning: } \\
\text { foundation knowledge, } \\
\text { culture and linguistic } \\
\text { strands. }\end{array}$ & $\begin{array}{l}\text { - Three main strands of } \\
\text { culture and culture } \\
\text { learning: foundation } \\
\text { knowledge, culture and } \\
\text { linguistic strands. }\end{array}$ & $\begin{array}{l}\text { - Three main strands of } \\
\text { culture and culture learning: } \\
\text { foundation knowledge, } \\
\text { culture and linguistic } \\
\text { strands. }\end{array}$ \\
\hline
\end{tabular}




\begin{tabular}{|c|c|c|c|}
\hline & $\begin{array}{l}\text { - No explicit recognition of } \\
\text { language and culture } \\
\text { integration, except in one } \\
\text { general education course. }\end{array}$ & $\begin{array}{l}\text { - No explicit recognition } \\
\text { of language and culture } \\
\text { integration, except in one } \\
\text { general education course. }\end{array}$ & $\begin{array}{l}\text { - No explicit recognition of } \\
\text { language and culture } \\
\text { integration, except in one } \\
\text { general education course. }\end{array}$ \\
\hline & $\begin{array}{l}\text { - Culture constructed as } \\
\text { knowledge about } \\
\text { particular culture. }\end{array}$ & $\begin{array}{l}\text { - Culture constructed as } \\
\text { knowledge about a } \\
\text { particular culture. }\end{array}$ & $\begin{array}{l}\text { - Culture constructed } \\
\text { knowledge } \\
\text { about } \\
\text { particular culture. }\end{array}$ \\
\hline & $\begin{array}{l}\text { - Reference to connections } \\
\text { between language learning } \\
\text { area and wider curriculum }\end{array}$ & $\begin{array}{l}\text { - No reference to } \\
\text { connections between } \\
\text { language learning area } \\
\text { and wider curriculum }\end{array}$ & $\begin{array}{l}\text { No reference to } \\
\text { connections between } \\
\text { language learning area and } \\
\text { wider curriculum }\end{array}$ \\
\hline & & & $\begin{array}{l}\text { - C1 knowledge constructed } \\
\text { as an instrumental } \\
\text { orientation to work in } \\
\text { tourism areas. }\end{array}$ \\
\hline & NCE & ETI & ETO \\
\hline \multirow[t]{2}{*}{$\begin{array}{c}\text { Principle } \\
1\end{array}$} & $\begin{array}{l}\text { Emphasis of language } \\
\text { comparisons in general } \\
\text { education courses from the } \\
\text { beginning. }\end{array}$ & $\begin{array}{l}\text { - Emphasis of language } \\
\text { comparisons in general } \\
\text { education courses from } \\
\text { the beginning. }\end{array}$ & $\begin{array}{l}\text { - Emphasis of language } \\
\text { comparisons in general } \\
\text { education courses from the } \\
\text { beginning. }\end{array}$ \\
\hline & $\begin{array}{l}\text { - Separate treatment of } \\
\text { culture and culture learning } \\
\text { in culture courses. }\end{array}$ & $\begin{array}{l}\text { - Separate treatment of } \\
\text { culture and culture } \\
\text { learning in culture } \\
\text { courses. }\end{array}$ & $\begin{array}{l}\text { - Separate treatment of } \\
\text { culture and culture learning } \\
\text { in culture courses. }\end{array}$ \\
\hline $\begin{array}{c}\text { Principle } \\
2\end{array}$ & $\begin{array}{l}\text { - Prioritised communicative } \\
\text { goals in the training } \\
\text { objectives. }\end{array}$ & $\begin{array}{l}\text { - Prioritised } \\
\text { communicative goals in } \\
\text { the training objectives. }\end{array}$ & $\begin{array}{l}\text { - Prioritised communicative } \\
\text { goals in the training } \\
\text { objectives. }\end{array}$ \\
\hline \multirow[t]{2}{*}{$\begin{array}{c}\text { Principle } \\
3\end{array}$} & $\begin{array}{l}\text { No reference to exploratory } \\
\text { approach to culture and } \\
\text { culture-in-language. }\end{array}$ & $\begin{array}{l}\text { No reference to } \\
\text { exploratory approach to } \\
\text { culture and culture-in- } \\
\text { language. }\end{array}$ & $\begin{array}{l}\text { No reference to exploratory } \\
\text { approach to culture and } \\
\text { culture-in-language. }\end{array}$ \\
\hline & $\begin{array}{l}\text { Reflective approach to } \\
\text { culture is stated in literature } \\
\text { courses. }\end{array}$ & $\begin{array}{l}\text { Reflective approach to } \\
\text { culture is stated in } \\
\text { literature courses. }\end{array}$ & $\begin{array}{l}\text { Reflective approach to } \\
\text { culture is stated in literature } \\
\text { courses. }\end{array}$ \\
\hline \multirow[t]{2}{*}{$\begin{array}{c}\text { Principle } \\
4\end{array}$} & $\begin{array}{l}\text { - Explicit comparisons and } \\
\text { connections } \\
\text { languages in } \text { between } \\
\text { education courses. }\end{array}$ & $\begin{array}{l}\text { Explicit comparisons } \\
\text { and connections between } \\
\text { languages in general } \\
\text { education courses. }\end{array}$ & $\begin{array}{l}\text { - Explicit comparisons and } \\
\text { connections } \\
\text { languages in getween } \\
\text { education courses. }\end{array}$ \\
\hline & $\begin{array}{l}\text { - Explicit comparisons and } \\
\text { connections between } \mathrm{C} 1 \text { and }\end{array}$ & $\begin{array}{l}\text { - Explicit comparisons } \\
\text { and connections between }\end{array}$ & $\begin{array}{l}\text { - Explicit comparisons and } \\
\text { connections between } \mathrm{C} 1\end{array}$ \\
\hline
\end{tabular}




\begin{tabular}{|c|c|c|c|}
\hline & $\begin{array}{l}\mathrm{C} 2 \text { in British and American } \\
\text { culture courses. }\end{array}$ & $\begin{array}{l}\mathrm{C} 1 \text { and } \mathrm{C} 2 \text { in British and } \\
\text { American culture } \\
\text { courses. }\end{array}$ & $\begin{array}{l}\text { and } \mathrm{C} 2 \text { in British and } \\
\text { American culture courses. }\end{array}$ \\
\hline & & $\begin{array}{l}\text { Explicit comparisons } \\
\text { between languages and } \\
\text { cultures in one } \\
\text { professional education } \\
\text { course. }\end{array}$ & $\begin{array}{l}\text { No recognition of } \\
\text { comparisons and } \\
\text { connections between } \\
\text { languages and cultures. }\end{array}$ \\
\hline \multirow{2}{*}{$\begin{array}{c}\text { Principle } \\
5\end{array}$} & $\begin{array}{l}\text { - Emphasis of } \\
\text { communicative competence } \\
(\mathrm{CC}) \text { as a standard of native- } \\
\text { speaker competence. }\end{array}$ & $\begin{array}{l}\text { - Emphasis of CC as a } \\
\text { standard of native- } \\
\text { speaker competence. }\end{array}$ & $\begin{array}{l}\text { - Emphasis of CC as a } \\
\text { standard of native-speaker } \\
\text { competence. }\end{array}$ \\
\hline & $\begin{array}{l}\text { - Emphasis of } \\
\text { communicative } \\
\text { effectiveness and } \\
\text { appropriateness in two } \\
\text { language skills courses. }\end{array}$ & $\begin{array}{l}\text { - No reference to } \\
\text { intercultural } \\
\text { communicative } \\
\text { competence }\end{array}$ & $\begin{array}{l}\text { - No reference to } \\
\text { intercultural communicative } \\
\text { competence }\end{array}$ \\
\hline
\end{tabular}

The findings revealed the limited view of culture and culture learning in the curriculum frameworks and in the national education policy. Three main findings can be mentioned. First, the importance of culture and culture learning in language learning is not emphasised, but an instrumental orientation to EFL is adopted to equip learners with knowledge of the English language and communication skills for future jobs. Second, the designation of culture to separate culture courses establishes a separate status, construct and treatment of culture and culture learning rather than integrating it into language learning. Third, culture is constructed as knowledge about a particular culture rather than with an exploratory and reflective approach to culture and culture-in-language.

However, some potential areas for developing intercultural language learning in Vietnamese tertiary EFL programmes can be identified. First, culture and culture learning are visible in the training objectives and the training standards of the programmes, which need to be developed into cultural objectives for language courses. Second, a focus on the learners' first language and culture at the beginning of language learning can foster learners' cultural self-awareness as a basis for them to engage in intercultural language learning. Third, the objectives of developing 
communicative effectiveness and appropriateness with native English speakers in the two language skills courses in the NCE should be promoted to engage learners in intercultural language learning in the EFL programmes. Finally, the objectives of interculturality could be integrated into the national education policy to fulfil its objectives of preparing Vietnamese learners of foreign languages for study and work in a multilingual and multicultural environment.

Overall, the curriculum review reveals the limited view of culture and culture learning in the curricular documents and in the national education policy; however, some potential areas for developing intercultural language learning in Vietnamese tertiary EFL programmes are also identified.

In the next chapter, I will outline the methodology for an analytical study of teachers and students regarding their perceptions and practices of culture teaching and learning. 


\section{Chapter IV \\ METHODOLOGY FOR AN ANALYTICAL STUDY OF \\ TEACHERS AND STUDENTS}

\subsection{Introduction}

This chapter outlines the methodological approaches used for an analytical study of teachers and students in the second phase of the study. Such a study goes beyond merely describing the characteristics. It is concerned with analyzing and explaining how or why the phenomenon being studied is happening, i.e., how the teachers and students perceived culture in language teaching and learning and why they addressed culture in a certain way in their actual classroom practices. The chapter starts with an overview, followed by its research design that details the teacher and student participants, the research process and procedures for data collection and methods for data analysis. Ethical considerations are also discussed. Finally, the chapter discusses issues of reliability and validity in relation to the study as well as its limitations.

\subsection{Overview of the second phase}

The second phase of the study investigated the teachers' perceptions of culture in language teaching and their culture teaching practices. It also examined the students' priorities and perceptions of culture learning. This analytical study addresses the following research questions (RQ):

RQ2: How is culture in language teaching evident in the perceptions and classroom practices of Vietnamese EFL teachers?

RQ3: How is culture in language learning evident in the priorities and perceptions of Vietnamese EFL students?

Both qualitative and quantitative approaches to the research design were adopted. As this was a classroom-based study, it was decided that a combination of both approaches could integrate the generated data with each other to produce a more complete analysis (Creswell, 2002). The qualitative approach involved classroom 
observations, teacher interviews and student focus-group interviews. By using the qualitative approach, the dynamic nature of events as well as the trends and patterns over time can be better represented (Cohen, Manion and Morrison, 2007). The qualitative approach also provides deeper insight into the personal, interpersonal or contextual factors (Sercu, 2005). The quantitative approach was used with the student questionnaire as it is more appropriate to describe, compare and attribute causality (Gall, Gall and Borg, 2005).

\subsection{Participants}

The participants in the second phase of this study were the EFL teachers and students at two Vietnamese universities.

\subsubsection{Teacher participants}

Fourteen Vietnamese EFL teachers participated in the classroom observations and interviews. The teacher participants' demographic information is given in Table 4.1.

TABLE 4.1

Demographic information of teacher participants

\begin{tabular}{llc}
\hline Category & & $\begin{array}{c}\text { Number of teachers } \\
(\mathbf{N}=\mathbf{1 4})\end{array}$ \\
\hline Gender & Male & 2 \\
& Female & 12 \\
Age group & $26-35$ & 4 \\
& $36-45$ & 8 \\
& $>45$ & 2 \\
\multirow{2}{*}{ Years of teaching experience } & $1-5$ & 1 \\
& $6-10$ & 6 \\
\multirow{2}{*}{ Degree } & $>10$ & 7 \\
& & \\
\multirow{3}{*}{ Have been abroad } & PhD & 1 \\
& MA & 11 \\
& BA & 2 \\
& & 5 \\
& Yes & 9 \\
\hline
\end{tabular}

The majority of the teacher participants are female in the 36-45 age group. This reflects the wider population of EFL teachers in Vietnam in which male teachers are 
usually outnumbered by female teachers. Half of the participants are senior teachers who have been teaching English for more than 10 years; the rest have been teaching for 6-10 years, except one young teacher with less than 5-year teaching experience. The majority of the participants have obtained their Masters' Degree in TESOL or Applied Linguistics. One-third of the teachers have been abroad, mainly studying in Australia for their Masters' Degree.

\subsubsection{Learner participants}

Two hundred Vietnamese EFL students completed a questionnaire and fifty-three Vietnamese EFL students participated in focus-group interviews. The students participated voluntarily in the study. The demographic information of the learner participants in the questionnaire and focus-group interviews is given in Tables 4.2 and 4.3 .

TABLE 4.2

Demographic information of learner participants in the questionnaire

\begin{tabular}{llc}
\hline \multicolumn{1}{c}{ Category } & Male & $\begin{array}{c}\text { Students } \\
(\mathbf{N = 2 0 0})\end{array}$ \\
\hline Gender & Female & 20 \\
& & 180 \\
Age & 18-22 years old & 173 \\
& 23-30 years old & 27 \\
& Year 1 & 34 \\
Year of Study & Year 2 & 26 \\
& Year 3 & 57 \\
& Year 4 & 83 \\
Years of learning English & 1-5 years & 19 \\
& 6-10 years & 124 \\
Have been abroad & $>10$ years & 57 \\
& & \\
& Yes & 4 \\
& No & 196 \\
\hline
\end{tabular}

It can be seen that the majority of the participants are female in the 18-22 age group. This reflects the wider population of English-majoring students in which male students are usually outnumbered by female students. A large range of participants from all the four years of study and different majors of English were chosen. Nearly half of the participants were fourth-year students, followed by a quarter being thirdyear students. First-year and second-year students were quite similar in number, 
around 30 each. The students' majors include English for Teacher Education, English for Translation and Interpretation and English for Tourism. Nearly two-thirds of the participants have been learning English for several years since secondary school. Only a small number of students have been learning English for a short time due to limited EFL education in remote areas. Most of the participants have never been abroad.

TABLE 4.3

Demographic information of learner participants in focus-group interviews

\begin{tabular}{llc}
\hline \multicolumn{1}{c}{ Category } & $\begin{array}{c}\text { Students } \\
(\mathbf{N}=\mathbf{5 3})\end{array}$ \\
\hline Gender & Male & 13 \\
& Female & 40 \\
Age group & 18-22 years old & 44 \\
& $23-30$ years old & 8 \\
& Year 1 & 11 \\
Year of Study & Year 2 & 5 \\
& Year 3 & 11 \\
& Year 4 & 26 \\
Years of learning English & $1-5$ years & 3 \\
& 6-10 years & 25 \\
Have been abroad & $>10$ years & 25 \\
& & \\
& Yes & 2 \\
\hline
\end{tabular}

\subsection{Research process and procedures}

This section describes the research process and procedures of the second phase of the study including piloting, ethical considerations, and data collection methods.

\subsubsection{Piloting}

The piloting of the teacher interviews and the student questionnaire was conducted in October 2008 before the actual data collection period in Vietnam. Three Vietnamese EFL teachers studying at Victoria University of Wellington participated in the piloting interview. These teachers offered their comments on the clarity of each interview question. Based on their feedback, the interview questions were revised for the final version. 
Regarding the student questionnaire, I first sought advice from a professional statistician at Victoria University of Wellington for its statistical feasibility. The questionnaire was then piloted with twenty Vietnamese students studying at Victoria University of Wellington who completed the questionnaire and offered comments. The following questions are the guidelines for their comments:

(a) Do you understand all the questions in the questionnaire?

(b) Which question do you find difficult to understand?

(c) Which question do you find difficult to answer?

(d) How long does it take you to complete the questionnaire?

(e) What comments do you have about the content of the questionnaire?

(f) Do you have any other comments about the questionnaire?

Based on the students' comments, the questionnaire was revised for the final version to be used in the actual data collection.

\subsubsection{Ethical considerations}

The study had obtained the approval of the Human Ethics Committee (HEC) from Victoria University of Wellington (Appendix 2) for the involvement of the teachers and students in the study before the data collection was conducted in Vietnam. The study also obtained the approval of the two Vietnamese universities for the research to take place in the English departments.

Before the data collection started, I provided all the teacher and student participants with information sheets (Appendices 3 and 4) and consent forms (Appendix 5). I explained every important point in the study and the teachers and students had a chance to ask questions about anything that was not clear to them. I also mentioned that I would not disturb their classroom performances in my role as a non-participant observer in the class.

\subsubsection{Data collection methods}

The second phase of the study took place over a period of three months from December 2008 to February 2009, using the following methods of data collection: 
(1) Classroom observations

(2) Teacher interviews

(3) Student questionnaire

(4) Student focus-group interviews

Each of these methods is described in detail below.

\subsubsection{Classroom observations}

As this research was a classroom-based study, classroom observation was used as a research method to examine the teachers' culture teaching practices in the naturalsetting EFL classroom. Classroom observation was chosen for the study as it helps to gather 'live' data from naturally occurring social situations (Cohen et al., 2007). These 'live' data enable the researcher to look afresh at everyday behaviour (Cooper and Schindler, 2001) that takes place in the classroom. According to Dornyei (2007), classroom observation is "invaluable for providing descriptive contextual information about the setting of the targeted phenomenon" (p.185). Cohen et al. (2007) also argue that classroom observation has the unique strength that is "the use of immediate awareness, or direct cognition, as a principal mode of research..., [which] has the potential to yield more valid or authentic data than would otherwise be the case with mediated or inferential methods" (p.396).

Eight teachers from the English departments at the two Vietnamese universities volunteered to participate in classroom observations. On the basis of the availability of classes for observations, four teachers were observed twice and the other four teachers were observed once: there were twelve classroom observations over two months. Table 4.4 details the characteristics of the twelve classroom observations. The speaking lessons used the textbook Let's Talk (Jones, 2002); the General English lessons used the textbook New Cutting Edge (Cunningham and Moor, 2005) and the American culture lessons used internal material ${ }^{8}$. Each classroom observation lasted for 90-100 minutes and was audio-recorded.

\footnotetext{
${ }^{8}$ The American culture material was compiled from different sources by an assigned teacher of the English department for use internally in this institution.
} 
TABLE 4.4

Characteristics of classroom observations

\begin{tabular}{cccc}
\hline Observation (N=12) & Type of lesson & Year of study & Major \\
\hline Observations 1-3 & Speaking & Years 1,2 & English \\
Observations 4-10 & General English & Year 1 & Non-English \\
Observations 11-12 & American Culture & Year 3 & English \\
\hline
\end{tabular}

To ensure reliability, every lesson was observed using a systematic observation scheme based on the same criteria including goals, input, task, teacher's role, student's role, setting and kind of task (Nunan, 1989) (Table 4.5). Such an observation scheme "makes the process more reliable and produces results that are comparable across classrooms and over time" (Dornyei, 2007, p.185).

TABLE 4.5

Classroom observation scheme (adapted from Nunan, 1989)

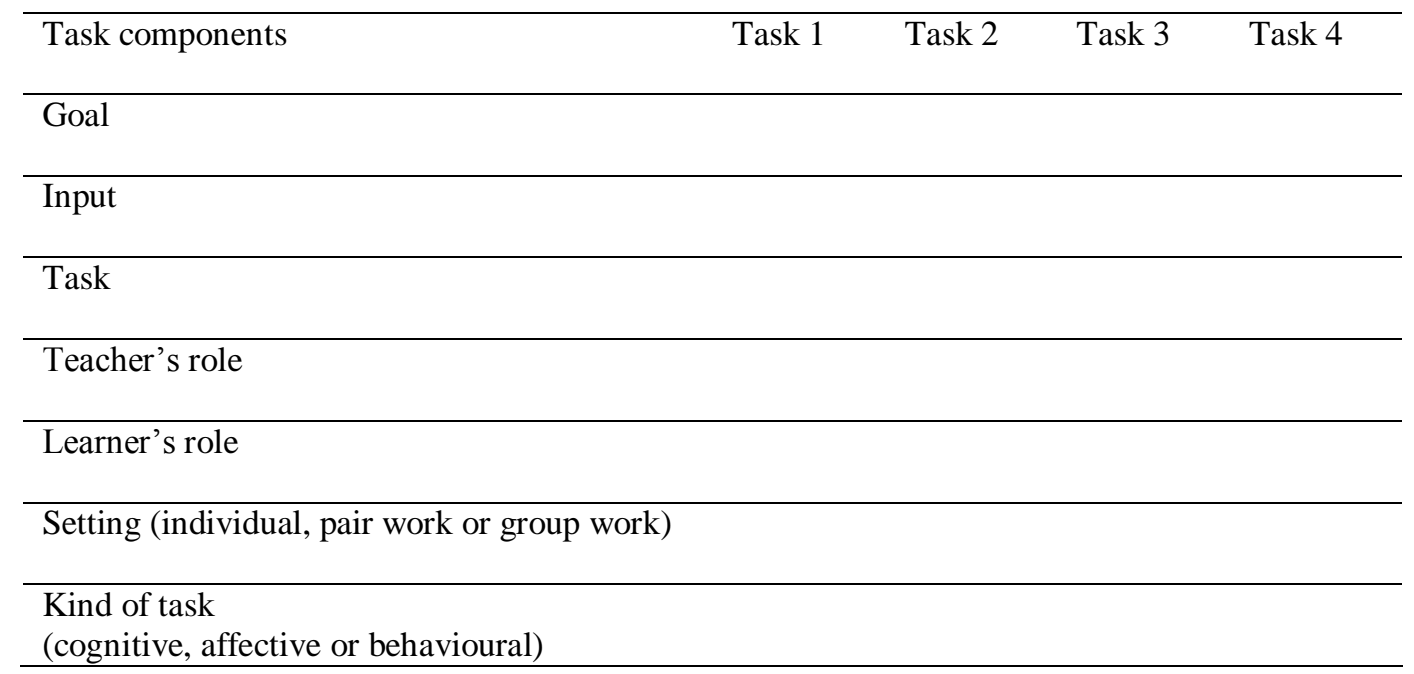

Field notes about each lesson were written in the observation scheme. A summary of classroom observations can be found in Appendix 6.

\subsubsection{Teacher interviews}

Teacher interviews were used to investigate the EFL teachers' perceptions of culture in language teaching. A qualitative interview was used as it could describe the life 
world of the interviewee and interpret the meaning of the described phenomena (Kvale, 1996). Sercu (2005) only uses a survey for teachers' perceptions of language and culture and suggests using teacher interviews. She argues that the use of teacher interviews has potential to lead to a better understanding of teachers' conceptions of the integration of language and culture teaching. Teacher interviews were therefore adopted in the study for this purpose.

Twelve out of fourteen teachers agreed to participate in the interviews. The interviews were scheduled at a convenient time for each teacher and were conducted individually in order to provide in-depth data. Each interview lasted for 30-45 minutes and was conducted in the first language of the teachers. Instead of using a structured interview that could limit the depth and breadth of the respondent's answers, the study used a semi-structured interview with a set of pre-prepared guiding questions to encourage the interviewees to elaborate on the issues raised in an exploratory manner (Dornyei, 2007). As McDonough and McDonough (1997) argue, the use of semistructured interview "allows for richer interactions and more personalized responses than the quasi-automaton interviewer armed with entirely pre-coded questions" (p.184). The interview schedule can be found in Appendix 7.

Stimulated recall was also used in the interviews with the teachers who had been observed in the classroom. Stimulated recall is "a technique in which the researcher records and transcribes parts of a lesson and then gets the teacher...to comment on what was happening at the time that the teaching and learning took place" (Nunan, 1992, p. 94). In this study, based on the field notes taken about parts of a specific observed lesson, I asked the interviewees to comment on their approach to culture teaching in the classroom. Stimulated recall is particularly useful as it provides insight into aspects of teaching that would be difficult to obtain in other ways (ibid). This technique also enables teachers to present their various interpretations that are explicitly linked to the prominent points in the lesson as well as enabling the voice of the teacher to be heard (ibid).

\subsubsection{Questionnaire}

The questionnaire was used to investigate the EFL students' priorities in EFL learning and their perceptions of culture learning. The questionnaire was chosen as a research method for its efficiency. Dornyei (2007) argues that a questionnaire can "find 
answers to questions in a systematic and disciplined manner" and is "extremely versatile and uniquely capable of gathering a large amount of information quickly in a format that is readily processible" (p.101). In addition, as the knowledge needed for the research is controlled by the questions, the questionnaire "affords a good deal of precision and clarity" (McDonough and McDonough, 1997, p.171).

Two hundred students from first-year to fourth-year studies agreed to complete the questionnaire (Appendix 8). They were invited to ask questions about anything they might not understand in the questionnaire. The questionnaire consists of nine questions with closed-ended and open-ended parts (Table 4.6).

TABLE 4.6

Summary of the questionnaire

\begin{tabular}{cll}
\hline Question & Type of question & Content \\
\hline Q1 & closed-ended & Purposes for learning English \\
Q2 & closed-ended & Priorities in language learning \\
Q3 & closed-ended & Topics in language learning \\
Q4 & closed-ended & Purposes for culture learning \\
Q5 & closed-ended & Culture learning activities in the classroom \\
Q6 & closed-ended & Culture learning activities outside the classroom \\
Q7 & closed-ended & Beliefs about aspects of culture learning \\
Q8 & $\begin{array}{l}\text { closed-ended } \\
\text { and open-ended }\end{array}$ & Benefits of culture learning \\
Q9 & $\begin{array}{l}\text { closed-ended } \\
\text { and open-ended }\end{array}$ & Teachability of English language and culture \\
\hline
\end{tabular}

The closed-ended part includes questions with ranking order of importance (e.g., most important, very important, important), multiple-choice (e.g., yes, no, with limitation) and 5-point Likert scale (e.g., 'strongly disagree' to 'strongly agree'). The open-ended part includes the two last questions so that the other items of the questionnaire would not be affected. The open-ended part has some merit. As Dornyei (2007) argues, "by permitting greater freedom of expression, open-format items can provide a far greater 
richness than fully quantitative data" (p.107). The questionnaire was translated into the students' first language to facilitate their understanding. The students completed the questionnaire in the classroom. It took them about 15-20 minutes to finish it.

\subsubsection{Student focus-group interviews}

The focus-group interviews were designed to complement the questionnaire. In order to gather a relatively large amount of qualitative data from a small group of students, the study used the student focus group interviews instead of individual ones to take advantage of "the collective experience of group brainstorming" (Dorneyi, 2007, p.144). This kind of interview can yield rich and high-quality data thanks to the 'synergistic group effect' (Stewart and Shamdasani, 1990) among and between group members that stimulates a deep and insightful discussion (Berg, 2007).

Fifty-three English-majoring students volunteered to participate in the focusgroup interviews. The interviewees were among the students who had completed the questionnaire. There were ten focus-group interviews, each of which consisted of five to six students. The interview schedule was structured using eight questions (Appendix 9). Each focus-group interview was conducted in the classroom right after class and lasted for 30-40 minutes. It was conducted in the students' first language to facilitate their understanding, which thus "remov[es] concerns about the proficiency of the learner impacting the quality and quantity of the data provided" (Mackey and Gass, 2005, p.174).

\subsubsection{Summary of data collection methods}

Data collection methods in the second phase of the study are summarised in Table 4.7. 
TABLE 4.7

Summary of data collection methods

\begin{tabular}{|c|c|c|c|}
\hline Methods & Participants & Time allocated & Total number of sessions \\
\hline Classroom observations & 8 teachers & 90-100 minute/lesson & 12 observations \\
\hline Teacher interviews & 12 teachers & $\begin{array}{l}30-45 \text { minute } \\
\text { interview/each teacher }\end{array}$ & 12 interviews \\
\hline Questionnaire & 200 students & 15-20 minute & 200 questionnaires \\
\hline $\begin{array}{l}\text { Student focus-group } \\
\text { interviews }\end{array}$ & 53 students & $\begin{array}{l}30-40 \text { minute } \\
\text { interview/each focus group }\end{array}$ & 10 focus groups \\
\hline
\end{tabular}

\subsection{Data analysis methods}

The data analysis methods used in the second phase of the study include the following:

(a) Content analysis

(b) Descriptive statistics

Each of these methods is described below.

\subsubsection{Content analysis}

Content analysis (Hsieh and Shannon, 2007) was used for the open-ended parts of the questionnaire, classroom observations, the teacher interviews and the student focusgroup interviews. Qualitative content analysis is defined as "a research method for the subjective interpretation of the content of text data through the systematic classification process of coding and identifying themes or patterns" (Hsieh and Shannon, 2007, p.111). The qualitative data of the questionnaire, the teacher interviews and student focus-group interviews was translated into English and coded using thematic analysis (Ezzy, 2002) in which themes or patterns were derived directly and inductively from the raw data. A summary of categories and coding for the open-ended parts of the questionnaire can be found in Appendix 10, the teacher interviews in Appendix 11 and the student focus-group interviews in Appendix 12.

The analysis of classroom observations was done in the following steps. First, 
the field notes were taken using the observation scheme in Table 4.5. Then the notes were coded using the following questions:

(a) To what extent was an aspect of culture evident in the lesson?

(b) What activities about the target culture did the teachers and students engage in?

(c) What did the classroom observation reveal about the teacher's practice of culture teaching?

Through the reading of the coded observation notes, the themes and patterns across the lessons were finally teased out to provide a picture of the teachers' culture teaching practices.

\subsubsection{Descriptive statistics}

Descriptive statistics were used to analyse the closed-ended data of the questionnaire. The data was recorded into SPSS software (version 17.0) so that each student's response was given a score. Dependent on each question, different descriptive statistics were carried out such as the sum of scores, factor analysis or comparisons of mean scores.

\subsection{Reliability and validity}

This section discusses the reliability and validity of the second phase of the study.

\subsubsection{Reliability}

Reliability is concerned with the replicability of research findings, i.e., a researcher can obtain the same results as those of a previous study by using the same methods (LeCompte and Goetz, 1982). LeCompte and Goetz mention two main kinds of reliability in research: internal reliability and external reliability. Internal reliability refers to the extent to which other researchers could match previously generated constructs with data in a similar way as the original researcher, whereas external reliability refers to the possibility of independent researchers discovering the same phenomena or generating the same constructs in similar research settings. Nunan 
(1992) argues that "if one is careful in the collection and analysis of one's data, and if one is explicit about the way the data was collected and analysed, then one can reasonably claim reliability for one's investigation" (p.62).

The study achieved a reasonable standard of reliability as it satisfied Nunan's (1992) statement above. First, a detailed description of teacher and student participants, the context and conditions under which the research was carried out was provided. Second, a 'methodological triangulation' (Mackey and Gass, 2005) was used with both qualitative and quantitative approaches. These approaches involved different data collection methods that captured how the teachers taught culture in their language practices (classroom observations), how the teachers perceived and why they addressed culture in a certain way in their lessons (teacher interviews), what the student priorities and perceptions of culture were (questionnaire) and why the students had such priorities and perceptions (focus-group interviews). The data gathered through these triangulated means were then cross-analysed for an in-depth understanding of the teacher and student perceptions of culture in language teaching and learning. This triangulation served as a means of refining, broadening and strengthening conceptual linkages (Goetz and LeCompte, 1984) and also reduced the observer or interviewer bias, thus enhancing the reliability and validity of the information (Johnson, 1997). Third, every lesson was observed using a systematic observation scheme based on the same criteria. All classroom observations, teacher interviews, and student focus-group interviews were also audio-recorded. Fourth, the questionnaire was also carefully designed in a way that could reflect the consistency of students' answers. Items in the questionnaire were addressed by a split-half method to ensure the consistency of students' response. This means that if students choose 'strongly agree' in the first sentence, they would be expected to choose 'strongly disagree' or 'disagree' in the next one and vice versa.

In brief, the reliability for the study can be ensured by careful consideration regarding participants, research context and conditions, and methods for data collection and analysis.

\subsubsection{Validity}

Validity is concerned with the accuracy of research findings (LeCompte and Goetz, 1982). To reduce the threats to the validity of a study, LeCompte and Goetz draw 
researchers' attention to five important issues: history and maturation, observer effects, selection and regression, mortality, and spurious conclusion. They also mention four factors that may affect the credibility of a study for cross-group comparisons: selection effects, setting effects, history effects, and construct effects.

A number of steps were taken to ensure the study achieved a satisfactory standard of validity. First, the teacher and student participants were recruited on a voluntary basis and all the participants signed a consent form for participation in the study. Second, classroom observations were done in a natural classroom setting and took place in normal scheduled learning periods, which reflected accurately the reality of the teacher and student practices of language teaching and learning. Third, Nunan (1992) mentions Labov's (1972) 'observer's paradox' which raises the issue of whether the presence of the researcher in the classroom may have some influence on the teacher and student behaviours. In my classroom observations, the teachers may have made more efforts in their teaching and the students may have worked harder in the class activities. However, through my classroom observations, I found that both the teachers and students appeared to be quite comfortable in spite of my presence. They had got used to being observed by other teachers during the semester as a requirement of the university, and so the impact of my presence in the classroom was likely to be minimal.

In brief, the validity of the present study can be ensured on the basis of the random selection of teacher and student participants, the natural-setting classroom observations and the minimal impact of the researcher's presence on the participants' performance in the classroom.

\subsection{Limitations}

The study had the following limitations.

First, the study investigated a small number of teacher participants $(\mathrm{N}=14)$ and so it was not possible to generalise the findings for the Vietnamese EFL education. A questionnaire with a larger sample of teacher participants in different universities in Vietnam would produce data which can be generalised.

Second, twelve classroom observations within a short period of time could not reveal all the teachers' culture teaching practices. More classroom observations over a longer period of time, for example one semester, with a variety of courses across the 
EFL curriculum, would provide a deeper understanding about the teachers' culture teaching practices.

Third, some teachers were interviewed without being observed due to the unavailability of their classes for observations, and consequently the results had to rely on these teachers' self-reports about their previous culture teaching experiences which were not directly observed.

\subsection{Summary}

This chapter has detailed all the research methods for data collection and analysis employed in the second phase of the study. The study adapted both quantitive and qualitative approaches to data analysis. The methodological triangulation provided rich data to answer the research questions comprehensively and thoroughly. The study achieved a satisfactory standard of reliability and validity through careful consideration regarding the selection of participants, research context, design and methods for data collection and analysis. Some limitations were also discussed.

In the next chapter, I will report and discuss the findings regarding the teachers' perceptions and culture teaching practices in the EFL classroom. 


\section{Chapter V \\ TEACHER PERCEPTIONS AND CULTURE TEACHING \\ PRACTICES: RESULTS AND DISCUSSION ${ }^{9}$}

\subsection{Introduction}

This chapter reports on the perceptions and classroom practices of teachers at the two Vietnamese universities concerning culture teaching in their EFL classes so as to address the following research question:

RQ2: How is culture in language teaching evident in the perceptions and classroom practices of Vietnamese EFL teachers?

The chapter first presents the results in two sections. The first section deals with the teachers' perceptions and beliefs concerning culture in language teaching, and the second section focuses on their culture teaching practices in EFL classes. The results are drawn from twelve classroom observations and interviews with twelve teachers. The chapter concludes with a discussion of main trends in the data and with a final chapter summary.

\subsection{Teachers' perceptions and beliefs concerning culture in language teaching}

This section reports on the teachers' perceptions and beliefs which are concerned with:

(a) What the teachers understood the term 'culture' to mean;

(b) How they viewed the relationship between language and culture in EFL teaching and learning;

(c) What they believed about culture teaching.

\footnotetext{
${ }^{9}$ A part of this chapter was published in Ho (2011).
} 


\subsubsection{Definitions of culture}

The teachers were asked to define what they understood the term 'culture' in EFL teaching and learning to mean. Their responses revealed two main classifications of culture: (1) culture in society and (2) culture in language and communication. Table 5.1 summarises the teachers' definitions of culture which are described in detail below (Twelve out of fourteen teachers gave definitions in the interviews).

TABLE 5.1

Teachers' definitions of culture

\begin{tabular}{|c|c|c|c|c|c|c|}
\hline No. & Teachers & \multicolumn{5}{|c|}{ Classifications of culture } \\
\hline & & \multicolumn{2}{|c|}{ Culture in society } & \multicolumn{3}{|c|}{ Culture in language and communication } \\
\hline & & $\begin{array}{l}\text { Big 'C' } \\
\text { Culture }\end{array}$ & $\begin{array}{l}\text { 'small c' } \\
\text { culture }\end{array}$ & $\begin{array}{c}\text { Culture in } \\
\text { language use }\end{array}$ & $\begin{array}{c}\text { Culture in } \\
\text { communication }\end{array}$ & $\begin{array}{c}\text { Culture in } \\
\text { linguistic } \\
\text { aspects }\end{array}$ \\
\hline 1. & Teacher 2 & & & $\sqrt{ }$ & $\sqrt{ }$ & \\
\hline 2. & Teacher 3 & & $\sqrt{ }$ & $\sqrt{ }$ & $\sqrt{ }$ & \\
\hline 3. & Teacher 4 & & $\sqrt{ }$ & & & $\sqrt{ }$ \\
\hline 4. & Teacher 5 & & & $\sqrt{ }$ & & \\
\hline 5. & Teacher 6 & $\sqrt{ }$ & $\sqrt{ }$ & & & \\
\hline 6. & Teacher 7 & $\sqrt{ }$ & $\sqrt{ }$ & $\sqrt{ }$ & $\sqrt{ }$ & \\
\hline 7. & Teacher 9 & & & $\sqrt{ }$ & $\sqrt{ }$ & \\
\hline 8. & Teacher 10 & & $\sqrt{ }$ & & & \\
\hline 9. & Teacher 11 & $\sqrt{ }$ & $\sqrt{ }$ & $\sqrt{ }$ & $\sqrt{ }$ & \\
\hline 10. & Teacher 12 & & $\sqrt{ }$ & & $\sqrt{ }$ & \\
\hline 11. & Teacher 13 & & $\sqrt{ }$ & $\sqrt{ }$ & $\sqrt{ }$ & $\sqrt{ }$ \\
\hline 12. & Teacher 14 & & $\sqrt{ }$ & & & \\
\hline
\end{tabular}

The teachers defined culture in society in terms of what is referred to as 'big C' culture and 'small c' culture. Nine out of the twelve interviewed teachers defined culture in terms of 'small c' culture which involves such elements as native speakers' manners, customs, beliefs, behaviours, moral values, habits, lifestyle, etiquette, conventions, ways of eating, ways of working, or kinds of food. Only three teachers defined culture in terms of 'big C' culture that involves such elements as rituals, religions, characteristics of each nation, a particular nation or people, typical and particular features of an ethnic group. 
Regarding culture in language and communication, seven teachers defined culture in relation to language use which involves vocabulary use, formal and informal language, colloquial language and speech acts. For example, one teacher mentioned culture in vocabulary use through the use of please which is used in English as a sign of politeness, whereas it is not often used in Vietnamese. This teacher also stated that the English expression as poor as a church mouse and the Vietnamese equivalent nghèo rớt mồng tơi can be explained only by studying the associated culture linked to each expression. Another teacher believed that the use of oh yeah, uh-huh is culturally determined. This teacher also related culture in the formal and informal language to the levels of politeness and highlighted culture in the use of colloquial language in communication:

(1) Students learning English who understand only formal language cannot communicate. Colloquial language is heavily cultural (Interview T9, Q1, P1).

The other three teachers mentioned culture in speech acts that involve greetings, ways of thanking, making requests or speech behaviour. One of these teachers explained that culture was clearly presented at the level of politeness through the manner of greetings at a hotel reception. This teacher believed that May I help you should be used instead of How can I help you at a three-star Vietnamese hotel, and a smile on the phone is a cultural behaviour to show one's attitudes to guests at a hotel reception counter.

In addition, seven teachers also defined culture in relation to communication which involves ways of communication, directness and indirectness, norms of interaction, ways of speaking and writing, cultural concepts, taboos, sense of humour and non-verbal language. For instance, one teacher believed that directness and indirectness are two different manners of communication between Westerners and Easterners:

(2) Culture shows differences in ways of communication, e.g., Westerners go straight to an issue, whereas Easterners tend to ask about each other before dealing with the issue (Interview T11, Q1, P1). 
Another teacher commented that culture in gift giving could be considered as a cultural norm of interaction in communication:

(3) In gift giving, Vietnamese people tend not to accept the gift right away but say some words of refusal before accepting it. They do not open it in front of the giver as this may be considered a sign of impoliteness. For English people, they open the gift to have a look and give compliments about it to show their interest (Interview T13, Q2, P1).

The other two teachers noted that culture in communication involves cultural concepts in small talk such as the 'weather talk' or 'health talk' in the target language culture:

(4) English people usually talk about the weather when they meet others. This is due to the geographic conditions of the place where the weather is changeable. Students can understand this issue when they are found in similar situations (Interview T12, Q1, P1).

(5) Vietnamese people seldom ask 'how are you?', but the English often talk about weather and health as a cultural behaviour (Interview T5, Q1, P1).

The cultural concepts in examples (4) and (5), however, can easily lead to cultural stereotypes if they are misused. One teacher expressed such concern about discussing the weather in the target language culture:

(6) Students think that English people usually talk about the weather in first meetings. They understand this cultural issue in a wrong way; it should be used according to appropriate situations and topics (Interview T2, Q8, P1).

Another teacher related culture in communication to taboos or the sense of humour:

(7) Culture is related to communication. Students can ask shocking questions [to speakers of the target language]. The sense of humour is also used differently across cultures; foreigners may find some jokes funny but Vietnamese people do not, and vice-versa. (Interview T12, Q1, P1). 
Moreover, two other teachers related culture in language teaching to linguistic differences between the Vietnamese language and the English language. The linguistic differences include verb formation, sentence structures and the use of tenses, voices, and intonation. These two teachers addressed the linguistic differences as a representation of culture in language:

(8) Culture concerns all that is different. The habits in verb formation, in the use of tenses or the construction of sentences in the target language have great influence on the students' language learning. For example, there are different uses of the past continuous tense in English and Vietnamese (Interview T4, Q1, P1).

(9) Writing an essay using the English style also deals with culture. For example, the passive voice is often used to deal with the action in English, whereas the active voice is used in Vietnamese (Interview T13, Q7, P1).

To sum up, the teachers defined culture in EFL teaching and learning in a broad range of ways from culture as seen in social structures to culture in instantiation of particular speech acts.

\subsubsection{Awareness of the relationship between language and culture}

The teachers were asked whether the target culture should be incorporated into English classes or should be taught in separate culture courses. Six out of the twelve interviewed teachers demonstrated an understanding about the relationship between language and culture. One teacher, for example, commented on the inseparability of language and culture in language learning:

(10) It is impossible to separate culture from language completely as it will become noncultural: it is impossible to separate two closely-connected parts in an entity. Language learning involves cultural behaviours; if they are separated it is difficult to teach the language as the core is lost (Interview T5, Q8, P1).

The teacher in (10) highlighted the involvement of cultural behaviours in the language learning process. This indicates that culture learning is considered as a way of behaving in a culturally appropriate manner. Another teacher also commented on the direct impact of culture on language: 
(11) Incorporating culture in other courses is necessary as nothing can be separated from culture, especially language. It will help students to see that culture defines language, not the other way around. Culture defines all the things that are closely connected with the customs and lifestyle of a particular group of people (Interview T12, Q8, P1).

The quote (11) above indicates that culture defines language through its links with customs and lifestyles. Culture learning is thus considered as a way to learn about people's daily life through the target language. The same teacher also highlighted the importance of cultural understanding in language teaching:

(12) Teaching language separately from culture will make students become like children who only repeat what adults say but do not understand the issue at all (Interview T12, Q1, P1).

The other two teachers were aware of the relationship between language and culture in social interaction:

(13) Culture needs to be incorporated in all courses as language cannot be separated from culture. It will make the lesson better and more interesting; students will use the language more accurately and know how to handle the situations (Interview T13, Q8, P1).

(14) Language is a part of culture. If language is misused, students do not understand the target culture and they will fail to use the language in communication. Culture and language are closely connected and related; teachers cannot teach a language without dealing with culture in any language courses (Interview T2, Q8, P1).

The quotes (13) and (14) above show that language and culture teaching helps students use the language more accurately for effective communication. This suggests that language and culture teaching would contribute to learners' success in intercultural communication.

In brief, six out of the twelve interviewed teachers were aware of the inseparability of language and culture in language teaching. The other six teachers made no comments about this relationship. 


\subsubsection{Beliefs about culture teaching}

The teachers' beliefs about culture teaching can be addressed in four categories:

(a) Topical dependence

(b) Separate treatment of culture teaching from language teaching

(c) Inadequate exposure to culture in language courses, and

(d) Constraints on culture teaching

Each of these categories is described in detail below.

\subsubsection{Topical dependence}

The teachers were asked about their perspectives on the cultural content of the materials in use in their EFL classes. One teacher noted that materials for language skills courses are topic-based or skills-based. This teacher recognised that topic-based materials tended to involve culture rather than skills-based materials that normally focus on developing language skills. She believed that culture was topically dependent because the topics in her lower level reading course were more related to culture than those in her advanced course which usually involved general knowledge (e.g., globalization or astronomy). Another teacher also supported this idea by stating that it depended on whether a topic had culture-embedded meaning (e.g., superstition). One of the observed teachers did not think that she would address culture in the lesson on 'healthy life', but could do it in the lesson on 'manners'. She argued:

(15) The topic 'healthy life' does not cause any culture shock, and so teachers do not feel important to mention any different cultural conceptions about healthy life...In the lesson on 'manners', on the other hand, it is important to teach culture for the whole lesson as the topic can cause culture shock. In this lesson, students have to acquire cultural knowledge about what kind of communication they need to know or foreigners need to avoid. If students have foreign friends coming to visit Vietnam, they need to tell them what they should or should not do (Interview T3, Q5, P1). 
This quote (15) indicates the teacher's belief that cultural teaching depends on a topic which is more likely to provoke potential culture shock for language learners. One teacher suggested that culture should be incorporated into language skills courses through cultural topics:

(16) In the speaking course, content should be cultural and language is the tool to talk about it. In the listening course, cultural topics need to be added as they are both beneficial and interesting and help change students' taste in language learning. In the reading course, reading texts related to culture should be chosen to make students gradually perceive the target culture (Interview T7, Q8, P1).

The above quote (16) demonstrates that culture teaching is some kind of add-on in language teaching through the provision of additional cultural topics, rather than a kind of teaching which is integrated with language teaching.

\subsubsection{Separate treatment of culture teaching from language teaching}

The teachers were asked which topics they considered the most important for students to learn. Three teachers mentioned that there was a teaching order of topics in the materials. One teacher of a speaking course commented that the materials usually focused on language functions around the types of verbal and non-verbal communication for first-year students, daily life issues for second-year students and broader issues such as cultural values, festivals and traditions, history, geography and political systems for third-year students. The other two teachers also emphasised that students needed to learn types of communication first, before learning about aspects of the target culture. They believed communication was the primary basis and the first goal to achieve in language learning. These views indicate the teachers believed that language should get the first priority rather than culture.

Two observed teachers argued that their language teaching did not necessarily involve culture teaching. One of them believed that her method to teach 'TV firsts' (e.g., the inventor of TV, the first TV programmes...) was appropriate in terms of language teaching. The goal of the lesson, according to her, was the use of simple past tense, whereas it was ineffective to focus on culture teaching. The same teacher, in another lesson on 'feelings', also considered that cultural situations would be 
necessary for English-majoring students, but not for non-English majoring students who needed to focus only on correct language usage. This teacher's view reveals that language teaching was treated separately from culture teaching. The other teacher also believed that she did not need to address culture in a topic even if it does involve some cultural differences (e.g., different school time in Britain or Australia). She argued that the importance of her lesson was to teach students how to communicate through a particular topic rather than provide cultural information. This teacher was more concerned with the communicative goals of a lesson rather than its cultural objectives.

\subsubsection{Inadequate exposure to culture in language courses}

In response to the question of whether the target culture should be incorporated into EFL classes or taught in separate culture courses, five teachers argued that it was not sufficient to teach culture in language courses. One teacher mentioned the limited and scattered cultural content; for example, the cultural content occupied only five percent of a speaking course. Another teacher considered that culture in language courses was too broad, general and not deep enough. Another teacher said that it was impossible to address all aspects of the target language culture (e.g., history, geography or a political system) in language courses. Another teacher's argument was that a great amount of time would be needed to talk about culture in language courses. Due to the inadequate exposure to culture in language courses, nine teachers suggested culture should be taught in culture courses, particularly at a higher level, for comprehensiveness, depth, logicality and systematicity of culture learning. Such views are addressed in the following examples:

(17) Culture courses are necessary as students approach cultural issues in a deeper way; they can understand better, discuss better and have more knowledge about the target culture as it is a course on culture (Interview T2, Q8, P1).

(18) As culture incorporated in language courses is inadequate, culture courses are still needed. Students have to learn more about culture in culture courses to know about cultural differences during their learning process. Students will have more general, deeper and wider background knowledge about the target culture to communicate 
more effectively. Separate culture courses are more systematic, deeper and offer a better overview of the target culture (Interview T4, Q8, P1).

The above quotes (17) and (18) show that these teachers believed teaching the target culture can be separated from teaching the target language. These views do not acknowledge the value of the cultural dimension in language teaching.

\subsubsection{Constraints on culture teaching}

The teachers' responses in the interviews revealed a variety of constraints that restricted opportunities for cultural teaching. Listed below are fifteen constraints on culture teaching as stated in the teachers' beliefs:

- area of study

- type of course

- topic/lesson content

- purposes, goals of the lesson

- time limit of the lesson

- traditional way of teaching

- student level of English

- students' background knowledge

- students' interests

- teacher's choices

- pressure on assessment

- teachers' teaching experience

- teachers' cultural knowledge

- historical and political contexts

- curriculum, testing and education policy constraints

Among the constraints mentioned above, the constraints chosen for discussion were the most common concerns among the interviewed teachers. These constraints included (a) students' cultural background knowledge, (b) students' level of language proficiency, (c) students' degree of receptiveness to culture learning, (d) teachers' cultural background knowledge, (e) time allowance for culture teaching, and (f) 
curriculum, testing and education policy constraints. Each of these constraints is discussed below.

\section{(a) Students' cultural background knowledge}

Seven teachers expressed concerns about students' limited cultural background knowledge. Three teachers found it hard to teach culture when students did not have enough cultural background knowledge. One of them stated that her students found it difficult to match the word cereal with the correct picture of milk as they have never had cereal with milk for breakfast. This example shows the cultural difference in breakfast between the learners' own culture and the target language culture and therefore can engage learners in culture learning. The other four teachers said that their students usually lacked cultural knowledge on such topics as festivals, history, political system, music, art or literature. One of these teachers commented that a lack of cultural background knowledge on a topic may make students reluctant to learn about it. She suggested that teachers' knowledge input would then be important to equip students with more cultural background knowledge for culture learning. Another teacher believed that the lack of either cultural background knowledge or language skills would not allow for culture teaching to take place. Another teacher believed that students would participate more actively in culture learning with both cultural background knowledge and good language skills.

\section{(b) Students' level of language proficiency}

Eight teachers believed students' level of language proficiency could restrict opportunities for culture teaching. For example, one teacher argued the incorporation of culture into language courses needed to be appropriate with students' level of language proficiency. Another teacher asserted that English beginners needed to attain at least the pre-intermediate level to engage in culture learning:

(19) For beginners, it is not necessary to teach the cultural element as they cannot understand the nature of vocabulary and it may influence the learning process. Incorporating culture should be done whenever students have attained a considerable 
level of English, for example from the pre-intermediate level onwards (Interview T9, Q8, P1).

The teacher's view in the above quote (19) indicates that culture could be taught separately from language at the beginner's level. However, four other teachers considered that it was important to incorporate culture learning right from the beginning. The following examples display this view:

(20) Incorporating culture should begin right at the time when students come to school. This will help students to develop their awareness of cultural differences and communication skills (Interview T14, Q8, P1).

(21) Incorporating culture in language courses is inevitable, right from Year 1, through the whole programme, frequently and continuously, to an extent that depends on each specific lesson (Interview T5, Q8, P1).

Another teacher also argued that the students' level of English was not a problem for their cultural acquisition as teachers could provide additional cultural knowledge through the learners' first language:

(22) If the students' level of English is limited, there are other ways to help them to understand about the target culture such as using the mother tongue. This does not influence their receptive ability. However, the use of students' mother tongue has to be appropriate with what teachers are dealing with in the lesson (Interview T12, Q8, $\mathrm{P} 1)$.

The other teacher suggested how to incorporate culture at the beginner's level:

(23) For beginners, culture should be incorporated in a simple way. Teachers should explain some vocabulary, encourage students to speak to develop their ability for language use. Then they can give comments, extend the lesson and explain more about the cultural elements (Interview T10, Q8, P1). 


\section{(c) Students' degree of receptiveness to culture learning}

Students' degree of receptiveness to culture learning refers to the extent to which students show their willingness for culture learning. Four teachers expressed concern about students' degree of receptiveness to culture learning. One teacher said that some students were interested in culture learning while other students were not. Another teacher tried to address culture in her lesson, but the students were only concerned with the language, and did not pay much attention to her purpose of providing additional cultural knowledge. Students' unwillingness to engage in culture learning could be also caused when teachers and students have different goals in language learning such as in the following example of a literature course:

(24) I am concerned with the development of trends in and main features of literature, whereas my students are more concerned with some famous playwrights such as Shakespeare or the famous singer Britney Spears [which is not the lesson content] (Interview T12, Q2, P1).

One teacher suggested how to deal with students' unwillingness for culture learning:

(25) To address culture in class, teachers should not use too much convention or imposition that makes students feel afraid of learning. Teachers do not need to use advanced reasoning, just something simple and familiar to students to create a comfortable atmosphere of learning in class (Interview T10, Q4, P1).

\section{(d) Teachers' cultural knowledge}

Three teachers highlighted the importance of teachers' cultural knowledge for culture teaching. One teacher of the American culture course reported that it was not easy to teach the course because of the large amount of knowledge required. Another teacher noted that an instructor's ability was a pre-condition to teach culture. In this teacher's view, language teachers needed to be well-informed, have profound cultural background knowledge, and be able to explore the target language culture themselves. Another teacher noted that the lack of cultural knowledge could prevent teachers from 
organizing cultural activities such as a field trip to a museum to explore the target culture:

(26) Teachers can comment only on the language such as the use of structure, pronunciation, presentation, but cannot comment on the accuracy of the cultural element involved (Interview T12, Q4, P1).

However, one teacher argued that the teacher's cultural knowledge was less important than students' active engagement in a social interaction with speakers of the target language:

(27) If teachers only provide cultural knowledge, students can easily forget it. Students need to use the language frequently, see with their eyes, directly communicate with many foreigners to understand more about the target culture (Interview T2, Q5, P1).

The quote (27) emphasizes the importance of students' intercultural experience in culture learning. Two other teachers also believed that students would learn about culture more effectively with a native English teacher than with a non-native teacher.

\section{(e) Time allowance for culture teaching}

The teachers were asked how much time they usually spent on culture teaching in their English lessons and whether they thought this time allowance was adequate. This question aimed to examine whether time causes any impact on culture teaching. The teachers' views about time allowance for culture teaching can be classified into two different categories: satisfactory and dependent on various factors.

Four teachers reported that time allowance for their culture teaching was satisfactory. One of them stated the purpose of her lesson was satisfactory, and so she did not need to address culture in her lesson. The other two teachers said they dealt with culture whenever the lesson was related to culture or whenever it was necessary. The last teacher believed that culture teaching in language skills courses was different from culture teaching in culture courses and therefore time allowance for these courses would be different. Among these teachers, two were willing to spend more time for culture teaching: 
(28) If I have more time for it, I will teach more about culture as language is closely connected with culture. Language will be used inefficiently without knowledge about culture (Interview T13, Q6, P1).

(29) I will spend more time for culture teaching in order to improve the teaching quality and motivate students as learning about culture is very interesting (Interview T6, Q6, P1).

Eight other teachers argued that the time allowance for culture teaching was dependent on various factors such as the course goals, the lesson topic, the lesson content, the teaching methodology, students' level of language proficiency, students' interests, teachers' choices and experience. One teacher said he would not spend more time for culture teaching as he was afraid it would influence the time limit for his lessons or go beyond the goals of his course. Another teacher stated that too much time for culture teaching would make the lesson boring and the lesson goals may not be achieved. Another teacher also argued that time for culture teaching may depend on the choices or the experience of the teacher who would determine and orient a lesson to the cultural dimension of a given topic. One teacher emphasised that it was not important to spend more time for culture teaching in the classroom:

(30) Culture needs time to be absorbed. Students can learn about culture in different ways, not only with teachers in class, but also through exchanges outside the classroom, meeting foreigners, reading books and newspapers (Interview T2, Q6, P1).

The teacher's view in the quote (30) highlighted the importance of cultural exploration for students. The other two teachers suggested a balance of language and culture teaching should be taken into consideration for efficient language learning:

(31) If culture is separated from language learning, the lesson will not be efficient. If too much culture is incorporated in the lesson, students will not understand it or get bored (Interview T4, Q8, P1).

(32) In the process of communication, culture plays an important role. Teachers need to be aware of incorporating culture in appropriate amount so that students can grasp both language and culture in language learning (Interview T7, Q1, P1). 


\section{(f) Curriculum, testing and education policy constraints}

The teachers were asked whether they were aware of any emphasis on culture in the curricular documents in their educational institution. This question aims to examine whether the curriculum, assessment and education policy have an impact on the teachers' culture teaching practices. The teachers reported that opportunities for their culture teaching in EFL classes were restricted due to the constraints from these sources. The curriculum review in chapter III can be referred to for more information regarding the curriculum constraints which involved the lack of emphasis on the importance of culture and culture learning, the separates status, construct, and treatment of culture learning, and the construct of culture as knowledge about a particular culture.

Regarding the constraints of assessment, two teachers stated that testing students' cultural knowledge occurred more in culture courses rather than in language courses. Seven other teachers argued that exams focused on testing students' language skills, language use and general knowledge rather than cultural competence in language courses. Four of the teachers recognised that culture was sometimes incorporated in language testing only by chance rather than on purpose. The other three teachers added that the native-speaker standard of language proficiency was considered the main goal in language testing. One of them highlighted the emphasis of the native-speaker standard in speaking tests:

(33) Students need to speak fluently, behave like native speakers or use vocabulary accurately to get good marks (Interview T9, Q7, P1).

Regarding the constraints of education policy, one teacher believed that none of the other teachers were aware of any document that emphasised the importance of culture in language teaching and learning. Another teacher believed that the Vietnamese education policy hardly focused on the teaching and learning of the target language culture. Two other teachers stated that they were not concerned with any education policy on a large scale. Another teacher also argued that the mechanism of the current education system caused an unfavourable impact on promoting a culture teaching approach in EFL classes: 
(34) Teachers want to change their teaching approach but they have to be concerned about students' marks and the assessment within the whole system. This can limit their creativity and flexibility in culture teaching (Interview T7, Q7, P1).

However, one teacher noted that the volunteer teaching by native English speakers at the English department and the students' internship with tourist companies and hotels could be considered as 'a culture teaching approach' in EFL teaching and learning.

In brief, the teachers' beliefs about culture teaching revealed a predictable priority for language teaching. The teachers were most concerned about a wide range of constraints that restricted their opportunities for culture teaching. These beliefs had a direct impact on the teachers' culture teaching practices that are described in the next section.

\subsection{Teachers' culture teaching practices}

This section reports on:

(a) How the teachers addressed culture in their classroom practices; and

(b) Why they addressed culture in a certain way in their language teaching.

\subsubsection{Teachers' culture teaching approaches}

To obtain information about how the teachers addressed culture in their EFL classes, I observed twelve lessons and analysed the teachers' self-reports on their culture teaching approaches. The cultural elements (in italics) observed in their classes are summarised in Table 5.2. The teachers' culture teaching practices can be classified into:
(a) teaching cultural connotations
(b) teaching cultural facts/knowledge
(c) teaching cultural awareness
(d) other ways of culture teaching

Each of these culture teaching practices is described in detail below. 
TABLE 5.2

Summary of classroom observations

\begin{tabular}{|c|c|c|}
\hline Observation & Lesson & Language teaching/culture teaching \\
\hline Observation 1 & $\begin{array}{l}\text { Describing things } \\
\text { and places }\end{array}$ & Language focus on describing objects and places \\
\hline Observation 2 & Family life & $\begin{array}{l}\text { - Cultural comparisons among family sizes } \\
\text { - Cultural comparisons in the choice of having children } \\
\text { - Solving a family problem (teacher sharing intercultural } \\
\text { experience) } \\
\text { - Language focus on married life }\end{array}$ \\
\hline Observation 3 & $\begin{array}{l}\text { Healthy life / } \\
\text { Sleep and dreams }\end{array}$ & $\begin{array}{l}\text { - Language focus on healthy life, sleep habits and dreams } \\
\text { - Cultural connotations of expressions (the early bird, the } \\
\text { night owl) }\end{array}$ \\
\hline Observation 4 & First time meeting & $\begin{array}{l}\text { Language focus on the use of simple past / past continuous } \\
\text { tense }\end{array}$ \\
\hline Observation 5 & Important firsts & $\begin{array}{l}\text { - Cultural facts/ knowledge about famous people } \\
\text { - Language focus on first-time events }\end{array}$ \\
\hline Observation 6 & $\begin{array}{l}\text { Leisure and } \\
\text { lifestyle }\end{array}$ & $\begin{array}{l}\text { - Cultural facts/ knowledge about famous people } \\
\text { - Personal questions in first meetings with American people } \\
\text { - Language focus with real-life situations }\end{array}$ \\
\hline Observation 7 & $\begin{array}{l}\text { Game and } \\
\text { Important firsts }\end{array}$ & $\begin{array}{l}\text { - Cultural facts about TV firsts (e.g., the inventor of } T V \text {, the } \\
\text { first TV programmes...) } \\
\text { - Language focus on simple past tense }\end{array}$ \\
\hline Observation 8 & Important firsts & $\begin{array}{l}\text { Language focus on time phrases, simple past tense with last } \\
\text { and adjectives for expressing feelings }\end{array}$ \\
\hline Observation 9 & $\begin{array}{l}\text { Leisure and } \\
\text { Lifestyle }\end{array}$ & $\begin{array}{l}\text { - Cultural knowledge (e.g., Union Jack, Boxing Day) } \\
\text { - Language focus on past events with simple past and real-life } \\
\text { situations }\end{array}$ \\
\hline Observation 10 & Important firsts & $\begin{array}{l}\text { - Language focus on past events, simple past with last, time } \\
\text { phrases, adjectives for expressing feelings } \\
\text { - Cultural connotations of vocabulary (palace, smile, sing a } \\
\text { lullaby) }\end{array}$ \\
\hline Observation 11 & American people & $\begin{array}{l}\text { - Cultural knowledge about American people and languages } \\
\text { in the US }\end{array}$ \\
\hline Observation 12 & $\begin{array}{l}\text { The United States } \\
\text { of America }\end{array}$ & - Cultural knowledge about the geography of the USA \\
\hline
\end{tabular}

Notes: Observations 1-3: Speaking lessons; Observations 4-10: General English lessons; Observations 11-12: American culture lessons 


\subsubsection{Teaching cultural connotations}

Connotation is defined in the Cambridge Dictionary as "the set of associations implied by a word in addition to its literal meaning". A word or an expression may carry different cultural connotations across languages. The teaching of cultural connotations in the observed lessons mainly involved vocabulary and expressions. In one lesson (observation 10), the cultural connotations of some vocabulary were stated; for example the teacher referred to a palace as a place for the king/queen in Vietnamese history; sing was linked to the expression singing a lullaby which, in the learners' home culture, is a kind of folk song that the mother traditionally sings to put her baby to sleep; and a smile was read as a sign of embarrassment or reluctance in the learners' home culture. In another lesson (observation 3), cultural connotations of some expressions were also addressed; for example, the advantage of the 'early' concept in the expression the early bird [catches the worm] was compared with the Vietnamese equivalent gà lên chuồng (chicken get back to their house for sleep literal translation) and ruồi đi ngủ (flies go to sleep - literal translation) in the learners' home culture; the expression the night owl in English was referred to those who usually stay up late, but it has no equivalent in the learners' first language.

Two interviewed teachers also reported that they sometimes dealt with cultural connotations of vocabulary in language teaching. One teacher explained that the word barbecue was unfamiliar to Vietnamese students as there was no such kind of outdoor party in their culture. The other teacher mentioned the cultural connotations of the words milkman and sandwich man. He explained that a milkman is a man who delivers milk in the countryside in England and a sandwich man is an advertising man in the USA who wears two wooden boards across the chest and the back. The teacher noted that his students had a different association with the meanings of these words due to the different cultural connotations in their first language. He also addressed the cultural connotations of the idiom it rains cats and dogs in English that was compared with the Vietnamese equivalent mura nhu cầm chinh đổ (it rains like a pouring jar of water - literal translation). 


\subsubsection{Teaching cultural facts}

The teaching of cultural facts was quite frequent in the observed lessons. For example, in two lessons (observations 5 and 6), facts about famous people in the target culture (e.g., John Lennon, Elvis Presley, William Shakespeare, Princess Diana) and in the learners' home culture (e.g., Ho Chi Minh, Xuan Quynh, Thanh Phuong) were provided. The students practised an interview using these facts without being given a chance to debate issues around the facts or choose their favourite person to talk about. In another lesson (observation 9), additional cultural knowledge about Britain (e.g., Union Jack, Boxing Day) was provided through a world knowledge quiz. Another lesson (observation 7) was observed where the teacher checked the students' comprehension about 'TV firsts' by asking questions about these facts.

Two American culture lessons (observations 11 and 12) required the students to learn about US culture. While the first lesson involved the students' group presentations about American people, languages in the US and differences between American English and British English, the second lesson was about the US geography. The teacher of the latter lesson argued for the rationale of her teaching:

(35) The students need to memorize all the facts about the USA as there is nothing for debate or discussion. This lesson on geography is more likely about American civilisation rather than its culture (Observation 12).

Notice in the above quote (35), the teacher used the term 'civilisation' to mean that all information about a country regarding geography, population, and political system were not necessarily cultural. She explained that people's habits and social activities in American society were more likely to be cultural. This indicates that the teacher considered culture in terms of people's ways of life, rather than the physical aspects of a particular country.

\subsubsection{Teaching cultural awareness}

The teaching of cultural awareness was done through cultural comparisons in two observed lessons. The speaking lesson on 'family life' (observation 2) required students to discuss the advantages and disadvantages of family sizes, and give reasons 
for having or not having children. It was the teacher, however, who mentioned cultural differences in each family size and also in the choice of having children between the learners' home country and English-speaking countries. The students also engaged in a problem-solving situation of an English family, but they only considered the solutions for the family life situation from their own cultural viewpoint. The teacher then shared her intercultural experience about how family responsibilities were shared between an Australian husband and wife from her Australian homestay. The classroom observation showed that the teacher tried to raise her students' cultural awareness, whereas the students tended to talk more about their own culture.

In another lesson (observation 6), learners' cultural awareness was raised through the use of personal questions in a first meeting between a Vietnamese and an American. The teacher emphasised that asking personal questions for Americans is considered impolite, whereas it expresses concern among the Vietnamese. The students practised a yes-no drill with personal and non-personal questions provided by the teacher. The teacher suggested which questions could be asked and those to be avoided when meeting Americans for the first time. The classroom observation demonstrated that the teacher provided the students with her own personal cultural knowledge rather than giving them opportunities to develop their own cultural awareness about the use and misuse of personal questions between the Vietnamese culture and the target language culture.

Four interviewed teachers also reported they used comparisons as a way of culture teaching to raise students' cultural awareness. For example, one lesson required students to make comparisons about a typical day between an American movie star and a Vietnamese. Students compared American and Vietnamese family models in a speaking lesson. Students in a reading lesson on 'culture shock' were asked to compare different ways of learning between their home country and an English-speaking country. Cultural differences were mentioned in a translation lesson in an opening and closing speeches between English and Vietnamese speakers.

\subsubsection{Other ways of culture teaching}

Other ways of culture teaching including localisation, simulations, and visual images were reported by the teachers in the interviews. Two teachers reported that they used a teaching strategy called the rule of localisation to make an unfamiliar topic familiar 
with the students. One of the teachers localised English table manners (e.g., the placement of cutlery) to a discussion on the use of chopsticks in the Vietnamese culture. This activity helped the students notice that every culture has particular table manners. The teacher argued that this rule of localisation facilitated the students' learning about an unfamiliar topic. Similarly, the other teacher also localised various kinds of world music to a discussion on Vietnamese songs and types of music within the learners' home culture. This activity was to familiarise the students with different types of world music.

Another way of culture teaching employed the use of simulations or roleplays. Two teachers reported that they used this method of culture teaching to engage learners in culture learning. One of the teachers talked about how she taught the students to learn the verb go skiing as her students had never experienced this kind of sport in their home country. Students in her lesson were put in a specific situation in which they were going to spend a holiday abroad where it was snowing. The teacher argued that the students could learn how to use the verb go skiing only in such a situation. The other teacher, in a translation lesson, put his students in pairs to create their own conversation based on one of three given situations. The students then roleplayed these conversations and added some humour to make the exercise more fun. The teacher stated that this way of teaching was challenging in terms of vocabulary, but it was quite efficient.

Three other teachers also reported that they used visual images for culture teaching. One of them used short video clips about festivals and the students discussed the clips in groups and presented their ideas in front of the class. Another teacher commented that the use of video clips was the most effective way to teach culture about customs and habits. This way of teaching, however, was usually restricted due to the lack of facilities, and so the teacher used visual images instead of the video. He gave visual examples such as a sack of money, the image of the World Bank or an image of peace to introduce a new lesson. The third teacher used pictures of Scottish men wearing kilts, or photos of bullfights in Spain to teach about different festivals. 


\subsubsection{Teachers' self-evaluation of culture teaching approaches}

The teachers were asked to explain their choice of culture teaching methodology. Nine teachers reported that they usually taught cultural facts from reading texts; three other teachers stated this culture teaching method was easily applied, saved time, and was the most efficient way to provide students with knowledge input. Ten teachers also used questions to ask about cultural facts; one of them stated that this way of culture teaching was suitable for students at a low proficiency level. Eight teachers also gave exercises about cultural facts such as multiple-choice or quizzes; one of them commented that this way of culture teaching made the lesson more fun and that students were more motivated to learn about culture. These teachers, in short, considered the methods of teaching of cultural facts as the most suitable and easiest way to address culture in EFL classes.

Other ways of culture teaching using techniques such as solving cultural dilemmas, exploring cultural values and beliefs, or sharing intercultural experiences were rarely employed by the interviewed teachers. One teacher argued that solving cultural dilemmas required a lot of additional material and preparation time, whereas another teacher believed that this form of culture teaching could be used for students at a higher proficiency level. Another teacher stated that exploring cultural values and beliefs was more suitable with tourism students. Three other teachers said that the teachers' intercultural experience was limited for teaching the target culture.

Five teachers, however, believed that their culture teaching methodologies were efficient and appropriate. One teacher, for example, thought that her manner of addressing a foreign culture helped her students learn better as it became more familiar to them. Another teacher believed her culture teaching approach was creative, interesting, and time saving. Another teacher stated her students enjoyed learning and were active during the lessons and felt comfortable. Only one teacher of the American culture course was not satisfied with her methodology because of the large amount of knowledge required by the course, the limited time for student discussions and their inadequate cultural background knowledge. Two other teachers argued that their culture teaching depended on the students' interests or the students' cultural background knowledge.

To sum up, the teaching of cultural facts was the most frequent culture teaching practice of the Vietnamese EFL teachers. Other ways of culture teaching 
were much less frequent and tended to depend on each teacher's personal experience. The teachers believed that their approaches to culture teaching were appropriate in their language teaching, which reflected their beliefs about culture teaching.

\subsection{Discussion}

This section discusses the main trends in the data concerning the teachers' perceptions of culture in language teaching and their cultural teaching practices.

\subsubsection{Culture defined as social structures and speech acts}

The teachers defined culture in EFL teaching and learning in a wide range of ways from culture as seen in social structures to culture in instantiation of particular speech acts. More teachers were concerned with 'small c' culture, and culture in language use and communication. Such perceptions of culture have potential to promote the culture as practice approach (Liddicoat et al., 2003) in Vietnamese EFL classes to engage teachers in intercultural language teaching. This approach to culture teaching can foster the learners' ability to interact in the target culture in informed ways and develop an intercultural perspective in which their own culture and the target culture are involved (Liddicoat et al., 2003). However, only half of the teachers demonstrated their understanding about the importance of teaching language and culture as an inseparable entity in language teaching. This suggests that the integration of language and culture should be enhanced in the curriculum and classroom experience of EFL teachers in Vietnam.

\subsubsection{Facts-oriented approach as culture teaching practice}

The teachers' treatment of culture teaching as a subordinate goal in the EFL classroom in this study corresponds with many previous studies. Wolf and Riordan (1991), for example, find that US language teachers did not prioritise culture learning. Byram and Risager (1999) find that Danish and British teachers valued the importance of linguistic competence over the cultural dimension. Allen (2000) argues that teachers might find it difficult to teach culture in the same way as they taught grammar or vocabulary. Castro et al. (2004) show that Spanish teachers overwhelmingly prioritised linguistic competence over cultural objectives. The 
findings of the present study were similar to the previous studies in that cultural objectives in language teaching were treated as less important than linguistic goals.

The teaching of cultural facts/knowledge in the present study was the most frequent approach to culture teaching in the Vietnamese EFL classes. This finding corresponds with some previous studies. Ryan (1995), for example, shows that Mexican teachers tended to teach culture as facts rather than for cultural understanding. Sercu et al.'s (2005) survey also shows that teachers passed on cultural knowledge rather than providing intercultural skills. Byram and Feng (2004) mention that the facts-oriented approach in culture teaching is not entirely abandoned, particularly in language learning situations with limited exposure to otherness such as in the present study. They argue that many critics take this facts-oriented approach to culture as inappropriate as it ignores the fact that culture is "a social construct, a product of self and other perceptions" (Kramsch, 1993, p.205). Byram and Feng also state that this facts-oriented approach may well lead to the teaching of stereotypes. $\mathrm{Hu}$ and Gao (1997) note that the knowledge of cultural facts is necessarily a starting point for culture learning; however, they warn of the risks in teaching stereotypical knowledge that could lead to superficial learning and enhance stereotypes and ethnocentrism. Hu and Gao propose a knowledge-for-scrutiny approach that provides learners with various presentations of cultural products and concepts under discussion. This approach could help learners develop awareness of hidden barriers, and eventually become intercultural speakers. The teaching of cultural facts/knowledge is contrary to one of the principles of intercultural language teaching which considers language acquisition as involving much more than the acquisition of only facts/knowledge (Liddicoat et al., 2003). Teachers should move beyond the teaching of cultural facts and engage students in an exploratory and reflective culture learning (Newton and Shearn, 2010b).

The classroom observations indicated that the main role that the teachers played in relation to culture teaching was to provide cultural information. As a result, the students were not given opportunities to take the initiative in culture learning. This approach to culture teaching suggests the ongoing influence of Confucianism with the teachers still acting as the expert knower of the target language in their role of providing knowledge and making learning occur rather than engaging the students in a learner-centred approach in which the students actively construct their own cultural knowledge through cultural explorations. Prabhu (1990) argues that for effective 
teaching and learning both teachers and learners need to be "active, alive or operational enough to create a sense of involvement" (Prabhu, 1990, p.173). Sowden (2007) also claims that teachers' success depends on the relationships they are able to develop in the classroom. He states that "the ability to build and maintain human relationships...is central to effective teaching, as it is to true intercultural communicative competence..." (p.308).

\subsubsection{Constraints on culture teaching}

The teachers believed that culture in language teaching should be addressed in a limited way. Interviews with the teachers identified various constraints on culture teaching in their EFL classes. I have chosen four of the constraints to discuss as these constraints are important to take into consideration. The constraints included (1) the students' level of language proficiency, (2) the teacher's expertise in the target language culture, (3) the effectiveness of native English teachers, and (4) the nativespeaker competence.

First, the teachers noted that the students' level of language proficiency restricted opportunities for culture teaching. This echoes Hadley's (2001) study in which teachers found that culture should be integrated in classrooms only at learners' higher proficiency levels and that grammar and linguistic skills should be developed first. This point of view, however, violates a major principle of intercultural language teaching which integrates language and culture from the beginning (Newton and Shearn, 2010b). As Liddicoat et al. (2003) argue, "culture is taught from the beginning of language learning and is not delayed until learners have acquired some of the language" (p.24). Kramsch (1993) also argues that culture "is always in the background, right from day one, ready to unsettle the good language learners when they expect it least, making evident the limitations of their hard-won communicative competence, challenging their ability to make sense of the world around them" (p.1).

Second, the teachers noted that the lack of the teacher's expertise in the target language culture and their intercultural experience restricted culture teaching. This does not reflect an intercultural perspective. Sowden (2007) argues teachers do not have to rely on their own experience and expertise as " $\mathrm{t}]$ eacher knowledge... should be understood in terms of the way [teachers] respond to their contexts of work, which shapes the way their knowledge is developed" (Tsui, 2003, p.64). The role of the 
teacher as a cultural expert in the EFL classroom has been reconsidered from an intercultural perspective. Alptekin (2002) argues that the teacher should become a mediator or a "gatekeeper" (p.58) who gives priority to the development of new attitudes, skills and critical cultural awareness in students. Kramsch (2004) also introduces the go-between concept that refers to the roles of the teacher as a mediator between languages, learners and institutions. In Kramsch's argument, the teacher as a mediator acts in three different roles. The teacher, as a cultural go-between, understands language and culture as a social semiotic and is able to use the language like a native and a non-native speaker. The teacher, as a methodological go-between, mediates between what can be taught and assessed, and what must be taught, but cannot be tested. The teacher, as a professional go-between, mediates between institutional constraints and educational values.

Third, the teachers noted that native English teachers would be more effective than non-native teachers in culture teaching. This is not necessarily true as both native speakers and non-native speakers can be rich cultural informants. However, Corbett (2003) argues that bilingual teachers are at an advantage over their monolingual colleagues in that they can broaden the input in the intercultural classroom to include material of learners' first language for comparison activities. Coperias Aguilar (2009) also argues that non-native teachers as intercultural teachers might be in a better position than native speakers as they can move between the learners' home culture and the target culture easily, and help students to connect their own culture with others, and raise curiosity about differences and otherness. Kramsch (2003) also claims that non-native speakers have the privilege of a "unique multicultural perspective" (p.252) which even native speakers do not have access to. It is this multicultural perspective, as Kramsch argues, makes non-native teachers valuable for intercultural language teaching.

Finally, the teachers noted that native-speaker competence should be stated as the main goal in language testing. This violates a principle of intercultural language teaching which emphasises intercultural communicative competence rather than native-speaker competence (Newton and Shearn, 2010b). From this intercultural perspective, native-speaker competence has been considered problematic in terms of its conceptualisation (Alptekin, 2002; Kramsch, 1993) and its applicability as a model for language teachers and learners (Byram, 1997). Native-speaker competence is seen 
as an unrealistic goal for most language learners as they have to ignore their own sociocultural identities and adopt a new one (Byram, 1997; Kramsch, 2006).

\subsubsection{Potential for adopting intercultural language teaching}

In spite of the constraints on culture teaching, some potential areas for adopting intercultural language teaching in Vietnamese EFL classes are identified. First, the teaching of cultural connotations of vocabulary and expressions in the present study can contribute to the development of learners' cultural awareness in language learning. Zhu (2010) argues that during the process of cultural development, learners' cultural awareness may affect the meanings of vocabulary and endow this vocabulary with different connotative meanings across languages. When learners are aware of cultural connotations of vocabulary and expressions in their first language and the target language, such awareness could help learners use the target language in a more culturally appropriate way.

Second, the students had opportunities to talk about their own culture. Intercultural language learning emphasises the importance of understanding one's own culture in relation to the target language culture (Liddicoat et al., 2003). An awareness of their own culture, therefore, provides a basis for the students to engage in intercultural language learning. However, as the students still judged the target culture from their cultural perspectives as in the family situation in observation 2 , teachers need to develop learners' ability to decentre from their own culture (Byram, 1997; Kramsch, 1993) and develop necessary skills and knowledge to achieve decentring (Liddicoat et al., 2003). It is only by decentring from their own culture that the students can judge other cultures from the others' perspectives.

Third, the real-life situations in the observed lessons (e.g., the family situations, the situations in a restaurant or in first meetings, etc.) are ideal examples for implementing intercultural language teaching as such situations involve many cultural differences between the students' first culture and the target language culture. To develop an intercultural approach in such activities, it is necessary to engage students in interpretation, interaction, action/production and reflection (Liddicoat et al., 2003). 


\subsection{Summary}

This chapter has presented and discussed the findings about the perceptions and culture teaching practices of Vietnamese EFL teachers. The findings showed that the teachers defined culture in a wide range of ways from culture as seen in social structures to culture in speech acts. Their beliefs about the constraints on culture teaching restricted their opportunities to address culture in their EFL classes. The facts-oriented approach was the most popular culture teaching practice in the EFL classes. The findings about the teachers' perceptions and culture teaching practices conform to Wood's (1996) argument that teachers' underlying beliefs, assumptions and knowledge determine their practice. The findings also echo Prosser and Trigwell (1999) and Williams and Burden (1997) in that there is a direct relationship between the teachers' beliefs and their classroom practices.

Given the inseparable relationship between language and culture, the importance of intercultural understanding in communication with people from other cultural backgrounds and potential for developing an intercultural approach to culture teaching in EFL classes in Vietnam, if Vietnamese EFL classes are to effectively equip students with the ability to become both linguistically and interculturally competent, then it may be necessary for Vietnamese EFL teachers to put more emphasis on cultural objectives in EFL teaching and learning.

In the next chapter, I will report and discuss the findings regarding the students' priorities in EFL learning and perceptions of culture learning. 


\section{Chapter VI \\ STUDENT PRIORITIES AND PERCEPTIONS OF CULTURE \\ LEARNING: RESULTS AND DISCUSSION ${ }^{10}$}

\subsection{Introduction}

This chapter reports on the priorities and perceptions of students at two Vietnamese universities concerning culture learning in their EFL classes so as to address the following research question (RQ):

RQ3: How is culture in language learning evident in the priorities and perceptions of Vietnamese EFL students?

The chapter first presents the results in two sections. The first section broadly deals with the students' priorities in EFL learning, and the second section focuses more narrowly on the students' perceptions concerning culture learning in their EFL classes. The results are drawn from two hundred questionnaire responses and focusgroup interviews with ten groups of five or six students. The chapter concludes with a discussion of main trends in the data and with a final chapter summary.

\subsection{Students' priorities in EFL learning}

This section reports on three dimensions of learners' priorities in EFL learning:

(a) Students' purposes for learning English

(b) Students' preferences for linguistic and cultural content

(c) Students' preferred topics in language learning

Each of these dimensions is presented in detail as follows.

\footnotetext{
${ }^{10}$ A part of this chapter was published in Ho (2011).
} 


\subsubsection{Purposes for learning English}

First, the questionnaire investigated the learners' purposes for learning English. The students were asked to identify three 'most important' purposes for learning English from a list of seven, and then rank their chosen purposes in order of importance ( $3=$ most important; $2=$ very important; $1=$ important). The results are given in Table 6.1 .

TABLE 6.1

Students' purposes for learning English

\begin{tabular}{lcccccc}
\hline Purposes & N & $\begin{array}{c}\text { Most } \\
\text { important } \\
(\mathbf{3})\end{array}$ & $\begin{array}{c}\text { Very } \\
\text { important } \\
(\mathbf{2})\end{array}$ & $\begin{array}{c}\text { Important } \\
\text { (1) }\end{array}$ & $\begin{array}{c}\text { Not } \\
\text { chosen }\end{array}$ & $\begin{array}{c}\text { Sum } \\
\text { of } \\
\text { scores }\end{array}$ \\
\hline 1. Getting a good job & 200 & 124 & 43 & 9 & 24 & 467 \\
2. Communication with foreigners & 200 & 39 & 69 & 45 & 47 & 300 \\
3. Reading English documents & 200 & 18 & 43 & 53 & 86 & 193 \\
4. Studying in a foreign country & 200 & 10 & 35 & 54 & 101 & 154 \\
5. Acquisition of cultural knowledge & 200 & 7 & 7 & 13 & 173 & 48 \\
6. Travelling to a foreign country & 200 & 1 & 3 & 12 & 184 & 21 \\
7. Others & 200 & 0 & 0 & 15 & 185 & 15 \\
\end{tabular}

Notes: N=Number of students $(200=124+43+9+24)$; Sum of scores: $467=124 * 3+43 * 2+9 * 1$

Due to the uneven number of students' responses in each purpose, the mean scores cannot be used. Instead, a sum of scores (SS) for each purpose was used to rank the students' purposes for learning English. The sum of scores was calculated by the combination of the multiplication of the number of students who chose the purpose and its corresponding order of importance (most important weighting of 3; very important 2; important 1). The sum of scores reaches the maximum value of 600 when a purpose is chosen as the most important by all 200 students and it obtains the minimum value of zero when a purpose is not chosen by any students. In other words, the closer to 600 the sum of scores of one purpose is, the greater its priority is.

The results show that getting a good job (SS=467) was the students' ultimate purpose for learning English, followed by communication with foreigners ( $\mathrm{SS}=300$ ), 
and reading English documents ( $\mathrm{SS}=193)$. Acquisition of cultural knowledge (SS=48) was well down the list of purposes in the fifth place. Only a few students chose travelling to a foreign country ( $\mathrm{SS}=21)$ and fewer students chose the 'others' option ( $\mathrm{SS}=15)$ which involved immigration to another country as their main purpose for learning English.

Fifty-three students in ten focus groups were also asked in the interviews about their purposes for learning English. All the student groups considered getting a good job and communication with foreigners as their main purposes for learning English. Four student groups additionally related their purposes for learning English to culture learning. One first-year group and two fourth-year groups stated that their purpose was to learn about other cultures and the second-year group also wished to have a better understanding about foreign cultures in order to avoid experiencing culture shock when working with foreigners.

In summary, the students mainly learned English as a tool to get a good job. They were also concerned with communication with foreigners, but did not place much value on culture learning as seen in the choice of their purposes for learning English.

\subsubsection{Preferences for linguistic and cultural contents}

Second, the questionnaire asked what priority the students gave to culture in relation to three aspects of language, i.e., vocabulary, grammar and phonetics. They were asked to rank these dimensions in language learning in order of priority $(4=$ most important, 1=least important). The results are presented in Table 6.2.

TABLE 6.2

Students' preferences in language learning

\begin{tabular}{llll}
\hline Content dimension & N & M & SD \\
\hline & & & \\
1. Vocabulary & 200 & 3.04 & .96 \\
2. Grammar & 200 & 2.92 & .96 \\
3. Phonetics & 200 & 2.63 & .98 \\
4. Culture & 200 & 1.43 & .75 \\
\hline
\end{tabular}

Notes: $\mathrm{M}=\mathrm{Mean} ; \mathrm{SD}=\mathrm{Standard}$ deviation; $\mathrm{M}$ and $\mathrm{SD}$ are calculated on a 4-point scale (1-4) 
As can be seen from Table 6.2, culture was accorded the lowest priority compared to the three aspects of language. Paired sample tests were conducted in order to examine whether culture was significantly different from the three aspects of language. The results show that there were significant differences between culture and vocabulary $(\mathrm{M}=-1.605, \mathrm{SE}=.099, t(199)=-16.218, p<.05, r=.75)$, culture and grammar $(\mathrm{M}=$ $-1.490, \mathrm{SE}=.099, t(199)=-15.052, p<.05, r=.73)$, and culture and phonetics $(\mathrm{M}=-$ $1.195, \mathrm{SE}=.093, t(199)=-12.828, p<.05, r=.67)$. These results indicate dramatic differences between culture and the three aspects of language with very large effect sizes (the effect size $r$ is considered large when it is above .5 (Field, 2009)). From these results, it can be said that culture $(\mathrm{M}=1.43)$ was considered the least important in comparison with vocabulary $(\mathrm{M}=3.04)$, grammar $(\mathrm{M}=2.92)$ and phonetics $(\mathrm{M}=2.63)$. The lowest standard deviation of culture also indicates little difference in the students' choice for this aspect.

In brief, the students were much less concerned with the cultural content than the linguistic content in language learning.

\subsubsection{Preferred topics in language learning}

Third, the questionnaire investigated which topics the students preferred to study in language learning. They were asked to choose three preferred topics from a list of eight, and rank them in order of preference ( $3=$ favourite; $2=$ very preferred; $1=$ preferred). The list of the topics was decided on the basis of the classroom observations. This question was designed to examine whether the students were more concerned with language learning or culture learning. The sum of scores (SS) for each topic was calculated to rank the students' preferred topics in language learning (similar explanations for the use of the sum of scores stated in section 6.2.1). The results are provided in Table 6.3.

Table 6.3 shows that the students' preferred topics can be grouped into two groups: the language-related topics and the non language-related topics. The first group was ranked high, while the second group was ranked low. The students' three preferred topics in language learning included types of verbal communication ( $\mathrm{SS}=397)$, daily life and routines ( $\mathrm{SS}=257)$ and cultural values and beliefs ( $\mathrm{SS}=149)$. Other topics were less preferred and cultural images and symbols $(\mathrm{SS}=44)$ was the least preferred. 
TABLE 6.3

Students' preferred topics in language learning

\begin{tabular}{|c|c|c|c|c|c|c|}
\hline Topics & $\mathbf{N}$ & $\begin{array}{c}\text { Favourite } \\
\text { (3) }\end{array}$ & $\begin{array}{c}\text { Very } \\
\text { preferred } \\
\text { (2) }\end{array}$ & $\begin{array}{c}\text { Preferred } \\
\text { (1) }\end{array}$ & $\begin{array}{c}\text { Not } \\
\text { chosen }\end{array}$ & $\begin{array}{c}\text { Sum of } \\
\text { scores }\end{array}$ \\
\hline $\begin{array}{l}\text { 1. Types of verbal } \\
\text { communication }\end{array}$ & 200 & 96 & 48 & 13 & 43 & 397 \\
\hline 2. Daily life and routines & 200 & 39 & 48 & 44 & 69 & 257 \\
\hline 3. Cultural values and beliefs & 200 & 18 & 29 & 37 & 116 & 149 \\
\hline $\begin{array}{l}\text { 4. Types of non-verbal } \\
\text { communication }\end{array}$ & 200 & 12 & 32 & 28 & 128 & 128 \\
\hline $\begin{array}{l}\text { 5. History, geography, political } \\
\text { system }\end{array}$ & 200 & 20 & 12 & 19 & 149 & 103 \\
\hline 6. Festivals and traditions & 200 & 5 & 11 & 30 & 154 & 67 \\
\hline 7. Music, drama, art, literature & 200 & 6 & 12 & 12 & 170 & 54 \\
\hline 8. Cultural images and symbols & 200 & 3 & 9 & 17 & 171 & 44 \\
\hline
\end{tabular}

Note: Same calculations as Table 6.1.

The students were also asked in the interviews about which topics in language learning they preferred to learn. Five student groups chose language-related topics as their preferred ones, particularly those concerning the types of communication, arguing that their main purpose for learning English was to use the language for communication with foreigners. In addition, these students also noted the cultural dimension of these topics. Three student groups highlighted cultural factors in communication. For example, the second-year group was concerned about the native speakers' ways of communication:

(1) We are concerned about how native English speakers communicate with each other as our communication in the Vietnamese style may make them feel embarrassed or dislike it (Interview SG3, Q3, P1).

The student group in example (1) showed that they were aware of the impact of their culturally-shaped ways of communication on interaction with English speakers. One fourth-year group also noted that language functions express politeness or respect 
towards others. Another fourth-year group highlighted the inseparability of verbal and non-verbal communication:

(2) If a person communicates well (say 'Nice to meet you') but does not know how to shake hands (shaking hands but not looking straight in the other's eyes), communication becomes meaningless. Correct language use, with inappropriate gestures, will not make communication successful (Interview SG7, Q3, P1).

Example (2) above indicates the student group understood the impact of cultural factors associated with both types of communication.

Two other groups also commented on the topic of 'daily life'. The second-year group mentioned the existence of cultural values in daily life, and a third-year group argued that an understanding about native speakers' daily life would help them avoid a negative reaction in communication. One fourth-year group also highlighted the importance of cultural knowledge about the topic of 'history, geography and politics' of the target country:

(3) It is important to learn about history, geography, and the political system. Englishspeaking countries have different political systems; inappropriate political behaviours in these countries can turn us into law-breakers (Interview SG7, Q3, $\mathrm{P} 1)$.

In short, the students preferred language-related topics to culture-related topics although five student groups were also concerned with the cultural dimension of some topics. The low scores for culture-related topics suggest that the students were less interested in culture learning than language learning.

To this point, I have reported results on the students' priorities in EFL learning broadly. The next section will focus more narrowly on the students' perceptions concerning culture learning in their EFL classes.

\subsection{Students' perceptions of culture and language learning}

This section reports on the students' perceptions of culture and language learning in relation to the following areas: 
(a) Students' definitions of culture

(b) Students' awareness of the relationship between language and culture

(c) Students' beliefs about culture learning

(d) Students' purposes for culture learning

(e) Students' judgement of the benefits of culture learning

(f) Students' experience of culture learning

Each of these areas is presented in detail below.

\subsubsection{Definitions of culture}

The students were asked in the interviews what they understood the term 'culture' to mean in their English studies. One third-year group mentioned that it was difficult to define culture in EFL learning rather than in other areas like tourism. The first-year, second-year and fourth-year groups defined culture in terms of both 'big C' culture and 'small c' culture, whereas the third-year groups defined culture in terms of 'small c' culture only. The 'big C' culture in the students' definitions involved such elements as history, geography, specific characteristics of a country, a territory or a region, economy, society and natural wonders. The 'small c' culture defined by the students involved such elements as people's behaviours, manners, customs, habits, beliefs, ways of communication, lifestyle, traditions, attitudes and gestures. Two fourth-year groups also mentioned culture in relation to communication as social conventions and appropriate social rules. The following example from one of these groups shows such a perception of culture:

(4) Culture in communication is the way of communicating according to appropriate rules set by a society. People communicating with culturally appropriate behaviours will be accepted by the society (Interview SG7, Q2, P1).

In brief, the students defined culture in terms of social structures only rather than in relation to language learning. Such definitions involved 'small c' culture, 'big C' culture and social conventions and rules in communication. 


\subsubsection{Awareness of the relationship between language and culture}

The students were asked in the questionnaire about the teachability of language and culture in EFL classes. In response to this question, only nine students acknowledged the relationship between language and culture. These students considered that language and culture are interdependent and reciprocal. Six of them related the interdependent relationship between language and culture to the close connections between these two components. Such a relation is demonstrated in the following examples:

(5) Culture and language learning is like theory and practice. It is important to combine language and culture in practice as this enriches the lesson (S121, Q9, P1).

(6) It will be very effective to learn language and culture together. Theory and practice will increase interest and effectiveness (S160, Q9, P1).

(7) The English language should be taught together with the target language culture for a better understanding about English as language is a part of culture (S137, Q9, P1).

The other three students mentioned the reciprocal relationship between language and culture as shown in the following examples:

(8) If we pay attention only to learning a language without learning about its associated culture, we cannot know much about that language. I think that culture should be taught together with language to complement each other, which will provide us with useful knowledge (S108, Q9, P1).

(9) Language and culture have a reciprocal relationship. Language reflects culture and culture impacts on language. Therefore, culture needs to be taught together with language in English classes. This will greatly support students' understanding and fluency in English (S122, Q9, P1).

(10) Language and culture should be taught simultaneously to be reciprocal. If so, we can easily compare and contrast our home culture with cultures of other countries (S131, Q9, P1).

Four out of the ten student groups in the interviews showed their awareness of the relationship between language and culture when they were asked the same question. 
For example, the second-year group was aware of the interactive relationship between language and culture:

(11) Language and culture complement each other; students can understand the language better when they learn language and culture together. It is impossible to learn English without cultural understanding. English teaching needs to deal with culture so that students can learn faster (Interview SG3, Q8, P1).

One fourth-year group also showed their understanding about the influence of culture on language use when they were asked about the importance of culture in their English learning:

(12) Language is a part of culture. For example, English people eat food on plates, and so they have the expression 'do the dishes'; while Vietnamese eat rice in bowls and they have the expression 'rưa chén' ('do the bowls'). Culture and language are linked to each other; therefore learners of English have to learn the target language culture (Interview SG9, Q2, P1).

In example (12), the student group highlighted the relationship between language and culture through the use of different linguistic expressions which bear the same meaning in the two languages.

To summarise, a minority of the students (nine out of two hundred students in the questionnaire and four out of ten student groups in the interviews) demonstrated a heightened awareness of the relationship between language and culture. Overall, most of the students showed little awareness of the relationship between language and culture.

\subsubsection{Beliefs about culture in language learning}

The students' beliefs about culture in language learning are expressed in terms of:

(a) their beliefs about culture and language learning

(b) their beliefs about aspects of culture learning 


\subsubsection{Beliefs about culture and language learning}

The focus-group interviews and the questionnaire revealed the students' beliefs about culture and language learning which can be classified into the following themes: (1) native-speaker standard of language proficiency as the goal; (2) cultural background knowledge as a prerequisite for culture learning; (3) inadequate exposure to culture in language courses; and (4) constraints on culture learning. These beliefs are described in detail below.

\section{(1) Native-speaker standard of language proficiency as the goal}

When the students in the interviews were asked about the importance of culture in their English learning, two groups considered that the native-speaker standard should be used as the main goal for culture learning. For example, a third-year group believed it was necessary to imitate behaviours of target culture members for cultural understanding:

(13) Learning English to understand English-speaking cultures requires learners to behave like native English speakers in order to understand about their culture (Interview SG4, Q2, P1).

When asked to describe how the students learned a certain topic in the classroom, one fourth-year group also highlighted the native-like standard in language learning:

(14) Learning a foreign language is to imitate what native speakers say and learners need to learn to speak it in a natural and native-like way (Interview SG8, Q3, P1).

However, one third-year group believed culture learning would not change their own cultural behaviours:

(15) Culture of a country belongs to that country; students learn all related to that culture, including unfamiliar topics or taboos. Students learn about culture for their cultural knowledge only, not for changing their own cultural behaviours (Interview SG5, Q3, P1). 
It can be observed that the student groups in examples (13) and (14) were concerned with the native-like standard in language and culture learning, whereas the group in example (15) was concerned with their own cultural identity when learning about other cultures.

\section{(2) Cultural background knowledge as a prerequisite for culture learning}

When the students in the interviews were asked about whether the target language culture should be taught in English language courses or in a separate culture course, six groups believed that cultural background knowledge was a prerequisite for students to engage in culture learning. On the one hand, two first-year groups believed culture incorporated in language courses served as basic cultural knowledge, and culture courses were needed for deeper understanding at a higher level. The secondyear group also supported the idea that culture needed to be incorporated in Years 1 and 2 as background knowledge so that students can focus on culture learning in culture courses in Year 3 or 4.

On the other hand, one third-year group believed culture courses should be taught at the beginning of language learning to provide students with necessary cultural background knowledge. One fourth-year group debated three ideas. The first idea involved incorporating culture in Years 1 and 2 to provide students with general cultural knowledge and specialising in culture courses in Years 3 and 4. The second idea involved teaching culture courses in Years 1 and 2 to provide students with cultural background knowledge and incorporating culture in Years 3 and 4 to facilitate students' culture learning. The third idea involved both incorporating culture and specialising in culture courses at the same time with a focus on specific content. Another fourth-year group also supported the last idea, arguing that incorporating culture in language courses could be more effective in situations of daily life, whereas culture courses may focus more on history, geography, political systems, housing or festivals.

In summary, the students considered that cultural background knowledge was a prerequisite for them to engage in culture learning. However, they were unsure about the source of this knowledge - whether to acquire it from language courses or culture courses at the beginning of language learning or from both types of courses learned at the same time. 


\section{(3) Inadequate exposure to culture in language courses}

In response to the same question stated in the section above, three student groups supported the teaching of the target language culture in a separate culture course. For example, one third-year group commented on the disadvantages of incorporating culture in language courses:

(16) The incorporation of culture in language courses may distract students from the language learning process because they have to pay more attention to the cultural content of the course. This may result in lower marks for them. So culture courses need to be taught separately to avoid such distraction (Interview SG5, Q8, P1).

Two fourth-year groups also supported the separate teaching of culture courses for effectiveness. One of these groups argued that culture incorporated in language courses was not adequate in the long run. The other group also believed it would be difficult to incorporate culture in language classes due to teachers' lack of knowledge about the target culture. They explained students would engage in culture courses more systematically with deeper understanding about many aspects of the target culture through different ways of learning such as video watching or short drama performances.

\section{(4) Constraints on culture learning}

Out of two hundred students who completed the questionnaire and the ten student groups who participated in the interviews, a number of the students noted a variety of constraints that restricted their opportunities and motivation for culture learning. These students stated that culture learning only helped them to a certain extent and that language and culture should be taught with limitations in EFL classes. The main constraints can be classified into the following categories: (a) primary focus on language; (b) little impact of culture on language learning; (c) limited cultural content of textbooks; (d) time limit for culture learning; (e) different English-speaking cultures; (f) students' level of language proficiency; and (g) students' receptiveness to culture learning. Each of these constraints is discussed below. 


\section{(a) Primary focus on language}

Ten students believed there should be a primary focus on language rather than on culture in language learning. These students were more concerned with learning the aspects of language such as grammar, vocabulary, phonetics and language skills rather than the cultural dimension. Such concerns are expressed in the following examples:

(17) I can choose communication style, and degree of politeness in a particular context. However, it is not very important as a thorough grasp of grammar and vocabulary is more important in learning English (S42, Q8, P1).

(18) In learning English, students can improve their English through culture lessons or communication with native speakers. However, learning about culture is not enough in language learning. This is because learning a new language needs many aspects of language rather than culture (S147, Q8, P1).

The students also considered learning the language first before learning about the target language culture. The following examples illustrate such a belief:

(19) Teachers should focus on communication skills. Once students are fluent in English, they can learn about the target language culture (S162, Q8, P1).

(20) I need to learn the English language first before learning about the target language culture. Culture learning only helps me understand about behaviours of native speakers (S47, Q8, P1).

Notice that both students in examples (19) and (20) did not acknowledge cultural dimensions in communication and therefore they only focused on the use of language in communication.

\section{(b) Little impact of culture on language learning}

Seven students believed culture had little impact on language learning. For these students, culture learning just provided additional cultural and social knowledge about the target country rather than improving their language proficiency. Such a belief is expressed in the following examples: 
(21) Culture is a particular characteristic of a country, whatever it is an English-speaking country or not. Learning about culture is learning about that country, not improving English proficiency (S48, Q8, P1).

(22) Learning about British or American culture only helps me understand more about the culture of these countries such as weather, festivals, food, traditional costumes and customs. It only provides me with additional cultural knowledge, but does not have much impact on my English learning, and if it does, it is just to provide some new vocabulary (S123, Q8, P1).

(23) Learning about English-speaking cultures first helps students learn differences in vocabulary use, ways of communication among these countries and improves their translation skills. However, culture only plays a neutral role as the language is not much different among the English-speaking countries. Therefore, culture learning only provides students with additional knowledge and partially enhances their language learning (S41, Q9, P1).

\section{(c) Limited cultural content of textbooks}

The cultural content of textbooks had an impact on the students' beliefs about culture learning. When the students in the interviews were asked about the cultural content of their English language materials, four groups pointed out the negative side of the cultural content of these materials. According to one third-year group, some cultural terms in reading texts were difficult to understand. One fourth-year group argued the materials consisted of unfamiliar and boring topics which were unrelated to students' own culture. Another fourth-year group stated the limit of cultural topics in language courses and some abstract topics such as science, IQ or genetics made it difficult for them to engage in culture learning. Another fourth-year group criticised the theoretic and stereotyped cultural content of textbooks in use:

(24) Cultural content is very theoretic. Teachers have not experienced cultural issues; they only teach cultural knowledge through books and students learn from them and books. In reality, culture always changes and so do cultural values and ways of recognition...Culture is globalised, but knowledge in the textbooks is out of date and information about a certain country is usually stereotyped, and so it may not reflect the reality about people of that country... (Interview SG8, Q4, P1). 
Example (24) shows that culture learning in Vietnamese EFL classrooms depended a lot on the theoretical cultural content of textbooks and the approach to culture teaching that adopts a static view of culture rather than engages students in exploring the changing cultural values of the target culture and moving beyond cultural stereotypes.

\section{(d)Time limit for culture learning}

Six students had different ideas about time allowances for culture learning. For three of them, time for culture learning was limited due to the overloaded lessons. The other three students believed culture learning would take a lot of time and therefore would affect the course. For example, one of them was afraid that too much time for culture learning would overwhelm students. Another student suggested the time for culture learning should not exceed the time for language learning:

(25) The purpose of learning English is to use it well and improve language skills. Culture needs to be taught, but not for more than the time for language learning as culture learning only supports an understanding about English (S52, Q9, P1).

Eight student groups in the interviews also argued that time allowance for culture learning in their English classes was limited and inadequate. For example, a first-year group and a fourth-year group said students had to learn about culture themselves as most of the time in lessons was spent on language functions and skills. Another fourth-year group also argued many examples and much knowledge were needed to deal with cultural issues in the lessons. A third-year group highlighted the language focus in exams due to which students had to learn about culture by themselves. Another third-year group argued the time limit of lessons would restrict culture teaching:

(26) It seems to be logical at first to incorporate culture in language courses, but in fact teachers can overindulge in culture teaching that goes beyond the time limit of the lesson. It is better for teachers to deal with culture when the lesson is related to it, and expand the lesson with their cultural knowledge (Interview SG4, Q8, P1). 
However, one fourth-year group argued it was important for teachers to use time effectively for culture teaching. Another group suggested an appropriate approach to culture teaching:

(27) Incorporating or separating culture is not important; what is important is the method of culture teaching. Teachers need to teach students how to perceive a culture so that when they learn a cultural issue they will remember it longer (Interview SG9, $\mathrm{Q} 8, \mathrm{P} 1)$.

\section{(e) Different English-speaking cultures}

Five students believed that it was not possible to teach culture in EFL classes because of different English-speaking cultures represented in the English language. For example, one student stated that it would be difficult to understand different Englishspeaking cultures. Another student said that it would take a lot of time to teach all English-speaking cultures. Taking such a belief into account, one student proposed that students should learn only cultures they know or those that have a certain influence on their own culture. Another student suggested typical English-speaking cultures should be taught for deeper understanding:

(28) Cultures of typical English-speaking countries (such as Britain, USA) should be taught so that students can have a deeper understanding of these specific cultures (S141, Q9, P1).

\section{(f) Students' level of language proficiency}

Five students believed students' levels of language proficiency could restrict culture learning. They considered that students could not acquire cultural knowledge at a low level of language proficiency. Such a belief is expressed in the following examples:

(29) My English is still weak and not flexible when communicating with foreigners. Therefore, I only talk about daily life and seldom use cultural knowledge (S169, Q9, P1).

(30) I am not fluent in English yet. Therefore, I do not find it easy to listen, speak English and understand the effectiveness of culture learning (S4, Q9, P1). 
(31) Students cannot acquire cultural knowledge in English when their level of English is not high enough to understand it. It will be illogical when they cannot understand English (S41, Q9, P1).

One fourth-year group in the interviews was also concerned about students' level of language proficiency for culture learning. The group believed culture should be incorporated when students have attained the intermediate level. They differentiated between culture learning in the first language and foreign language:

(32) Children acquire things around them unconsciously. If culture is incorporated in lessons, they do not recognize the cultural elements as they just learn to speak naturally. It is the purpose of the teacher to incorporate culture so that children can learn the language in a natural way. On the other hand, foreign language learners have to attain the secondary or tertiary level to perceive the importance of culture (Interview SG8, Q8, P1).

The student group in example (32) believed that culture in foreign language learning cannot be acquired unconsciously, as in first language acquisition, but only consciously at a certain level of language proficiency.

\section{(g) Students' receptiveness to culture learning}

Four students stated their unwillingness to engage in culture learning. This unwillingness involved their fear of being affected by the target language culture and being kept away from their native culture. This attitude towards culture learning was expressed in the following examples:

(33) Learning English with culture incorporated will help us perceive the beauty of the English language, but learning a lot about English-speaking cultures will affect the thinking of Vietnamese people (S13, Q9, P1).

(34) English is a popular foreign language in Vietnam; children from Grade 1 can learn English. If English culture is taught together with the language, Vietnamese children and other students will distance themselves from their home culture (S51, Q9, P1). 
(35) Culture teaching should be limited to some extent so as to avoid Westernisation and denationalisation (S164, Q9, P1).

Three student groups in the interviews also believed culture learning might have some negative impact on students' behaviours and cultural values. This made them reluctant to learn about the target culture. For example, one fourth-year group believed learning too much about the target culture may cause students to display cross-cultural behaviours in their ways of life and speech. Two other groups also said their own cultural values were challenged by different values of the target culture. The following example shows a conflict in family values between the two cultural systems:

(36) The family model of married couples without children is not encouraged in Vietnam as these people do not have responsibilities within the community. They do not want to have children and so do not take responsibility for their country where labour force is needed to replace the old one (Interview SG3, Q4, P1).

Example (36) indicates the student group did not acknowledge the perceived family value of the target language culture. Such an attitude had a negative impact on their engagement in culture learning.

In summary, the students' beliefs about culture and language learning revealed a priority for language learning. The students were most concerned about a variety of constraints which restricted opportunities for culture learning in EFL classes.

\subsubsection{Beliefs about aspects of culture learning}

In the questionnaire, the students were asked to express their opinions about the value of aspects of culture learning in eight given statements on a five-point Likert scale (1=strongly disagree; $5=$ strongly agree). The results are given in Table 6.4.

One-sample tests were conducted with each mean score in order to examine the extent to which the students perceived the value of aspects of culture learning on the five-point Likert scale in each statement. The result shows that in item (1), $\mathrm{M}=4.32$ was significantly different from $4(t(199)=4.226, p<.05)$. In items (2), (3) and (4), $\mathrm{M}=4.12, \mathrm{M}=3.98$ and $\mathrm{M}=3.81$ are all closer to $4(t(199)=1.699, \mathrm{p}>.05$, 
$t(199)=-.226, \mathrm{p}>.05$ and $t(199)=-1.942, p>.05$ respectively). In item (5), M=3.80 is significantly different from 3 and $4(\mathrm{t}(199)=10.355, p<.05$ and $t(199)=-2.670$, $p<.05$ respectively). In item (6), M=3.57 is significantly different from 3 and 4 $(\mathrm{t}(199)=6.689, p<.05$ and $t(199)=-5.046, p<.05$ respectively). In item (7), M=3.33 is significantly different from 3 and $4(t$ (199) $=4.066, p<.05$ and $t$ (199) $=-8.254, p<.05$ respectively $)$. In item (8), $\mathrm{M}=2.85$ is closer to $3(t(199)=-1.468$, $\mathrm{p}>.05)$.

TABLE 6.4

Students' beliefs about aspects of culture learning

\begin{tabular}{|c|c|c|c|}
\hline Aspects of culture learning & $\mathbf{N}$ & $\mathbf{M}$ & SD \\
\hline $\begin{array}{l}\text { 1. I need to understand my own culture first before learning } \\
\text { about other cultures. }\end{array}$ & 200 & 4.32 & 1.054 \\
\hline $\begin{array}{l}\text { 2. Learning about culture is as important as learning about } \\
\text { language in an English class. }\end{array}$ & 200 & 4.12 & .957 \\
\hline $\begin{array}{l}\text { 3. I need to learn about the language first before learning } \\
\text { about the target culture. }\end{array}$ & 200 & 3.98 & 1.252 \\
\hline $\begin{array}{l}\text { 4. I need to abandon my own cultural identity while acquiring } \\
\text { native-like fluency in English. }\end{array}$ & 200 & 3.81 & 1.420 \\
\hline $\begin{array}{l}\text { 5. Learning about culture helps me become more tolerant and } \\
\text { open-minded towards other peoples and cultures. }\end{array}$ & 200 & 3.80 & 1.086 \\
\hline $\begin{array}{l}\text { 6. My own culturally-shaped knowledge does not influence } \\
\text { much the way I interact with people from other cultural } \\
\text { backgrounds. }\end{array}$ & 200 & 3.57 & 1.205 \\
\hline $\begin{array}{l}\text { 7. I can acquire both additional cultural knowledge and } \\
\text { intercultural skills in the classroom. }\end{array}$ & 200 & 3.33 & 1.148 \\
\hline $\begin{array}{l}\text { 8. Misunderstanding in intercultural communication is mostly } \\
\text { due to language problems rather than cultural differences. }\end{array}$ & 200 & 2.85 & 1.445 \\
\hline
\end{tabular}

Note: $\mathrm{M}$ and SD are calculated on a five-point scale (1-5).

The results reveal that the students agreed that their understanding about their own culture was important when learning about other cultures $(\mathrm{M}=4.32)$ as well as interacting with people from other cultural backgrounds $(\mathrm{M}=3.57)$, and cultural identity was salient to them $(M=3.81)$. They agreed to some extent that culture 
learning would develop tolerance and open-mindedness $(\mathrm{M}=3.80)$, and that both cultural knowledge and intercultural skills could be acquired in the classroom $(\mathrm{M}=3.33)$. However, although the students considered that culture learning was as important as language learning $(\mathrm{M}=4.12)$, they still believed language learning could be separated from culture learning $(\mathrm{M}=3.98)$. This might be the reason why they were not sure whether misunderstanding in intercultural communication was caused by language problems or cultural differences $(M=2.85)$.

To summarise, the students were aware of the importance of understanding their own culture in culture learning, but they were not aware of the relationship between language and culture and lacked intercultural skills to deal with misunderstandings in intercultural communication.

\subsubsection{Purposes for culture learning}

In the questionnaire, the students were asked about the importance they attached to their purposes for culture learning by ranking seven statements on a five-point Likert scale (1=least important; $5=$ most important). Factor analysis was first performed in order to classify the students' responses into distinct components of intercultural competence (IC). The dimensionality of the seven statements was analysed using Principle Component Analysis. Factor extraction was conducted with eigen value greater than 1. Obtained factors were rotated using a Varimax rotation procedure. The rotated solution is given in Table 6.5.

The result shows that the KMO (Kaiser-Meyer Olkin measure of sample adequacy) value was equal to $.666, t(21)=262.831, p<.05$, which is reliable for the analysis (Field, 2009). The factors accounted for $69.492 \%$ of the item variance in which factor 1 accounted for $26.211 \%$, factor 2 accounted for $22.786 \%$ and factor 3 accounted for $20.495 \%$. The Cronbach's alpha in each factor $(\alpha=.676, \alpha=.715$, $\alpha=.598$ for factors $1,2,3$ respectively) also shows the reliability of the factor loadings as Cronbach's alpha from 0.6 and above is an acceptable level of reliability (Peterson, 1994; Slater, 1995).

The factors classified by factor loadings in Table 6.5 were then labelled cognitive capacities (items 1, 2, 3), affective capacities (items 4, 5) and behavioural capacities (items 6,7) as three components of IC. These three IC components correspond to Byram's (2006) classification of intercultural competence. As the factor 
loading of each item was nearly equivalent, the mean of each factor was then calculated for comparisons. The results of the students' purposes of culture learning are presented in Table 6.6.

TABLE 6.5

Factor loadings for students' purposes for culture learning

\begin{tabular}{llcc}
\hline Purposes for culture learning & \multicolumn{2}{c}{ Factors } \\
& 1 & 2 & 3
\end{tabular}

1. Acquiring knowledge about the target culture

2. Developing the ability to interpret events of the target culture and relate them to one's own culture.

3. Developing critical cultural awareness of one's own and the target culture.

4. Acknowledging the value of the identities of others.

5. Showing respect for otherness, empathy and tolerance towards other peoples and cultures.

6. Developing communicative awareness of rules appropriate for intercultural communication.

7. Adapting one's behaviour to different requirements and situations.

$$
\begin{array}{cccc}
\text { Reliability (Cronbach’s alpha) } & .676 & .715 & .598 \\
\text { \% of Variance } & 26.211 & 22.786 & 20.495
\end{array}
$$

TABLE 6.6

Students' purposes for culture learning

\begin{tabular}{ccccc}
\hline Factors & IC components & N & M & SD \\
\hline & & & & \\
2 & Behavioural capacities & 200 & 4.19 & .95 \\
1 & Cognitive capacities & 200 & 3.59 & .80 \\
3 & Affective capacities & 200 & 3.26 & 1.00 \\
\hline
\end{tabular}

Note: $\mathrm{M}$ and SD are calculated on a five-point scale (1-5).

Paired samples tests were conducted among the three IC groups to examine whether their means were significantly different. The results show that there were significant 
differences between behavioural capacities and cognitive capacities $(\mathrm{M}=-.60$, $\mathrm{SE}=.08, t(199)=-7.786, p<.05, r=.48)$, behavioural capacities and affective capacities $(\mathrm{M}=.93, \mathrm{SE}=.08, t(199)=10.880, p<.05, r=.60)$, and cognitive capacities and affective capacities $(\mathrm{M}=.33, \mathrm{SE}=.07, t(199)=4.426, p<.05$, $r=.29$ ). From these results, it can be said that the students considered behavioural capacities $(\mathrm{M}=4.19)$ the most important purpose of culture learning, followed by cognitive capacities $(M=3.59)$, and affective capacities $(M=3.26)$.

In short, the students considered behavioural capacities the most important purpose for culture learning while they valued affective capacities less in culture learning.

\subsubsection{Benefits of culture learning}

The two last questions in the questionnaire addressed the benefits of culture learning and the teachability of language and culture in EFL classes. Because the students' responses to the second question covered similar ideas to the first question, these two questions are discussed together in this section. The questions had a multiple-choice part and an open-ended part asking the students to state the reasons for their choice.

Firstly, I will provide the results of the multiple-choice questions. In the first question, the students rated the extent to which culture learning has helped them in language learning. They were given three options $(1=$ not at all; $2=$ to a certain extent; $3=$ very much). The result is given in Table 6.7 .

TABLE 6.7

Students' rating of the benefits of culture learning

\begin{tabular}{cccccc}
\hline $\mathbf{N}$ & Very much & $\begin{array}{c}\text { To a certain } \\
\text { extent }\end{array}$ & Not at all & M & SD \\
\hline 200 & 97 & 102 & 1 & 2.48 & .511 \\
\hline
\end{tabular}

Note: M and SD are calculated on a three-point scale (1-3).

To examine whether the mean $\mathrm{M}=2.48$ is closer to 2 or 3 on the three-point scale, one-sample tests were conducted with the mean. The results show that the mean $\mathrm{M}=2.48$ is significantly different from both 2 and $3(t(199)=13.290, p<.05$ and $t(199)=-14.397, p<.05$ respectively). This indicates the mean score is located 
between 2 and 3. In other words, the students considered culture learning beneficial for their language learning.

In the second question, the students were asked to rate the extent to which they supported the teachability of language and culture in Vietnamese EFL classes. They were given three options ( $1=$ no; $2=$ with limitation; $3=y e s)$. The result is given in Table 6.8 .

TABLE 6.8

Students' opinions about the teachability of language and culture

\begin{tabular}{cccccc}
\hline $\mathbf{N}$ & Yes & $\begin{array}{c}\text { With } \\
\text { Limitation }\end{array}$ & No & M & SD \\
\hline 200 & 152 & 48 & 0 & 2.76 & .428 \\
\hline
\end{tabular}

Note: M and SD are calculated on a three-point scale (1-3).

To examine whether the mean $\mathrm{M}=2.76$ is closer to 3 than to 2 , a one-sample test was conducted. The result shows that the mean $\mathrm{M}=2.76$ is significantly different from 3 ( $t$ $(199)=-7.927, p<.05)$. This indicates the mean is located between 2 and 3. In other words, the students supported the teachability of language and culture in EFL classes although it was not completely so.

Secondly, I will report the results of the open-ended parts of the two questions above. In their responses, the students referred to the benefits they would gain from culture learning and from the teaching of language and culture in EFL classes. These benefits can be classified into three main themes: (a) culture learning facilitates language learning; (b) culture learning develops communication skills and (c) culture learning increases cultural knowledge and understanding. These benefits are summarised in Table 6.9. 
TABLE 6.9

Students' opinions about the benefits of culture learning

\begin{tabular}{|c|c|c|c|}
\hline Main themes & Subthemes & Description & $\begin{array}{c}\text { No. of student } \\
\text { responses }(\mathrm{N}=200)\end{array}$ \\
\hline \multirow{3}{*}{$\begin{array}{l}\text { Facilitating } \\
\text { language } \\
\text { learning }\end{array}$} & $\begin{array}{l}\text { Vocabulary } \\
\text { learning }\end{array}$ & $\begin{array}{l}\text { word origin, slang, jargon, idioms, } \\
\text { expressions, synonyms, accurate and } \\
\text { appropriate use of vocabulary }\end{array}$ & 33 \\
\hline & $\begin{array}{l}\text { Language } \\
\text { acquisition }\end{array}$ & $\begin{array}{l}\text { acquire the language more easily, better } \\
\text { understanding about language use, accurate } \\
\text { and appropriate language use in daily life } \\
\text { and specific situations }\end{array}$ & 31 \\
\hline & $\begin{array}{l}\text { Developing } \\
\text { language skills }\end{array}$ & $\begin{array}{l}\text { reading, writing, listening and speaking } \\
\text { skills }\end{array}$ & 13 \\
\hline \multirow{4}{*}{$\begin{array}{l}\text { Developing } \\
\text { communication } \\
\text { skills }\end{array}$} & $\begin{array}{l}\text { Appropriate } \\
\text { communication } \\
\text { and behaviour }\end{array}$ & $\begin{array}{l}\text { communicate and behave appropriately } \\
\text { according to the target language culture, } \\
\text { develop an understanding about native } \\
\text { speakers' communication styles and } \\
\text { behaviours }\end{array}$ & 27 \\
\hline & Confidence & build confidence in communication & 15 \\
\hline & $\begin{array}{l}\text { Intercultural } \\
\text { skills }\end{array}$ & $\begin{array}{l}\text { handle situations, prolong conversations, } \\
\text { adjust behaviours, avoid misunderstanding } \\
\text { in communication }\end{array}$ & 10 \\
\hline & $\begin{array}{l}\text { Intercultural } \\
\text { attitudes }\end{array}$ & $\begin{array}{l}\text { build empathy, respect and tolerance, avoid } \\
\text { hurting other people's feelings }\end{array}$ & 6 \\
\hline $\begin{array}{l}\text { Increasing } \\
\text { cultural } \\
\text { knowledge and } \\
\text { understanding }\end{array}$ & & $\begin{array}{l}\text { enrich cultural knowledge about the target } \\
\text { country and understanding about other } \\
\text { cultures, understanding about people's } \\
\text { lifestyle, behaviours and values }\end{array}$ & 47 \\
\hline
\end{tabular}

The following are representative quotes for each of the categories mentioned in Table 6.9. 


\section{(a) Facilitating language learning}

(37) Culture learning helps me understand how to use vocabulary in different contexts and avoid the misuse of synonyms; for example an American English word may be used differently from a British English word though both words deal with the same thing (S140, Q8, P1).

(38) It is a big shortcoming for students of a foreign language not to learn about the target culture of a language. Cultural understanding will benefit them a lot in acquiring a language. This is because language is highly affected by culture, including history. As many words, expressions, idioms originate from culture and are used with the habits of native speakers, culture learning will help us grasp the language better (S93, Q8, P1).

(39) Culture learning helps me understand the context, vocabulary use in some situations and apply cultural knowledge in learning vocabulary or phonetics. Reading books, literature, listening to music and exploring cultural values also help me improve my listening, speaking, reading skills and help me to love the language I am learning (S152, Q8, P1).

These typical examples indicate that culture learning would facilitate the students' language learning through the appropriate use of vocabulary, expressions, and idioms and developing language skills.

\section{(b) Developing communication skills}

(40) Learning about English-speaking cultures helps us communicate and behave correctly, politely and appropriately according to native English speakers' ways of communication (S1, Q8, P1).

(41) A good English learner without any concern about English culture is not necessarily a successful learner as sometimes he/she may make a negative impression on native speakers. "When in Rome, do as the Romans do". Knowing how to behave will build self-confidence and empathy with people in communication (S111, Q8, P1).

(42) If you learn only the language [without learning about the target culture], you will surely have trouble afterwards at work or in communication [with speakers of the target language]. There will be many unexpected situations, even misunderstandings that you cannot solve though you are good at the language (S138, Q8, P1). 
(43) The general purpose of learning English is for communication with foreigners, to understand others and to be understood by others; but one important thing is to show respect towards them. Culture learning can help us do that (S111, Q9, P1).

These typical examples indicate that culture learning would develop the students' communication skills with appropriate behaviours, problem-solving skills and positive attitudes towards speakers of the target language.

\section{(c) Increasing cultural knowledge and understanding}

(44) Culture is very important in human life. Culture is a beautiful thing and people will live better if they have an understanding of culture. A cultural understanding helps us to gain an insight into the life, character, behaviours as well as the thoughts of others (S128, Q9, P1).

(45) Foreign language learning will be easier when students can approach the target culture. Culture learning will help them understand more deeply about the countries and cultural values of English-speaking countries (S159, Q9, P1).

These typical examples indicate that culture learning would help the students gain a better insight and deepen their cultural understanding about other cultures.

Apart from the students' responses in the questionnaire, the student groups in the interviews also reported similar benefits of culture learning. For example, one firstyear group considered that culture learning would help them easily adapt and behave appropriately as well as learn English better. Another first-year group stated the need of culture learning to express themselves differently in English and Vietnamese, to use English as an international language and to avoid misunderstanding when travelling overseas. One fourth-year group mentioned the need to build more solid cultural knowledge for students to communicate with foreigners. Another fourth-year group stated various benefits of culture learning from the incorporation of culture in language classes:

(46) Culture needs to be incorporated in language classes for many reasons. Learners can learn about what really happens in daily life; it is very practical. They can acquire culture little by little through the whole learning process. They can remember the lessons more easily. They can understand the relationship between 
language and culture for more effective learning. They can learn ways of communication that convey particular features of a culture so that they will not feel unfamiliar with those cultural issues in interactions with foreigners (Interview SG10, Q8, P1).

The example (46) given above reflects the students' appreciation of the benefits that culture learning can bring for them for more effective language learning.

To sum up, the students considered cultural learning beneficial to language learning and supported the teachability of language and culture in EFL classes thanks to various benefits they would inherit from culture learning.

\subsubsection{Experience of culture learning}

This section reports on the results regarding the students' experience of culture learning in the classroom and beyond the classroom.

\subsubsection{Culture learning in the classroom}

The students were asked in the questionnaire to choose any culture learning activities they often had in the classroom from a list of eight. They were also asked to rank the usefulness of the selected activities on a five-point Likert scale (1=least useful; $5=$ most useful). The number of the students' responses was used to rank the culture learning activities in order of their popularity. Due to the uneven number of students' responses in each activity, the mean scores cannot be used for ranking the activities for comparisons, but are used only for interpreting the usefulness of each activity. The results are given in Table 6.10 .

As can be seen from Table 6.10, the learning of cultural facts was the most popular culture learning activity for the majority of the students (98\% chose learning cultural facts from reading texts; $76.5 \%$ answering teacher's questions about cultural facts). Learning cultural facts from reading texts was also considered very useful ( $\mathrm{M}=$ 4.05). Discussing cultural similarities and differences was the third most popular activity (66\%). Interestingly, solving cultural dilemmas was the second least popular $(28.5 \%)$ and was not considered very useful $(\mathrm{M}=3.46)$. Although watching videos 
about the target culture was done the least in the classroom (22\%), it was considered very useful $(\mathrm{M}=3.91)$.

TABLE 6.10

Students' culture learning activities in the classroom

\begin{tabular}{lccc}
\hline Culture learning activities & $\begin{array}{c}\text { No. of } \\
\text { responses* }\end{array}$ & M & SD \\
\hline 1. Learning cultural facts from reading texts & 196 & 4.05 & 1.01 \\
2. Answering teacher's questions about cultural facts & 153 & 3.71 & .96 \\
3. Discussing cultural similarities and differences & 132 & 4.01 & .99 \\
4. Doing exercises about cultural facts & 97 & 3.62 & 1.11 \\
5. Exploring values and beliefs of the target culture & 78 & 3.97 & 1.07 \\
6. Sharing experiences about the target culture & 75 & 3.85 & 1.01 \\
7. Solving cultural dilemmas & 57 & 3.46 & 1.46 \\
8. Watching videos about the target culture & 44 & 3.91 & 1.01 \\
& & & \\
\hline
\end{tabular}

Notes: * The responses are based on a total of 200 students; M and SD are calculated on a five-point scale (1-5).

All the student groups in the interviews also confirmed that the activities related to cultural facts were the most popular in the classroom. On the one hand, two student groups believed that this way of culture learning had some advantages. For example, while the second-year group considered that learning cultural facts through a comprehension check could raise students' curiosity so that they would self-explore an issue, the fourth-year group commented that this traditional way of learning might be convenient for both teachers and students. On the other hand, six other student groups argued this way of culture learning had a lot of shortcomings. One first-year group considered it impractical, and the two third-year groups found it ineffective and boring. Three fourth-year groups stated this way of culture learning was theoretical, impractical and uninteresting.

The student groups also discussed some other ways of culture learning which may help them learn about culture more effectively. These ways included exploring cultural values, watching video/films, cultural comparisons, solving cultural problems, learning with native English speakers, and sharing intercultural experience. 
For example, one third-year group argued that exploring cultural values would help students construct their own cultural knowledge through self-exploration. One fourthyear group considered video watching as appealing and impressive and that it would help students compare with their own culture. Another fourth-year group also commented on the advantage of cultural comparisons, which require students to acquire knowledge of their own and the target culture for culture learning:

(47) Comparison between home and target culture requires students to have knowledge of their own culture as nobody can be sure about his or her own culture. Students need to have knowledge of both their own and the target culture for culture learning (Interview SG7, Q5, P1).

Two fourth-year groups also considered solving cultural problems particularly efficient. For one group, students could put themselves in different situations to discover cultural differences between their own culture and the target culture. For the other group, students could role-play in cultural situations so that they could remember a cultural issue longer. A group of third-year students also claimed that native English speakers invited to teach in the classroom could be a rich cultural source for students to learn about the target culture directly rather than depending on cultural information from textbooks and the Internet. One fourth-year group were particularly interested in the way their teacher of the American culture course ${ }^{11}$ shared his life experience in America without teaching much from the textbooks. They considered this way of culture learning useful as it helped them imagine the life in America and remember the lesson more easily. Nevertheless, the students also said that teachers who spent only a short time overseas may not have deep intercultural experience to teach about culture. In addition, there was an argument in one fourthyear group about whether it was necessary for people to live in the target country to truly understand its culture. In this group, while some students considered it difficult to understand the target culture without going to that country, the others disagreed with this idea:

(48) Learning about culture in English is to learn about a country and people of that country, so it is not necessary for people to live in that culture to understand it. If

\footnotetext{
${ }^{11}$ This teacher has been to America for one year as a Fullbright scholar.
} 
so, people cannot understand other cultures and there will be no human civilization...For example, we do not live in England but we can still understand its culture to some extent (Interview SG7, Q2, P1).

To sum up, the learning of cultural facts was the most popular culture learning activity in the EFL classroom. This approach to culture learning was considered both advantageous and disadvantageous. The students expected to achieve more effectiveness through other ways of culture learning which were much less frequently pursued in the classroom.

\subsubsection{Culture learning beyond the classroom}

It is also important to investigate how students experience culture learning beyond the classroom as their knowledge of cultural background may have an impact on their culture learning. In the questionnaire, the students were asked to choose any culture learning activities they often experienced beyond the classroom and then rank the usefulness of the selected activities. The instructions for these activities are the same as those in section 6.3.6.1. The results are given in Table 6.11.

TABLE 6.11

Students' culture learning activities beyond the classroom

\begin{tabular}{lccc}
\hline Culture learning activities & $\begin{array}{c}\text { No. of } \\
\text { responses }\end{array}$ & M & SD \\
\hline & 165 & 4.13 & .98 \\
1. Reading English newspapers/magazines & 143 & 4.07 & 1.09 \\
2. Watching English TV channels (BBC, CNN...) & 128 & 3.87 & .95 \\
3. Searching for cultural information on the Internet & 117 & 4.33 & 1.05 \\
4. Communicating with native English speakers (NES) in public & 104 & 3.84 & 1.03 \\
5. Meeting NES visiting your school & 74 & 3.46 & 1.17 \\
6. Reading English literature & 67 & 4.21 & 1.02 \\
7. Participating in cultural exchanges with NES & 38 & 3.76 & 1.02 \\
8. Exchanging emails with NES & & & \\
\hline
\end{tabular}

Note: Same calculations as Table 6.10. 
The results show that the students' most popular culture learning activities beyond the classroom involved the media $(82.5 \%$ chose reading English newspapers and magazines, $71.5 \%$ watching English TV channels, and 64\% searching for cultural information on the Internet). Although only $58.5 \%$ of the students had opportunities to communicate with native English speakers (NES) in public, and 33.5\% participated in cultural exchanges with NES, these activities were considered very useful (M=4.33 and $\mathrm{M}=4.21$ respectively). Exchanging emails with NES was the least undertaken (19\%), but it was also considered quite useful $(\mathrm{M}=3.76)$.

The student groups in the interviews were asked to share their intercultural experiences beyond the classroom. Generally, they reported that their limited English proficiency created a barrier to communication with English speakers. For a first-year group, a cultural barrier was not a problem in first meetings. The second-year group stated linguistic competence was more important than cultural competence although they believed good cultural skills would make students understand a foreigner better. A third-year group also mentioned they experienced no cultural barrier in communication with native English speakers as no specific characteristics of their culture were referred to in their talks. These students reported they just had difficulty in expressing their feelings due to a lack of vocabulary. Three fourth-year groups also argued they mainly encountered a linguistic barrier in expressing themselves, and there was no cultural barrier recognised in first meetings.

However, the student groups also reported some cultural barriers they experienced in communication with native English speakers. For example, one firstyear group felt unfamiliar with foreign behaviour and attitudes in first meetings. One third-year group experienced the discomfort shown by an American teacher when she was asked about her marital status. One fourth-year group had the same concern about the issue of personal questions in communication:

(49) Students in communication with native English speakers do not know what to talk about, not because of lack of vocabulary, but because they are afraid of dealing with personal issues foreigners do not like to talk about (Interview SG9, Q7, P1).

Another fourth-year group also experienced cultural barriers concerning how to start a conversation and how to keep a conversation going. For example, different interests 
between the students and foreigners, such as in political issues or over personal questions, made it difficult for them to continue the conversation:

(50) Vietnamese students and foreigners have different interests as foreigners come from another culture. Students have to maintain the conversation by talking about different things, but they gradually do not know what to talk about (Interview SG8, Q7, P1).

In addition, one fourth-year group stated they were aware of their own behaviours. The following example shows how a student tried to adapt to the target culture by changing the way he shook hands with respected people in his culture:

(51) What would my Vietnamese teacher think about me if I shook hands with him with one hand only? I feel more comfortable when I shake hands with foreigners with one hand (Interview SG7, Q7, P1).

In summary, the students mainly learned about the target language culture through the media, but found it very useful to engage in communication with native English speakers and in practical cultural exchanges. They mainly experienced limited language proficiency as a barrier to communication with native English speakers rather than cultural barriers.

\subsection{Discussion}

This section discusses the main trends in the data regarding the students' priorities in EFL learning and their perceptions of culture in language learning.

\subsubsection{Culture as a subordinate priority in language learning}

The students' ultimate priority for getting a good job as a reason for learning English is entirely congruent with their reasons for study at university. The high ranking of communication with foreigners is important from an intercultural perspective because such communication is fundamentally intercultural. It offers opportunities for intercultural language learning through communication practice with intercultural 
dimensions. This priority, therefore, should be reinforced to actively engage the students in genuine intercultural interactions in order to develop their intercultural communicative competence. However, the low priority given to the acquisition of cultural knowledge indicates that culture learning is not seen by the learners as a valued end in itself. For an increased cultural component in the curriculum to be accepted by the learners, they may need to be made aware of its value in their use of the English language in their future careers and in interactions with English speakers. In addition, the students also demonstrated a priority for the linguistic dimension over the cultural dimension of language learning. This priority echoes Guntermann, Hendrickson and de Urioste (1996), who show that very few French and Spanish tertiary students ranked culture first in relation to the four language skills. This finding is consistent with Chavez (2002) who points out that students frequently did not value foreign language culture in the language classroom. This suggests that the cultural dimension of language learning should get more emphasis in the EFL classroom so that students can have a better understanding about its value in language learning.

\subsubsection{Culture defined as social structures}

The students' definitions of culture as social structures correspond with Kramsch's (2006) modernist perspective about culture that involves both humanistic and sociolinguistic concepts. The students were more likely to be concerned with culture as social structures rather than in relation to language learning. This indicates that such perceptions of culture may have resulted from their culture learning about a particular culture rather than about the cultural dimension of language learning.

From such perceptions of culture, only a minority of the students acknowledged the relationship between language and culture in language learning. The students believed that language learning could be separated from culture learning. This is contrary to one principle for intercultural language teaching and learning which states that language and culture should be integrated from the beginning (Newton and Shearn, 2010b). This suggests that there is considerable scope for enhancing the integration of language and culture in the curriculum and classroom experience of EFL students in Vietnam. In addition, the four-year student groups were more likely to be aware of the relationship between language and culture than the 
other groups, which was perhaps because of their greater language learning experience. This suggests culture learning should be enhanced in the first years of EFL learning so that students can become more aware of the relationship between language and culture right at the beginning of their language learning.

\subsubsection{Behavioural capacities as the ultimate purpose for culture learning}

That the students considered behavioural capacities the most important purpose for culture learning is a positive disposition for developing intercultural communicative competence. However, the students valued affective capacities in culture learning less. These capacities should be fostered by engaging students in affective dimensions of culture learning so that they can develop positive intercultural attitudes towards other cultures such as respect for otherness, tolerance for ambiguity and empathy (Byram, 2006). Paige, Jorstad, Siaya, Klein, and Colby (2003) also argue that students need to engage in culture learning not only cognitively, but also behaviourally and affectively in order to develop intercultural communicative competence.

In contrast with the consideration of behavioural capacities as the most important purpose for culture learning as mentioned above, only a very small number of students mentioned the development of intercultural skills as a benefit of culture learning. This is because the students lacked intercultural skills to deal with misunderstandings in intercultural communication and this suggests that intercultural skills were overlooked in the Vietnamese EFL classroom. It raises the question about whether students can develop intercultural skills in a homogenous context where they lack contact with native English speakers or people from other nations or ethnic groups. According to Sowden (2007), it is necessary to live within a culture for a good period of time as a sojourner (Byram, 1997) to develop one's familiarity with that culture and improve one's real intercultural skills. Sowden argues learners need to experience the target culture from inside as "an active participant in a community" (Barro, Jordan and Roberts, 1998, p.83). Such experience can be gained through overseas study in a country where the target language is spoken as a first language. However, Kramsch (1991) shows that study abroad per se might not be enough for students to develop cross-cultural understanding. Cortazzi and Jin (1999) support this idea, arguing that a person does not need to travel to encounter representatives of other cultures as the multicultural nature of many societies will give them the chance 
to meet members of other cultural groups sooner or later. This suggests that culture learning can benefit learners when they are given opportunities to engage in interaction with texts, artifacts and with their own cultural preconceptions in the classroom and beyond.

\subsubsection{Culture learning focused on cultural facts}

The learning of cultural facts as the students' most popular culture learning practice is well matched with the teaching of cultural facts as the teachers' most popular culture teaching practice in the previous chapter. As this approach to culture learning was considered very useful by the students in the questionnaire, it may have a value in the Vietnamese EFL classroom. However, the fact that the student groups in the interviews reported a lot of shortcomings in this approach and commented on the effectiveness of other ways of culture learning suggests that this facts-oriented approach should be combined with other approaches in order to engage students more effectively in culture learning.

In addition, the students mainly learned cultural information about the target culture through the media due to the lack of contact with native English speakers beyond the classroom. As a result, they were more likely to experience limited language proficiency as a barrier to communication with native English speakers rather than the cultural barrier. This indicates that a lack of students' awareness of cultural differences in intercultural encounters prevented them from developing intercultural competence. Opportunities to participate in genuine intercultural interactions, therefore, become crucial for students to develop their awareness of cultural differences and consequently intercultural competence.

\subsubsection{Constraints on culture learning}

The students noted that a variety of constraints restricted their opportunities for culture learning. I have chosen to discuss four of the constraints they mentioned as these constraints are important for being taken into consideration. The constraints included (1) little impact of culture on language learning, (2) students' level of language proficiency, (3) limited and stereotyped cultural content, and (4) students' receptiveness to culture learning. 
Firstly, the students noted that culture had little impact on language learning as culture learning provided them with only additional cultural and social knowledge rather than improving their language proficiency. This indicates the lack of the students' awareness of the relationship between language and culture as inseparable components in language learning. As Liddicoat et al. (2003) claim, language and culture interact with each other in a way that culture connects to all levels of language use and structures, i.e., there is no level of language which is independent of culture. Byram's (1997) model of intercultural communicative competence also suggests that linguistic competence is not the only competence learners have to acquire in their foreign language learning, but they need to acquire sociolinguistic competence, discourse competence and intercultural competence as well. This suggests that foreign language learners are successful language learners only when they are both linguistically and interculturally competent.

Secondly, the students noted that students' level of language proficiency restricted opportunities for culture leaning. This belief assumes that students must attain a reasonable level of language proficiency before engaging in culture learning. This is not the case as culture learning cannot be delayed until learners have acquired a certain level of language (Liddicoat et al., 2003). This means that students should start learning the target language culture at the time they start learning the target language so that they will be able to become both linguistically and interculturally competent.

Thirdly, the students noted that the limited and stereotyped cultural content of textbooks had a negative impact on their culture learning. According to Sercu (2002), today's societies consist of members of many different groups who bear different cultural identities. In Sercu's view, the cultural content of foreign language courses needs to use a concept of culture that adequately reflects the nature of the world in which learners live. Atkinson (1999) argues that "the acknowledgement and acceptance of multiple, complex cultural identities should be a first principle of ESL teaching and teacher preparation" (p.644). In addition, as culture is dynamic and always changing, the cultural content of textbooks can easily become outdated or stereotyped. Gray (2000) suggests that it is important to have "critical engagement with the course book as a cultural artefact and bearer of messages" (p.280) which makes "both cross-cultural and educational sense" (p.274). 
Finally, the students noted that their receptiveness to culture learning was constrained as they were afraid of being distanced from their native culture and having their own cultural values challenged by those of the target culture. This unwillingness for culture learning echoes Harlow and Muyskens (1994) who find that French and Spanish tertiary students had very little motivation in learning about culture. Kramsch (1993) also argues that learners are often unwilling to distance themselves from their native culture and familiar educational discourse. This learner attitude is incongruent with the aims of intercultural language learning which prioritise understanding of one's own culture in relation to the target culture as a means of learning about the target culture (Liddicoat et al., 2003). Nevertheless, learners have to grow out of their cultural shell (Kaikkonen, 2001, p.64) in order to learn about the target culture and reach a common ground where different points of views are negotiated and accepted (Liddicoat et al., 2003, p.46). When learners reach this place, they would not feel that they are distanced from their native culture or that their own cultural values are threatened.

\subsubsection{Potential for adopting intercultural language learning}

In spite of all the constraints on culture learning, there is potential for the uptake of intercultural language learning in Vietnamese EFL classes. First, the students' high ranking of communication with foreigners as a second priority for learning English and behavioural capacities as the most important purpose for culture learning offers an opportunity for intercultural language learning to take place. Developing communicative competence, therefore, can be a good starting point for the students to develop intercultural communicative competence as long as they are provided with opportunities to engage in communication practice with intercultural dimensions to achieve this goal.

Secondly, the students' strong awareness of the importance of their own culture in learning about other cultures and in interaction with people from other cultural backgrounds provides a foundation for them to engage in intercultural language learning as they need to develop an understanding of their own culture in relation to the target language culture (Liddicoat et al., 2003).

Thirdly, the students considered culture learning beneficial for their language learning and supported the teachability of language and culture in EFL classes 
although it was not completely so as seen from the statistical results. This provides opportunities to promote intercultural language learning in EFL classes. However, it is important to consider the students' concerns about various constraints on culture learning in order to make sure that effective intercultural language learning takes place in the EFL classroom.

\subsection{Summary}

This section has provided insight into the Vietnamese EFL students' priorities in EFL learning and their perceptions of culture in language learning. The findings revealed that their ultimate priority for getting a good job as a purpose for learning English is congruent with their purposes of studying at university, while culture learning is not seen as a valued end in itself. The students also prioritised the linguistic dimension over the cultural dimension of language learning. Although the students considered culture learning beneficial for their language learning and supported the teachability of language and culture in EFL classes, a number of them believed that a variety of factors constrained their opportunities for culture learning in the EFL classroom. The students' culture learning practice in the classroom mainly focused on cultural facts, while their culture learning beyond the classroom was mainly done through the media. In spite of all the constraints on culture learning, there is potential for implementing intercultural language learning in the Vietnamese EFL classes. This potential provides impetus to adopt an intercultural stance in this context, which is the rationale for the third phase of the study.

In the next chapter, I will describe the methodology for an intercultural intervention in a Vietnamese tertiary EFL class. 


\section{Chapter VII \\ METHODOLOGY FOR THE INTERCULTURAL \\ INTERVENTION}

\subsection{Introduction}

This chapter outlines the research design and details the methodological approaches for an empirical study in the third phase of the study which investigated intercultural learning in a Vietnamese EFL class through an intervention study. The chapter starts with an overview of the research questions and the research design, and then describes the participants, the research process and procedures for data collection and methods for data analysis. Finally, the chapter discusses issues of reliability and validity in relation to the study as well as its limitations.

\subsection{Overview of the third phase}

The empirical study in the third phase of the study investigated the effect of adopting an intercultural stance into English speaking lessons on development of learners' intercultural competence in order to address the following research questions (RQ):

RQ4: To what extent did the intercultural competence of students in the intercultural class develop compared to that of students in the standard class?

RQ5: What was the nature of the development of intercultural competence of students in the two classes?

RQ6: How did the students of the intercultural class perceive intercultural language learning?

The empirical study took the form of a process-product study with a quasiexperimental design in three stages (Table 7.1) which involved comparisons between two intact and equivalent classes, known as the Standard class (ST class) and the Intercultural class (IC class). Each stage is described below. 
TABLE 7.1

Scheme of quasi-experimental design

ST Class IC Class

Stage 1: Pre-test

Intercultural Competence Inventory

\section{Stage 2: Intervention}

\section{Standard lessons}

(1) Students participate in normal speaking lessons

(2) All students write three reflective journals on nine lessons during nine weeks

(3) Case studies of two students

\section{Intercultural lessons}

(1) Students participate in intercultural speaking lessons

(2) All students write three reflective journals on nine lessons during nine weeks

(3) Case studies of two students

Stage 3: Post-test

Intercultural Competence Inventory

Self-evaluation questionnaire

Focus group interviews (IC class)

The first stage involved the use of an Intercultural Competence Inventory (ICI) for the pre-test. This pre-test had a two-fold purpose:

(1) To examine the comparability of the two classes in terms of learners' initial intercultural competence prior to the intercultural intervention.

(2) To provide a basis for selecting two case study students in each class.

The second stage involved running an intercultural teaching innovation in which eighteen English speaking lessons in the two classes were observed over a nine-week teaching period (1x 90 minutes/lesson/week). For the IC class, the lessons were adapted to reflect the principles of intercultural language learning. For the ST class, no changes were made. All the students in both classes were asked to write three reflective journals in which they reflected on their culture learning in each lesson. Two case studies were also carried out in each class. 
The third stage took place when the nine-week teaching period was finished. Both classes completed a post-test which was the same ICI used in the pre-test. The posttest investigated whether there was a significant difference between the two classes regarding the development of the learners' intercultural competence after the intercultural intervention. The students in both classes also completed a selfevaluation questionnaire which examined whether the students in the IC class had a better experience of intercultural language learning than those in the ST class. In addition, ten students in the IC class also participated in two focus-group interviews to provide further information about their experience of intercultural language learning.

\subsection{Participants}

The participants in the third phase of this study include an EFL teacher and students from a Vietnamese university.

\subsubsection{Teacher participant}

An EFL teacher agreed to participate in the research with interest. She was in charge of teaching the two classes over the nine-week teaching period. These two classes were a part of her normal teaching responsibilities at the English Department of the university. The teacher has been teaching English for more than 10 years and obtained her Master's Degree in TESOL in Australia.

\subsubsection{Learner participants}

Seventy-one second-year English-majoring students ( $\mathrm{N}=38$ for the ST class; and $\mathrm{N}=33$ for the IC class) participated in the third phase of the study (Table 7.2). As can be seen from Table 7.2, the majority of the students in both classes are female in the 18-22 age group. Most of the students had similar experience of learning English for 6-10 years and have learned English with native English speakers. Most of them have never been abroad, except for a few students in the ST class who have been to some Asian countries. 
TABLE 7.2

Demographic information of learner participants

\begin{tabular}{llcc}
\hline \multicolumn{1}{c}{ Category } & & $\begin{array}{c}\text { ST class } \\
(\mathbf{N}=\mathbf{3 8})\end{array}$ & $\begin{array}{c}\text { IC class } \\
(\mathbf{N = 3 3})\end{array}$ \\
\hline \multirow{3}{*}{ Gender } & Male & 1 & 4 \\
& Female & 37 & 29 \\
Age & $18-22$ years old & 37 & 32 \\
& $23-30$ years old & 1 & 1 \\
Years of learning English & 1-5 years & 7 & 5 \\
& 6-10 years & 24 & 27 \\
Have been abroad & $>10$ years & 7 & 1 \\
& & & 33 \\
Frequency of communicating with NES & No & 35 & 0 \\
& Yes & 12 & 4 \\
& Never & 26 & 29 \\
Have learned English with NES & Sometimes & 0 & 0 \\
& Usually & 1 & 3 \\
& No & 37 & 30 \\
\hline
\end{tabular}

\subsection{Lessons used in both classes}

The lessons used in both classes belong to the English speaking material, Speaking 3 (Nguyen and Le, 2007). It is internal material which was used for the second-year English-majoring students at the English Department of the university where the research took place. The speaking course was chosen for the study as it is topic-based, and thus has potential for adopting an intercultural stance. The lessons used in both classes consisted of nine units:

Unit 1: Buying and selling

Unit 2: Men and women

Unit 3: Festivals and holidays

Unit 4: Exceptional people

Unit 5: Interpersonal communication

Unit 6: Animals

Unit 7: Feelings

Unit 8: Science and Technology

Unit 9: The best age 
These lessons were used for the study as they were scheduled in the actual learning process of the two classes. Due to the limited time for each speaking lesson (90 minutes/ lesson/ week), the teacher did not cover all the material in each unit, but only selected the main activities for teaching. The lessons in the Standard class used material from Speaking 3, whereas the lessons in the Intercultural class were adapted from those in the Standard class for intercultural language learning. These two types of lessons are described below.

\subsubsection{The standard lessons}

Each of the nine units in the Standard class is structured as two lessons A and B which are related to the topic of each unit. For example, Unit 6, Animals, consists of $A$ wild bunch as lesson A and Man's best friend as lesson B. Each of these lessons normally consists of three parts. The first part provides a range of vocabulary and/ or some expressions and phrases for language use, e.g., I agree strongly, It doesn't bother me, etc. The second part consists of a short reading text and some questions for discussion. The third part consists of some situations for discussion in pairs or groups. At the end of each unit, there is a section of class talk that consists of different questions for further discussion. The lessons in the Standard class had a primary focus on language.

\subsubsection{The intercultural lessons}

The intercultural lessons in the Intercultural class were adapted from the lessons in the Standard class as described in section 7.4.1, using the same structure of each unit. The intercultural lessons adapted these materials along six components:

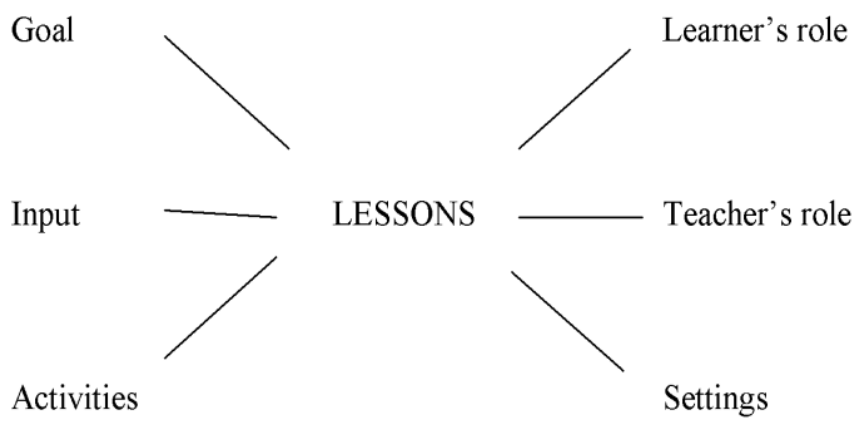

(Adapted from Nunan, 1989, cited in Corbett, 2003, p.41) 
Each of these components is described in detail below.

\subsubsection{Goals}

Of the four main components of intercultural competence, i.e., knowledge, skills, attitudes and awareness, two components - intercultural awareness and attitudes were selected as the two main goals of the intercultural lessons. There were two reasons for setting up these main goals. First, the result in the second phase of the study revealed that the students valued affective capacities the least compared to behavioural and cognitive capacities in culture learning. Therefore, affective capacities for intercultural competence were focused on in the intercultural lessons. Second, it was impossible to measure all of the four components of intercultural competence in a nine-week teaching period. This corresponds to Deardorff (2006) who shows that intercultural competence can be measured in its separate components rather than holistically. The two components of intercultural competence, i.e., intercultural awareness and attitudes, were thus chosen as the main goals of the lessons to explore the nature of learners' intercultural development in details.

\subsubsection{Input}

The main sources of input of intercultural knowledge in the intercultural lessons involved the following sources:

\section{(1) Students' own research on cultural issues in each lesson}

The students were required to prepare for the lessons by doing their own research on cultural issues in each lesson before class and then sharing with other students through pair or group discussions in class. The reading texts in each unit provide the main source of cultural information for the students to explore issues through their own research and discussion in the classroom. This cultural exploration helped the students become more active in constructing their own intercultural knowledge rather than depending on the textbook or the teacher. 


\section{(2) Teacher's cultural input}

The teacher provided the following sources of cultural input:

- English advertisements (Lesson 1)

- Cartoons about gender differences and gender roles (Lesson 2)

- A cultural situation about a Vietnamese couple's visit to an American home (Lesson

3)

- A cultural situation about an American disabled student at an American university (Lesson 4)

- Cross-cultural communication situations (Lesson 5)

- A cultural situation of a woman who was sentenced to six months in prison due to maltreatment of her dog (Lesson 6)

- A story about a little girl in England who faced fear (Lesson 7)

- A cultural situation of an old Vietnamese man living in a nursing home in California (Lesson 9b)

The cultural situations provided by the teacher aimed to engage the students in real situations in the target culture. The situations were adapted from culture assimilators which have been widely used in language learning. A culture assimilator is described as

...a programmed learning tool consisting of a number of short case descriptions, each picturing an intercultural encounter in which a person from the foreign culture behaves in a particular way. Usually four explanations are offered of this behaviour. One of these is the insider explanation by informants from the foreign culture. The three others are native choices by outsiders. The student picks one answer and receives a comment explaining why the answer chosen was correct or incorrect (Hofstede and Hofstede, 2005, p.361).

The four explanations in the culture assimilator assume that there is only one single cultural interpretation of the given event and its understandings are either right or wrong (Liddicoat, 2004). Liddicoat argues that this cultural interpretation "construct[s] the target culture as inflexible in its construction of meaning and essentialise[s] cultural meanings as easily learned, mono-faceted conceptualisations of experience" (p.55). To avoid such shortcomings of the culture assimilator, the cultural 
situations used in the intercultural lessons were redesigned with open questions in place of four given explanations. These open questions aimed to develop students' critical thinking in intercultural language learning.

In addition, the teacher's cultural input aimed to provide some authentic materials for culture learning to compensate for the lack of communication with native English speakers in the classroom. Authentic materials are valuable classroom resources which are "written or spoken texts that have not been produced primarily for teaching purposes" (Corbett, 2003, p.42). As Corbett argues, authentic materials can be used as evidence of how a culture operates. Some authentic L2 material from the Internet was used for the intercultural tasks. For example, two real-life stories were used as cultural situations in units 6 and 9. One real-life story from an online news source was about a San Francisco woman who was sentenced to six months in prison due to maltreatment of her dog. Another real-life story was about how an old Vietnamese man was treated by his Vietnamese-American sons in California. Such real-life stories offered the students the possibility of developing a better understanding about cultural practices in the target culture.

\subsubsection{Teacher's role}

The present study adopted a constructivist approach for the intercultural lessons. The role of the teacher as an authority or the main source of knowledge was replaced by that of a facilitator who guided the students through the intercultural activities in the classroom. In other words, the students were exposed to a learner-centred approach with the teacher acting as a guide or an adviser (Corbett, 2003).

\subsubsection{Learner's role}

With the constructivist approach, the students actively participated in constructing their own intercultural knowledge. Their construction of knowledge about the target culture was done in a variety of ways as follows:

(a) They did their own research on the cultural issues in the lessons.

(b) They shared cultural knowledge with their peers through discussions and presentations in class. 
(c) They explored the target culture by interviewing a native English teacher who was invited to the classroom.

(d) They role-played and offered problem-solving solutions in cultural situations.

\subsubsection{Classroom settings}

Intercultural language learning focuses on the learner in their learning process. A variety of classroom settings were therefore used in the intercultural lessons so that learners could benefit not only from their peer-group interaction but also from their individual reflections on their culture learning in some solitude (Corbett, 2003). As Corbett argues, a range of classroom settings through a series of activities will satisfy most learners at some point and also train them in useful strategies of co-cooperation and individual development. The intercultural tasks allowed for a wide range of settings in each lesson:

(a) Individual work (students' own research)

(b) Pair work (pair discussions, role-plays)

(c) Group work (group discussions and presentations)

(d) Whole class (class talk)

\subsubsection{Activities}

The intercultural lessons were adapted from the existing speaking lessons to reflect the five principles of intercultural language learning proposed by Liddicoat et al. (2003): (1) Active construction; (2) Making connections; (3) Social interaction; (4) Reflection and (5) Responsibility. These five principles are described in turn below.

\section{(1) Active construction}

The constructivist approach was adopted in the intercultural lessons to actively engage the students in culture learning. This means that the students constructed their own intercultural knowledge through cultural exploration rather than being dependent on the teacher's provision of knowledge to learn about the target culture. Cultural exploration allowed students to construct their intercultural understandings from firsthand experience and reflections in order to engage more deeply in the process of 
intercultural language learning. The students constructed their intercultural knowledge by doing their own research, by peer discussions, by interviewing a native speaker of the target language and by role-playing and problems solving in critical incidents. The intercultural lessons involved the following topics:

- Shopping

- Advertising

- Men and women

- Festivals and holidays

- Exceptional people

- Interpersonal communication

- Animals and pets

- Pet hates, fears and phobias

- Science and technology

- Kindergarten education

- The elderly

\section{(2) Making connections}

The students explored their selves, developed awareness of cultural stereotypes and new insight into the target culture in relation to which they made connections with their own culture. By connecting the target culture with their home culture, the students were able to develop critical cultural awareness about different aspects of the target culture and their own culture. The process of noticing is emphasised in this principle as it is fundamental to intercultural language learning (Liddicoat et al., 2003). The process of comparison is multilayered in that it allows space for comparisons between the learner's home culture and the target culture as well as between their lingual and cultural background knowledge and the new input from noticing (Liddicoat, 2008).

\section{(3) Social interaction}

The students in the IC class participated in two types of social interaction including: (a) role-plays and (b) ethnographic interview. 


\section{(a) Role-play}

Role-play is a drama-like classroom activity in which students act out the roles of different participants in a given situation (Richards, Platt and Platt, 1992). Role-play has been frequently used as a classroom activity in language teaching due to the benefits it brings. The use of role-play in the classroom can promote the teaching of language "along the cultural faultline" (Kramsch, 1993, p.205). Kim and Gudykunst (1999) argue that role-play enhances the effective involvement of students, particularly the affective and the behavioural components, in the instructional process. Putnam and Conrad (1999) also mention that role-play tasks are very efficient in demonstrating effective and appropriate communicative behaviours and provide concrete exemplars of abstract concepts. In the present study, the students participated in role-plays in the situations in Units 3 and 5.

\section{(b) Ethnographic interview}

According to Bateman (2004), ethnographic interviews can engage students in culture learning cognitively, affectively and behaviourally. Bateman argues that learners engaging in ethnographic interviews enhance not only their attitudes towards the speakers and the target culture, but also their communicative competence with people from other cultures and awareness of the influence of their own culture in their lives. The students in the IC class participated in a social interaction with a native English speaker invited to the classroom through an ethnographic interview. The ethnographic interview is defined as a method where there is an on-going respectful relationship with interviewees characterized by 'genuine exchange of views' (p.369) that elicits the meaning interviewees make of the world around them (Heyl, 2001). The students in the IC class interviewed the native speaker of the target language to gain the perspective of the interviewee, which was informed by her position within her own social context, on the cultural meanings of the topics that she made of her own experiences in her own culture. The ethnographic interview with the native speaker of English was a good opportunity for the students to engage in cultural explorations and develop a new insight into the target culture for a better understanding of it. 


\section{(4) Reflection}

Students participated in group discussions and reflected critically and constructively on their experience of cultural learning in the classroom. Reflections can develop learners' critical thinking, increase their consciousness of cultural similarities and differences in values and help them become more aware of the assumptions of English-speaking cultures and their own culturally-shaped assumptions (Tomalin and Stempleski, 1993). Reflections can help learners reduce ethnocentrism and develop ethnorelative attitudes towards other cultures once they have developed an understanding of the shared meanings of values in their home culture and the target culture.

\section{(5) Responsibility}

According to Liddicoat et al. (2003), students ideally develop positive attitudes and disposition towards culture learning. They need to show willingness to interact with people from diverse languages and cultures. In other words, they need to take responsibility for making communication successful and developing an intercultural perspective that values other cultures and people. The intercultural lessons engaged the students with this responsibility so as to develop their willingness for intercultural interactions and intercultural perspectives.

\subsubsection{Summary of lessons}

The differences between the two classes in lesson design are given in Table 7.3. The summary of the lesson content in the two classes is given in Table 7.4. A sample lesson (Unit 3) can be found in Appendix 13. 
TABLE 7.3

Differences between the two classes in lesson design

\begin{tabular}{|c|c|c|}
\hline & ST class & IC class \\
\hline Goals & $\begin{array}{ll}\text { Developing learners' linguistic } \\
\text { competence }\end{array}$ & $\begin{array}{l}\text { Developing learners' intercultural } \\
\text { awareness and attitudes }\end{array}$ \\
\hline Input & $\begin{array}{l}\text { - Information from the textbook } \\
\text { - The teacher's knowledge }\end{array}$ & $\begin{array}{l}\text { - Cultural information from the textbook } \\
\text { - Students' own construction of cultural } \\
\text { knowledge } \\
\text { - The teacher's cultural input }\end{array}$ \\
\hline Teacher's role & Teacher-centred & Facilitator \\
\hline Learner's role & $\begin{array}{l}\text { Students depended on the teacher's } \\
\text { provision of knowledge }\end{array}$ & $\begin{array}{l}\text { Students constructed their own cultural } \\
\text { knowledge }\end{array}$ \\
\hline $\begin{array}{c}\text { Classroom } \\
\text { setting }\end{array}$ & $\begin{array}{l}\text { - individual work } \\
\text { - whole class }\end{array}$ & $\begin{array}{l}\text { - individual work (presentations) } \\
\text { - pair work } \\
\text { - group work (role-plays) } \\
\text { - whole class }\end{array}$ \\
\hline \multirow{5}{*}{ Activities } & $\begin{array}{l}\text { Students answered the teacher's } \\
\text { questions and the questions in the } \\
\text { textbook. }\end{array}$ & $\begin{array}{l}\text { Principle 1: Active construction } \\
\text { Students constructed their intercultural } \\
\text { knowledge through: } \\
\text { - their own research } \\
\text { - peer discussions and presentations } \\
\text { - ethnographic interview with a native } \\
\text { speaker of English } \\
\text { - role-plays and problem-solving }\end{array}$ \\
\hline & $\begin{array}{l}\text { Students discussed the topics without } \\
\text { making any connections between } \\
\text { cultures. }\end{array}$ & $\begin{array}{l}\text { Principle 2: Making connections } \\
\text { Students made connections with the target } \\
\text { culture in relation to their own culture. }\end{array}$ \\
\hline & No social interaction & $\begin{array}{l}\text { Principle 3: Social interaction } \\
\text { Students participated in role-plays and an } \\
\text { ethnographic interview. }\end{array}$ \\
\hline & $\begin{array}{l}\text { Students discussed the topics with a } \\
\text { focus on knowledge. }\end{array}$ & $\begin{array}{l}\text { Principle } 4 \text { : Reflection } \\
\text { Students reflected on cultural differences } \\
\text { and their intercultural behaviour. }\end{array}$ \\
\hline & $\begin{array}{l}\text { Students focused on their speaking } \\
\text { language skills. }\end{array}$ & $\begin{array}{l}\text { Principle 5: Responsibility } \\
\text { Students developed an intercultural } \\
\text { perspective. }\end{array}$ \\
\hline
\end{tabular}


TABLE 7.4

Summary of the lesson content in the two classes

\begin{tabular}{|c|c|c|}
\hline Lessons & ST class & IC class \\
\hline $\begin{array}{c}\text { Buying and } \\
\text { selling }\end{array}$ & $\begin{array}{l}\text { - Discuss the purpose of } \\
\text { advertisements and things to be } \\
\text { controlled in advertising. } \\
\text { - Match the advertising techniques } \\
\text { with their descriptions and give } \\
\text { examples of products in learners' } \\
\text { country for each technique. } \\
\text { - Describe places to shop and } \\
\text { changes in shopping habits between } \\
\text { the past and the present. } \\
\text { - Discuss online shopping }\end{array}$ & $\begin{array}{l}\text { - Discuss cultural factors in advertisements } \\
\text { and things to be controlled in Vietnamese } \\
\text { and English advertisements. } \\
\text { - Compare different products and the use of } \\
\text { different advertising techniques in English } \\
\text { and Vietnamese advertisements. } \\
\text { - Discuss typical places to shop across } \\
\text { cultures and cultural factors that influence } \\
\text { shopping habits of Vietnamese and English } \\
\text { people. } \\
\text { - Discuss positive and negative effects of } \\
\text { online shopping on people's lives in } \\
\text { learners' country. }\end{array}$ \\
\hline $\begin{array}{l}\text { Men and } \\
\text { women }\end{array}$ & $\begin{array}{l}\text { - Describe personalities of boys and } \\
\text { girls with different adjectives. } \\
\text { - Discuss differences between boys } \\
\text { and girls from the facts about boys. } \\
\text { - Discuss gender differences and } \\
\text { the equality between men and } \\
\text { women in different areas in the past } \\
\text { and present. }\end{array}$ & $\begin{array}{l}\text { - Reflect on cultural stereotypes in } \\
\text { personalities and behaviours of boys and } \\
\text { girls across cultures. } \\
\text { - Deal with people from other cultures who } \\
\text { behave differently. } \\
\text { - Reflect on cultural stereotypes on gender } \\
\text { differences and gender roles and the equality } \\
\text { between men and women in different areas } \\
\text { in learners' culture and English culture. }\end{array}$ \\
\hline $\begin{array}{c}\text { Festivals and } \\
\text { holidays }\end{array}$ & $\begin{array}{l}\text { - Classify different festivals and } \\
\text { holidays into different types. } \\
\text { - Discuss holiday preferences of } \\
\text { British people. } \\
\text { - Compare ways of entertaining } \\
\text { guests in Japan, Spain and the USA } \\
\text { with those in learners' culture. } \\
\text { - Compare ways of entertaining } \\
\text { customers by businesspeople in } \\
\text { some countries with learners' } \\
\text { culture. } \\
\text { - Discuss the ways of entertaining } \\
\text { male clients by an American } \\
\text { businesswoman. }\end{array}$ & $\begin{array}{l}\text { - Compare different festivals and holidays } \\
\text { and reflect on cultural influence from the } \\
\text { ones imported from English-speaking } \\
\text { countries into learners' culture. } \\
\text { - Reflect on the lifestyle of British people } \\
\text { through the way they spend holidays and } \\
\text { their worries on holidays. } \\
\text { - Reflect on cultural differences in ways of } \\
\text { entertaining guests in Japan, Spain and the } \\
\text { USA in relation to learners' culture. } \\
\text { - Engage in a situation about a Vietnamese } \\
\text { couple's visit to an American home to } \\
\text { interpret and deal with different cultural } \\
\text { norms of receiving guests by people from }\end{array}$ \\
\hline
\end{tabular}




\begin{tabular}{|c|c|c|}
\hline & $\begin{array}{l}\text { - Apply criteria of a restaurant to } \\
\text { three situations (e.g. food, price, } \\
\text { service, atmosphere...). }\end{array}$ & $\begin{array}{l}\text { other cultures. } \\
\text { - Reflect on ways of entertaining male } \\
\text { clients by American businesswomen in } \\
\text { relation to learners' culture. } \\
\text { - Engage in different cultural practices of } \\
\text { socialising in eating out situations. }\end{array}$ \\
\hline $\begin{array}{c}\text { Exceptional } \\
\text { people }\end{array}$ & $\begin{array}{l}\text { - Discuss the impact of high } \\
\text { achievers in history on others. } \\
\text { - Discuss the impact of high } \\
\text { achievers in learners' country on } \\
\text { people in their country. } \\
\text { - Set up one's own guiding } \\
\text { principles. } \\
\text { - Discuss the definition of everyday } \\
\text { heroism } \\
\text { - Offer to make a difference in } \\
\text { three situations. }\end{array}$ & $\begin{array}{l}\text { - Discuss the cultural impact of high } \\
\text { achievers on people from other countries. } \\
\text { - Reflect on cultural differences regarding } \\
\text { the concept of fame between learners' } \\
\text { culture and English culture. } \\
\text { - Discover the self and one's cultural } \\
\text { perspective in shaping one's guiding } \\
\text { principles. } \\
\text { - Reflect on cultural differences in the } \\
\text { concept of everyday heroism. } \\
\text { - Engage in a situation with a disabled } \\
\text { American student. }\end{array}$ \\
\hline Interpersonal & $\begin{array}{l}\text { - Discuss the purpose of } \\
\text { communication. } \\
\text { - Discuss different tips and ways of } \\
\text { communication to become a good } \\
\text { communicator. } \\
\text { - Give examples in which people } \\
\text { say one thing but mean something } \\
\text { else. } \\
\text { - Match the sentences to the } \\
\text { pictures of body language. } \\
\text { - Discuss the purpose of body } \\
\text { language. } \\
\text { - Describe reactions with different } \\
\text { expressions of the eyes. }\end{array}$ & $\begin{array}{l}\text { - Discuss the importance of intercultural } \\
\text { communication. } \\
\text { - Discuss rules and norms of interaction in } \\
\text { intercultural communication. } \\
\text { - Discuss ways to deal with challenges in } \\
\text { cross-cultural communication. } \\
\text { - Reflect on cultural misunderstandings in } \\
\text { three cross-cultural communication } \\
\text { situations. } \\
\text { - Reflect on different gestures across } \\
\text { cultures and how to react to unfamiliar } \\
\text { gestures in intercultural communication. } \\
\text { - Deal with eye contact in communication } \\
\text { with English people. }\end{array}$ \\
\hline Animals & $\begin{array}{l}\text { - Discuss different uses of animals } \\
\text { in people's life. } \\
\text { - Express opinions about ways of } \\
\text { treating animals and protecting } \\
\text { endangered animals. } \\
\text { - Express opinions about a school } \\
\text { letting pupils watch their pets being } \\
\text { killed on a farm. }\end{array}$ & $\begin{array}{l}\text { - Discuss kinds of pets in learners' country } \\
\text { and English-speaking countries. } \\
\text { - Discuss different ways of animal treatment } \\
\text { and protection in learners' culture and } \\
\text { English-speaking cultures. } \\
\text { - Reflect on the way an English school lets } \\
\text { pupils watch their pets being killed on a } \\
\text { farm in relation to learners' culture. }\end{array}$ \\
\hline
\end{tabular}




\begin{tabular}{|c|c|c|}
\hline & $\begin{array}{l}\text { - Find a suitable pet for different } \\
\text { situations. } \\
\text { - Compare the treatment of pets in } \\
\text { Britain to that in learners' country. }\end{array}$ & $\begin{array}{l}\text { - Reflect on the choice of pets in different } \\
\text { situations in the target culture. } \\
\text { - Reflect on cultural differences in the } \\
\text { treatment of pets in Britain and learners' } \\
\text { culture, and engage in a situation about an } \\
\text { imprisonment of a woman in the US for } \\
\text { maltreatment of a dog. }\end{array}$ \\
\hline Feelings & $\begin{array}{l}\text { - Describe one's pet hates (dislikes) } \\
\text { using different expressions } \\
\text { - Describe one's fears and phobias } \\
\text { using a vocabulary list. } \\
\text { - Discuss ways to help a person } \\
\text { overcome phobia in learners' home } \\
\text { country. }\end{array}$ & $\begin{array}{l}\text { - Discuss different pet hates across cultures } \\
\text { and how to deal with foreigners' pet hates. } \\
\text { - Reflect on cultural differences in fears and } \\
\text { phobias of Vietnamese and English people. } \\
\text { - Reflect on how a phobia can be treated } \\
\text { differently in another culture through a story } \\
\text { of a little girl in Britain. }\end{array}$ \\
\hline $\begin{array}{l}\text { Science and } \\
\text { Technology }\end{array}$ & $\begin{array}{l}\text { - Express opinions about } \\
\text { statements about computers and the } \\
\text { Internet. } \\
\text { - Discuss positive and negative } \\
\text { consequences of some scientific } \\
\text { events. } \\
\text { - Discuss the importance of some } \\
\text { technological inventions. } \\
\text { - Reflect on how a practice of an } \\
\text { American religious group without } \\
\text { modern technology influences their } \\
\text { way of life. }\end{array}$ & $\begin{array}{l}\text { - Discuss the influence of the Internet on } \\
\text { communication among people from different } \\
\text { cultural backgrounds. } \\
\text { - Reflect on different cultural values in some } \\
\text { scientific events between learners' culture } \\
\text { and English-speaking cultures. } \\
\text { - Discuss how some technological } \\
\text { inventions have become cultural phenomena } \\
\text { in learners' culture. } \\
\text { - Reflect on the cultural values of a lifestyle } \\
\text { of an American religious group without } \\
\text { modern technology. }\end{array}$ \\
\hline The best age & $\begin{array}{l}\text { - Describe commandments of } \\
\text { kindergarten in learners' home } \\
\text { country. } \\
\text { - Discuss what children learn in } \\
\text { kindergarten from a text. } \\
\text { - Talk about the likes and dislikes } \\
\text { at one's present age and the choice } \\
\text { of an ideal age. } \\
\text { - Discuss the concept of old age } \\
\text { and the treatment of the elderly in } \\
\text { learners' home country. }\end{array}$ & $\begin{array}{l}\text { - Compare commandments of kindergarten } \\
\text { in learners' country with those in England. } \\
\text { - Reflect on different values of kindergarten } \\
\text { education between learners' home country } \\
\text { and England. } \\
\text { - Explore the self at one's present age and } \\
\text { the choice of an ideal age across cultures. } \\
\text { - Reflect on cultural differences in the } \\
\text { treatment of the elderly between learners' } \\
\text { culture and English culture. } \\
\text { - Reflect on the challenge of a cultural clash } \\
\text { in a situation about an old Vietnamese man } \\
\text { living in a nursing home in California. }\end{array}$ \\
\hline
\end{tabular}




\subsection{Research process and procedures}

This section will describe the research process and procedures of the third phase of the study including piloting, ethical considerations, and data collection methods.

\subsubsection{Piloting}

The piloting involved the ICI and one intercultural lesson. It was conducted in Vietnam in classes that were not the ones in the main study and took place in the first and second weeks before the actual data collection period. The ICI was piloted twice with 80 students who had a similar background with those who actually participated in the main study (i.e., second-year students, same age range, etc.). The students completed the ICI in class and offered their feedback in response to the same questions used in section 4.4.1, chapter IV. Through piloting, questions with overlapping content were removed and abstract ideas were revised in a more concrete way to facilitate students' understanding. As no student rated their intercultural competence at the extremely high level on Fantini's (2009) six-point scale $(0=$ not at all; 5=extremely high), the ICI was revised to a 5 -point scale $(1=$ not at all; $5=$ very well). An intercultural lesson was also piloted in an English speaking class with the same level as the one that was used for the main study.

\subsubsection{Ethical considerations}

The study had obtained the approval of the Human Ethics Committee (HEC) from Victoria University of Wellington for the whole study (refer to Appendix 2). Before the data collection started, I provided all the teacher and student participants with information sheets (Appendices 14 and 15) and consent forms (refer to Appendix 5). I also provided the students in both classes with a research schedule (Appendix 16) for them to follow the research process more easily. I clearly explained every important point in the research schedule and the students had a chance to ask questions about anything unclear to them. I also talked about my role as a non-participant observer in the class so as not to disturb their learning. 


\subsubsection{Principles for selecting the Standard and Intercultural classes}

A randomisation of the participants into two groups for an experiment would be ideal

as it facilitates "control for extraneous characteristics of the participants that might influence the outcomes" (Creswell, 2005, p.284). However, this randomisation was not feasible in the setting of this study because I had to depend completely on the learning schedule of the university where the research was conducted. A quasiexperimental design was therefore adopted. Within this kind of research design, the students' learning was not interfered with or disrupted due to the reassignment of the students into experimental and control groups. In addition, it was less likely to meet resistance from the teacher who would not feel under pressure because of time taken from classes as the curriculum was already overloaded.

Two intact and equivalent classes were therefore chosen as the ST class and the IC class. Mackey and Gass (2005) argue that intact classes have the advantage of enhancing the face validity of the research. The ST class was taught first, followed by the IC class in order to minimize the carry-over effect of intercultural teaching by the same teacher. It was important that the students in these two intact classes had a similar background before an empirical study could be conducted. In order to make both classes comparable, the following issues were taken into consideration:

(1) Both classes had similar backgrounds in terms of the students' history of learning English. In fact, they had been randomly assigned into different classes in the first year based on their university entrance examination scores. All of them were second-year students who majored in English for Teacher Education and had quite similar level of English proficiency.

(2) Both classes were taught by the same EFL teacher over the teaching period.

(3) Both classes used the same speaking material.

(4) Both classes received the teacher's instruction on the same day.

\subsubsection{Data collection methods}

The third phase of the study took place over a period of fourteen weeks from 23 August to 30 November, 2009 using the following methods of data collection: 
(1) Intercultural Competence Inventory (pre-test and post-test)

(2) Classroom observations

(3) Reflective journals

(4) Case studies

(5) Self-evaluation questionnaire

(6) Student focus-group interviews

The reasons for the combination of various methods for data collection in the present study correlate with Deardorff's (2004) study with top intercultural scholars and administrators. Deardorff shows that the mixture of quantitative and qualitative measures is considered the best way to assess intercultural competence; the participants agreed most with the use of case studies and interviews, followed by analysis of narrative diaries, self-report instruments and observation by others. Therefore, my empirical study adopted both quantitative and qualitative measures of ICC with case studies, interviews, reflective journals, IC Inventory and classroom observations as data collection methods for the intercultural intervention. The combination of these methods aimed to provide more comprehensive accounts of intercultural phenomena (Fantini, 2006; Straffon, 2003) and reveal more layers and nuances in the development of intercultural competence (Sinicrope et al., 2007).

\subsubsection{Intercultural Competence Inventory}

The Intercultural Competence Inventory (ICI) (Appendix 17) was adapted from Fantini's (2009) Assessment of Intercultural Competence Form (AIC). As Fantini's original AIC was designed for students during an intercultural sojourn in the host country, it was adapted to be used for students in the classroom in the present study. The statements in the ICI were paraphrased in the students' first language to make the questions more understandable for them. The ICI was used as a pre-test and a posttest for assessment of the differences in the development of the learners' intercultural competence between the two classes. The students were asked to rate their competency on a five-point Likert scale (1=not at all; 5=very well) for the four dimensions of IC that include Knowledge, Attitude, Skills and Awareness. It took about 20 minutes for the students to complete the ICI. 
The ICI was validated by reliability analysis to check the internal consistency estimates of reliability of the pre-test and post-test in each class. Cronbach's alpha $(\alpha)$ is calculated for each dimension of the ICI as it is the most commonly used measure of the internal consistency reliability in questionnaire research (Brown, 2001). The Cronbach's alpha $(\alpha)$ for the four dimensions of the ICI - Knowledge, Attitudes, Skills and Awareness in the pre-test of the ST class were .728, .814, .819 and .762 respectively (Table 7.5 ) and in the pre-test of the IC class were $.801, .806, .846$ and .826 respectively.

TABLE 7.5

Reliability analysis of the pre-test in the Standard class

\begin{tabular}{|c|c|c|c|c|c|}
\hline IC dimension & Question & $\begin{array}{l}\text { Scale mean if } \\
\text { item deleted }\end{array}$ & $\begin{array}{l}\text { Scale variance if } \\
\text { item deleted }\end{array}$ & $\begin{array}{l}\text { Cronbach's } \\
\text { alpha if item } \\
\text { deleted }\end{array}$ & $\begin{array}{c}\text { Cronbach's } \\
\text { alpha }\end{array}$ \\
\hline \multirow{9}{*}{ Knowledge } & Q1 & 19.29 & 16.427 & .686 & \multirow{9}{*}{$\alpha=.728$} \\
\hline & Q2 & 20.05 & 17.294 & .698 & \\
\hline & Q3 & 20.00 & 16.811 & .693 & \\
\hline & $\mathrm{Q} 4$ & 20.00 & 15.784 & .684 & \\
\hline & Q5 & 20.21 & 17.684 & .725 & \\
\hline & Q6 & 20.42 & 16.845 & .704 & \\
\hline & Q7 & 20.32 & 18.060 & .723 & \\
\hline & Q8 & 19.76 & 16.888 & .697 & \\
\hline & Q9 & 19.53 & 17.499 & .724 & \\
\hline \multirow{7}{*}{ Attitudes } & Q10 & 19.45 & 17.767 & .781 & \multirow{7}{*}{$\alpha=.814$} \\
\hline & Q11 & 19.84 & 18.028 & .788 & \\
\hline & Q12 & 19.74 & 15.983 & .759 & \\
\hline & Q13 & 19.68 & 17.087 & .779 & \\
\hline & Q14 & 19.89 & 17.881 & .784 & \\
\hline & Q15 & 19.32 & 19.357 & .810 & \\
\hline & Q16 & 18.97 & 20.243 & .820 & \\
\hline \multirow{5}{*}{ Skills } & Q17 & 9.66 & 6.610 & .785 & \multirow{5}{*}{$\alpha=.819$} \\
\hline & Q18 & 8.74 & 6.956 & .820 & \\
\hline & Q19 & 9.08 & 6.453 & .779 & \\
\hline & Q20 & 9.74 & 5.875 & .750 & \\
\hline & Q21 & 9.95 & 6.862 & .777 & \\
\hline \multirow{9}{*}{ Awareness } & Q22 & 24.53 & 18.797 & .732 & \multirow{9}{*}{$\alpha=.762$} \\
\hline & Q23 & 25.89 & 17.448 & .724 & \\
\hline & Q24 & 25.00 & 19.622 & .749 & \\
\hline & Q25 & 25.18 & 17.506 & .723 & \\
\hline & Q26 & 25.58 & 18.250 & .740 & \\
\hline & Q27 & 25.11 & 18.853 & .742 & \\
\hline & Q28 & 25.95 & 17.349 & .722 & \\
\hline & Q29 & 25.18 & 19.452 & .775 & \\
\hline & Q30 & 25.37 & 18.077 & .746 & \\
\hline
\end{tabular}


The Cronbach's alpha $(\alpha)$ for Knowledge, Attitudes, Skills and Awareness in the posttest of the ST class were $.678, .645, .626$ and .647 respectively, and in the post-test of the IC class were $.867, .689, .768$ and .713 respectively. The reliability statistics show that the pre-test and post-test in the two classes were reliable for measuring learners' intercultural competence as Cronbach's alpha from 0.6 and above is an acceptable level of reliability (Peterson, 1994; Slater, 1995).

\subsubsection{Classroom observations}

During the nine-week teaching period, eighteen classroom observations were conducted in both classes. Multiple observations conducted in both classes aimed at developing a "more multilayered understanding" of the participants and their context (Mackey and Gass, 2005, p.176). Each lesson in each class lasted for about 90 minutes. All lessons were audio-recorded and classroom notes were taken regarding student performance of cultural learning in each lesson. The classroom observations were used to interpret the students' reflections in their journals or interviews.

\subsubsection{Reflective journal}

The study used a journal-centred approach to culture learning. The use of reflective journals in this study had a dual role as they were both a tool for measuring learners' intercultural competence and also a crucial part of the intervention. Learner diaries or journals have been used as a suitable vehicle for process research, especially in investigations of affective factors which cannot be observed by tests or experiments (McDonough and McDonough, 1997). Reflective journal is referred to as a kind of autoethnography, which is "an autobiographic genre of writing that displays multiple layers of consciousness, connecting the personal to the cultural" (Kumaravadivelu, 2008, p.184). Autoethnography is an appropriate culture teaching method as it provides learners with opportunities to critically reflect on the target culture as well as to re-evaluate their own cultural self (Aubrey, 2009). Deardorff $(2006,2008)$ states that the learner journal is a valuable tool as it can "encourage students' mindfulness and process orientation needed for intercultural competence development" as well as "help hone the necessary critical thinking skills of relating, evaluating and 
synthesizing" (Deardorff, 2008, p.45). Various purposes for using reflective journals are given by Moon (1999) as follows:

To deepen the quality of learning, in the form of critical thinking or developing a questioning attitude

To enable learners to understand their own learning process

To increase active involvement in learning and personal ownership of learning

To enhance professional practice or the professional self in practice

To enhance the personal valuing of the self towards self-empowerment

To enhance creativity by making better use of intuitive understanding

To free-up writing and the representation of learning

To provide an alternative 'voice' for those not good at expressing themselves

To foster reflective and creative interaction in a group

(Moon, 1999, pp.188-194)

In the present study, students in both classes were asked to write three reflective journals (Appendix 18) over a period of nine weeks. Keeping a reflective journal over the nine-week teaching period encouraged the students to reflect on their evolving intercultural competence. The journal consists of a descriptive part in which students described their culture-related activities in the last three lessons and a reflective part in which students expressed their thoughts and attitudes about these activities. To ensure that the students would write their reflections in manageable amounts, three suggested questions were provided as follows:

(1) Describe some specific culture-related activities that you recall in your last three English lessons.

(2) What were your thoughts and attitudes about the specific activities in each lesson? (e.g., Which activity made you think, surprised or interested you most? How? Why?)

(3) What, if anything, did you learn from each of these activities in each lesson? (e.g., about your own culture, English-speaking cultures, communicating with native English speakers, communicating across cultures, etc.) 
All these questions were clearly explained to the students at the beginning of the teaching period. Students were asked to hand in each journal after three finished lessons. The corpus of the learner journals is summarised in Table 7.6.

TABLE 7.6

The learner journal corpus

\begin{tabular}{ll}
\hline Learner journal & Characteristics \\
\hline Total number of journals & 213 journals (1 journal / student / every 3 lessons) \\
Total number of students & 71 students \\
Medium & handwriting \\
Content & reflections on culture-related activities in lessons \\
Text type & informal reflections \\
Language & learners' first language \\
Time & 9 weeks \\
\hline
\end{tabular}

For the sake of the research, the students' first language (L1) was used in the reflective journals. There were a variety of reasons for this purpose. First, the use of L1 was supported in many previous studies (Anton, DiCamilla and Lantolf, 2003; Bauer, DeBenedette, Furstenberg, Levet and Waryn, 2006; O’Dowd, 2003). L1 can act as a psychological mediating tool in L2 learning (Anton et al., 2003). Second, the use of L1 produces positive results as students are put on an equal linguistic footing when differences in their proficiency levels in the foreign language are eliminated and they can express their views fully and in detail without being limited by variation of linguistic abilities (Bauer et al., 2006). Third, the use of L1 also promotes learners' reflections on their cultural understanding and engages them in the process of interpretation and discovery without being constrained by their L2 knowledge (Elola and Oskoz, 2008).

\subsubsection{Case studies}

The study also used the case study approach as a guide to investigate the learners' intercultural competence development. The case study was chosen as a research method for the following reasons: 
The case study is an excellent method for obtaining a thick description of a complex social issue embedded within a cultural context. It offers rich and in-depth insights that no other method can yield, allowing researchers to examine how an intricate set of circumstances come together and interact in shaping the social world around us...[C]ase studies display a high degree of completeness, depth of analysis and readability, and they are effective in generating new hypotheses, models and understandings about the target phenomena (Dornyei, 2007, p.155).

Stake (2005) distinguishes three types of case study:

(a) The 'intrinsic case study' is undertaken to understand the intriguing nature of a particular case. The case is of interest as it illustrates its own value or speciality;

(b) The 'instrumental case study' provides insight into a wider issue while the actual case is of secondary interest; it facilitates our understanding of something else;

(c) The 'multiple or collective case study' involves a number of cases that are studied jointly in order to investigate a phenomenon or general condition; a multiple case study is therefore an instrumental case study extended to several cases.

Referring to Stake's classification of case studies above, the case studies in the present study belonged to the second type, i.e., the instrumental case study. These case studies provide further insight into differences between the two classes concerning the learners' intercultural competence development. The process of selection and data collection for the case studies are described below.

\section{(1) Principles for case study selection}

Two students from each class were selected for the case studies. This was done on the basis of the intercultural (IC) scores of the pre-test in each class. An average percentile for the IC scores of the pre-test was calculated for all students in both classes and their scores were then divided into three IC score groups: high, medium and low. To differentiate between the students in the case studies in each class, one 
student was randomly chosen in the low IC score group and another in the high IC score group. The principles for case study selection are given in Table 7.7.

TABLE 7.7

Principles for case study selection

\begin{tabular}{lccc}
\hline Class & $\begin{array}{c}\text { Low } \\
\text { IC score average }\end{array}$ & $\begin{array}{c}\text { Medium } \\
\text { IC score average }\end{array}$ & $\begin{array}{c}\text { High } \\
\text { IC score average }\end{array}$ \\
\hline ST class & $37.1-52.0$ & $52.6-60$ & $60.6-82.3$ \\
IC class & $29.1-51.4$ & $53.1-58.3$ & $59.4-77.7$ \\
\hline
\end{tabular}

(2) Demographic information of case study students

The pseudonyms below are used for the case study students. Binh and Phuoc belonged to the ST class; Thanh and Ngoc belonged to the IC class. Binh and Thanh had low IC scores, while Phuoc and Ngoc had high IC scores.

Binh - a female participant aged 19. She comes from a mountainous region where there are limited conditions for English learning. Due to her bad health when she was at high school, she often had to stay at home. She encountered different learning styles when she entered the university and she was surprised at the frequent use of English in class. She is not very happy with her current English knowledge.

Phuoc - a female participant aged 20. She comes from a rural area where conditions for learning English are not good. She has been learning English for five years since she was 16 years old at high school. Her troubles in learning English are mainly linked to grammar, pronunciation, vocabulary, listening and speaking skills. She wants to become a good teacher of English in the future.

Thanh - a female participant aged 20. She comes from a poor rural area in Vietnam where conditions for learning English are not good. She has been learning English for eight years since high school. She learns English because she wants to use it in her future job as well as in daily life. 
Ngoc - a female participant aged 19. She comes from a rural area in Vietnam. She has learned English since grade 6 but her learning was discontinued due to lack of teachers of English. She used to learn only grammar at secondary school. She could not improve her speaking of English as her teachers spoke a lot of Vietnamese in the classroom. She does not feel confident enough to communicate with foreigners as she feels her social and cultural knowledge is inadequate and she is afraid of making mistakes in communication.

\section{(3) Data collection methods for case studies}

The case studies were conducted using two methods of data collection: reflective journals and interviews. Each case study student wrote three reflective journals like the other students over the nine-week teaching period. Each case study student was also interviewed every two weeks during the teaching period. As there were nine lessons all together, the first interview dealt with three lessons while the other interviews dealt with two lessons each. Each interview lasted for about 20 minutes and was arranged with the students at an appropriate time, usually after the class or the following day so that the students still had the lessons fresh in their mind. To triangulate with data from the learners' reflective journals, the interviews used the main questions in the journals (see section 7.5.4.3). Other questions were developed from the students' responses in the interviews. The data from the interviews and reflective journals will support each other to produce a more precise picture about each case study student's development of intercultural competence across the lessons.

\subsubsection{Self-evaluation questionnaire}

At the end of the nine-week teaching period, all students in both classes completed a short self-evaluation questionnaire (Appendix 19). The purpose of this questionnaire was to examine how the students perceived intercultural language learning. The selfevaluation questionnaire consisted of nine questions that the students responded to on the basis of a five-point Likert scale ( $1=$ strongly disagree; $5=$ strongly agree). To ensure the consistency of students' response, negative and positive questions were counterbalanced in the questionnaire. The summary of the self-evaluation questionnaire is given in Table 7.8. 
TABLE 7.8

Summary of self-evaluation questionnaire

\begin{tabular}{cl}
\hline Question & Content \\
\hline Q1 & Insight into aspects of one's own culture \\
Q2 & Insight into aspects of the target language culture \\
Q3 & $\begin{array}{l}\text { Development of critical thinking about aspects of one's own and the target language } \\
\text { culture }\end{array}$ \\
Q4 & Impact of one's own perspectives on understanding other cultures \\
Q5 & Awareness of the relationship between language and culture \\
Q6 & Approach to EFL learning \\
Q7 & Effect of journal writing on culture learning \\
Q8 & Motivation for learning English \\
Q9 & Confidence in intercultural interactions \\
\hline
\end{tabular}

\subsubsection{Student focus-group interviews}

At the end of the teaching period, ten students from the IC class participated voluntarily in two focus-group interviews, each of which consisted of five students and lasted for about 30 minutes. The interview schedule can be found in Appendix 20. The student focus-group interviews were conducted to provide extra information about the learners' experience of intercultural language learning.

\subsubsection{Summary of data collection methods}

The data collection methods are summarised in Table 7.9. 
TABLE 7.9

Summary of data collection methods

\begin{tabular}{lll}
\hline Methods of data collection & Participants & Frequency \\
\hline Intercultural Competence Inventory & ST class and IC class & 71 pre-tests and 71 post-tests \\
Classroom observations & ST class and IC class & $\begin{array}{l}9 \text { lessons / class / } 9 \text { weeks } \\
90 \text { minutes / lesson }\end{array}$ \\
& ST class and IC class & 213 journals \\
Reflective journals & 2 case study students/ class & $\begin{array}{l}4 \text { interviews/student } \\
20-30 \text { minutes/interview }\end{array}$ \\
Case study & & 71 questionnaires \\
Self-evaluation questionnaire & ST class and IC class & 2 focus groups \\
Focus group interviews & 10 students in IC class & 30 minutes / interview \\
& & \\
\hline
\end{tabular}

\subsection{Data analysis methods}

The data analysis methods for the third phase of the study involve the following:

(a) Descriptive statistics

(b) Content analysis

Each of these methods is described in detail as follows.

\subsubsection{Descriptive statistics}

Descriptive statistics involved the reliability analysis of the ICI, independent t-tests for the pre-test and the post-test and the self-evaluation questionnaire. The descriptive statistics involved the following:

(1) Reliability analysis was conducted to validate the four IC components (Knowledge, Attitudes, Skills and Awareness) of the pre-test and post-test.

(2) Independent t-tests were conducted with the pre-test and post-test to examine the comparability of both classes at the beginning of the teaching period and whether there was a significant development of the learners' intercultural competence in the IC class after the intercultural intervention. 
(3) The Repeated Measures Logistic Regression and the Generalized Estimating Equations were conducted to examine the relationship between the variables in the learners' reflective journals.

(4) Independent t-tests were conducted with the self-evaluation questionnaire to examine whether there was a significant impact of the intercultural lessons on the learners' experience of intercultural language learning in the IC class. The negative sentences (questions $2,4,7,8$ ) of the questionnaire were scored in the reverse way to ensure consistency with the positive questions.

\subsubsection{Content analysis}

This section describes the approaches to content analysis that the study adopted and details the process in which the qualitative data was coded. The inter-rater reliability of the data coding is also reported.

\subsubsection{Approaches to content analysis}

Directed content analysis (Hsieh and Shannon, 2007) was chosen as the method of data analysis for the student's reflective journals, case studies and student focus-group interviews. Coding categories were derived from both the existing theory and the data itself. The aim of using this approach was to validate and extend a conceptual framework or theory as the existing theory can be supported, refined, extended or enriched (ibid). This is the main strength of the directed approach to content analysis that this study adopted.

At the beginning of the analysis, all relevant texts in the students' reflective journals and case studies were first highlighted according to the research concerns and then translated into English for coding. Extract samples of the learners' reflective journals are given in Appendix 21. To reduce the large amount of qualitative data to be manageable for in-depth analysis, the data from six topics in the nine lessons was selected for analysis, including (1) men and women; (2) festivals and holidays; (3) interpersonal communication; (4) animals; (5) kindergarten education ; and (6) the elderly. The topics were selected on the basis of their suitability for intercultural competence depth. A mixture of quantitative and qualitative approaches was used for 
the content analysis of the learners' reflective journals. The quantitative content analysis was first conducted for an overview of differences between the two classes (Appendix 22). This quantitative analysis used the same quantitative method in the study of Elola and Oskoz (2008) that involved the analysis of differences in the blogs made by the study abroad and at home students. The qualitative content analysis was then presented with the synthesis of data from the six topics and highlighted examples for illustrations. The data from the case studies had only qualitative content analysis.

\subsubsection{Coding scheme}

To come up with a final coding scheme for data analysis (Table 7.10), a systematic and principled approach to understanding the process of students' intercultural competence acquisition was developed and applied through a refine-trial-revise-testapply process.

First, existing theory and relevant research findings of intercultural language learning were used to identify key concepts as initial coding categories. Subcategories were also identified under the main categories.

Second, the data transcripts were coded using the predetermined codes. Any texts that did not fit the predetermined codes were given a new code.

Third, the initial coding scheme was then revised and refined. A short definition of each code was also provided so that any piece of data could be fitted into the right code.

Finally, all the codes were then organised into a coding scheme that formed the basis for the data analysis.

The coding scheme was developed from the literature of intercultural competence and inspired by the ideas of Bennett (1993), Byram (2006), Deardorff (2008) and Skopinskaja (2009). The coding scheme was revised and refined again through collaboration with a second rater. QSR N'Vivo (version 8.0) was used to classify raw data into the categories of the coding scheme for qualitative analysis. 
TABLE 7.10

Coding scheme for data analysis

\begin{tabular}{|c|c|c|c|}
\hline $\begin{array}{c}\text { IC } \\
\text { component }\end{array}$ & Low level of IC & Medium level of IC & High level of IC \\
\hline \multirow{4}{*}{$\begin{array}{l}\text { A. } \\
\text { reultural } \\
\text { vareness }\end{array}$} & A1.1 General knowledge & $\begin{array}{l}\text { A2.1. Understanding of the } \\
\text { other culture }\end{array}$ & $\begin{array}{l}\text { A3.1 Communicative } \\
\text { awareness }\end{array}$ \\
\hline & $\begin{array}{l}\text { Learners state only facts } \\
\text { or general information } \\
\text { about an aspect of the } \\
\text { target culture. }\end{array}$ & $\begin{array}{l}\text { Learners explain or evaluate } \\
\text { an aspect of the target culture } \\
\text { with understanding of its } \\
\text { underlying cultural values. }\end{array}$ & $\begin{array}{l}\text { Learners anticipate } \\
\text { culturally appropriate } \\
\text { behaviours in dealing } \\
\text { with the target culture. }\end{array}$ \\
\hline & $\begin{array}{l}\text { Al.2 Cultural } \\
\text { comparison }\end{array}$ & A2.2.Cultural self-awareness & $\begin{array}{l}\text { A3.2 Ethnorelative } \\
\text { awareness }\end{array}$ \\
\hline & $\begin{array}{l}\text { Learners give simple } \\
\text { comparison of cultural } \\
\text { similarities and/or } \\
\text { differences between their } \\
\text { own and the target } \\
\text { culture. }\end{array}$ & $\begin{array}{l}\text { Learners explain or evaluate } \\
\text { an aspect of their own culture. } \\
\text { They may also suggest what } \\
\text { should be done in their culture } \\
\text { by referring to the good values } \\
\text { of the target culture. }\end{array}$ & $\begin{array}{l}\text { Learners understand } \\
\text { cultures relative to one } \\
\text { another within a cultural } \\
\text { context by } \\
\text { acknowledging different } \\
\text { values in each culture. }\end{array}$ \\
\hline & $\begin{array}{l}\text { B1. Ethnocentric } \\
\text { attitudes }\end{array}$ & $\begin{array}{l}\text { B2.Openness, respect and } \\
\text { tolerance }\end{array}$ & $\begin{array}{l}\text { B3. } \\
\text { attitudes }\end{array}$ \\
\hline $\begin{array}{l}\quad \text { B. } \\
\text { Intercultural } \\
\text { Attitudes }\end{array}$ & $\begin{array}{l}\text { Learners indicate that the } \\
\text { worldview of their own } \\
\text { culture is central to all } \\
\text { reality. They judge an } \\
\text { aspect of the target } \\
\text { culture from their own } \\
\text { cultural perspective. }\end{array}$ & $\begin{array}{l}\text { Learners show curiosity and } \\
\text { openness, readiness to suspend } \\
\text { disbelief about other cultures } \\
\text { and belief about one's own. } \\
\text { They also accept lack of } \\
\text { clarity and ambiguity and are } \\
\text { able to deal with it } \\
\text { constructively. }\end{array}$ & $\begin{array}{l}\text { Learners show empathy } \\
\text { with other cultural } \\
\text { identities by considering } \\
\text { the other's perspective in } \\
\text { their judgment. They are } \\
\text { also able to adopt a new } \\
\text { intercultural perspective } \\
\text { in dealing with different } \\
\text { cultures. }\end{array}$ \\
\hline $\begin{array}{l}\text { Generic } \\
\text { comments } \\
\text { (Non-IC) }\end{array}$ & \multicolumn{3}{|c|}{$\begin{array}{l}\text { Learners give generic comments or ideas that do not show any evidence of intercultural } \\
\text { awareness and attitudes. }\end{array}$} \\
\hline
\end{tabular}

\subsubsection{Units of analysis}

The unit of analysis is the basic unit of text to be coded for content analysis. It is used as a tool to scrutinize a data log (Lofland and Lofland, 1995). Defining the coding unit is one of the most fundamental and important decisions for analysis (Weber, 1990) as differences in the unit definition can affect coding decisions (De Wever, Schellens, Valcke and Van Keer, 2006). However, according to De Wever et al. 
(2006), it is difficult to choose an appropriate unit of analysis. To their knowledge, most authors do not mention arguments for selecting or determining the unit of analysis and there is no clear definition of the unit of analysis and reports of interrater reliability measures concerning the segmentation procedure. This corresponds with many previous studies on intercultural competence. For example, Liaw (2006) uses the entire entry of students' discussion in an online forum as a unit of analysis. She states that "while most entries demonstrated the characteristics of more than a single category, the researcher decided to list only the categorization which seemed to be more obvious than the others" (p.56). This definition of the unit of analysis and coding decisions based on what appeared "more obvious" are, however, highly subjective. Vogt (2006) analyses students' development of attitudes with regard to observable instances of Byram's (1997) learning objectives. This also causes difficulties in deciding what precise chunk of text to code into the learning objectives. To code students' blog entries, Elola and Oskoz (2008) use the units of analysis that "varied from short sentences to entire paragraphs" (p.464). This coding is too vague as no criteria for the choice of the sentences or paragraphs as the units of analysis were stated. Due to the absence of a definition of an appropriate unit of analysis in previous studies, no unit of analysis has been seen as sufficiently reliable, valid and efficient to achieve pre-eminence (Rourke, Anderson, Garrison and Archer, 1999). Consequently, Hew and Cheung (2003) claim that "the choice of the unit of analysis 'involves considerable compromise' (Krippendorf, 1980, p. 64) between meaningfulness, productivity, efficiency, and reliability" (p.255).

The units of analysis in the present study were carefully considered from a variety of units of analysis in the literature. For example, Mackey and Gass (2005) offer a list of coding units that can be used for oral and written data. These coding units include T-units, Suppliance in obligatory context (SOC) counts, CHAT convention, turns, utterances, sentences, communication units, tone units, speech units, idea units, clauses, S-nodes per sentence, type-token ratios and target-like used counts (p.231). Foster, Tonkyn and Widdlesworth (2000) propose to use speech unit (AS-unit) to measure spoken language. Berg (2009) also suggests seven major elements in written messages that can be counted in content analysis. These include words or terms, themes, characters, paragraphs, items, concepts and semantics (pp. 348-349). From these various units of analysis, an idea unit with categorical distinctions was chosen as the most suitable unit of analysis for the students' journal 
entries and case study students' interviews in this study. An idea unit is defined as "a chunk of information which is viewed by the speaker/writer cohesively..." (Kroll, 1977, p.85). Categorical distinctions "define units by their membership in class or category - by their having something in common" (Krippendorff, 2004, p.105). The idea unit used as the unit of analysis in this study was refined through the inter-rater reliability procedures and was conceptualised as follows:

An idea unit expresses one main concept which may have supporting ideas. The idea unit belongs to a semantic unit that can stand on its own. If the supporting ideas in an idea unit are representatives of different categories, the same idea unit may be coded into more than one category. Semantic units in the students' reflections are separated to form a unit of analysis for practical and analytical purposes and to represent each category in the coding scheme as accurately as possible (My definition).

Table 7.11 gives examples of the units of analysis coded for a data sample of the topic of 'Animals' in the learners' reflective journals.

TABLE 7.11

Examples of units of analysis (selected quotes from learners' reflective journals)

\begin{tabular}{|c|l|l|}
\hline $\begin{array}{c}\text { IC } \\
\text { components }\end{array}$ & \multicolumn{1}{|c|}{ Category } & \multicolumn{1}{c|}{ Unit of analysis } \\
\hline \multirow{5}{*}{$\begin{array}{c}\text { A. Intercultural } \\
\text { awareness }\end{array}$} & General knowledge & $\begin{array}{l}\text { Pets in Europe or England are treated equally or } \\
\text { even better than people. For example, in Australia, } \\
\text { people and pets stay in the same house and have } \\
\text { meals like family members. }\end{array}$ \\
\cline { 2 - 3 } & $\begin{array}{l}\text { Understanding of the other } \\
\text { culture }\end{array}$ & $\begin{array}{l}\text { In Vietnam, dogs at the same level as other animals, } \\
\text { but in Western countries, pets are ranked after } \\
\text { children but before women. This is why pets are } \\
\text { considered family members and have particular } \\
\text { importance; they are treated like people. }\end{array}$ \\
& $\begin{array}{l}\text { Every family in Canada has a pet. A family without } \\
\text { pets is considered to have no love and a family with } \\
\text { pets is full of love. This is a conception I am } \\
\text { particularly interested in. I have known that they } \\
\text { treat pets very well like children, but I did not think } \\
\text { they loved pets as family members. }\end{array}$ \\
\cline { 2 - 4 } & Cultural self-awareness & $\begin{array}{l}\text { A story told by the teacher in her study in Australia } \\
\text { makes me very surprised. In Australia, pets are } \\
\text { treated like children. This is completely different } \\
\text { from my country. This makes me think about the } \\
\text { treatment of pets in my country as so far I have seen } \\
\text { my family, friends and other people in my country }\end{array}$ \\
\hline
\end{tabular}




\begin{tabular}{|c|c|c|}
\hline & & $\begin{array}{l}\text { do not treat pets as well as Australians do. I think } \\
\text { this is a good cultural feature in the target culture. }\end{array}$ \\
\hline & Communicative awareness & $\begin{array}{l}\text { I learn to love pets as people in the target culture do. } \\
\text { If I have a chance to live in the target culture, I will } \\
\text { treat them like a person. It is because a normal } \\
\text { action towards pets in my culture may be } \\
\text { unacceptable in other cultures and we can be } \\
\text { punished for doing that. }\end{array}$ \\
\hline & Ethnorelative awareness & $\begin{array}{l}\text { Each country and each culture has different } \\
\text { treatment of pets. It is said that pets are treated better } \\
\text { than children in England. It is important to } \\
\text { understand that English people love pets so much } \\
\text { that they consider pets as a family member. In our } \\
\text { country, pets are not treated like that but they are } \\
\text { also loved. They simply have different roles. }\end{array}$ \\
\hline \multirow{3}{*}{$\begin{array}{l}\text { B. Intercultural } \\
\text { attitudes }\end{array}$} & Ethnocentric attitudes & $\begin{array}{l}\text { I feel shocked that pets are treated as equal to people } \\
\text { in English-speaking countries. Pets can sleep on the } \\
\text { sofa or in bed like people. This is hard to accept as it } \\
\text { is different in Asian countries. I do not like this as } \\
\text { pets in my country have a given position and role; it } \\
\text { is hard to treat them like people. }\end{array}$ \\
\hline & $\begin{array}{lll}\text { Openness, } & \text { respect } & \text { and } \\
\text { tolerance } & & \end{array}$ & $\begin{array}{l}\text { For pets in the target culture, we should treat them } \\
\text { like children; it is a normal thing when a meal } \\
\text { portion is shared between us and the pet. It does not } \\
\text { mean that the Australians do not respect us but it is } \\
\text { because pets are treated as a family member in } \\
\text { Australia. So try to accept it and do not feel insulted } \\
\text { as it is their culture which is different from ours. } \\
\text { From this perspective, we can build good relations } \\
\text { with them. }\end{array}$ \\
\hline & Ethnorelative attitudes & $\begin{array}{l}\text { People in Vietnam normally have pets like dogs to } \\
\text { look after the house. These animals have a more } \\
\text { practical use than pets in English-speaking countries } \\
\text { where they are treated like family members. We } \\
\text { therefore need to respect the way pets are treated in } \\
\text { those countries. }\end{array}$ \\
\hline $\begin{array}{l}\text { Non-IC } \\
\text { component }\end{array}$ & Generic comments & $\begin{array}{l}\text { I learn to love pets more as they are close friends of } \\
\text { humans. }\end{array}$ \\
\hline
\end{tabular}

\subsubsection{Inter-rater reliability}

To ensure the data coding for analysis was reliable, inter-rater reliability was assessed. Inter-rater reliability is a statistical tool used to measure the internal reliability of coding decisions, i.e., the extent to which the scores given by one rater on a measured variable correlate with the scores given by another rater (Gall, Gall and Borg, 2005). 
The inter-rater reliability of data coding for the students' journal entries was assessed with a data sample of the topic of 'Animals'. The data sample was rated by two raters, the researcher as Interrater 1 and another rater as Interrater 2. As the training and the experience of the raters are important for reliable coding (Neuendorf, 2002), the second rater was carefully chosen. The second rater was a researcher doing a $\mathrm{PhD}$ in Linguistics at Victoria University of Wellington with experience in discourse analysis. As her research project was on a related topic, this helped her understand the present study more easily. As a researcher, she was also familiar with data coding and inter-rater reliability. The assessment of the inter-rater reliability took place with three stages as follows:

\section{(1) Training session}

At the beginning of this training session, the second rater was provided with all the materials for the coding. She read the initial definition of the unit of analysis and the definitions of all the subcategories in the coding scheme. I gave her explanations whenever necessary. Then the second rater was provided with some examples for coding. First, she decided which main category a unit of analysis belonged to, i.e., intercultural awareness or intercultural attitudes. Then she decided which subcategory in the main category the unit of analysis went to, e.g., cultural self-awareness or understanding of the other culture. Finally, she coded the unit of analysis into that subcategory. During this training section, the second rater discussed the definition of the unit of analysis and some difficulties in identifying the units of analysis for coding.

The discussion with the second rater helped refine the definition of the unit of analysis and the initial coding scheme. The category of 'generic comments' was added in the coding scheme to refer to idea units that do not show any evidence of intercultural competence. The category 'flexibility' was combined into the category 'communicative awareness' as these categories were quite overlapping in the sense that both refer to how the students predicted their interculturally appropriate behaviours in contact with people of the target culture. The category 'ethnorelative views' was also separated into 'ethnorelative awareness' and 'ethnorelative attitudes' as this term involves both intercultural awareness and attitudes. 


\section{(2) Independent coding}

Based on the refined definition of the unit of analysis and the coding scheme, both raters independently coded a data sample that contained $10 \%$ of the whole data sample of the two classes. To calculate the inter-rater reliability of the two ratings, the confusion matrix of Hamilton, Gurak, Findlater, and Olive (2003), adapted by Marques and McCall (2005), was used. This confusion matrix for inter-rater reliability is given in Table 7.12. Hamilton et al. (2003) use the 'accurate rate' (AC) for the inter-rater reliability with the following formula: $A C=(a+d) /(a+b+c+d)$. Using the confusion matrix and the 'accurate rate' of Hamilton et al. (2003), the interrater reliability of the independent coding between the two raters for the two classes had the outcomes as shown in Table 7.13.

TABLE 7.12

Confusion matrix (Marques and McCall, 2005, p.453)

\begin{tabular}{|c|c|c|c|}
\hline & & \multicolumn{2}{|c|}{ Interrater 1 } \\
\hline & & Agree & Disagree \\
\hline \multirow{2}{*}{ Interrater 2 } & Agree & $\mathrm{a}$ & $\mathrm{b}$ \\
\cline { 2 - 4 } & Disagree & $\mathrm{c}$ & $\mathrm{d}$ \\
\hline
\end{tabular}

Notes:

$\mathrm{a}=$ the number of agreements that Interrater 1 listed in comparison with Interrater 2

$\mathrm{b}=$ the number of disagreements that Interrater 1 listed in comparison with Interrater 2

$\mathrm{c}=$ the number of disagreements that Interrater 2 listed in comparison with Interrater 1

$\mathrm{d}=$ the total number of disagreements that both interraters listed.

TABLE 7.13

Confusion matrix in independent coding

\begin{tabular}{|c|c|c|c|}
\hline & & \multicolumn{2}{|c|}{ Interrater 1 } \\
\hline & & Agree & Disagree \\
\hline \multirow{2}{*}{ Interrater 2 } & Agree & 57 & 10 \\
\cline { 2 - 4 } & Disagree & 8 & 18 \\
\hline
\end{tabular}

Inter-rater reliability for both classes: $\mathrm{AC}=(57+18) /(57+10+8+18)=80.6 \%$. 


\section{(3) Coding with consensus between the raters}

After the independent coding, the two raters met again to discuss any differences in an attempt to reach a consensus in the coding decisions. The outcomes of the coding with consensus between the raters are given in Table 7.14.

TABLE 7.14

Confusion matrix in coding with consensus

\begin{tabular}{|c|c|c|c|}
\hline & & \multicolumn{2}{|c|}{ Interrater 1 } \\
\hline & & Agree & Disagree \\
\hline \multirow{2}{*}{ Interrater 2 } & Agree & 69 & 2 \\
\cline { 2 - 4 } & Disagree & 2 & 4 \\
\hline
\end{tabular}

Inter-rater reliability for both classes with consensus: $\mathrm{AC}=(69+4) /(69+2+2+4)=$ $94.8 \%$. This outcome of the coding with consensus between the raters for both classes established the inter-rater reliability that was adopted for the coding of the remaining data in the students' reflective journals.

\subsection{Reliability and validity}

This section discusses the reliability and validity of the third phase of the study.

\subsubsection{Reliability}

Measures were taken to ensure that the study achieved a satisfactory standard of reliability. First, a detailed description of teacher and student participants, the context and conditions for the research was provided. Second, the study used multiple research methods for data collection to triangulate various sources of data, including the pre-test and post-test, classroom observations, reflective journals, student focusgroup interviews and case studies. All the primary data of the study were audiorecorded. Third, the pre-test and post-test in each class were validated by reliability analysis for the internal consistency estimates of reliability. Fourth, the self-evaluation questionnaire was designed with both positive and negative questions to ensure respondents' consistency. Fifth, the coding of qualitative data in the learners' reflective journals obtained a high inter-rater reliability for analysis. 
In brief, the reliability for the study was ensured by careful consideration regarding participants, research context, design and methods for data collection and analysis.

\subsubsection{Validity}

A number of steps were taken to ensure that the study achieved a satisfactory standard of validity. First, there was no bias in the selection of the two classes as they were chosen randomly from a number of speaking classes. Second, all the variables of the learner participants in the two classes were carefully taken into account. The profiles of the student participants in both classes were matched for age range, year of study, level of language proficiency and frequency of contact with native English speakers. Third, the case study students in both classes were selected on clear principles in order to make distinctions between them. Fourth, classroom observations were done in natural-classroom settings and took place in normal scheduled learning periods, which reflected accurately the reality of the teacher and student practices of language teaching and learning.

In brief, the validity for the study can be ensured by careful consideration regarding the selection of classes and learner participants for a quasi-experienced design.

\subsection{Limitations}

The present study had the following limitations.

First, the teacher who taught the IC class in the intercultural intervention had not been trained for intercultural language teaching. Although I provided the teacher with some key theory on intercultural language learning before the intercultural intervention and the teacher also had some intercultural experience from her study in Australia, this was not extensive. Through my classroom observations, I found that the teacher's traditional way of teaching still, to some extent, affected the way she conducted the intercultural lessons in the IC class. In addition, due to limited time allowance for each lesson, the teacher did not have enough time to engage the students in all the intercultural activities thoroughly. Consequently, the students did not reflect on all the intercultural activities in their reflective journals, which made it 
difficult to assess the whole process of the learners' intercultural competence acquisition.

Second, the intercultural lessons in the study were adapted from the existing lessons to adopt an intercultural stance on the basis of the five principles of intercultural language learning rather than being designed as new intercultural lessons for a specialised programme on intercultural language learning. These adapted intercultural lessons had to depend a lot on the linguistic content of the existing lessons as a requirement in the course outline to prepare the students for their final speaking test at the end of the semester. As a result, this constraint reduced the degree of interculturality involved in each lesson. In addition, as each lesson involved a different topic, the development of the learners' intercultural competence could be assessed only across the topics rather than over time.

Third, the students' intercultural attitudes reported in their reflective journals were mostly indirect and declarative and so were one step removed from the attitudes or skills they reflected on, although I had a chance to observe their attitudes through their discussions and role-plays in the lessons. The use of video recordings in this case would be helpful to offer a better interpretation about their actual attitudes towards a particular cultural issue they were discussing in the classroom.

Fourth, the interviews with the case study students in the third phase of the study were conducted right after the lessons before they wrote their reflective journals. If the case study students joined a follow-up interview that was developed on the basis of their reflections in the journals, they would have the chance to interpret their reflections in their journals and a better connection could be established between what they wrote in the journals and what they reported in the interviews. This would also help reduce the effect of the interviews on the learners' reflections in the journals.

\subsection{Summary}

This chapter has detailed all the research methods for data collection and analysis employed in the third phase of the study for an intercultural intervention in a tertiary EFL class. The study used both quantitative and qualitative approaches to data analysis. The methodological triangulation with various methods of data collection provided rich data to answer the research questions comprehensively and thoroughly. 
Measures were taken to ensure that the study achieved a satisfactory standard of reliability and validity. Some limitations were also discussed.

In the next chapter, I will report and discuss the results of the intercultural intervention. 


\section{Chapter VIII \\ THE INTERCULTURAL INTERVENTION: \\ RESULTS AND DISCUSSION}

\subsection{Introduction}

This chapter describes the results and discussion of the intercultural intervention in the third phase of this study. This phase involved an empirical study which investigated the effect of adopting an intercultural stance into English speaking lessons on the development of learners' intercultural competence. Data was collected using a pre-test and post-test, reflective journals, case studies, self-evaluation questionnaire, and student focus-group interviews. The empirical study addresses the following research questions (RQ):

RQ4: To what extent did the intercultural competence of students in the intercultural class develop compared to that of students in the standard class?

RQ5: What was the nature of the development of intercultural competence of students in the two classes?

RQ6: How did the students of the intercultural class perceive intercultural language learning?

There are five main sections in this chapter. Sections 8.2-8.4 present results for each research question, section 8.5 deals with the discussion of key points from the results, and section 8.6 covers the summary and conclusion.

\subsection{Development of the learners' intercultural competence}

This section addresses research question 4 which investigates the extent to which the students' intercultural competence developed in the Intercultural class (IC class) compared to that in the Standard class (ST class). The results report on the data collected on students' responses to the pre-test and post-test in the two classes. These tests used the Intercultural Competence Inventory (ICI) described in section 7.5.4.1 in 
chapter seven. The results of the pre-test and post-test in the two classes are given in Tables 8.1-8.4.

TABLE 8.1

Pre-test and post-test for intercultural knowledge

\begin{tabular}{|c|c|c|c|c|c|c|c|c|}
\hline \multirow{3}{*}{ Questions } & \multicolumn{4}{|c|}{ ST class $(\mathrm{N}=38)$} & \multicolumn{4}{|c|}{ IC class $(\mathrm{N}=33)$} \\
\hline & \multicolumn{2}{|c|}{ Pre-test } & \multicolumn{2}{|c|}{ Post-test } & \multicolumn{2}{|c|}{ Pre-test } & \multicolumn{2}{|c|}{ Post-test } \\
\hline & M & SD & $\mathbf{M}$ & SD & $\mathbf{M}$ & SD & M & SD \\
\hline $\begin{array}{l}\text { 1. I have basic knowledge of the } \\
\text { cultural component in the English } \\
\text { language. }\end{array}$ & 3.16 & .886 & 3.24 & .675 & 3.03 & .984 & 3.82 & .727 \\
\hline $\begin{array}{l}\text { 2. I have knowledge of the processes } \\
\text { of socialization in my own and the } \\
\text { target culture (e.g. formality, } \\
\text { interactional norms, taboos, etc.). }\end{array}$ & 2.39 & .790 & 2.92 & .673 & 2.70 & .728 & 3.33 & .924 \\
\hline $\begin{array}{l}\text { 3. I can contrast important aspects of } \\
\text { the target language and culture with } \\
\text { my own (e.g. ways of expressing, etc). }\end{array}$ & 2.45 & .860 & 2.89 & .798 & 2.24 & .969 & 3.18 & .882 \\
\hline $\begin{array}{l}\text { 4. I have knowledge of the national } \\
\text { memory of my own culture and how } \\
\text { its events are seen from the perspective } \\
\text { of other cultures. }\end{array}$ & 2.45 & 1.005 & 3.18 & .730 & 2.30 & .984 & 3.55 & .905 \\
\hline $\begin{array}{l}\text { 5. I have knowledge of the national } \\
\text { memory of the target culture and how } \\
\text { its events are seen from the perspective } \\
\text { of my own culture. }\end{array}$ & 2.24 & .943 & 2.32 & .775 & 1.82 & .882 & 3.00 & 1.031 \\
\hline $\begin{array}{l}\text { 6. I can cite important historical and } \\
\text { socio-political factors that shape my } \\
\text { own culture and the target culture. }\end{array}$ & 2.03 & .944 & 2.84 & .679 & 1.91 & .914 & 3.12 & .857 \\
\hline $\begin{array}{l}\text { 7. I can describe interactional } \\
\text { behaviours common among target } \\
\text { culture members in social and } \\
\text { professional areas (e.g., family roles, } \\
\text { team work, problem-solving, etc.) }\end{array}$ & 2.13 & .844 & 2.45 & .760 & 2.18 & 1.044 & 3.24 & .867 \\
\hline $\begin{array}{l}\text { 8. I can contrast my own behaviours } \\
\text { with those of target culture members in } \\
\text { important areas (e.g., social } \\
\text { interactions, daily routines, etc.) }\end{array}$ & 2.68 & .873 & 2.92 & .673 & 2.70 & 1.015 & 3.48 & .795 \\
\hline $\begin{array}{l}\text { 9. I have knowledge of social } \\
\text { distinctions and their principal markers } \\
\text { in my own and the target culture (e.g., } \\
\text { clothing, food, language variety, non- } \\
\text { verbal behaviour, etc). }\end{array}$ & 2.92 & .969 & 3.13 & .811 & 3.00 & 1.118 & 3.61 & 747 \\
\hline
\end{tabular}

Notes: $\mathrm{M}=\mathrm{Mean} ; \mathrm{SD}=\mathrm{Standard}$ Deviation. $\mathrm{M}$ and $\mathrm{SD}$ are calculated on a five-point scale (1-5). 
TABLE 8.2

Pre-test and post-test for intercultural attitudes

\begin{tabular}{|l|c|c|c|c|c|c|c|c|}
\hline \multicolumn{2}{|c|}{ Questions } & \multicolumn{3}{|c|}{ ST class (N=38) } & \multicolumn{3}{c|}{ IC class (N=33) } \\
\cline { 2 - 9 } & \multicolumn{2}{|c|}{ Pre-test } & \multicolumn{2}{c|}{ Post-test } & \multicolumn{2}{c|}{ Pre-test } & \multicolumn{2}{c|}{ Post-test } \\
\cline { 2 - 9 } & M & SD & M & SD & M & SD & M & SD \\
\hline $\begin{array}{l}\text { 10. I demonstrate willingness to seek } \\
\text { out or take up opportunities to engage } \\
\text { with the otherness in the target culture. }\end{array}$ & 2.97 & .664 & 2.87 & .875 & 2.73 & .674 & 3.33 & .957 \\
\hline $\begin{array}{l}\text { 11. I demonstrate interest in } \\
\text { discovering other perspectives on } \\
\text { interpretation of familiar and unfamiliar } \\
\text { phenomena both in my own and the } \\
\text { target culture and cultural practices. }\end{array}$ & 2.97 & .492 & 2.24 & .971 & 2.85 & .619 & 3.03 & .984 \\
\hline $\begin{array}{l}\text { 12. I demonstrate willingness to } \\
\text { question values or presuppositions in } \\
\text { cultural practices and products in one's } \\
\text { own environment. }\end{array}$ & 2.95 & .613 & 2.68 & .739 & 3.00 & .661 & 3.64 & .822 \\
\hline $\begin{array}{l}\text { 13. I demonstrate willingness to } \\
\text { understand differences in the } \\
\text { behaviours, values, attitudes, and styles } \\
\text { of target culture members. }\end{array}$ & 2.79 & .474 & 3.00 & .735 & 3.09 & .687 & 3.36 & 1.055 \\
\hline $\begin{array}{l}\text { 14. I demonstrate readiness to engage } \\
\text { with the conventions and rites of verbal } \\
\text { and non-verbal communication and } \\
\text { interaction in the target culture. }\end{array}$ & 2.92 & .632 & 2.55 & .891 & 2.67 & .645 & 3.09 & .980 \\
\hline $\begin{array}{l}\text { 15. I demonstrate readiness to deal with } \\
\text { different ways of perceiving, } \\
\text { expressing, interacting, and behaving in } \\
\text { the target culture. }\end{array}$ & 2.55 & .645 & 2.95 & .957 & 2.97 & .585 & 3.52 & .906 \\
\hline $\begin{array}{l}\text { 16. I demonstrate readiness to suspend } \\
\text { judgment of any strange behaviour and } \\
\text { appreciate different ways of } \\
\text { communicating and interacting } \\
\text { interculturally. }\end{array}$ & 2.74 & .860 & 3.39 & .595 & 2.91 & .723 & 3.79 & .960 \\
\hline
\end{tabular}

Note: M and SD are calculated on a five-point scale (1-5). 
TABLE 8.3

Pre-test and post-test for intercultural skills

\begin{tabular}{|l|c|c|c|c|c|c|c|c|}
\hline \multirow{2}{*}{ Questions } & \multicolumn{3}{c|}{ ST class (N=38) } & \multicolumn{3}{c|}{ IC class (N=33) } \\
\cline { 2 - 9 } & \multicolumn{2}{|c|}{ Pre-test } & \multicolumn{2}{c|}{ Post-test } & \multicolumn{2}{c|}{ Pre-test } & \multicolumn{2}{c|}{ Post-test } \\
\cline { 2 - 9 } & M & SD & M & SD & M & SD & M & SD \\
\hline $\begin{array}{l}\text { 17. I am able to interact appropriately } \\
\text { in a variety of different social situations } \\
\text { in the target culture (e.g. at work, in } \\
\text { public places, etc.) }\end{array}$ & 2.13 & .811 & 2.63 & .819 & 2.03 & 1.015 & 2.73 & 1.008 \\
\hline $\begin{array}{l}\text { 18. I am able to monitor my behavior } \\
\text { and its impact on my target culture } \\
\text { interlocutors. }\end{array}$ & 3.05 & .837 & 3.13 & .741 & 2.88 & 1.053 & 3.00 & 1.061 \\
\hline $\begin{array}{l}\text { 19. I am able to identify similarities } \\
\text { and differences between my language } \\
\text { and culture and those of the target } \\
\text { language and culture in order to ensure } \\
\text { thorough understanding in interaction. }\end{array}$ & 2.71 & .835 & 2.66 & .627 & 2.55 & 1.034 & 3.18 & .917 \\
\hline $\begin{array}{l}\text { 20. I am able to identify areas of } \\
\text { misunderstanding and dysfunction in } \\
\text { interactions with target culture } \\
\text { members and explain them in terms of } \\
\text { each of the cultural systems present. }\end{array}$ & 2.05 & .899 & 2.18 & .865 & 2.27 & 1.126 & 3.42 & .969 \\
\hline $\begin{array}{l}\text { 21. I am able to resolve cross-cultural } \\
\text { conflicts and misunderstandings in } \\
\text { interactions with target culture } \\
\text { members to avoid communication } \\
\text { breakdown. }\end{array}$ & 1.84 & .718 & 2.21 & .741 & 1.97 & .951 & 2.97 & .951 \\
\hline
\end{tabular}

Note: M and SD are calculated on a five-point scale (1-5). 
TABLE 8.4

Pre-test and post-test for intercultural awareness

\begin{tabular}{|c|c|c|c|c|c|c|c|c|}
\hline \multirow{3}{*}{ Questions } & \multicolumn{4}{|c|}{ ST class $(\mathrm{N}=38)$} & \multicolumn{4}{|c|}{ IC class $(\mathrm{N}=33)$} \\
\hline & \multicolumn{2}{|c|}{ Pre-test } & \multicolumn{2}{|c|}{ Post-test } & \multicolumn{2}{|c|}{ Pre-test } & \multicolumn{2}{|c|}{ Post-test } \\
\hline & $\mathbf{M}$ & SD & $\mathbf{M}$ & SD & $\mathbf{M}$ & SD & $\mathbf{M}$ & SD \\
\hline $\begin{array}{l}\text { 22. I demonstrate awareness of myself } \\
\text { as a 'culturally conditioned' person } \\
\text { with personal preferences and habits }\end{array}$ & 3.05 & .517 & 3.08 & .784 & 3.18 & .846 & 4.00 & .791 \\
\hline $\begin{array}{l}\text { 23. I demonstrate awareness of } \\
\text { identifying and interpreting explicit or } \\
\text { implicit values in my own and the target } \\
\text { culture. }\end{array}$ & 2.42 & .683 & 2.71 & .654 & 2.36 & .994 & 3.85 & .795 \\
\hline $\begin{array}{l}\text { 24. I demonstrate awareness of how my } \\
\text { cultural values are reflected in specific } \\
\text { situations. }\end{array}$ & 2.82 & .563 & 2.63 & .675 & 2.82 & .727 & 3.12 & .893 \\
\hline $\begin{array}{l}\text { 25. I demonstrate awareness of target } \\
\text { culture members' reactions to me that } \\
\text { may reflect their cultural values that are } \\
\text { different from mine in specific } \\
\text { situations. }\end{array}$ & 2.71 & .565 & 2.87 & .578 & 2.91 & .805 & 3.58 & .969 \\
\hline $\begin{array}{l}26 . \text { I demonstrate awareness of } \\
\text { similarities and differences across my } \\
\text { own and the target language and } \\
\text { culture. }\end{array}$ & 2.37 & .633 & 2.71 & .611 & 2.73 & .626 & 3.58 & .830 \\
\hline $\begin{array}{l}\text { 27. I demonstrate awareness of how } \\
\text { varied situations may require modifying } \\
\text { my interactions with target culture } \\
\text { members for appropriateness. }\end{array}$ & 2.87 & .623 & 3.00 & .735 & 2.94 & .788 & 3.58 & .751 \\
\hline $\begin{array}{l}\text { 28. I demonstrate awareness of } \\
\text { differences in ideological perspectives } \\
\text { across cultures in order to communicate } \\
\text { flexibly with target culture members. }\end{array}$ & 2.39 & .823 & 2.68 & .989 & 2.58 & .830 & 3.33 & .957 \\
\hline $\begin{array}{l}\text { 29. I demonstrate awareness of possible } \\
\text { misconceptions of generalizing } \\
\text { individual behaviours as representative } \\
\text { of the whole culture. }\end{array}$ & 2.95 & .928 & 3.58 & .858 & 2.94 & .933 & 3.70 & .728 \\
\hline $\begin{array}{l}\text { 30. I demonstrate awareness of my own } \\
\text { level of intercultural development. }\end{array}$ & 3.00 & 1.013 & 2.62 & .714 & 2.67 & .924 & 3.06 & 659 \\
\hline
\end{tabular}

Note: $\mathrm{M}$ and SD are calculated on a five-point scale (1-5). 
In order to see differences between the two classes in terms of the four components of intercultural competence, independent samples t-tests were conducted. These t-tests examined whether both classes were comparable before the intervention and whether the intervention contributed to the development of the learners' intercultural competence in the IC class. The results of the independent samples t-tests are given in Table 8.5. Development of learners' intercultural competence in the two classes in terms of intercultural knowledge, attitudes, skills and awareness are presented in Figures 8.1-8.4.

TABLE 8.5

Independent-samples t-tests for pre-test and post-test in the two classes

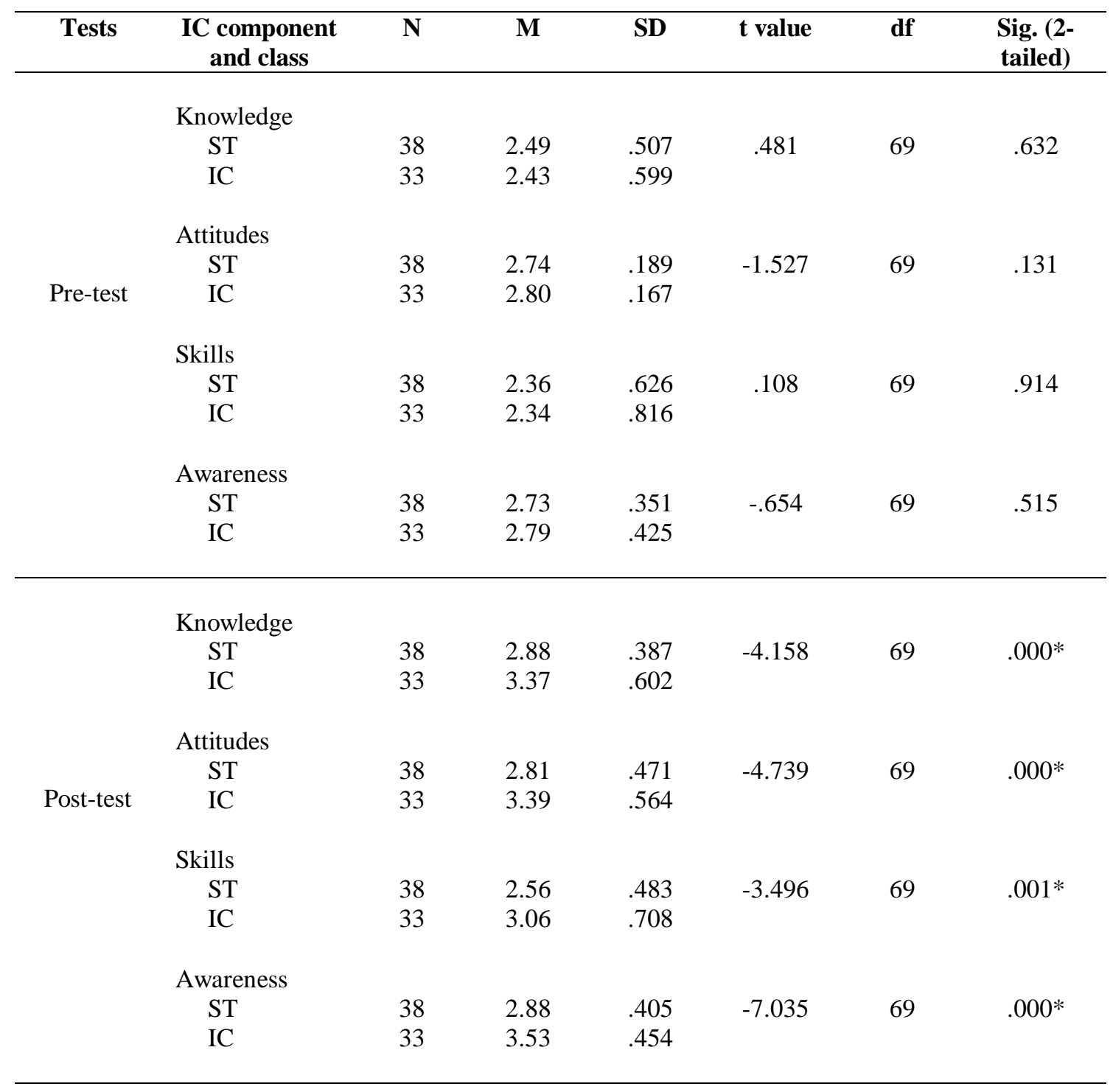

Note: *p<.05; ST=Standard class; IC $=$ Intercultural class, $\mathrm{M}$ and $\mathrm{SD}$ are calculated on a five-point scale (1-5). 
FIGURE 8.1

Development of learners' intercultural knowledge in the two classes

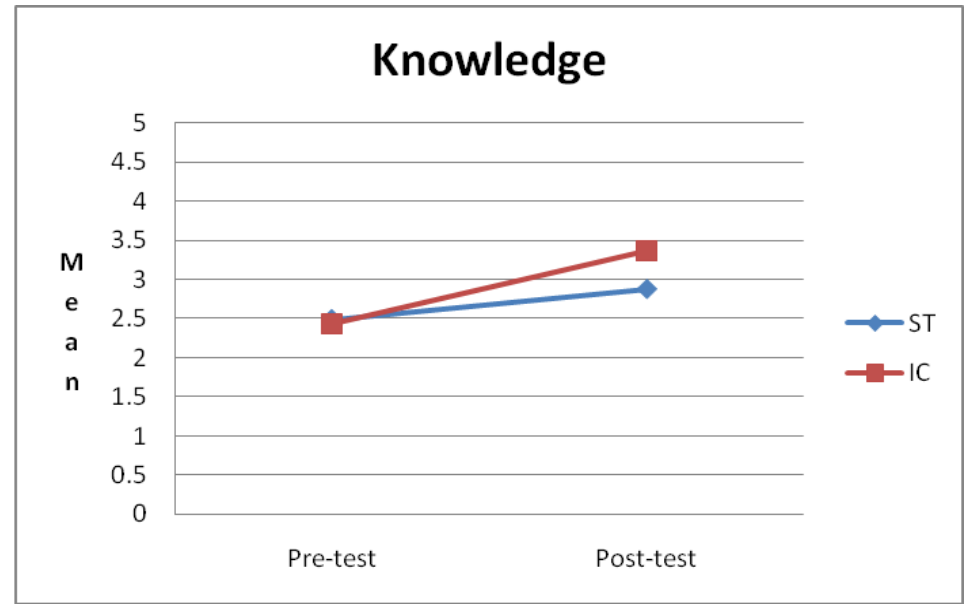

FIGURE 8.2

Development of learners' intercultural attitudes in the two classes

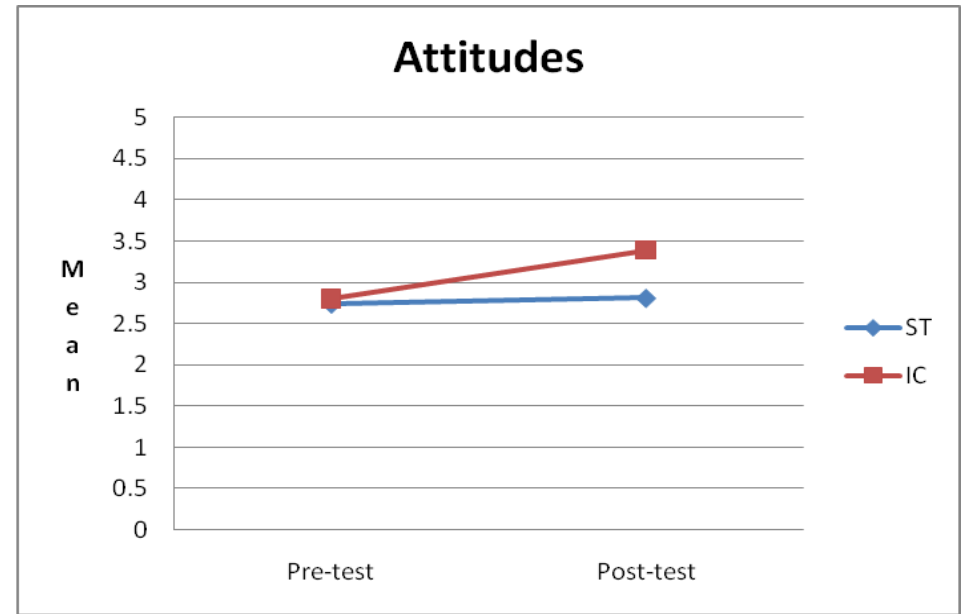

FIGURE 8.3

Development of learners' intercultural skills in the two classes

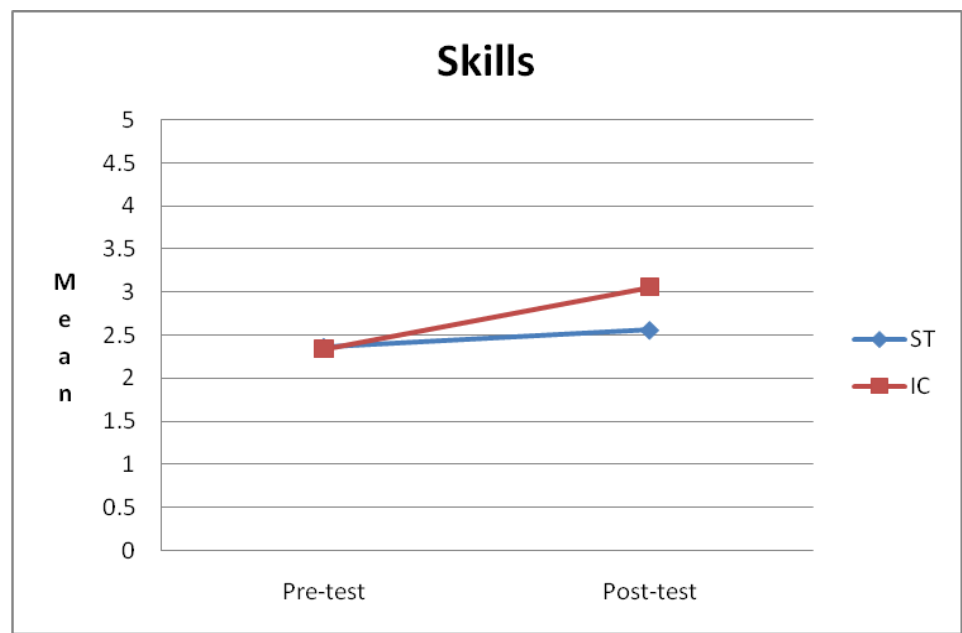


FIGURE 8.4

Development of learners' intercultural awareness in the two classes

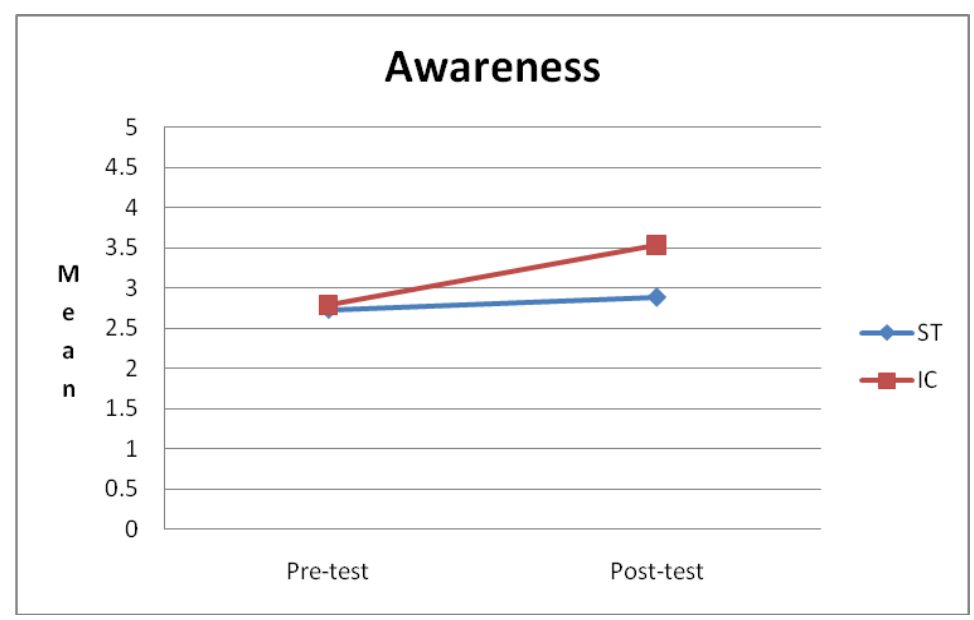

The statistic significance for an independent-samples t-test is determined by the pvalue (sig-2 tailed). The p-value for the pre-test shows no significant differences at the .05 level between the IC class and the ST class regarding knowledge $(t(69)=.481$, $p>.05)$, attitudes $(t(69)=-1.527, p>.05)$, skills $(t(69)=.108, p>.05)$ and awareness $(t$ $(69)=-.654, p>.05)$. This result indicates that both classes were similar in terms of their initial intercultural competence before the intervention.

Nine weeks following the experimental period, the students in both classes completed the same inventory a second time to provide pre-post test comparison data. Results of the post-test show statistically significant differences at the .05 level between the IC class and the ST class across the four IC components: knowledge $(t(69)=-4.158, p<.05)$, attitudes $(t(69)=-4.739, p<.05)$, skills $(t(69)=-3.496$, $p<.05)$ and awareness $(t(69)=-7.035, p<.05)$. The gains in the IC class in all cases were significantly higher than those in the ST class.

Examining whether the intercultural gains in both classes were significantly different, independent-samples t-tests were conducted for both classes. Table 8.6 and Figure 8.5 present the results of these tests. Results indicate the biggest gains were in knowledge with a mean score of .94 and .39, followed by awareness with .74 and .15, then skills with .72 and .21, and finally attitudes with .59 and .07 for the IC class and the ST class respectively. The intercultural gains between the two classes were statistically significantly different at the .05 level across the four IC components: knowledge $(t(69)=-3.846, p<.05)$, attitudes $(t(69)=-4.063, p<.05)$, skills $(t(69)=$ 
$-2.778, p<.05)$ and awareness $(t(69)=-4.883, p<.05)$. The result suggests that knowledge was the foundation for the development of other intercultural competencies, while attitudes seemed to be more resistant to development than the other competencies. The result confirms that the intercultural intervention contributed to the development of the learners' intercultural competence in the IC class.

TABLE 8.6

Independent-samples t-tests for intercultural gains in the two classes

\begin{tabular}{|c|c|c|c|c|c|c|c|}
\hline $\begin{array}{c}\text { IC } \\
\text { component }\end{array}$ & Class & $\mathbf{N}$ & $\mathbf{M}$ & SD & t value & df & $\begin{array}{l}\text { Sig (2- } \\
\text { tailed) }\end{array}$ \\
\hline $\begin{array}{c}\text { Knowledge } \\
\text { gain }\end{array}$ & $\begin{array}{l}\text { ST } \\
\text { IC }\end{array}$ & $\begin{array}{l}38 \\
33\end{array}$ & $\begin{array}{l}.39 \\
.94\end{array}$ & $\begin{array}{l}.661 \\
.539\end{array}$ & -3.846 & 69 & $.000 *$ \\
\hline Attitude gain & $\begin{array}{l}\text { ST } \\
\text { IC }\end{array}$ & $\begin{array}{l}38 \\
33\end{array}$ & $\begin{array}{l}.07 \\
.59\end{array}$ & $\begin{array}{l}.491 \\
.581\end{array}$ & -4.063 & 69 & $.000 *$ \\
\hline Skills gain & $\begin{array}{l}\text { ST } \\
\text { IC }\end{array}$ & $\begin{array}{l}38 \\
33\end{array}$ & $\begin{array}{l}.21 \\
.72\end{array}$ & $\begin{array}{l}.784 \\
.776\end{array}$ & -2.778 & 69 & $.007 *$ \\
\hline $\begin{array}{l}\text { Awareness } \\
\text { gain }\end{array}$ & $\begin{array}{l}\text { ST } \\
\text { IC }\end{array}$ & $\begin{array}{l}38 \\
33\end{array}$ & $\begin{array}{l}.15 \\
.74\end{array}$ & $\begin{array}{l}.492 \\
.534\end{array}$ & -4.883 & 69 & $.000 *$ \\
\hline
\end{tabular}

Note: ${ }^{*} \mathrm{p}<.05 ; \mathrm{M}$ and $\mathrm{SD}$ are calculated on the differences of the mean scores between the pre-and post tests.

FIGURE 8.5

Intercultural gains in the two classes

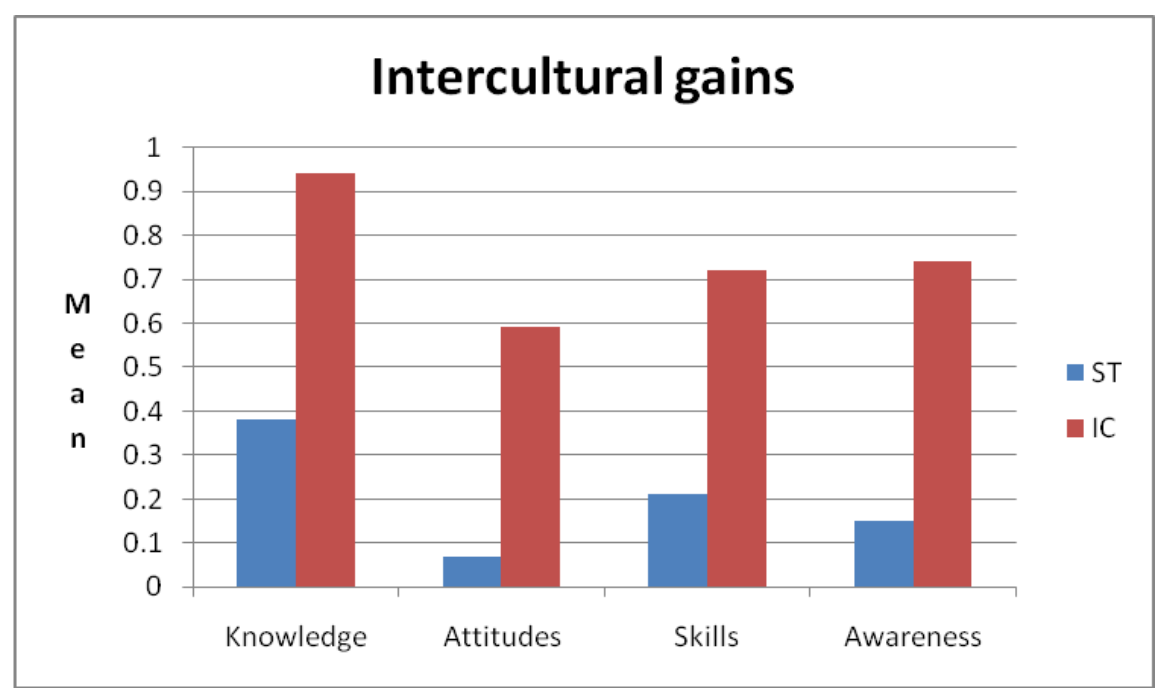


Moreover, the post-test also showed a positive correlation among the four IC components as shown in Table 8.7. The strength of correlation was interpreted according to Gall, Borg and Gall (1996) (refer to notes under Table 8.7). The post-test scores on the knowledge component showed a substantial positive correlation with that of the skills component $(r=.615, p<.01)$; two moderate positive correlations were found with that of the attitudes component $(r=.527, p<.01)$ and the awareness component $(r=.599, p<.01)$. The post-test scores on the attitudes component showed a moderate positive correlation with that of the skills component $(r=.527, p<.01)$ and the awareness component $(r=.551, p<.01)$. The post-test scores on the skills component also showed a moderate positive correlation with that of the awareness component $(r=.566, p<.01)$. The results indicate the coherence of the four IC components with the existence of moderate to substantial relationships among them.

TABLE 8.7

Correlation among the IC components in the post-test

\begin{tabular}{lccc}
\hline Variables & Knowledge & Attitudes & Skills \\
\hline Knowledge & & & \\
Attitudes & $.527^{* *}$ & & \\
Skills & $.615^{* *}$ & $.527^{* *}$ & \\
Awareness & $.599^{* *}$ & $.551^{* *}$ & $.566^{* *}$ \\
\hline
\end{tabular}

Notes: ${ }^{* *} \mathrm{p}<.01$, two-tailed; Strength of correlation (Gall, Borg and Gall, 1996): .01-.1 = very low; $.2-.3=$ low; $.4-.5=$ moderate; $.6-.7=$ substantial; $.8-.9=$ very high

To summarise, the results of the pre-test and the post-test indicated a significant development of the learners' intercultural competence across the four components of knowledge, attitudes, skills, and awareness in the IC class compared with the ST class. The IC class, in addition, had more significant intercultural gains than the ST class over the nine-week period. There was also a positive correlation among the four IC components of the post-test. 


\subsection{Nature of the learners' intercultural competence development}

This section addresses research question 5 which examines the nature of the learners' intercultural development in the two classes. The nature of this development focuses on the learners' intercultural awareness (ICAW) and intercultural attitudes (ICAT) as two of the four main components of intercultural competence. The results report on data obtained from the six topics selected in the learners' reflective journals. Students were asked to reflect on the cultural issues of each topic in these journals. Four case studies in both classes were also analysed to provide further insight into the students' intercultural competence development.

The section has two parts: the quantitative and the qualitative ones. The quantitative results are first presented with the correlations between the variables involving the two classes, the six topics and the areas of ICAW and ACAT, followed by an overview of differences in students' demonstration of intercultural competence between the two classes. The qualitative results involve an analysis of qualitative data across the six topics to gain an important insight into the learners' ICAW and ICAT in the two classes. The students in the IC class and the ST class are labelled as the IC students and the ST students respectively. The four case studies are finally presented by individual case.

\subsubsection{Quantitative results}

This section reports the results on correlations between variables involved in the data, and an overview of differences regarding the students' demonstration of intercultural competence between the two classes.

\subsubsection{Correlations between variables}

Each topic in the learners' reflective journals involves three subject factors which are the Class, the Topic and the Area (the coding categories in each topic). These factors can be classified into two main variables: the independent variables consist of the Class and the Topic, and the independent variables consist of the Area. Table 8.8 gives details of these variables. 
TABLE 8.8

Independent and dependent variables

\begin{tabular}{ll}
\hline Independent variables & Dependent variables \\
\hline \multicolumn{1}{c}{ Class } & Area \\
Class 1 = ST class & Area 1: General Knowledge \\
Class 2 = IC class & Area 2: Cultural Comparisons \\
& Area 3: Understanding Other Cultures \\
Topic & Area 4: Cultural self-awareness \\
Topic 1: Men and Women & Area 5: Communicative Awareness \\
Topic 2: Festivals and Holidays & Area 6: Ethnorelative Awareness \\
Topic 3: Interpersonal Communication & Area 7: Ethnocentric Attitudes \\
Topic 4: Animals & Area 8: Openness, Respect and Tolerance \\
Topic 5: Kindergarten education & Area 9: Ethnorelative Attitudes \\
Topic 6: The elderly & Area 10: Generic comments \\
& \\
\hline
\end{tabular}

These three subject factors were correlated to determine relationships. As the outcome variable was binary (took two values only), the Repeated Measures Logistic Regression (RMLR) Model and the Generalized Estimating Equations (GEE) method were used to examine the hypotheses whether or not the subject mentioned a given topic in a given area depended on Class, Topic and/ or Area. The RMLR Model allowed for the correlations among the students when they responded to a given topic in a given way. This analysis allows for student to student variability. No students in the ST class made any comments in the area of Ethnorelative attitudes (Area 9) on any topic, and so this area was excluded from the RMLR Model. The results of the application of this model are given in Table 8.9. The parameter estimates of the model are shown in Table 8.10. The QLICC (Corrected Quasi Likelihood under Independence Model criterion) gives a measure of the goodness of fit of the model $($ QLICC $=2496.384)$. However, since it is not a full likelihood (excluding Area 9), it cannot be used as an absolute measure of goodness of fit, but can only be used in a relative sense. 
TABLE 8.9

Results of the RMLR Model

\begin{tabular}{cccc}
\hline Model & Factors & p-value & QLICC \\
\hline All main factors + & Class & 0.000 & 2496.384 \\
Class x Area & & & \\
& Area & 0.000 & \\
& Topic & 0.000 & \\
& Class x Area & 0.000 & \\
&
\end{tabular}

TABLE 8.10

Parameter estimates of the RMLR Model

\begin{tabular}{llll}
\hline Parameter & B & $\mathbf{E x p}(\mathbf{B})$ & p-value \\
\hline Intercept & -2.742 & 0.064 & 0.000 \\
Class $=1$ & 1.203 & 3.329 & $0.000^{*}$ \\
Class $=2$ & 0 & 1 & \\
Topic $=1$ & -0.185 & 0.831 & 0.103 \\
Topic $=2$ & -0.023 & 0.977 & 0.844 \\
Topic $=3$ & 0.137 & 1.147 & 0.207 \\
Topic $=4$ & 0.330 & 1.391 & $0.005^{*}$ \\
Topic $=5$ & 1.172 & 3.228 & $0.000^{*}$ \\
Topic $=6$ & 0 & 1 & \\
Class $=1 *$ Area $=1$ & -0.208 & 0.813 & 0.554 \\
Class $=1 *$ Area $=2$ & -1.500 & 0.223 & $0.000^{*}$ \\
Class $=1 *$ Area $=3$ & -2.421 & 0.089 & $0.000^{*}$ \\
Class $=1 *$ Area $=4$ & -1.751 & 0.174 & $0.000^{*}$ \\
Class $=1 *$ Area $=5$ & -1.903 & 0.149 & $0.000^{*}$ \\
Class $=1 *$ Area $=6$ & -3.623 & 0.027 & $0.000^{*}$ \\
Class $=1 *$ Area=7 & 2.267 & 9.648 & $0.000^{*}$ \\
Class $=1 *$ Area $=8$ & -3.115 & 0.044 & $0.000^{*}$ \\
Class $=1 *$ Area $=10$ & 0 & 1 & \\
Class $=2 *$ Area=1 to 10 & 0 & 1 & \\
\hline
\end{tabular}

Notes: $* \mathrm{p}<.05$

The results of the model in Tables 8.9 and 8.10 can be interpreted as follows. 
There are only categorical Variables (Class, Topic and Area), so this model uses Dummy Variables to define different categories. That means for each variable, it sets a baseline category (Class $=2$, Topic $=6$ and Area $=10$ ), and fits a dummy variable which is 1 for a given category of the variable, and 0 otherwise. The coefficient of this dummy variable measures the effect of that category compared to the baseline category. Thus from the parameter estimates of the model in Table 8.6, the following interpretations can be made:

(1) The differences between the two classes were statistically significant since $B=1.203, p<.05$.

(2) Topics 1 and 2 were less likely to be mentioned than Topic 6 (the baseline), because $B=-0.185$ and $B=-0.023$ respectively. In fact, though, Topics 1 and 2 were not statistically different from Topic 6 , since $p>.05$. Topic 3 was more likely to be mentioned than Topic 6 since $B=0.137$ (greater than 0 ), though not statistically different $(p>.05)$. Topic 4 and Topic 5, however, were more likely to be mentioned than Topic 6 and were statistically different since $B=0.330, p<.05$ and $B=1.172$, $p<.05$ respectively.

(3) Class differences were indicated mainly in the interaction between Class and Area. The ST class students were significantly less likely to make a mention in their journal entries if the Area was one of 2, 3, 4, 5, 6, or 8 since $p<.05$ in all of these areas. This indicates that the IC class was more likely to develop their intercultural awareness and attitudes than the ST class at the medium and high levels of IC as the more frequently mentioned areas in the IC class belonged to these levels. The ST students were more likely to make a mention if the area was Area 7, which was statistically significant since $B=2.267, p<.05$. If we refer to the $\operatorname{Exp}(\mathrm{B})$ as the odds ratio, there was a more than nine-fold odds of a mention (Odds Ratio=9.648) in Area 7 (ethnocentric attitudes) in the ST class than in any other areas. This indicates that ethnocentric attitudes were the most prevalent in the ST class across the topics. 


\subsubsection{Overview of differences in students' demonstration of intercultural competence between the two classes}

A quantitative analysis was first conducted to provide an overview of differences in students' demonstration of intercultural competence between the two classes across the six topics. This quantitative analysis involved the calculation of the nonintercultural and intercultural instances in both classes on the basis of the total number of the coded units of analysis found in each category within the six topics. The results are given in Table 8.11.

TABLE 8.11

Differences in students' demonstration of intercultural competence between the two classes

\begin{tabular}{|c|c|c|c|c|c|c|c|c|}
\hline \multirow{3}{*}{$\begin{array}{l}\text { Total IC instances } \\
532\end{array}$} & \multicolumn{4}{|c|}{$\mathrm{ST}$ class $(\mathrm{N}=38)$} & \multicolumn{4}{|c|}{ IC class $(N=33)$} \\
\hline & \multicolumn{2}{|c|}{ Instances } & \multicolumn{2}{|c|}{ Percentage } & \multicolumn{2}{|c|}{ Instances } & \multicolumn{2}{|c|}{ Percentage } \\
\hline & GKN & 25 & GKN & 4.7 & GKN & 12 & GKN & 2.3 \\
\hline & $\mathrm{CCO}$ & 37 & $\mathrm{CCO}$ & 7.0 & $\mathrm{CCO}$ & 51 & $\mathrm{CCO}$ & 9.6 \\
\hline & $\mathrm{UOC}$ & 19 & UOC & 3.6 & UOC & 67 & $\mathrm{UOC}$ & 12.6 \\
\hline & CSA & 27 & CSA & 5.1 & CSA & 54 & CSA & 10.2 \\
\hline & $\mathrm{COA}$ & 27 & $\mathrm{COA}$ & 5.1 & $\mathrm{COA}$ & 70 & $\mathrm{COA}$ & 13.2 \\
\hline & ERA & 1 & ERA & 0.2 & ERA & 37 & ERA & 7.0 \\
\hline & ECA & 43 & ECA & 8.1 & ECA & 1 & ECA & 0.2 \\
\hline & ORT & 4 & ORT & 0.8 & ORT & 40 & ORT & 7.5 \\
\hline & EAT & 0 & EAT & 0.0 & EAT & 17 & EAT & 3.2 \\
\hline Total non-IC & GEC & 29 & GEC & 90.6 & GEC & 3 & GEC & 9.4 \\
\hline $\begin{array}{c}\text { instances } \\
32\end{array}$ & & & & & & & & \\
\hline
\end{tabular}

Key:

GKN: General Knowledge

CCO: Cultural comparison

UOC: Understanding of other cultures

CSA: Cultural self-awareness

COA: Communicative awareness
ERA: Ethnorelative awareness

ECA: Ethnocentric attitudes

ORT: Openness, respect and tolerance

EAT: Ethnorelative attitudes

GEC: Generic comments 
Results indicate that a total of 32 non-intercultural instances were found in the two classes in which $90.6 \%$ were found in the ST class, whereas only $9.4 \%$ were found in the IC class. This indicates that the IC class was much more aware of cultural differences in language learning than the ST class.

A total of 532 intercultural instances were found in both classes in which $65.8 \%$ were found in the IC class and $34.6 \%$ in the ST class. The instances of general knowledge and cultural comparisons were quite similar in both classes with $11.7 \%$ and $11.9 \%$ in the IC class and ST class respectively. The IC class showed more instances of understanding of other cultures (12.6\% vs. 3.6\%) and more instances of cultural self-awareness $(10.2 \%$ vs. $5.1 \%)$ than the ST class. Concerning the higher level of IC, while the IC class showed $13.2 \%$ instances of communicative awareness, only $5.1 \%$ were found in the ST class. A big difference was found in the instances of ethnorelative awareness with $7.0 \%$ in the IC class compared to $0.2 \%$ in the ST class.

There was also great difference between the two classes regarding students' intercultural attitudes. While the ST class showed $8.1 \%$ instances of ethnocentric attitudes, only $0.2 \%$ was found in the IC class. The IC class provided more instances of openness, respect and tolerance $(7.5 \%$ vs. $0.8 \%)$ and those of ethnorelative attitudes $(3.2 \%$ vs. $0.0 \%)$ than the ST class.

\subsubsection{Summary}

The differences between the two classes concerning the development of the learners' intercultural competence were statistically significant. Some topics were less likely to be mentioned than others, which was probably due to the nature of each topic. The IC class was much more aware of cultural differences than the ST class as $90 \%$ of generic comments, i.e., comments that did not show evidence of intercultural competence, were found in the ST class. Intercultural awareness and intercultural attitudes demonstrated twice as much across the six topics in the IC class as compared to the ST class. The ST class was more likely to develop their intercultural awareness and attitudes at the low and medium levels of IC, while such development was found at the medium and high levels of IC with better articulation of ethnorelative awareness and attitudes in the IC class. Ethnocentric attitudes were the most prevalent in the ST class across the topics. The results confirm the positive effect of the 
intercultural intervention in the IC class on the development of the learners' intercultural competence.

\subsubsection{Qualitative results}

This section reports the qualitative results on the students' demonstration of intercultural awareness and attitudes in their reflective journals.

\subsubsection{Students' demonstration of intercultural awareness}

The students' demonstration of intercultural awareness in the two classes is described through five main features of intercultural awareness below. Only typical examples are given to illustrate the students' main insight into intercultural awareness.

\section{(1) Awareness of cultural similarities and differences}

The low level of intercultural awareness involves general knowledge about an aspect of the target culture and cultural comparisons at a factual level. Both classes gave quite similar instances of general knowledge and cultural comparisons across the six topics; however, the IC class showed more awareness of cultural differences than the ST class.

The facts about the target culture stated in the ST class involved superficial assumptions about the target culture, whereas cultural comparisons in the IC class reflected cultural awareness. Such differences can be seen in examples (1) and (2):

(1) In English-speaking countries, dogs and cats are treated like people. They can sleep with the owner and their food is put in the fridge together with the food for people. The order of respect in these countries is: women-children-pets-men. However, in Vietnam and other Asian countries, men are in the first place and pets are not treated equally with them (ST6, J2, Lesson 4).

(2) Pets in English-speaking countries are treated like family members. They can eat, sleep or go for a walk with the owner and there is no distinction between the pet and the owner. This is very different from my country and I find it very interesting. This helps me understand about the target culture and avoid embarrassment or shock in contact with them (IC22, J2, Lesson 4). 
The ST student in example (1) had a superficial assumption about the importance of pets in the target culture whereas the IC student in example (2) was more aware of cultural differences in the treatment of pets in her own culture and the target culture.

More similarities between cultures were found in the ST class than the IC class. The following examples concerning kindergarten education illustrate this difference:

(3) Kindergarten education in each country has different rules for children since they are a few years old. In spite of differences in education, I realise that the basic rules are similar: high self-awareness, unity, self-reliance and mutual help. I am interested in and agree with the rules children learn in kindergarten as these rules are the foundation for the development and improvement of children's personalities (ST26, J3, Lesson 9a).

(4) There are more differences than similarities in the rules of kindergarten education between English-speaking countries and my country. For example, children in those countries learn self-help skills or problem-solving skills that help them to become more self-reliant than Vietnamese children of similar ages who mostly depend on their parents (IC27, J3, Lesson 9a).

Examples (3) and (4) indicate that the ST student was more concerned with similar basic rules for developing children's personalities in kindergarten education, whereas the IC student was more aware of cultural differences between the two education systems.

\section{(2) Awareness of cultural stereotypes and underlying cultural values}

The IC class showed a deeper understanding of the target culture than the ST class. This understanding was demonstrated through an awareness of cultural stereotypes and underlying cultural values of the target culture.

In the lesson on 'men and women', the IC class moved beyond the mere description of personalities and behaviours of boys and girls to deal with cultural stereotypes that exist across cultures. Classroom observations showed that the IC class demonstrated awareness of cultural stereotypes, as they had been made aware of this during the lesson, while there was no such demonstrated evidence in the ST class. 
This awareness involved gender differences and gender roles, entertainment of guests, and body language across cultures. Such awareness is illustrated in the examples given below:

(5) There are still cultural stereotypes across cultures about men who take on social responsibilities and women who stay at home to take care of children or do housework as shown in the cartoons. Nowadays there have been changes across cultures about the roles of women in the family and society where they hold important positions and contribute to society (IC6, J1, Lesson 2).

(6) I like the way the Japanese receive guests at home with a lot of hospitality. Foreign guests are usually served with sushi, a traditional Japanese food. However, it does not mean that Japanese people only eat sushi, which is a stereotype. When Sumie has Japanese guests, they are served all kinds of food such as spaghetti, Chinese food and steaks. This means that we should avoid cultural stereotypes to have a better understanding of the other culture (IC16, J1, Lesson 3).

(7) I find it interesting when a Hungarian agrees with a head shake. This shows that the meaning and content of body language have been extended and do not follow a stereotype. As body language differs across cultures, it requires everybody to learn about it in order to communicate successfully with foreigners and avoid misunderstandings (IC22, J2, Lesson 5).

The deeper cultural understanding of the students in the IC class also resulted from an awareness of the underlying cultural values of the target language culture. The following examples are about different ways of entertaining guests across cultures:

(8) There are different ways of receiving and entertaining guests in different countries, which highlights their particular cultures. For example, Japanese people like to welcome guests at home and they are very polite and formal, whereas Americans like to organise parties outdoors with a comfortable and informal style (ST10, J1, Lesson 2).

(9) In America, it is necessary to call or email in advance before visiting someone to avoid embarrassment for not having prepared. The English expression 'Drop in anytime' does not mean you can come at any time, but it is a polite way to show friendliness and a desire to extend relations with you. The most important thing in communication with target culture members is that you need to observe their attitudes in order to understand their feelings (IC7, J1, Lesson 3). 
Example (8) shows that the ST student demonstrated only a general understanding of different ways of receiving guests in Japan and America, whereas example (9) shows the IC student's understanding of the underlying norms of receiving guests in American culture through the expression 'Drop in any time' in an intercultural lesson.

The lesson on 'interpersonal communication' in the ST class involved general communication, whereas the one in the IC class focused more on rules and challenges in intercultural communication. Therefore, the IC students became more aware of cultural norms of interaction in intercultural communication, while the ST students were concerned with strategies for general communication. The following examples can show this difference:

(10) I am interested in the tips for successful communication and in finding out why people fail to communicate. This is very useful for us as it helps us to discover the most efficient way to become a good communicator and become more confident in communication. The use of body language is also a good way to interest the listener and to allow our intentions to be perceived more easily and avoid misunderstandings. This is because I was not self-confident and quite afraid of communication. (ST17, J2, Lesson 5).

(11) I am concerned about the norms of interaction in the target culture. There are cultural differences in the standard of distance between the American and Vietnamese people. While Americans keep a certain distance in communication, which is not too close or too far, this does not matter much for Vietnamese people. Voice needs to be moderate, otherwise it is considered impolite. It is also important to know when to start a conversation as you need to know when to ask to get an answer (IC26, J2, Lesson 5).

The ST student in example (10) showed interest in tips for success in general communication, whereas the IC student in example (11) was aware of various cultural norms of interaction in intercultural communication such as the standard of distance, the standard of loudness or when to start a conversation. Such awareness could help students avoid misunderstanding or communication breakdown in intercultural communication:

(12) Communication is a daily cultural activity. Ways of communication differ across cultures and it is easy for misunderstanding to occur in face-to-face communication. 
A lack of understanding of cultural norms in each culture can lead to misunderstanding in communication or even communication breakdown. It is therefore necessary to learn about the cultural norms of interaction in communication with people from the target culture. It is mutual cultural understanding that arouses interest and satisfaction of both interlocutors (IC10, J2, Lesson 5).

The IC students' understanding of the target language culture also contributed to the development of their critical cultural awareness. Notice the differences, for example, in the way the students in the two classes understood the treatment of the elderly in the target culture in the examples given below:

(13) In Vietnam, the traditional culture is highly appreciated, for example, young people respect elderly people and usually give seats to them, whereas in English-speaking countries, elderly and young people are treated with equality, which does not show any respect for the elderly. (ST8, J3, Lesson 9b).

(14) In Vietnamese culture with its age-old traditions, many generations still live under the same roof, and therefore children pay respect and filial piety towards their parents and grandparents. On the contrary, Canadian people like to live independently from their children when they become old. They consider that they can be self-reliant and do not want to depend on their children, so they do not ask for any help from their children and try to express themselves (IC3, J3, Lesson 9b).

Example (13) indicates the ST student did not express any understanding of the value of equality in the target culture and therefore this value was underestimated in comparison with the value of respect in his/her own culture. The IC student in example (14), on the other hand, put the value of the independent lifestyle of elderly people in the target culture on the same level with the tradition of respecting the elderly in his/her own culture. This appreciation of the target culture resulted from the IC students' participation in an ethnographic interview with a native English speaker, a Canadian English teacher, who was invited to the classroom. Similar understanding about the close relationship between pets and people and the influence of kindergarten education on the development of children's self-reliance and life experience in Canada also resulted from the students' ethnographic interview as shown in examples (15) and (16): 
(15) Every family in Canada has a pet. A family without pets is considered to have no love and a family with pets is full of love. This is a conception I am particularly interested in. I have known that they treat pets very well like children, but I did not think they loved pets as family members (IC27, J2, Lesson 6).

(16) A variety of useful activities in kindergarten education in Canada help to develop children's creativity, critical thinking, and self-reliance. This gives them a lot of experience for their life and therefore they can live and study independently (IC21, J3, Lesson 9a).

\section{(3) Awareness of the self}

The IC students were more likely to develop better cultural self-awareness than the ST ones because they had deeper understanding of the target culture across the topics. There was no evidence about the ST students' self-awareness in the topic of interpersonal communication. Example (17) shows how an IC student demonstrated self-awareness in communication with people from other cultures:

(17) I wonder whether Vietnamese students are confident enough to conduct a successful face-to-face communication with people from other cultures, or whether the young generation have used body language well or should use a lot of gestures in intercultural communication. I also wonder whether I can understand enough about the norms of interaction in the target culture and can express myself in a culturally appropriate manner in intercultural communication (IC10, J2, Lesson 5).

The teacher's sharing of intercultural experience about the target culture in the intercultural lesson on 'pets' also helped the IC students develop a better cultural selfawareness about their own culture than the ST students. The following examples illustrate this difference:

(18) I think it is essential to protect and take good care of pets. The government of my country also need policies to condemn bad treatment of pets as well as raise public awareness about the treatment of pets (ST15, J2, Lesson 6).

(19) A story told by the teacher about her study in Australia makes me very surprised. In Australia, pets are treated like children. This is completely different from my country. This makes me think about the treatment of pets in my country since so far 
as I have seen, my family, friends and other people in my country do not treat pets as well as Australians do. I think this is a good cultural feature in the target culture (IC11, J2, Lesson 6).

The ST student in example (18) suggested actions for the Vietnamese government to employ concerning the situation of pet treatment in his/her country, whereas the IC student in example (19) reflected on his/her own self concerning the treatment of pets in his/her country. Similarly, engagement in a cultural situation about the pet protection law in America also encouraged the IC students to critically reflect on their own culture. Example (20) illustrates such demonstrated evidence:

(20) I like the way pets are treated as children in English-speaking countries. There is a strict law on maltreatment of animals in America. I wonder why there is no such law in Vietnam. For example, a woman in San Francisco was imprisoned as she 'forgot' to feed her dog and let it starve to death. Will people in Vietnam be angry or get upset due to the death of a dog? I am sure only a few people will. As Vietnamese people usually think highly of affection and righteousness, I hope that a new law on equal treatment of animals in Vietnam will come into being one day (IC24, J2, Lesson 6).

A critical cultural self-awareness was also found in the IC class in comparison with the ST class as shown in the following examples about kindergarten education:

(21) Educating children is very important as it is the first bridge that forms their personalities. We should adopt the Western education in which students are 'centred' and have the right to express their opinions and the teacher is a guide. However, only the teaching methods should be changed, but the tradition of respecting teachers should be maintained and preserved (ST32, J3, Lesson 9a).

(22) Children in English-speaking countries learn to live independently, acquire lifeskills and live a balanced life. I wonder if these good values in the target culture should be applied in my country. On the one hand, it is necessary that Vietnamese children learn these good skills to grow up independently. On the other hand, they also need to learn other values in their own culture to fulfil their filial duty to their parents. This means that Vietnamese children not only need to learn good values from Western education, but also need to know about their own cultural values to preserve their own cultural identity (IC10, J3, Lesson 9a). 
In examples (21) and (22), the ST student acknowledged the student-centred kindergarten education system of the target culture, whereas the IC student critically evaluated the cultural values of kindergarten education in his/her own culture with an appreciation of good values in the target culture. Similar demonstration of cultural self-awareness can also be seen in the following examples regarding the treatment of the elderly:

(23) After I have learned about elderly people in Western countries, I can understand about the fact that aged parents are sent to nursing homes. And nowadays, Vietnam is also likely to follow this world trend. I am sure that this will happen but do hope that people still maintain what is meaningful in their tradition in whatever they do (ST25, J3, Lesson 9b).

(24) I think a lot about the moral values with regards to respecting and looking after aged parents and grandparents in my culture, and Western values. I wonder whether the young generation in my country can maintain good cultural values of their country or become like the sons of a lonely old man living in California who desperately waited for his sons to come and take him home away from the nursing home. From this story, I think we should know how to acquire, select and promote the good values of the target culture but also maintain those of our own culture (IC10, J3, Lesson 9b).

The ST student in example (23) anticipated a similar treatment of the elderly in her country as a world trend, whereas the IC student in example (24) was challenged by different cultural values concerning the elderly treatment between her culture and the target culture. The ST student wanted to maintain only her own values, while the IC student was concerned about acquiring and promoting the positive values of both cultures.

\section{(4) Awareness of how to act appropriately in intercultural interactions}

The IC class was likely to develop richer communicative awareness than the ST class across the six topics, especially in the topic of 'interpersonal communication' in which the former developed this competency more than twice as much as the latter. Notice the differences in the students' demonstration of communicative awareness between the two classes in the following examples: 
(25) I have learned some skills for successful communication. For example, I need to choose topics that are appropriate to the context, pay attention to maintaining eye contact with the interlocutor and creating a comfortable atmosphere. There are different ways of communication across cultures. The same gesture may mean different things across cultures (ST26, J2, Lesson 5).

(26) There are many challenges in cross-cultural communication, such as different ways of thinking, different ways of communication or attitudes. I pay much attention to different norms of interaction in intercultural communication. For example, many Americans typically speak in a loud voice to emphasise a point in the conversation, whereas some Vietnamese people speak loudly but not for this reason, which may make Americans think that the Vietnamese speaker is angry. It is important that the interlocutors understand the other's norm of interaction to avoid a communication breakdown. A mutual understanding of each other's culture contributes to the success of communication (IC16, J2, Lesson 5).

The ST student in example (25) considered that he/she had learned some good skills for successful communication, whereas the IC student in example (26) tried to engage and deal with challenges in intercultural communication. Such engagement helped the IC student develop better communicative awareness for effective intercultural communication.

In the topic of 'the elderly', the IC students were also able to demonstrate an awareness of how to act appropriately according to norms of the target culture, whereas no such evidence was demonstrated in the ST class. Example (27) shows this evidence:

(27) In communication with target culture members, it is necessary to be open-minded and friendly. In case we feel there is something in our words or behaviour that may make them feel uncomfortable, we need to explain that we come from two different cultures, which can easily cause misunderstanding. For example, when we are in contact with elderly people, we need to pay attention to their attitudes and not treat them as we treat Vietnamese people as they may want to be self-reliant (IC27, J3, Lesson 9b).

The IC students also anticipated various skills that could contribute to the success of intercultural communication. These skills involved maintaining relationships with 
people from the target culture, using the sense of humour in tense situations, dealing with misunderstandings due to cultural differences in body language, recognising the impact of one's culturally-shaped assumptions on communication, or suspending one's judgment about unfamiliar behaviours. Example (28) shows the importance of the ability to maintain relations with people from the target culture for cultural understanding:

(28) I learn to communicate effectively, make relations better as well as maintain relations for better understanding in communication with people from the target culture. Such cultural understanding will improve our knowledge about the diversity of other cultures and help us avoid misunderstanding or culture shock in communication (IC35, J2, Lesson 5).

A sense of humour was also considered an important ability in tense situations like the one of a delayed meal at a restaurant in the intercultural activity about challenges in intercultural communication as shown in the example below:

(29) In intercultural communication, we need to take advantage of our sense of humour and show our willingness to make the communication successful such as the case of the waiter and the customer at a restaurant. This is the key to success in situations with tension (IC24, J2, Lesson 5).

Example (29) indicates the IC student was willing to take responsibility for contributing to the success of intercultural communication. Such willingness would help learners engage more actively in intercultural language learning. The ability to recognise the impact of one's culturally-shaped assumptions on communication with others would also contribute to a successful communication:

(30) We are usually not aware that culture is acting upon us when we communicate with others. Sometimes we do not recognise that we have cultural values or assumptions that are different from others. To be successful in intercultural communication, I think that we need to be aware of not only our own cultural values but also that of others. (IC29, J2, Lesson 5). 
In addition, the IC students also showed evidence of adaptability to the target culture whereas there was little demonstrated evidence of this competency in the ST class. Notice the differences in the way the students from each class anticipated appropriate behaviours towards entertaining guests in the following examples:

(31) I have learned things that I need to do when I go to other countries. For example, in such a strictly-disciplined country like Japan, try to be polite and modest when having a meal; try to be comfortable and get along well with others when you are with American or Spanish people; especially if you want to do business in America it is necessary to pay a lot of attention to one's own behaviours in public (ST19, J1, Lesson 3).

(32) In the situation of the Vietnamese couple's visit to an American home, if I were the Vietnamese couple, I would observe American's host attitude and try to think why he got upset. If I were the American host, I would try to invite them to sit down and have a cup of tea or something rather than let them stand. In both cases, I would observe the other's attitudes to see whether they are pleased or not so that I can adjust my behaviour accordingly (IC11, J1, Lesson 3).

In examples (31) and (32) above, the ST student suggested ways to behave with people from other cultures, while the IC student tried to adjust her behaviour based on her observation of the other's attitudes. Classroom observation showed that this adaptability resulted from the IC students' active engagement in the role-plays in the cultural situation of a Vietnamese couple's visit to an American home. A similar adaptability about eye contact is also noted in the examples given below:

(33) In communication, in some cultures, eye contact needs to be maintained with the interlocutor. I have learned how to communicate better with target culture members and avoid making them feel uncomfortable (ST24, J2, Lesson 5).

(34) In communication, English people usually maintain eye contact with the interlocutor. It is assumed that this shows the willingness for communication and friendliness. I used to think that maintaining eye contact was not a good thing as this is not very appropriate for communication between two Vietnamese people. I felt embarrassed when another person maintained eye contact with me. In spite of this, I will try to adapt to it in different situations, for example, if I talk to an English speaker who uses eye contact, I will try to adapt to it to become familiar 
with it gradually. Anyway, it is their culture in communication. As I am learning the target language culture, I need to make adjustments to be appropriate (IC6, J2, Lesson 5).

The ST student in example (33) stated the need to maintain eye contact with the interlocutor, whereas the IC student in comparison, in example (34), showed her adaptability to the target culture regarding eye contact with English people by overcoming embarrassment in her own experience.

Moreover, the ability to mediate between cultures is considered the most important goal in intercultural language learning. While this crucial competence was not demonstrated in the ST class, it was evident in the IC class. The following examples show how the students in the two classes dealt with the treatment of pets:

(35) Pets are treated like a family member, which makes me think a lot. I learn how to treat pets well when visiting someone in the target country (ST37, J2, Lesson 6).

(36) The sharing of a portion of rice between the guest and the dog in an Australian homestay can be shocking for Vietnamese people. I may not do the same but I will treat pets in a different way that still shows my positive attitude towards pets as people in the target culture do (IC8, J2, Lesson 6).

The ST student, in example (35), learned to behave well with pets in the target country, whereas the IC student, in example (36), tried to mediate between her own culture and the target culture to find a way that is more appropriate with people in the target culture. A similar ability was found in eye contact with English people:

(37) Most Vietnamese people are quite reserved in communication, especially women who seldom maintain eye contact. It is probably because eye contact for Vietnamese people may make the other interlocutor feel unnatural. For me, I like people to maintain eye contact in communication. Maintaining eye contact shows that we are listening to the interlocutor and focusing on the issue. While communicating with English people, Vietnamese people can maintain eye contact and use some gestures like a friendly smile or a light nod at the same time, which can help them avoid any embarrassment (IC6, J2, Lesson 5). 
Example (37) shows that the IC student was aware of how to mediate between the two cultures by maintaining eye contact with English people, which is a cultural norm of interaction in the target culture, and at the same time using accompanied gestures to avoid any embarrassment such eye contact may cause due to cultural differences with her own culture. Classroom observations showed that an interaction with a native English speaker in the classroom also contributed to the development of this ability. Example (38) shows how the ability to mediate between the two cultures was demonstrated in the relationship between the teacher and students in the classroom:

(38) Vietnamese students usually stand up to greet the teacher as a sign of politeness, whereas in Canadian culture, students usually clap hands to show their appreciation while seated. I think this is a friendly gesture. Vietnamese students can keep their tradition of greeting the teacher by standing up while at the same time clapping hands to show their eagerness to welcome the teacher (IC26, J3, Lesson 9a).

While mediating between cultures, cultural identity became salient to the IC students. Example (39) shows the importance of maintaining one's cultural identity in intercultural communication:

(39) In communication with people from the target culture, it is not necessary to imitate the other's behaviours but instead one should behave in a way that will not disturb the other interlocutor but still maintain their cultural identity (IC2, J1, Lesson 2).

\section{(5) Awareness of cultural relativity}

Students are aware of cultural relativity, i.e. ethnorelative awareness, when they understand two cultures in relation to each other. Ethnorelative awareness was demonstrated in the IC class while this competency was barely found in the ST class. The IC students particularly articulated more ethnorelative awareness in the topics of 'men and women', 'animals' and 'interpersonal communication' as compared to other topics.

In the topic of 'men and women', the IC students understood different personalities and behaviours of boys and girls across cultures. Example (40) shows an awareness of the relativity of behaviours of boys and girls in each society: 
(40) The learned behaviours of boys and girls vary from culture to culture and it depends on the culture in which they grow up and learn different behaviours. For example, many Vietnamese girls can cook and are family-oriented if they are taught in their family. Similarly, girls in Western countries are career-oriented if they are taught about that. As culture is changing, these learned behaviours can be changed according to the changes in each society (IC10, J1, Lesson 2).

This ethnorelative awareness also helped students develop an ability to explain different cultural phenomena across cultures as shown in example (41):

(41) Cultural understanding can help me explain different cultural phenomena across cultures. For example, the smoking behaviour of a foreign woman is considered normal, while that of a Vietnamese woman may annoy other people in Vietnam. This is because of the social prejudice that makes people have such a negative attitude (IC31, J1, Lesson 2).

The IC students' ethnorelative awareness was also demonstrated through their understanding of different roles of pets and the family relations in each culture. Examples (42) and (43) illustrate such awareness:

(42) In Western countries, pets are treated like children in the family. They can eat with people, listen to music, go for walk, be taken to school or shops, etc., with the owner, which is very normal. In Vietnam, on the contrary, the rearing and care for pets is much simpler. From this, I recognise that pets have a different role and function between this ethnic group and another, between this culture and another (IC6, J2, Lesson 6).

(43) The treatment of pets like children in Britain is completely different from Vietnam. It is because the relations among family members in Britain are different from that in Vietnam. We can easily see a dog included in an English family as a family member (IC6, J2, Lesson 6).

The IC students also showed awareness of the cultural relativity in the norms of communication: 
(44) Culture stands at the root of communication challenges. Culture affects the way people from different cultures approach issues and events and the way they participate in communication. For example, many American people have a loud voice to emphasize a point in the conversation, whereas in other cultures this may be considered a sign of impoliteness or anger (IC1, J2, Lesson 5).

There was also evidence of ethnorelative awareness about other topics in the IC class. In an activity about different ways of entertaining guests in different countries, for example, classroom observations showed that some ST students would be reluctant to bring food to share at a potluck as they were not familiar with this cultural practice in their culture. The IC students, however, felt more comfortable with this type of dining, as they were given the chance to reflect on the relativity of entertaining guests in each culture. This awareness can be seen in example (45):

(45) There are different values in the ways of entertaining guests across cultures. For example, the hospitality of Japanese people in receiving guests is quite similar to that in Vietnam. There is a saying in Vietnamese culture "khách đến nhà không gà thì vịt" ("visitors at home will be served chicken or duck" - my translation), which is a sign of hospitality by the Vietnamese host. In America, on the other hand, informality is valued at pot luck parties where guests usually bring a plate or a bottle of wine to share (IC2, J1, Lesson 3).

Regarding the treatment of the elderly, while the ST students underestimated the values of respect among people in the target culture, the IC students evaluated such values in relation to their own culture. Example (46) shows this ethnorelative awareness in the IC class:

(46) The treatment of the elderly differs across cultures. While the elderly in Vietnam are usually looked after by their children at home, those in Western countries usually live independently from their children. This does not mean that the elderly in these countries are not respected. There are different ways to respect the elderly in each culture. For example, the elderly in Vietnam usually get priority in family and society. They are usually greeted by younger people. In Western countries, the elderly are also respected, but in a different way. I see that the front seats on the bus are usually reserved for the disabled and the elderly and there are signs in the street 
for drivers to give way to the elderly. Such things indicate the respect of the society towards the elderly in Western countries (IC19, J3, Lesson 9b).

Only one ST student mentioned the cultural relativity regarding the values of kindergarten education. Notice the difference between the two classes in the following examples:

(47) It is interesting that different regulations at school have important influence on the formation of our behaviours. Depending on each culture, each country has different rules at school or different moral standards. An understanding of such differences will be an important advantage in the attempt to be successful at communication (ST3, J3, Lesson 9a).

(48) Each educational system has different values. For example, while children in English-speaking countries learn to play fair or live a balanced life, children in Vietnam learn to be polite with their grandparents, parents, teachers and adults. Rules in English-speaking countries tend to make children more independent while those in Vietnam tend to make children more disciplined (IC16, J3, Lesson 9a).

The ST student in example (47) generally mentioned different rules and moral standards represented in regulations at school across cultures, while the IC student in example (48) put the educational values of self-reliance and independence in the target culture in relation to those of good behaviours and discipline in their own culture. This ethnorelative awareness helped the IC student gain a better understanding of the educational value in each culture.

So far, I have presented differences in the students' demonstration of intercultural awareness in the two classes. In the next section, I will present the students' demonstration of intercultural attitudes.

\subsubsection{Students' demonstration of intercultural attitudes}

The students' demonstration of intercultural attitudes in the two classes is described in four main features of intercultural attitudes below. Only typical examples are given to illustrate the students' main insight into intercultural attitudes. 


\section{(1) Judging another culture from one's own cultural perspectives}

When students judge an aspect of other cultures from their own cultural perspectives, they have ethnocentric attitudes. In other words, students with ethnocentric attitudes put their own culture at the centre of their worldviews. It was found that there was almost no evidence of ethnocentric attitudes in the IC class, whereas the ST class tended to show ethnocentric attitudes quite consistently across the six topics. The prevalence of ethnocentric attitudes in the ST class resulted from a lack of understanding of the target culture. These attitudes were shown more in the topics of 'the elderly' and 'animals' than in the other topics.

Three-fourths of the students in the ST class showed ethnocentric attitudes towards the treatment of the elderly. These students believed that the treatment of the elderly in their own culture reflected the Eastern values of internal beauty and high moral standards, which they considered superior to the values in the target culture. Such attitudes can be seen in examples (49) and (50), which feature a contrast between equality and respect in the target culture:

(49) In the Vietnamese tradition of 'Seniores priores', elderly people are respected, and priority is given to children and elderly people in getting on board public transport or in queuing up. This attitude is suitable for Vietnamese culture as well as Eastern cultures and should be promoted and maintained as it is a good lifestyle. On the other hand, in Western countries, only equality is respected. I think this is very rigid. Equality and respect are important ethic values of human beings but the latter is much more important (ST2, J3, Lesson 9b).

(50) I am surprised and do not agree with the way children and elderly people are treated in English-speaking countries. It is very good when children are treated with equality as they will be able to develop their independence and confidence. However, this sometimes makes the family ties less tight and close. I do not find it good when elderly people are not much appreciated. In Vietnam, elderly people are respected and well treated in the family and community. It is the opposite in Western countries where elderly people usually feel lonely, discriminated against and lack family love (ST10, J3, Lesson 9b).

Similarly, ethnocentric attitudes were demonstrated by one-third of the ST students in the topic of 'pets'. When these students were asked to reflect on the treatment of pets 
in Britain which is considered better than children, they expressed disagreement, unacceptance, intolerance or even culture shock. Such attitudes can be seen in examples (51) and (52):

(51) There are many reasons to explain why people in English-speaking countries treat pets like children or even more than that. Perhaps, people in these countries rely on pets because they want to make up for a limited spiritual life or a lack of trust with other people (ST16, J2, Lesson 6).

(52) I am very surprised with the order of importance in Britain: pets-children-womenmen. I do not understand why English people love their pets so much that they treat them better than children. This is intolerable and inappropriate in Vietnamese culture (ST22, J2, Lesson 6).

Evidence of ethnocentric attitudes was also found in the ST class in other topics, although they were much less prevalent than the above two topics. These ethnocentric attitudes were related to the students' pride about the tradition of family care, the hospitality of receiving guests, the supremacy of the teacher role in the learner's own culture, and a lack of family relations in the target culture. The following two examples can illustrate such attitudes:

(53) I find that Japanese people are also hospitable like people in my country when receiving guests at home. This shows a very good Eastern tradition when the host prepares all the food for the guests. This is completely different from the pot luck in America where you have to bring something to share. Bringing some food to a party makes me feel uncomfortable (ST21, J1, Lesson 3).

(54) Schools in Vietnam impose punishments on children, whereas in Western schools this hardly ever happens. Correcting children using words is sometimes not enough. Therefore, it is appropriate that children should be punished with a smack on the hands. This represents the supremacy of the teacher over children. Whereas in Western countries, this is considered an insult to other people's bodies but the teacher's position is not as properly respected as in Vietnam (ST32, J3, Lesson 9a). 


\section{(2) Showing openness, respect and tolerance towards other cultures}

The IC class showed a great deal of openness, respect and tolerance towards the target culture, in contrast with the ST class, particularly in the topics of 'animals', 'men and women' and 'the elderly'.

The IC class showed the most evidence of openness, respect and tolerance in the topic of animals in contrast with only one mention of such evidence in the ST class. Notice the difference between the two classes in the following examples:

(55) In Asia, people are much more respected than pets, whereas in some Western countries, there is equality between pets and people. Therefore, when living in such countries, we will not get shocked with the way people treat pets as they do with other people (ST35, J2, Lesson 6).

(56) I am surprised at the treatment of pets in the target culture and the way English people raise and take care of pets. I find this useful for me as it helps me avoid culture shock when their treatment of pets is completely different from the treatment of pets in my country. Therefore, when I hear English people talk about their pets, I will not be so surprised and I will be able to respect their points of view (IC12, J2, Lesson 6).

The ST student in example (55) was tolerant with the way the target culture people treat their pets, while the IC student in example (56) showed both tolerance and respect towards this treatment. Classroom observations showed that the IC students' positive attitudes for the treatment of pets were developed from their engagement in a cultural situation concerning the imprisonment of an American woman due to maltreatment of her dog. An IC student showed such an attitude by learning from this situation:

(57) I am very surprised at the way people in the target culture treat their pets. In Vietnam, people are imprisoned when they hurt others, not animals, whereas in America a woman was imprisoned for 6 months when she left her dog to starve to death. I wonder whether this comparison means that target culture members treat pets better than the way Vietnamese people treat other people. However, this is their specific cultural feature. An understanding of the attitudes of target culture 
members towards their pets helps me avoid culture shock and negative thoughts about them and helps me respect their points of view (IC16, J2, Lesson 6).

The IC students' positive attitudes towards the target culture were also developed from the teacher's sharing of her intercultural experience in her Australian homestay as illustrated in example (58):

(58) For pets in the target culture, we should treat them like children, even anticipating that it is a normal thing when a meal portion is shared between the guest and the pet in an Australian homestay. It does not mean that they do not respect us but it is because they consider pets as a family member. So try to accept it and do not feel insulted as it is their culture. From this perspective, we can build good relations with them. (IC27, J2, Lesson 6).

The IC students also learned to be tolerant with unfamiliar behaviours of people from other cultures in the lesson on 'men and women'. This intercultural attitude is expressed in the following example:

(59) Women who smoke or go to nightclubs are quite normal in Western countries whereas it is not a good thing for women in my country to do. Behaviours of people from English-speaking cultures may be different from those in my country. However, I understand that their behaviours are influenced by the culture they are living in. Therefore I feel more tolerant towards them (IC15, J1, Lesson 2).

Similar attitudes were found concerning the treatment of the elderly, but there was only one mention of tolerance in the ST class towards the life of the elderly in nursing homes in the target culture. Notice the difference between the two classes in the following examples:

(60) I am proud of the national tradition of respecting elderly people in my country but I will not get surprised to see that most elderly people in Western countries live in nursing homes (ST35, J1, Lesson 2).

(61) I highly respect the way elderly people are treated in my country as it is a good tradition which needs to be maintained and promoted. However, I still respect the way elderly people are treated in Western countries as this is their culture where 
people get used to living independently from a very young age and because of this they prefer freedom. Being aware of this way of treatment towards the elderly in the target culture, I will not get shocked but try to adapt to it for better communication with them (IC27, J3, Lesson 9b).

In examples (60) and (61) above, both the ST student and the IC student were concerned about the traditional values of respecting elderly people in their country. However, while the ST student was tolerant about the lives of Western elderly people in nursing homes, the IC student demonstrated respect towards such treatment based on an understanding of their lifestyle.

\section{(3) Adopting an attitude change}

The students in the IC class reported that they experienced an attitude change in the intercultural lessons, whereas this evidence was barely found in the ST class. The attitude change resulted from the IC students' positive attitudes towards the target culture. It was about the stereotyped personalities of English people, the norms of socialising, and unfamiliar gestures in the target culture. Reflecting on British people's holiday preferences, for example, one IC student reported an attitude change about their stereotyped personality:

(62) In discussions about English people's holiday preferences, I thought that they were very reserved but it was not true. They are in fact very enthusiastic in some contexts but they prefer quietness and individuality (IC7, J1, Lesson 3).

Another attitude change resulted from the IC students' engagement in the situation of having dinner with an American friend which showed a big contrast in cultural values between their culture and American culture. Classroom observation showed that the students had different reactions to the situation. Some, at first, were shocked with the 'American way' of socialising. They assumed that the American friend should have paid the bill as he was the one who had invited them. Other students became more empathetic with the American as they understood his behaviour as a norm of socialising in the target culture. This attitude can be seen in example (63): 
(63) At first, I feel shocked when the American only paid for his own food. Then I find it acceptable when I understand that American people usually do that in socialising and invitation was the mere purpose to get more people to join. In my culture, the bill is sometimes split up among friends (IC29, J1, Lesson 3).

An understanding of cultural differences in the treatment of pets also led to a shift of attitudes in the IC class as shown in examples (64) and (65):

(64) My thoughts and attitudes gradually change when I am aware of cultural differences in lifestyles, habits and interests of target culture members. For example, I used to dislike and feel uncomfortable with the treatment of English people towards their pets. As far as I have been aware of differences between their culture and mine, I do not feel uncomfortable any more (IC6, J2, Lesson 6).

(65) My thoughts and attitudes about target culture members also change. For example, I used to think that English people were very cold and unfriendly, but I find that they are also friendly through the way they treat their pets (IC34, J2, Lesson 6).

The ethnographic interview, particularly, with the native English speaker in the classroom, contributed to an attitude change in the IC class, which was shown in following example regarding the treatment of the elderly in the target culture:

(66) By interviewing the Canadian teacher, I recognise new viewpoints of target culture members that make me change my own views. For example, the treatment of elderly people in English-speaking countries makes me surprised. Some people may not accept this way of treatment. However, these new things change our way of thinking and attitudes towards target culture members. (IC11, J3, Lesson 9b).

\section{(4)Judging another culture from the others' perspectives}

When students judge an aspect of other cultures from the others' perspectives, they have ethnorelative attitudes. Students with ethnorelative attitudes put themselves in the other's shoes and show empathy towards the others. They also show the ability to adopt an intercultural perspective about different cultures. It was found that this kind of attitude was quite resistant to development across the six topics. However, some ethnorelative attitudes were evident in the IC class, whereas there was relatively little 
evidence of these attitudes in the ST class. For example, in the lesson on 'men and women', an IC student considered the normality of the smoking and drinking behaviours of women in the target culture with an ethnorelative attitude:

(67) There are many things that girls can do in another culture which they cannot do in my culture. For example, it is normal to see a woman who goes mountain climbing, does boxing, smokes or drinks in a Western country. I think it depends on our ways of thinking. For me, the smoking and drinking behaviours of a woman is completely normal as long as it fits in with the norms of a society. There are prejudices against women who smoke or drink in my culture, but in fact some elderly Vietnamese women do smoke and many women drink in business with men in Vietnam nowadays (IC16, J1, Lesson 2).

An ethnorelative attitude was also shown when the others' point of view was taken into account in intercultural communication:

(68) Attitude is an important factor for me in intercultural communication. While frankness is a virtue for many American people, it is not appropriate for Vietnamese people to address an issue directly. I may ask others some questions that seem natural to me but intrusive to them. We need to consider the others' point of view before we can understand them. We should not jump to any conclusions so quickly (IC16, J2, Lesson 5).

An intercultural perspective was also developed when the IC students had an ethnorelative attitude. Classroom observations showed that an intercultural perspective about the judgment of cultural habits of people from another culture was developed from the students' empathy towards the lives of old American people in nursing homes:

(69) I have empathy towards most elderly people in Western countries living in nursing homes although this is against the Vietnamese tradition. However, feelings or attitudes depend on and are ruled over by each culture. It is, therefore, not possible to judge cultural habits of people in this culture on the basis of cultural behaviours of people from another culture (IC22, J3, Lesson 9b). 
Similarly, an intercultural perspective was developed from an ethnorelative attitude about gestures across cultures:

(70) The gesture of calling a person using the palm in an upward position, which is considered to be a way of calling a dog according to Vietnamese people's way of thinking, should be reconsidered. It is possible that what is good and polite for someone in one culture does not necessarily mean the same to others from another culture and vice versa. We should accept and learn from what we consider not good for our own culture, but may be good in another culture (IC5, J2, Lesson 5).

Example (70) shows that the IC student adopted an intercultural perspective with an appreciation of values across cultures.

\subsubsection{Summary}

The findings showed that the ST students mainly developed their intercultural awareness around the low and medium levels of IC, whereas this development was demonstrated around the medium and high levels of IC in the IC class. Although both classes had similar instances of general knowledge and cultural comparisons, the IC class showed more awareness of cultural differences. They demonstrated a deeper understanding of the target culture and deeper insight into their own culture with critical cultural awareness. They also developed a richer communicative awareness with adaptability and ability to mediate between cultures. Particularly, the IC students demonstrated an increased awareness of cultural relativity; however, they still had limited understanding of the variation of L2 culture. Cultural relativity was barely found in the ST class.

The findings also showed many differences between the two classes in terms of the learners' intercultural attitudes across the six topics. While the ST class tended to have prevalent ethnocentric attitudes with which they judged the target culture from their own cultural perspectives, the IC class showed more openness, respect and tolerance towards the target culture. Such positive attitudes resulted from their better understanding of the target culture. There was also some evidence of ethnorelative attitudes in the IC class with which the students considered the target culture from the 
others' perspective and adopted an intercultural perspective with an appreciation of values across cultures.

Overall, the intercultural intervention contributed to a better development of the students' intercultural competence in the IC class. This development resulted from the students' active engagement in the intercultural lessons. The IC class lessons dealt with culture explicitly and the students actively engaged in culture learning cognitively, behaviourally, affectively, and therefore their intercultural development became more obvious than the ST class. The ethnographic interview with a native English speaker invited to the classroom also contributed to the enhancement of the IC students' understanding and positive intercultural attitudes towards the target culture.

\subsubsection{Case studies}

Apart from the differences in the students' demonstration of intercultural awareness and attitudes as mentioned in the previous sections, four case studies were also analysed in order to provide further insight into the development of the students' intercultural awareness and attitudes in the two classes. The description of these case studies can be referred to in section 7.5.4.4 in chapter seven. The results report on data from each case study student's reflective journals and individual interviews. Only typical examples are given to illustrate each case study student's main insight into intercultural awareness and attitudes.

\subsubsection{Case study 1}

The first case study involved Binh who belonged to the ST class.

\section{Intercultural awareness}

Binh developed her intercultural awareness across the six topics in a limited way. She had some generic comments regarding differences between boys and girls and things to learn at school, which did not show any evidence of intercultural awareness. At the low level of IC (refer to Figure 8.6 for the levels of IC), she stated more general knowledge about festivals, interpersonal communication, and animals. In making 
comparisons about different festivals, she highlighted the importance of traditional values. She also made some comparisons about body language and the treatment of the elderly. Example (71) shows her comparison about the treatment of the elderly between the target culture and her own culture:

(71) The treatment of elderly people reveals the culture of each country. For example, elderly people in Western countries are sent to nursing homes for better healthcare, whereas in Vietnam people take care of their aged parents at home (CS1, Interview 4, Lesson 9b).

When making comparisons about the rules in kindergarten education, Binh was more concerned about the commonality rather than cultural differences across cultures:

(72) The cultural feature is represented in education for children: how to behave towards others. Many countries have different ways of education for children, but there is something in common: all want to teach children life skills (CS1, Interview 4, Lesson 9a).

At the medium level of the three levels of IC, Binh showed some understanding of the target culture in the topics of 'animals' and 'kindergarten education'. She understood, for example, the values of educating children to love and protect animals at an English school, and acknowledged the act of knitting sweaters for the penguins in danger and the choice of pets as a way to develop children's responsibility. She acknowledged the influence of the educational environment on the development of children's personalities in the target culture:

(73) There are good things in the target culture that children in Vietnam need to learn. I felt so surprised that children in the target culture learn so many things. Education is very important for children. I used to think that children in the target culture became mature due to their living conditions in family, not through education at school. From this, I understand that the educational environment has allowed for the formation of good skills in children (CS1, Interview 4, Lesson 9a).

Binh was more likely to develop cultural self-awareness. This self-awareness was about the personalities of boys and girls, the use of clichés as a way of 
communication, and the relationship between people and pets in her own culture. Example (74) shows her cultural self-awareness about pets:

(74) English people tend to love pets more than Vietnamese people as in Vietnam people make a clear distinction between people and animals although they also have pets at home (CS1, Interview 3, Lesson 6).

At the high level of IC, Binh showed limited communicative awareness and no evidence of ethnorelative awareness. For example, she was aware of the importance of having different perceptions of animals across cultures for effective intercultural communication:

(75) Treatment of animals is different across cultures. We need to have knowledge about this in order to communicate with the target culture members appropriately. For example, we should avoid talking about animals that are considered unlucky in some cultures (CS1, Interview 3, Lesson 6).

\section{Intercultural attitudes}

Binh developed her intercultural attitudes in a very limited way. She was more likely to express ethnocentric attitudes in some topics. Talking about the roles of women across cultures, for example, she considered that there was a lack of family care for women in the target culture. She also denied cultural differences in the way of greetings in the target culture which made her feel embarrassed and uncomfortable:

(76) Men and women in English-speaking countries sometimes greet each other by hugging or kissing on the cheeks, which makes me feel embarrassed and uncomfortable as it does not suit Vietnamese culture (CS1, Journal 1, Lesson 2).

She was also concerned about the value of her own culture rather than the value of the target culture in the treatment of the elderly:

(77) I completely agree with the way elderly people are treated in my country. We are responsible for looking after our parents and grandparents who have nurtured us. In addition, the society also needs to take care of homeless elderly people to 
compensate for their hardship and disadvantage. We should continue the good tradition of looking after elderly people to make them happy. In Vietnam, there are also many other traditions where we show respect to elderly people such as the longevity anniversary for elderly people which displays the concern of the society for them and provides an opportunity for people to show their gratitude to their parents and grandparents (CS1, Journal 3, Lesson 9b).

The only evidence of openness Binh had was about the relationship between a man and a woman for a business lunch:

(78) Regarding eating out between a man and a woman, the relation may be an advantage for Westerners but a disadvantage for Easterners. There are some negative ideas about this relation. My ideas are completely opposite. I think it is completely normal for such a business lunch between a man and a woman. I do not accept the negative ideas except if the woman is married, but it is completely all right for a business lunch. (CS1, Interview1, Lesson 3).

The above example (78) shows that Binh considered the business relationship between a man and a woman normal; however, she still put her own cultural perspective in the judgment about the business relationship of a married woman with her male clients.

In brief, Binh demonstrated intercultural awareness and attitudes in a limited way across the topics. She stated more general knowledge, had little recognition of cultural differences, and was more concerned about traditional values and commonality among cultures. She was more likely to demonstrate awareness of her own culture than understanding of the target culture. She showed limited communicative awareness and no evidence of ethnorelative awareness. Her intercultural attitudes were still underdeveloped with more ethnocentric attitudes than openness, which tended to keep her away from developing ethnorelative attitudes towards the target culture.

\subsubsection{Case study 2}

The second case study involved Phuoc who belonged to the ST class. 


\section{Intercultural awareness}

Phuoc developed her intercultural awareness across the six topics quite beyond the low level of facts. She only made some simple cultural comparisons about kindergarten education and the treatment of the elderly at this level. At the medium level of IC, she demonstrated her intercultural awareness with some understanding of the target culture about animals and communication styles. Reflecting on different issues about animals, for example, she acknowledged the values in educating children to protect animals, the act of sending sweaters to penguins in danger and different ways to protect animals in the target culture. Apart from some generic comments about interpersonal communication, she showed understanding of the value of different communication styles between her culture and the target culture:

(79) Communication differs across cultures. In Vietnam, politeness is much appreciated; people live in a society where there is a hierarchy in communication (from older to younger people with different address forms). In the US, communication is quite comfortable as people are equal (I and you) (CS2, Interview 2, Lesson 5).

Phuoc particularly developed a lot of cultural self-awareness. Her cultural selfawareness involved the development of personalities of boys and girls, the increasing use of body language, kindergarten education, and the concept of old age in her culture. She acknowledged, for example, the good values of kindergarten education in the target culture, critically evaluating those of her own culture, and exploring herself by looking back to her own education:

(80) Both Vietnamese culture and English-speaking cultures help children to develop their personalities by teaching them good qualities such as love, unity, hygiene and honesty. However, Vietnamese culture only deals with that, i.e children are only taught the qualities of a good child. On the other hand, English-speaking cultures also teach children how to live and study, to have a balanced life, which is very strange for children in Vietnam. I questioned myself whether children are taught how to behave and live a balanced life, whether it is too early for them and whether it is necessary to do it...I thought about my family, about how I was educated in childhood...I found a shortcoming for children in Vietnam: it is necessary to 
prepare them to face things they do not know in their childhood in order to avoid any difficulties (CS2, Interview 4, Lesson 9a).

Similarly, she also critically evaluated the concept of old age in her culture from learning about the dynamic lifestyle of people over fifty in the UK in the lesson:

(81) In Vietnam, elderly people are always respected but they are not thought to be able to do many things for society. They only relax in their old age, and take care of grandchildren. There are not many activities for them. Old age in English-speaking countries is not based on the real age but on the mental life and a sound mind. Many elderly people are still very dynamic and participate in many social activities. In Vietnam, due to low living standard and lack of concern from the society for elderly people, their mental needs are not met (CS2, Interview 4, Lesson 9b).

At the high level of IC, Phuoc demonstrated only communicative awareness across the topics without any evidence of ethnorelative awareness. Her communicative awareness was about the importance of maintaining eye contact and expressing one's willingness through body language. She was also aware of a variety of appropriate behaviours in contact with people from Japan, Spain, and America through their ways of entertaining guests:

(82) I have learned things that I need to do when I go to other countries. For example, in such a strictly-disciplined country like Japan, try to be polite and modest when having a meal with them; try to be comfortable and get along well with others when you are with American or Spanish people; especially if you want to do business in America it is necessary to pay a lot of attention to one's own behaviour in public (CS2, Journal 1, Lesson 2).

Phuoc showed her flexibility in dealing with the treatment of pets in the target culture. Her knowledge about the elderly in the target culture also facilitated her adaptability:

(83) I learn about the way elderly people in English-speaking countries participate in social and outdoors activities and how they are treated in society (most of them live independently from their children). This knowledge helps me to learn to adapt to a 
globalized world where people from different cultures have a chance to contact one another for a better mutual understanding (CS2, Journal 3, Lesson 9b).

\section{Intercultural attitudes}

Phuoc developed her intercultural attitudes in a limited way. She did not demonstrate much evidence of positive attitudes. For example, she was more concerned about preserving her own cultural values than being open to new things from other cultures:

(84) It is not recommended to quickly grasp new things from other cultures and distort our own cultural values that have been inherited from our ancestors (CS2, Journal1, Lesson 2).

The only evidence of her positive attitudes was her interest in discovering other cultures through different uses of body language across cultures, and her openness about the social prejudice against the way of entertaining clients by American businesswomen. The latter evidence can be seen in the example below:

(85) There are still many prejudices against women's business relations. There are two ways: women invite their male business partners to a quiet place or they can take them to places where many colleagues may come in order to make their relations clear. These ways are only temporary as the importance is to change the prejudice of the society against this (CS2, Interview1, Lesson 2).

In brief, Phuoc was more likely to develop intercultural awareness than intercultural attitudes. Although she moved beyond the factual level and showed some understanding of the target culture, she was more likely to demonstrate awareness of her own culture. She showed communicative awareness with some adaptability and flexibility, but no evidence of ethnorelative awareness. Her intercultural attitudes were quite limited with little evidence of openness and respect towards the target culture. 


\subsubsection{Case study 3}

The third case study involved Thanh who belonged to the IC class.

\section{Intercultural awareness}

Thanh mainly developed her intercultural awareness at the medium and high levels of IC. At the medium level, her understanding of the target culture and her own culture involved awareness of a variety of issues such as gender differences and gender roles, the equality of men and women in family and society, holiday preferences, cultural norms of interaction in intercultural communication, animal protection and the values of kindergarten education. For example, discussing gender differences in the cartoons in the lesson, she became aware of cultural stereotypes and understood gender differences and roles across cultures:

(86) There are many stereotypes about gender differences and gender roles in the cartoons. For example, men are supposed to be bossier and messier whereas women are supposed to be more complicated and more aggressive. Similarly, women are supposed to do the housework while men are watching TV or reading newspaper. I think these gender differences and roles can vary from person to person and from culture to culture depending on their learned behaviours in family and society. In Vietnam, gender roles are changing and men are taking on more responsibilities by sharing housework with their wives (CS3, Journal 1, Lesson 2).

For the treatment of pets in the target culture, Thanh considered that a mutual understanding of each other's culture would shorten distance between people from different cultures. She acknowledged the values of the target culture and critically evaluated her own culture from the situation of an imprisonment of an American woman in the lesson:

(87) The story about an American woman who was imprisoned for 6 months due to maltreatment of her dog shows the love for pets in the target culture. This beautiful cultural value should be learned by Vietnamese people. This not only shows the awareness of each individual but also represents a beautiful culture. I completely agree with the protection of animals in the US. In Vietnam, there is no such law and 
I completely agree with the decision of the judge. This law helps people develop their awareness of the importance of animals and be more responsible for them. In Vietnam, people are not very friendly towards animals. From this story, I became aware of the importance of animals and love them more (CS3, Interview 3, Lesson $6)$.

The interview with the native English speaker in the classroom, particularly, helped Thanh develop a better understanding of the treatment of the elderly in the target culture:

(88) The elderly in Canada like to live independently. Children are taught to be selfreliant right from a young age in the kindergarten. Therefore, when growing up, they like to be self-reliant, even in old age. That is why elderly people prefer to live in nursing homes rather than live with their children although they are still well treated by their children. They do not need their children to look after them (CS3, Journal 3, Lesson 9b).

At the high level of IC, Thanh showed much communicative awareness for intercultural communication. Learning from the situation of a Vietnamese couple's visit to an American home in the lesson, for example, she demonstrated an awareness of how to deal with cultural misunderstanding in potential intercultural encounters from her understanding of the expression 'drop in any time':

(89) I understand that both the American host and the Vietnamese couple were upset due to cultural misunderstanding. The American host did not mean the Vietnamese couple could come any time when they said 'Drop in any time'; an advanced arrangement should have been made. Similarly, the American host did not meet the expectations of the Vietnamese culture as he/she did not show their hospitality to welcome his/her guests. From this situation, I find that it is important to know how to interpret and deal with the misunderstanding by observing the other's attitudes and feelings. An explanation may also help to solve the cultural misunderstanding (CS3, Journal 1, Lesson 3).

Thanh argued that it was important to understand people's intentions and cultural norms of interaction to have a successful communication. She became more aware of 
her own behaviours in communication with people from other cultures. She also considered the influence of one's own culture on intercultural communication and the necessity to understand other people from their point of view:

(90) There are factors we need to be aware of in intercultural communication. Our culture usually influences the way we approach problems and participate in communication. The importance is that you need to know the influence of your culture on the way you communicate with people from other cultures and try to understand them from their point of view (CS3, Interview 2, Lesson 5).

Thanh also showed an awareness of adaptability to the target culture. For example, she tried to maintain eye contact in communication with English people although it was not her habit:

(91) The nature of eye contact differs across cultures. English people tend to maintain eye contact with you, while Vietnamese people do it from time to time. Although maintaining eye contact is not my habit, I think I would maintain eye contact with English people when I communicate with them as it can help me know the other's attitudes and mood so that I can adjust my behaviour when necessary (CS3, Interview 2, Lesson 5).

She tried to adapt to the target culture by acquiring its good values while still maintaining her own cultural identity through the treatment of the elderly in America:

(92) In the case of the cultural situation about elderly people in America, I think that 'while in Rome, do as the Romans do'. But in this case, the Vietnamese cultural values are still valid for Vietnamese people living in the US. This means that when living in another country, we do not need to be assimilated to the target culture, but maintain our own values while acquiring the good values of the target culture (CS3, Interview 4, Lesson 9b).

Moreover, Thanh also showed ethnorelative awareness from her understanding of the relativity of cultures. For example, learning from the cross-cultural communication situations in the lesson, she understood the relativity of indirectness and directness as a communication style across cultures: 
(93) It is often assumed that English people are direct and Vietnamese people are indirect. This is not true when I learn from the cross-cultural communication situations in which people do not mean what they say. Indirectness is still used in both cultures in different contexts in a different way, especially to avoid hurting other people's feelings.

Other evidence of her ethnorelative awareness can be seen in her judgment about the educational values of the target culture and her own culture:

(94) I think each educational system has its own values. For example, while children in English-speaking countries learn self-reliance skills and life skills, Vietnamese children learn to be polite with parents, teachers and other adults. I find the values in the target culture are also good for Vietnamese children to learn alongside with their own traditional values (CS3, Interview 4, Lesson 9a).

\section{Intercultural attitudes}

Thanh showed much openness, respect, and tolerance towards the target culture across the topics. Her positive attitudes were about the smoking behaviour of women in the target culture, the prejudice against American businesswomen, the unfamiliar gestures of people from other cultures, and the different treatment of pets in the target culture. For example, she disagreed with the prejudice against American businesswomen that still existed in American society:

(95) I am very surprised at the prejudice against the way the American businesswoman entertained her male clients. I thought it did not exist in American society. I find it completely normal for women to entertain their male clients. It is important to get rid of such an old-fashioned way of thinking. There is similar prejudice about women in my country. What is important is that you need to be yourself and not go beyond the business relations (CS3, Journal 1, Lesson 3).

A similar attitude can be seen in her acceptance of the treatment of the elderly in America: 
(96) In Vietnamese tradition, elderly people are always respected. They are looked after by their children and live with them under the same roof. Culture is different in California where aged parents or elderly people are sent to nursing homes where they can be happy with other old friends. People may have different ways to show their attitude towards their aged parents. I do not agree with the way the Vietnamese-American sons treated their old father as I find it too heartbreaking. However, if this happens with American people in California, I can accept it as Californians may have different ways to show their attitude to their aged parents such as creating a happy atmosphere for elderly people to live with other elderly people in the nursing homes (CS3, Interview 4, Lesson 9b).

The above example (96) shows that Thanh made a distinction between VietnameseAmerican and American people. Vietnamese-American people, for her, had to preserve their traditional values of taking care of their aged parents, whereas she still accepted the way American people treated the elderly. She also expressed empathy towards the treatment of the elderly in the target culture through this situation.

Thanh also showed evidence of ethnorelative attitude. She expressed respect towards the treatment of pets in the target culture by considering different ways of keeping pets in each culture:

(97) People in Vietnam normally have dogs to look after the house. These animals have a more practical meaning than dog pets in English-speaking countries where they are often treated as family members. We, therefore, need to respect the way pets are treated in those countries (CS3, Journal 2, Lesson 6).

In brief, Thanh developed her intercultural awareness and intercultural attitudes at the medium and high levels of IC across the topics. She showed an understanding of the target culture and her own culture in relation to various topics. She demonstrated communicative awareness with adaptability and ethnorelative awareness. She also showed positive intercultural attitudes consistently across the topics and highlighted the importance of cultural identity in the integration into other cultures.

\subsubsection{Case study 4}

The fourth case study involved Ngoc who belonged to the IC class. 


\section{Intercultural awareness}

Ngoc developed her intercultural awareness at the medium and high levels of IC across the six topics. At the medium level of IC, her understanding of the target culture and her own culture involved awareness of gender roles, the underlying values of receiving guests in America, the treatment of pets as family members and the values of kindergarten education in the target culture. For example, she understood the underlying values of receiving guests in each culture:

(98) Vietnamese people usually do not give advanced notice when visiting someone as they think it can surprise the host. This is completely different in America when the Vietnamese couple paid a visit to an American couple without giving advanced notice. The misunderstanding was caused due to the fact that both did not understand each other's culture in the way guests are received (CS4, Interview 1, Lesson 2).

Discussing the situation of maltreatment of pets in America in the lesson, Ngoc critically evaluated the status of animal protection in her own culture:

(99) From the cultural situation, if that happened in Vietnam, the woman would not be put in prison as people are put in prison whenever they harm other people, not animals. But that is the law in America and it can be accepted. There is no law about imprisonment of people who maltreat pets in my country. I was so surprised that an American woman was imprisoned for 6 months because she made her dog starve to death (CS4, Interview 3, Lesson 6).

She also acknowledged the values of training children in the target culture with selfreliance and critically evaluated the way children are educated in her own culture:

(100) In Western countries, children are trained to be self-reliant from a very young age; they have their own room and do not sleep with their parents. They are nurtured and given guidance regarding their future careers. In Vietnam, kindergarten education still does not get much emphasis; children do not learn much apart from learning how to behave properly and they are not given enough opportunities for development (CS4, Interview 4, Lesson 9a). 
At the high level of IC, Ngoc developed both communicative awareness and ethnorelative awareness across the topics. Her communicative awareness involved the ability to suspend judgment about others' unfamiliar behaviours and the ability to deal with cultural misunderstandings. For example, she tried to suspend her judgment about the smoking behaviour of women in the target culture:

(101) Before judging someone's behaviour, I usually put myself in their shoes to think about the positive side instead of the negative side where I may have a prejudice against or unfriendly opinion about them. Alternatively, before judging them, I also observe their behaviour such as the way they hold the cigarette or smoke and what language they use. From this, I can judge the type of person they are. This means that I will suspend my judgement of a person's behaviour on the surface (CS4, Interview 1, Lesson 2).

She paid much attention to challenges and different norms of interaction in intercultural communication to avoid communication breakdown:

(102) There are many challenges in cross-cultural communication, such as different ways of thinking, different ways of communication or attitudes. I pay much attention to different norms of interaction in intercultural communication. For example, many Americans typically speak in loud voices to emphasise the conversation, whereas some Vietnamese people speak loudly not for that reason, which may make Americans think the Vietnamese people are angry. It is important that the interlocutors understand the other's norm of interaction to avoid a communication breakdown. A mutual understanding of each other's culture contributes to the success of communication (CS4, Journal 2, Lesson 5).

She was also concerned about the other's attitudes and feelings in communication with English people. She highlighted the ability to observe the other's attitudes to deal with potential cultural misunderstandings in intercultural interaction:

(103) I learn a practical lesson from a story of two American and Vietnamese couples. There was a serious misunderstanding between them as they did not understand each other's culture. From this lesson, I recognize that whenever I am not sure about the other's culture, I will pay attention to their attitudes to see if they are 
comfortable or not in communication in order to manage all possible misunderstandings. Above all, it is necessary to learn about the other's culture before communication takes place (CS4, Journal 1, Lesson 2).

Particularly, Ngoc demonstrated the ability to mediate between cultures when her cultural values were found to conflict with those of the target culture. Dealing with the different treatment of pets in the target culture, she tried to mediate between the two cultures by not treating pets like target culture members, but in her own way, with responsibility. She also tried to mediate between the two cultures in dealing with cultural differences in the treatment of the elderly:

(104) The Vietnamese tradition of respecting elderly people is always appreciated and I myself always maintain this tradition. On the other hand, in Western countries, elderly people live independently from their children as they like to be treated with equality. I wonder what I should do to please them, but not lose the traditional values of my own culture if I have a chance to live with them. It is difficult but I think I just need to listen and observe so that in each situation I can behave appropriately in order to make both myself and my interlocutor feel comfortable. I will have specific actions that make them see my feelings coming from my heart and from the cultural values I have inherited from my own culture (CS4, Journal 3, Lesson 9b).

The above example (104) shows Ngoc trying to behave in a way that was appropriate within the target culture while still maintaining her own cultural identity. She attempted to reach an intercultural position where both she and the other interlocutor would feel comfortable. Cultural identity, in this process of mediation, became salient to her:

(105) For myself, whatever environment I live in, I need to perceive and select what is appropriate for me and my living condition. I do not need to imitate behaviours of target cultures...I think in any circumstances, we can acquire other culture but should not imitate the other's behaviour to become a clone of them (CS4, Interview 4, Lesson 9b). 
Ngoc also showed ethnorelative awareness in some topics. Reflecting on different ways of entertaining guests in Japan, Spain and America, she relativised the values of hospitality in her own culture to those of an American potluck:

(106) The ways of receiving guests in each culture have their own values. I am very interested in the hospitality in Japan as Vietnamese people are also very hospitable in receiving guests. The pot luck in America is also very interesting although we do not have potluck. While Vietnamese people tend to treat the others with their prepared meals to show their hospitality, the potluck in America shows the concern of the invited people who contribute their food to the party (CS4, Journal 1, Lesson 2).

She understood the relativity of cultures in the treatment of pets in the target culture through the English expression 'Love me, love my dog':

(107) There are different ways of keeping pets across cultures. As people in Vietnam tend to live in an extended family, pets are not considered a family member for them. On the other hand, English people usually live independently and so they treat pets like family members. The English expression 'Love me, love my dog' shows that pets are actually family members for English people. There is no such expression in Vietnamese. Keeping pets therefore has a different meaning in their culture. It is therefore important to respect the treatment of pets in English-speaking cultures although it is very different from my country (CS4, Journal 2, Lesson 6).

She also relativised the value of independence brought by kindergarten education in the target culture with the value of discipline in her own culture:

(108) Each educational system may represent different values. For example, while children in English-speaking countries learn to play fair or live a balanced life, children in Vietnam learn to be polite with grandparents, parents, teachers and adults. Rules in English-speaking countries tend to make children more independent while those in Vietnam tend to make children more disciplined (CS4, Journal 3, Lesson 9a). 


\section{Intercultural attitudes}

Ngoc demonstrated positive intercultural attitudes quite consistently across the topics. She became tolerant, for example, towards the different treatment of pets in the target culture. Reacting to the fact that an American woman was imprisoned for maltreating her dog, Ngoc expressed an attitude change from her understanding of the attitudes of target culture members towards their pets:

(109) I was first very surprised and even shocked at the way people in the target culture treat their pets. In Vietnam, people are imprisoned when they hurt others, not animals, whereas in America a woman was imprisoned for 6 months when she caused the death of her dog. I wonder whether this comparison means that target culture members treat pets better than the way Vietnamese people treat other people. However, this is their specific cultural feature. An understanding of the attitudes of target culture members towards their pets helps me avoid negative thoughts and respect their viewpoints (CS4, Journal 2, Lesson 6).

She also showed respect towards the way American people treated their aged parents in nursing homes:

(110) For American people, the fact that the elderly live in nursing homes is acceptable as it is their customs; the lifestyle of elderly people is different from Vietnamese people; children want their parents to have a life of freedom. It is not necessary to live with parents to take care of them (CS4, Interview 4, Lesson 9b).

Particularly, Ngoc showed ethnorelative attitudes and took the others' perspective into consideration. For example, she expressed empathy towards the smoking behaviour of women in the target culture and unfamiliar norms of socializing in the target culture. By learning different norms of interaction and ways of communication in the crosscultural situations in the lesson, she addressed the issues of directness and indirectness with an ethnorelative attitude:

(111) Attitude is an important factor for me in intercultural communication. While frankness is a virtue for many American people, it is not appropriate for Vietnamese people to address an issue directly. I may ask others some questions 
that seem natural to me but intrusive to them. We need to consider the other's point of view before we can understand them. We should not jump to any conclusions so quickly (CS4, Journal 2, Lesson 5).

Her ethnorelative attitude was also expressed towards the way of looking after the elderly in each culture:

(112) Behaviours and attitudes of Vietnamese and American people towards the elderly are different but we cannot say which country respects elderly people better than the other as each country has its own culture. In Vietnam, elderly people always expect their children to look after them, whereas in Western countries people learn to be self-reliant at an early age; so elderly people like to have an independent life. Ways of looking after elderly people are therefore different in each country and it is necessary to respect the different treatment in each culture (CS4, Interview 4, Lesson 9b).

In brief, Ngoc developed both intercultural awareness and attitudes quite consistently across the topics at the medium and high levels of IC. She showed understanding of the target culture and her own culture. She also demonstrated communicative awareness and was able to mediate between cultures while maintaining her own cultural identity. She also had ethnorelative awareness about different values of each culture. Additionally, she showed positive intercultural attitudes towards the target culture and empathy towards the target culture.

\subsubsection{Summary}

Although Binh and Phuoc belonged to the ST class, there were some differences between them. Binh moved from unawareness with generic comments in some topics to intercultural awareness with facts and some understanding of the target culture. She had little recognition of cultural differences, and was more concerned about traditional values and commonality among cultures. Phuoc, however, was more aware of cultural differences, although she also had some generic comments about interpersonal communication. While Binh developed her intercultural awareness mainly at the factual level, Phuoc had a deeper level of understanding with a focus on 
her own culture. Phuoc also demonstrated better communicative awareness with some flexibility and adaptability to the target culture. However, both Binh and Phuoc did not show any ethnorelative awareness. Both also had limited intercultural attitudes and Binh was likely to demonstrate prevalent ethnocentric attitudes. The distinction between Binh and Phuoc is consistent with the fact that Binh belonged to the low IC score group, while Phuoc belonged to the high IC score group in the selection at the beginning of the study.

There was, however, not much distinction between Thanh and Ngoc in the IC class although they were also selected on the same principles, i.e. Thanh belonged to the low IC score group and Ngoc belonged to the high IC score. However, as both of them were exposed to explicit culture teaching and learning in the IC class, both demonstrated a development of intercultural awareness and attitudes quite consistently across the topics. Both showed understanding of the target culture and their own culture. While Thanh developed communicative awareness with adaptability and flexibility, Ngoc was even able to mediate between cultures. Both were also able to negotiate cultural identity in dealing with other cultures. Thanh and Ngoc also had ethnorelative awareness about values across cultures. Both had prevalent positive intercultural attitudes across the topics, but Ngoc was likely to show more ethnorelative attitudes towards the target culture.

\subsection{Students' experience of intercultural language learning}

This section addresses the research question 6 that investigates how the students perceived intercultural language learning. The quantitative results report on the data from the self-evaluation questionnaire which was completed by students in the two classes at the end of the teaching period. The qualitative results provide further evidence about the IC students' experience of intercultural language learning with data from the student focus-group interviews and reflective journals.

\subsubsection{Quantitative results: self-evaluation questionnaire}

The results of the independent t-tests for the differences between the two classes concerning students' experience of intercultural language learning are given in Table 8.12 . 
TABLE 8.12

Independent t-tests for students' experience of intercultural language learning

\begin{tabular}{|c|c|c|c|c|c|c|c|}
\hline $\begin{array}{c}\text { Experience of } \\
\text { intercultural language learning }\end{array}$ & Class & $\mathbf{N}$ & $\mathbf{M}$ & SD & t value & df & $\begin{array}{l}\text { Sig (2- } \\
\text { tailed) }\end{array}$ \\
\hline $\begin{array}{l}\text { 1. Insight into aspects of one's own } \\
\text { culture }\end{array}$ & $\begin{array}{l}\text { ST } \\
\text { IC }\end{array}$ & $\begin{array}{l}38 \\
33\end{array}$ & $\begin{array}{l}3.21 \\
3.61\end{array}$ & $\begin{array}{l}.843 \\
.496\end{array}$ & -2.361 & 69 & $.021^{*}$ \\
\hline $\begin{array}{l}\text { 2. Insight into aspects of the target } \\
\text { language culture }\end{array}$ & $\begin{array}{l}\text { ST } \\
\text { IC }\end{array}$ & $\begin{array}{l}38 \\
33\end{array}$ & $\begin{array}{l}3.03 \\
3.79\end{array}$ & $\begin{array}{l}.822 \\
.740\end{array}$ & -4.079 & 69 & $.000 *$ \\
\hline $\begin{array}{l}\text { 3. Development of critical thinking } \\
\text { about aspects of one's own and the } \\
\text { target language culture }\end{array}$ & $\begin{array}{l}\text { ST } \\
\text { IC }\end{array}$ & $\begin{array}{l}38 \\
33\end{array}$ & $\begin{array}{l}2.47 \\
3.18\end{array}$ & $\begin{array}{l}.528 \\
1.109\end{array}$ & -3.352 & 69 & $.001 *$ \\
\hline $\begin{array}{l}\text { 4. Impact of one's own perspectives on } \\
\text { understanding other cultures }\end{array}$ & $\begin{array}{l}\text { ST } \\
\text { IC }\end{array}$ & $\begin{array}{l}38 \\
33\end{array}$ & $\begin{array}{l}2.27 \\
3.82\end{array}$ & $\begin{array}{l}.876 \\
1.136\end{array}$ & -6.337 & 69 & $.000 *$ \\
\hline $\begin{array}{l}\text { 5. Awareness of relationship between } \\
\text { language and culture }\end{array}$ & $\begin{array}{l}\text { ST } \\
\text { IC }\end{array}$ & $\begin{array}{l}38 \\
33\end{array}$ & $\begin{array}{l}3.05 \\
3.79\end{array}$ & $\begin{array}{l}.985 \\
1.023\end{array}$ & -3.081 & 69 & $.003^{*}$ \\
\hline 6. Effective approach to EFL learning & $\begin{array}{l}\text { ST } \\
\text { IC }\end{array}$ & $\begin{array}{l}38 \\
33\end{array}$ & $\begin{array}{l}2.61 \\
3.26\end{array}$ & $\begin{array}{l}1.144 \\
1.223\end{array}$ & -2.326 & 69 & $.023^{*}$ \\
\hline $\begin{array}{l}\text { 7. Effect of journal writing on culture } \\
\text { learning }\end{array}$ & $\begin{array}{l}\text { ST } \\
\text { IC }\end{array}$ & $\begin{array}{l}38 \\
33\end{array}$ & $\begin{array}{l}3.24 \\
4.03\end{array}$ & $\begin{array}{l}.913 \\
.585\end{array}$ & -4.282 & 69 & $.000 *$ \\
\hline 8. Motivation for learning English & $\begin{array}{l}\text { ST } \\
\text { IC }\end{array}$ & $\begin{array}{l}38 \\
33\end{array}$ & $\begin{array}{l}2.39 \\
3.89\end{array}$ & $\begin{array}{r}.899 \\
1.008\end{array}$ & -6.577 & 69 & $.000^{*}$ \\
\hline $\begin{array}{l}\text { 9. Confidence in intercultural } \\
\text { interactions }\end{array}$ & $\begin{array}{l}\text { ST } \\
\text { IC }\end{array}$ & $\begin{array}{l}38 \\
33\end{array}$ & $\begin{array}{l}3.34 \\
3.91\end{array}$ & $\begin{array}{l}.781 \\
.579\end{array}$ & -3.431 & 69 & $.001 *$ \\
\hline
\end{tabular}

Note: *p<.05. M and SD are calculated on a five-point scale (1-5).

The results show that there was a statistically significant difference at the .05 level between the IC class and the ST class concerning students' experience of intercultural language learning. In question $1, \mathrm{M}=3.61$ was significantly greater than $\mathrm{M}=3.21(t$ $(69)=-2.361, p<.05)$, which indicates the IC class had better insight into aspects of their own culture. In question $2, \mathrm{M}=3.79$ was significantly greater than $\mathrm{M}=3.03$ ( $t$ (69) $=-4.079, p<.05)$, which indicates the IC class had better insight into aspects of the target language culture. In question $3, \mathrm{M}=3.18$ was significantly greater than $\mathrm{M}=2.47$ $(t(69)=-3.352, p<.05)$, which indicates the IC class had better critical thinking regarding aspects of their own culture and the target language culture. In question 4, $\mathrm{M}=3.82$ was significantly greater than $\mathrm{M}=2.27$ ( $t(69)=-6.337, p<.05)$, which indicates the IC class had a better recognition of the impact of their own perspectives 
on understanding of other cultures. In question $5, \mathrm{M}=3.79$ was significantly greater than $\mathrm{M}=3.05(t(69)=-3.081, p<.05)$, which indicates the IC class was more aware of the relationship between language and culture. In question $6, M=3.26$ was significantly greater than $\mathrm{M}=2.61(t(69)=-2.326, p<.05)$, which indicates the IC class believed that they learned English using a more effective approach than before. In question 7, $\mathrm{M}=4.03$ was significantly greater than $\mathrm{M}=3.24(t(69)=-4.282, p<.05)$, which indicates the IC class found the journal writing had a great effect on their culture learning. In question $8, \mathrm{M}=3.89$ was significantly greater than $\mathrm{M}=3.29$ ( $t$ (69) $=-6.577, p<.05)$, which indicates the IC class became more motivated in English learning. Finally, in question 9, M=3.91 was significantly greater than $\mathrm{M}=3.34$ ( $t$ (69) $=-3.431, p<.05)$, which indicates that the IC class was potentially more confident in intercultural interactions.

In brief, the students in the IC class had a good experience of intercultural language learning over the nine-week period. This confirms that the intercultural intervention had a positive effect on the development of the learners' intercultural competence.

\subsubsection{Qualitative results: interviews and journals}

The students' experience of intercultural language learning in the IC class was further analysed with supporting data from the student focus-group interviews and reflective journals. The following nine themes derived from the self-evaluation questionnaire were used to demonstrate the IC students' experience of intercultural language learning. Only typical examples are given for illustration.

\section{(a) Insight into aspects of one's own culture}

The students stated that they had good insight into aspects of their own culture thanks to making connections with the target culture in the lessons. Such evidence can be seen in the examples given below:

(113) The lessons helped me to understand more about my own culture and cultural differences between my country and other countries. The more I discover my own culture, the more I feel interested in learning about other cultures (IC29, J1). 
(114) I have become increasingly aware of differences between my own culture and other cultures through comparisons. In order to have such comparisons, it is essential that I have to master my own culture. This is very useful for me in learning a foreign language (IC18, J2).

Examples (113) and (114) highlighted the importance of students' understanding of their own culture in culture learning. Such an understanding also motivated them to learn more about other cultures.

\section{(b) Insight into aspects of the target culture}

The interviewed students stated they had very good insight into aspects of the target culture. The most useful lessons for them were Lesson 2 (Men and Women), Lesson 3 (Festivals and Holidays), Lesson 5 (Interpersonal Communication), Lesson 6 (Animals), and Lesson 9 (The Best Age) because they explained that cultural differences in these lessons were more noticeable than in the others. The students stated that they understood how people in the target culture behaved and that they were able to adjust their own behaviours according to the target culture. They also experienced an attitude change, which helped them adopt an intercultural perspective towards the target culture. The following examples show such evidence:

(115) Before, I knew very little about English-speaking cultures and even did not understand them. But now I can understand English-speaking cultures better through the lessons and also have some changes in my thoughts and attitudes towards the target culture (IC22, J2).

(116) An understanding of the target culture is both interesting and surprising for me. It has helped me adopt an intercultural perspective about English-speaking cultures (IC20, J3).

(c) Developing critical thinking about aspects of one's own culture and the target culture

The interviewed students reported that the intercultural lessons contributed to developing their critical cultural awareness about different aspects of their own 
culture and the target one. For example, they commented on the issue of hospitality in their home culture with a critical cultural awareness:

(117) The Japanese see guests off until they do not see them any more. We need to learn this beautiful cultural feature. Although Vietnamese people are also well-known for their hospitality, they do not express it very clearly as the Japanese do (Interview SG2, Q3, P2).

\section{(d) Impact of one's perspectives on understanding of other cultures}

The students said that they became more aware of the influence of their own cultural perspectives on understanding other cultures. This awareness was particularly important for the students as it helped them decentre from their home culture to understand other cultures. Consequently, they were able to develop empathy and adopt an intercultural perspective towards other cultures. The following examples show how the students were able to avoid the impact of their own cultural perspectives on others in their judgment about other cultures:

(118) The intercultural activities helped me look at the target culture more properly. We cannot judge Westerners with an Eastern eye. We need to do it on the basis of a common facet that is the culture of each country in order to have an accurate judgement about people's behaviours in other cultures (IC22, J1).

(119) In order to be successful in communication with target culture members, we need to understand their culture, avoid taboos in communication and avoid imposing our own culture on others. It is necessary to be friendly, open-minded and change one's views about things that are not appropriate for one's own culture. Consequently, this will help us to avoid misunderstanding and cultural shock in communication with people from other cultures (IC16, J3).

The following example also shows that the students expressed empathy towards the elderly living in nursing homes in America without imposing their own cultural perspectives:

(120) Vietnamese people living in the USA have a lot of pressure with financial problems and housing. It is necessary to show empathy with the sons as it is their living 
condition that made them leave their father in the nursing home. If the old man lives at home, he must be looked after, and the sons do not have time to do it as they have to earn their living. That is why the old man has been sent to the nursing home. This is also common practice for many other elderly people in America. It is therefore necessary to accept it (Interview SG1, Q3, P2).

\section{(e) Awareness of the relationship between language and culture}

The intercultural lessons contributed to developing students' awareness of the relationship between language and culture. The following example shows students' understanding of the English expression 'drop in anytime' in the cultural situation of a Vietnamese couple's visit to an American home used in the lesson:

(121) The expression 'drop in anytime' in lesson 3 showed a close relationship between language and culture. This expression shows the good will of the American couple who wanted to welcome the Vietnamese couple at their home. Without understanding the underlying cultural value in this expression, the Vietnamese couple made the American host upset when they visited his/her home without advance notice (Interview SG1, Q3, P2).

Similarly, the students also showed their understanding about the target culture's family values through the expression 'Love me, love my dog' which expresses the close relationship between the target culture members and their pets:

(122) The treatment of pets like a family member in the target culture can be understood through the expression 'Love me, love my dog'. This expression shows that pets seem to be an inseparable part of an English family. On the other hand, the equivalent Vietnamese expression involves the relationship with extended family members rather than with pets (Interview SG2, Q3, P2).

\section{(f) Effective approach to EFL learning}

The interviewed students reported that the intercultural lessons helped them become more dynamic in language learning as they had opportunities to participate in class discussion and actively construct their intercultural knowledge and understanding of 
the target culture. They were able to improve their speaking skills through classroom discussion, and accumulate experience for future intercultural encounters.

Moreover, the students also considered that learning language and culture together is an effective methodology in EFL learning:

(123) A good method to learn a foreign language effectively is to understand thoroughly the culture of the country where that language is spoken (IC22, J1).

(124) Before I used to think that learning English was only to learn how to listen, speak, read and write and I was completely indifferent to learning culture. But now I recognise that in order to learn English well it is important to have a thorough understanding of the target language culture (IC2, J3).

They also acknowledged the value of intercultural language learning in the EFL classroom:

(125) Before engaging in contact with native English speakers, it is important for students to understand the target culture first. For example, students did not learn how people treat pets or the disabled in the target culture. An understanding of the target culture would prevent them from having a conflict with target culture members. Students would not get shocked or surprised when they encounter similar situations in real life and they can confidently explain cultural phenomena based on their understanding of the target culture (Interview SG2, Q7, P2).

Particularly, the intercultural lessons enabled the students to enhance intercultural awareness and attitudes towards other cultures as shown in the examples given below:

(126) The intercultural lessons trained me to have better awareness of the target culture and skills. I know how to select different viewpoints, receive the positive ones and eliminate the negative ones in order to be successful in intercultural communication (IC33, J2).

(127) The intercultural lessons provided students with a lot of experience and altered their thoughts in that they trained students to think from the others' perspective based on their cultural understanding about their own culture and the target culture (Interview SG1, Q5, P2). 


\section{(g) Effect of reflective journal writing on cultural learning}

Reflective journal writing was reported to have a positive impact on learners' culture learning. The interviewed students stated that it was a good way to review what had been learned in the lesson in a systematic way. Reflective journal writing also helped them better understand different cultural issues in their own culture and the target one which they had not been aware of before. With such an understanding, they were able to recognise the need to adjust their own behaviours to be more appropriate in future intercultural encounters with target culture members. Particularly, the students reported that journal writing helped them speak their thoughts freely and more easily. Reflective journal writing gave them an ability to express their identity without any imposition from the teacher:

(128) Students can write freely without feeling restricted by teachers as some teachers tend to impose their beliefs on students. If our thoughts do not match with those of the teachers, our ideas may be considered wrong. Reflective journal writing helps us to write out our own thoughts and be ourselves (Interview SG1, Q4, P2).

They also considered reflective journal writing a good method for both teachers and students. This method served as a bridge that connected teachers and students in culture teaching and learning:

(129) Reflective journal writing is an indirect channel between teachers and students which reveals how students perceive the target culture. It can help both teachers and students adjust their ways of culture teaching and learning to be more effective (Interview SG2, Q4, P2).

\section{(h) Motivation for learning English}

The intercultural lessons motivated the students to discover more about other cultures and get more interested in language learning. The following examples illustrate this evidence: 
(130) The intercultural activities in the lessons not only made me interested in other cultures, but also inspired me to discover other cultures in the world, which is the best way to learn a foreign language (IC2, J1).

(131) The intercultural activities stimulated my desire for language learning, my critical thinking as well as helped me actively search for information about the target culture rather than being passive in language learning (IC8, J2).

\section{(i) Confidence in interacting with people from other cultures}

The intercultural lessons potentially developed the students' confidence in interacting with people from other cultural backgrounds. This evidence can be seen in the examples given below:

(132) The intercultural lessons helped us become more confident in dealing with a cultural phenomenon based on our understanding of an aspect of the target culture (Interview SG2, Q5, P2).

(133) Culture learning helped me get in touch with target culture members more easily and learn from them. But culture learning practice requires my own efforts. Culture learning is the link to approach and understand other cultures and it helps me to avoid any embarrassment in intercultural communication (IC19, J2).

\subsubsection{Summary}

The results of the self-evaluation questionnaire showed a positive effect of the intercultural intervention on the learners' experience of intercultural language learning. The students in the IC class had a better experience of intercultural language learning than those in the ST class. They had better insight into different aspects of the target culture and their own culture. They were more aware of the impact of their own cultural perspectives on understanding of other cultures and the relationship between language and culture and were able to develop critical cultural awareness. The students also became more motivated by discovering other cultures and felt potentially more confident in intercultural interactions. In addition, learning language and culture together was considered an effective method in EFL learning as it helped the learners develop not only speaking skills but also enhanced their intercultural 
awareness and attitudes. Reflective journal writing was also considered an effective method for culture teaching and learning.

\subsection{Discussion}

This section discusses the key points from the results about the development of learners' intercultural competence. Two models of intercultural awareness and intercultural attitudes which emerged from the qualitative analysis of the learners' reflective journals are proposed. These models contain a contiguous series of levels of development that reflect the learners' process of acquiring intercultural competence. The proposed models are based on the structure of Baker's (2009) model of intercultural awareness which involves both conceptual and practice-orientated components. The content of these models was developed from my own study.

\subsubsection{A proposed model of intercultural awareness}

The proposed model of intercultural awareness (ICAW) in Figure 8.6 consists of three levels of development: low level of intercultural competence (IC), medium level of IC and high level of IC.

There is a distinction between conceptual ICAW and practice-orientated ICAW in the model. Conceptual ICAW involves learners' knowledge and understanding towards other cultures and their own culture, whereas practiceorientated ICAW involves the learners' ability to draw on their conceptual intercultural knowledge and apply it in intercultural communication. The model suggests a combination of knowledge, skills, and awareness that are interrelated and support one another.

There is also a distinction among the three levels of the model. Each level of ICAW feeds into the others, which shows a possible development of learners' ICAW from a lower level to a higher level. The low level of IC of the model involves learner's general knowledge about the target culture and a basic awareness of cultural similarities and differences at a factual level. With this knowledge and awareness, learners make cultural comparisons between the target culture and one's own culture. 
FIGURE 8.6

A proposed model of intercultural awareness

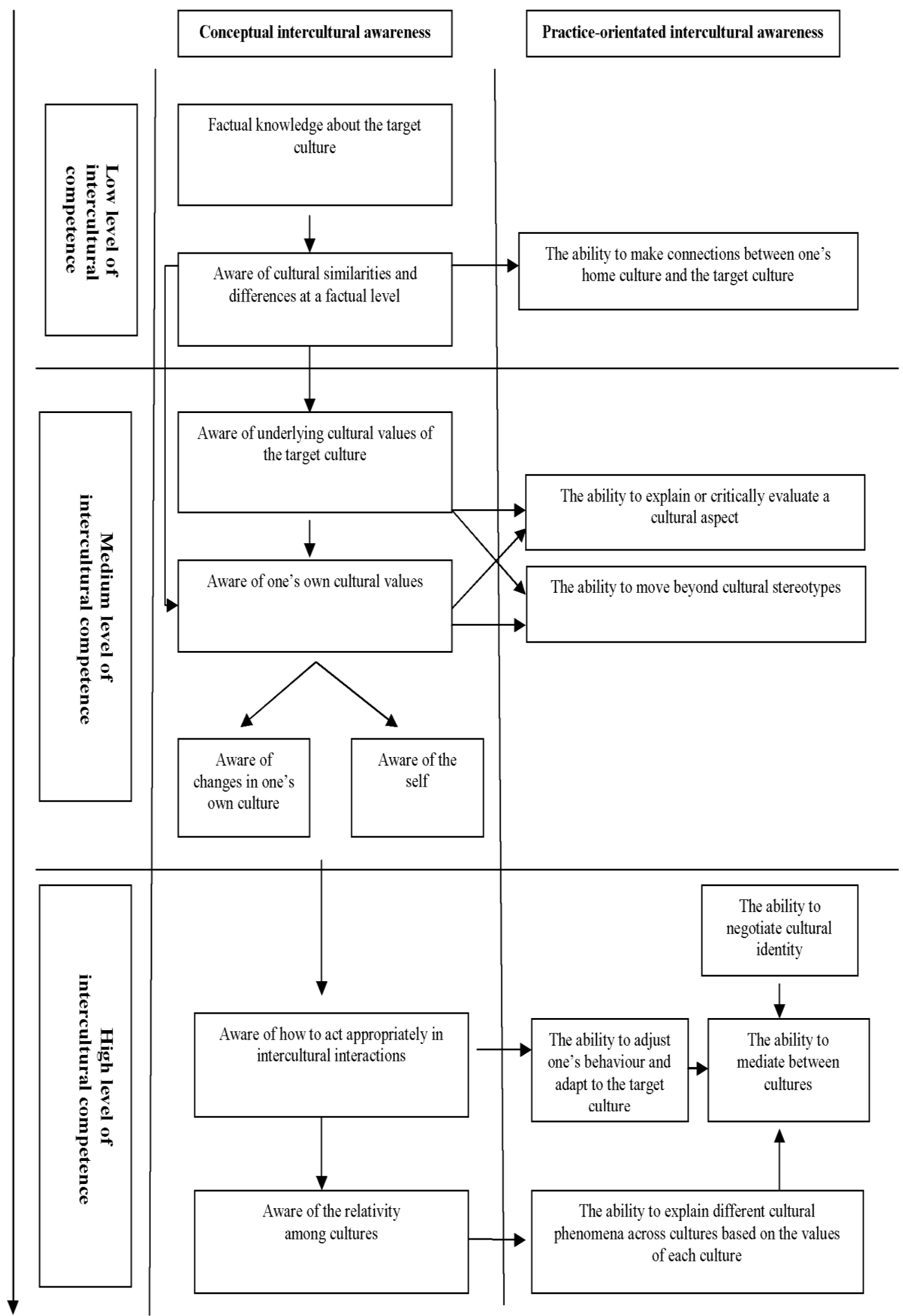


The medium level of IC involves learners' understanding of underlying cultural values in the target culture and their own culture. Learners show the ability to explain or critically evaluate other cultures or their own culture and move beyond cultural stereotypes. An understanding of other cultures would allow learners to refer to their own culture with an awareness of the self and changes in their own culture. The high level of IC indicates that learners can demonstrate an awareness of how to act appropriately in intercultural interactions. This level also involves learners' ethnorelative awareness, i.e. awareness about the relativity of cultures in relation to one another. This ethnorelative awareness combined with the ability to adjust behaviours and adapt to the target culture would help students mediate between cultures to reach an intercultural position where different points of view can be negotiated through expressions of cultural identity.

\subsubsection{A proposed model of intercultural attitudes}

The proposed model of intercultural attitudes (ICAT) in Figure 8.7 consists of three levels of development: ethnocentric attitudes, openness, respect and tolerance, and ethnorelative attitudes.

There is a distinction between conceptual ICAT and practice-orientated ICAT of the model. Conceptual ICAT involves the types of learners' attitudes towards other cultures and their own culture, whereas practice-orientated ICAT involves learners' ability to apply these types of attitudes in intercultural communication. The model suggests that the ability in practice-orientated ICAT is dependent on the types of attitudes developed in conceptual ICAT.

There is also a distinction among the three levels. Each level of ICAT feeds into the others, which shows a possible development of learners' ICAT from a lower level to a higher level. The first level, ethnocentric attitudes, is the lowest level of intercultural attitudes which involves learners' judgment about other cultures from their own cultural perspectives. Learners, at this level, consider their own culture superior to the target culture and therefore deny any values of the target culture. The second level, which involves openness, respect and tolerance, shows learners' acceptance of cultural differences across cultures with positive attitudes that enable them to suspend their judgment about unfamiliar behaviours in other cultures as well as shift attitudes. 
FIGURE 8.7

A proposed model of intercultural attitudes

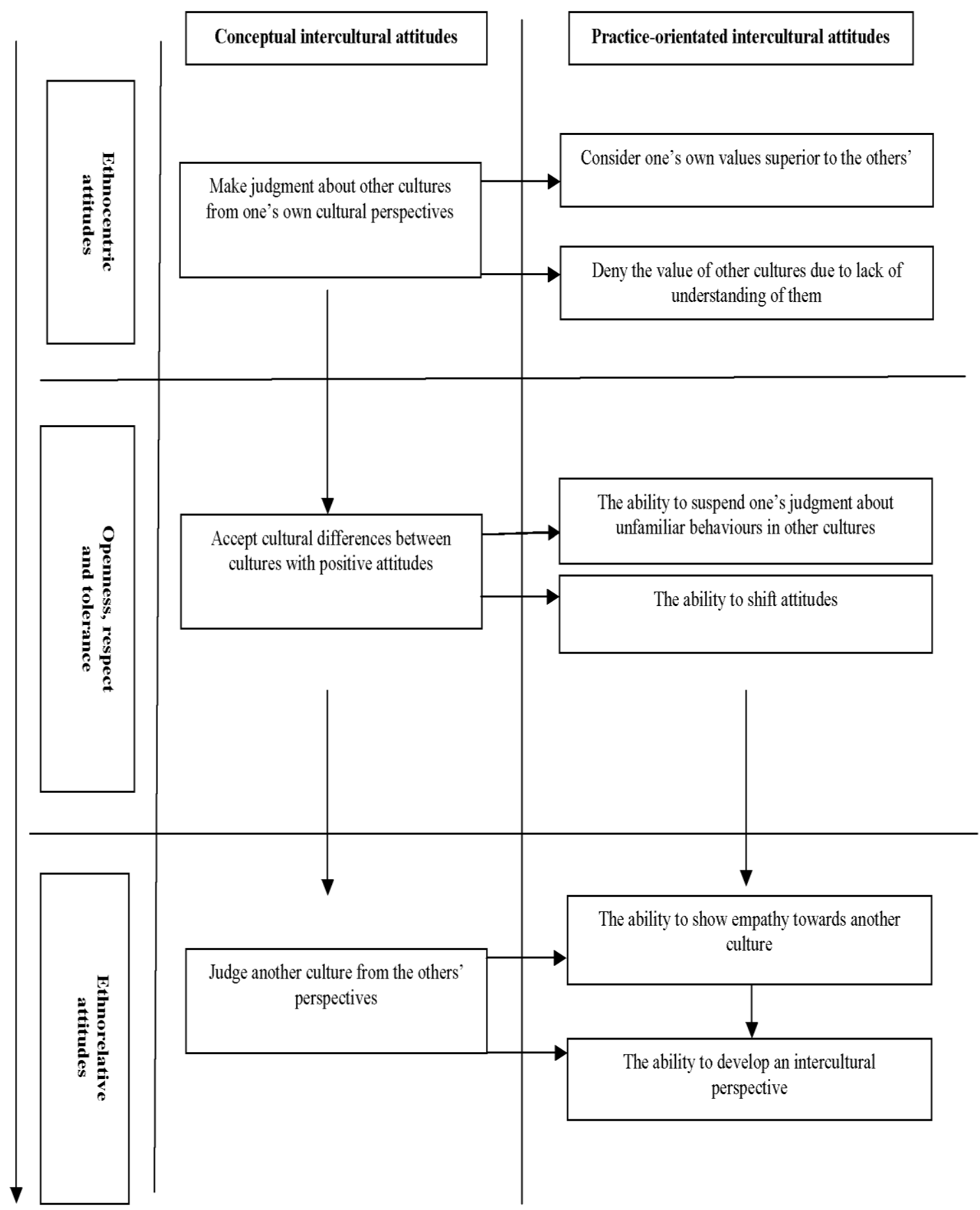

The third level, which involves ethnorelative attitudes, indicates learners' judgements about another culture from the others' perspectives. These attitudes enable them to develop empathy and an intercultural perspective towards other cultures. 


\subsubsection{Dimensions of the learners' developing intercultural competence}

This section discusses nine dimensions of the learners' developing intercultural competence from the findings of the study.

\subsubsection{Learning about the 'other'}

Both classes had some kind of understanding of the 'other' when they were exposed to intercultural issues. The IC class, however, tended to show a deeper understanding of the target culture as they were more aware of cultural differences across the six topics. This deeper understanding in the IC class was expressed by the students' awareness of cultural stereotypes and the underlying cultural values in the target culture.

The IC students developed awareness of cultural stereotypes as a way of understanding other cultures by moving beyond the cultural facts. Cultural stereotypes are an "exaggerated set of expectations and beliefs about the attributes of a class membership category" (Ting-Toomey, 1999, p.161). Cultural stereotypes can easily lead to intolerance towards out-class members and impede intercultural communication (Kim, 2001; Ting-Toomey, 1999). Tomalin and Stempleski (1993) believe that cultural stereotypes can be harmful as they do not allow for individuality, but encourage negative judgment and can easily lead to misunderstanding. Byram, Morgan et al. (1994) also argue that learners need to become aware of cultural stereotypes and actively confront them in order for change to occur. The IC students' awareness of cultural stereotypes in this study echoes Itakura's (2004) study in that students modified their cultural stereotypes against previously held assumptions when they developed an understanding of the target culture. Such awareness was found to be beneficial as it helped the students become more aware of the ever-changing nature of cultures. It also enabled them to avoid generalising individual behaviours to the whole culture and consequently develop a better understanding of other cultures.

The results also showed that the IC students developed a better understanding of the target culture than the ST class when they engaged in discovering the underlying cultural values of other cultures. This discovery of underlying values in the target culture resulted from the students' active engagement in the critical incidents in the 
lessons and the ethnographic interview with a native English speaker invited to the classroom.

Understanding of the other is important, but moving beyond cultural differences towards diversity in cultures is even more essential. Alvarez Valencia and Bonilla Medina (2009) argue that we need to see one's self and the other as the product of diversity in human beings. Such a perspective contributes to developing learners' interest and curiosity as well as their openness in learning about other cultures. There was such evidence in the IC class when the students showed interest in discovering the diversity of cultures through different norms of interaction in intercultural communication.

\subsubsection{Learning about the self}

Learning about the other cannot be separated from learning about the self in intercultural language learning. The conceptualisation of intercultural competence emphasises the ability to engage in reflective practice about one's personal culture (Arthur and Collins, 2005). This means that apart from positioning cultural influences on the 'other' in cultural learning, one's personal socialisation and experiences are also examined due to the strong influence of beliefs and practices (Guo, Arthur and Lund, 2009). Self-awareness is an essential foundation for intercultural competence to develop (ibid). Bennett (2009) argues that cultural self-awareness is a necessary precursor of intercultural learning as students will find it difficult to recognize and manage cultural differences without a mental baseline for their own culture. The present study showed that when comparing cultures, students related an aspect of the target culture to their home culture; however, a deeper understanding of the target culture was more likely to lead to a better cultural self-awareness. The IC students showed a better cultural self-awareness about their home culture as they had a deeper understanding of the target culture than the ST students.

Critical thinking generally is not really salient to Vietnamese students due to the influence of Confucian ideology. According to Hongladarom (1998), Asian philosophy has traditions of critical thinking, logic, and argumentative thinking, but these behaviours have been suppressed in favour of other Asian values such as social harmony and intuitive thinking. Hongladarom argues that it is appropriate for Asian cultures to emphasize critical thinking over other values thanks to the increasing 
amount of information and cross-cultural contacts that learners are exposed to in their society. The present study supported Hongladarom's ideas for a better development of critical cultural awareness about different aspects of the target culture and the learners' home culture in the IC class.

Liddicoat et al. (2003) argue that learners cannot develop their intercultural competence unless they understand their own culture first. Although one's own culture seems to be obvious for everyone, no-one can know enough about their own culture. Communication with people from different cultural backgrounds does not necessarily allow for self examination of one's own culture. Weaver's (1993) cultural iceberg shows that a large proportion of our culture is invisible. It is, therefore, important for learners to develop awareness of their invisible culturally-influenced behaviours that occur unconsciously in daily life. There was evidence in the IC class which indicated that the students became more aware of their own behaviours in communication with people from other cultures. This awareness helped them adjust their behaviours to be more appropriate in intercultural interactions.

Learners, however, need to go beyond cultural self-awareness. They need to get out of their own cultural shell (Kaikkonen, 2001, p.64) in order to engage in learning about another culture. The present study showed that the case study students Binh and Phuoc in the ST class were more likely to demonstrate awareness of their own culture. Many other students in the ST class were also in their own cultural shell, and consequently, their own cultural perspective was at the centre of their judgment about other cultures. Students in the IC class, on the other hand, became more aware of the impact of their cultural perspectives on understanding other cultures. This awareness was particularly important for them to gradually decentre from their own culture (Byram, 1989; Kramsch, 1993) before being able to engage in comparing, contrasting and reflecting on different cultural values in the target culture. The ability to decentre would help learners "explor[e] and encounter difference and diversity with a mindset more open for authentic dialogue and less likely colored by stereotyped views and prejudice" (Forsman, 2010, p.517).

Moreover, Finkbeiner (2009) proposes a 'Human GPS' in which the self is put at the core of the acculturation process. Finkbeiner's 'Human GPS' indicates that the understanding of one's self is the starting point where learners can step back to develop their second perspective about the other and then navigate below the surface to discover its hidden cultural dimensions. For example, the case study student Ngoc 
in the IC class, being aware of cultural stereotypes in the roles of men and women, looked back to her own self and developed a better understanding of gender roles in her own culture as well as the equality between men and women in the target culture.

\subsubsection{Becoming ethnographers}

The ethnographic interview with the native English speaker invited to the classroom largely contributed to developing the IC students' understanding and positive attitudes towards the target culture. From this interview with the native speaker, the students became ethnographers who were able to actively construct their intercultural knowledge and enhance their awareness, skills and attitudes. The outcomes of the ethnographic interview in this study correspond with Bateman (2004) who shows that ethnographic interviews can help students achieve cognitive, affective, and positive behavioural outcomes in culture learning. Bateman argues that learners engaging in ethnographic interviews enhance not only positive attitudes and communicative competence towards speakers of the target language, but also awareness of the influence of their own culture in their lives.

\subsubsection{Developing intercultural relationships}

Good relations with target culture members can be built on the learner's intercultural attitudes. Sparrow (2000) argues that relationships with cultural hosts can be a measure of intercultural success. Imahori and Lanigan (1989) state that intercultural competence derives from "dynamic interactive processes of intercultural relationships" and should lead to "an effective relational outcome" (cited in Shaules, 2007, p.99). Developing good relationships with cultural hosts is, therefore, not only an end product but also a driving force of intercultural learning (Shaules, 2007). Shaules (2007) argues that the emphasis on the formation of relationships strengthens the interactive process of intercultural learning. The findings of the present study confirmed Shaules' ideas in that the IC students were aware of establishing good relationships with members of the target culture through their intercultural awareness about the treatment of pets in the target culture.

Building the relationship, maintaining it, and showing a willingness to interact with people from other cultures are also the keys to success in intercultural 
communication. Such evidence was found in the IC class in which the students appreciated the use of a sense of humour from a conversation between the waiter and the customer in a restaurant to develop their intercultural relationship and willingness to interact with people from other cultures. Zhang and You (2009) argue that "the power of humour lies not only in making people laugh, but also in lubricating the interpersonal relationship, showing one's friendliness and tolerance towards others, eliminating miseries and troubles so as to be optimistic and open-minded, promoting one's self-restraint and creating a meaningful life" (p.101).

\subsubsection{Negotiation of cultural identity}

In the process of developing intercultural relationships with people from other cultures, language learners may need to negotiate their cultural identity, especially in situations where there is a contrast between their own values and those of the target culture. Littlewood (2001) emphasizes the importance of cultural identity negotiation as a frame of reference in the interpretation of one's intentions and meanings. Byram (1997) also acknowledges the importance of identity and affiliation for negotiated communication in which no interlocutor is held as the ideal model for the other to conform to. Kim (2009) introduced the concept of 'intercultural identity' which is conceived as "a continuum of adaptive changes from a monocultural to an increasingly complex and inclusive character" (Kim, 2009, p.56, italics in the original). Kim argues that in the process of becoming intercultural, the individual becomes competent in making deliberate choices of constructive actions. There was evidence in the IC class to show that the issue of cultural identity became more salient for the students in the process of becoming intercultural, such as in dealing with different behaviours of people from other cultures, or the treatment of the elderly in America.

Maintaining one's own cultural identity while attempting to integrate into the target culture can help learners become 'intercultural speakers'. Intercultural speakers are those who can "establish a relationship between their own and the other cultures, to mediate and explain differences - and ultimately to accept that difference and see the common humanity beneath it" (Byram and Fleming, 1998, p.8). There was evidence in the IC class that some students became intercultural speakers. These students were able to mediate between cultures in dealing with cultural differences in 
eye contact or the relationship between the teacher and students. The case study student Ngoc in the IC class also showed that she was able to mediate between cultures when dealing with the treatment of pets and the treatment of the elderly in the target culture. Corbett (2010) argues, however, the ability to mediate between cultures "is delicate, sophisticated and demands sensitivity and maturity" (p.32).

\subsubsection{Developing acculturation attitudes}

Engaging in different values in other cultures during the negotiation of cultural identity may lead students to the challenges of different acculturation attitudes. Berry, Kim, Power, Young and Bujaki (1987) establish a relationship between attitudes towards the importance of maintaining contact with home and host cultures and the four levels of acculturation that an individual can demonstrate: integration, assimilation, separation, and marginalization. Berry et al. (1987) state an integrated acculturation attitude means that individuals are concerned with both maintaining their own cultural identity and extending relations in the host culture. Individuals with an assimilated acculturation attitude are more concerned about integrating into the host culture while still maintaining their home culture. Separation involves individuals who have a greater focus on maintaining their own culture than the host one. Marginalization, in the last category, is where individuals have little concern for either their own culture or the host community.

The two case study students Thanh and Ngoc in the IC class both showed similar perspectives about how they dealt with the challenges of acculturation through the situation of the treatment of an old Vietnamese man living in a nursing home in California. Both of them showed respect towards the treatment of the elderly in nursing homes in American society, but they treated Vietnamese expatriates living in the US differently from the target culture members. Both Thanh and Ngoc, according to Berry et al.'s (1987) levels of acculturation described above, had a separated acculturation attitude as they believed that people from their own culture living in the host country still needed to preserve their own traditional values. This attitude was influenced by the morality in the Vietnamese philosophy of Confucianism, that is, 'Kinh lão đắc thọ' ( 'respect the elderly').

Finkbeiner (2008) argues that there is a bias about what can be considered 'good' behaviour or action. Filial piety is considered a typical Vietnamese value. It is 
strongly connected to Vietnamese people's responsibilities towards their aged parents and ancestors in terms of caring and financial support. Finkbeiner states this bias is not simply the Western versus non-Western dichotomy but it needs to be considered on a more subtle and sub-cultural level, taking into account other factors such as culture, language, political viewpoint or philosophical belief. The filial piety towards the aged parents for Vietnamese people living in the U.S., therefore, needs to be reconsidered at a sub-cultural level rather than in contrast with the life of the elderly in nursing homes in American culture. Vietnamese people living in the US have to embrace the culture where they are living, but it is also important for them not to forget who they are, who their parents are, and continue with that culture.

\subsubsection{Overcoming ethnocentrism}

The findings of the present study showed that ethnocentric attitudes were the most prevalent in the ST class across the topics as they put the worldview of their own culture central to all reality (Bennett and Bennett, 2004). Berry and Kalin (1995) state ethnocentrism shows "a lack of acceptance of cultural diversity, a general intolerance for outclasses and a relative preference for one's ingroup over most outclasses" (p.303). Bennett and Bennett (2004) also argue that ethnocentric views would form stereotypical attitudes towards the target culture. Ethnocentrism occurred in the ST class due to a lack of student understanding of the target culture. One-third of the ST students considered the treatment of pets like children in the target culture unacceptable or intolerant. Three-fourths of the ST students also underestimated the value of respect towards the elderly in the target culture. It is ethnocentrism that led those students to misunderstand the target culture and reduced their willingness to communicate interculturally. As ethnocentrism is "an obstacle to intercultural communicative competence" (Neuliep and McCroskey, 1997, p.389), learners need to overcome ethnocentrism, move away from their culturally-shaped assumptions, and consider the other's perspective. An attitude change is, therefore, essential for students to develop intercultural perspectives towards other cultures. 


\subsubsection{Attitude change}

The result of the post-test showed that intercultural attitudes were more likely to be resistant to development than the other components of intercultural competence. This may be reasonable with a short-term teaching period of nine weeks. Attitude change, however, was reported in the process of acquiring intercultural competence in the IC class. This attitude change can be seen in the learners' attitudes towards the stereotyped personalities of English people, the norms of socialising, the unfamiliar gestures in the target culture, the treatment of pets and the treatment of the elderly in the target culture. The attitude change corresponds to Taylor's (1994) transformative learning theory for the learning process of becoming interculturally competent. Taylor's theory involves the transformative experience of sojourners who move to another country to live for an extended period. His theory is applied to the long-term process of learning with sojourners studying abroad. However, Taylor's transformative learning theory also reflects the IC class students' process of becoming interculturally competent through their attitude change. It was with this attitude change that the learners developed openness and ethnorelative attitudes towards the target culture.

\subsubsection{Developing ethnorelativism}

Bennett's (1993) Developmental Model of Intercultural Sensitivity (DMIS) suggests that learners develop their intercultural competence on the continuum from ethnocentric stages to ethnorelative stages. The findings of the present study support Bennett's model in that the Vietnamese EFL learners developed their intercultural competence in a linear way across different topics. However, the results did not show linear development across time. Shaules (2007) argues that learners can be found in mixed states of resistance, acceptance, and adaptation at the same time. The positive effect of the intercultural intervention indicated that there were almost no ethnocentric attitudes evident in the IC class. This suggests that a focus on developing learners' intercultural awareness and attitudes at the beginning of language learning is essential as it can largely help them minimise ethnocentric attitudes and develop ethnorelative awareness and attitudes towards other cultures. 
Students with ethnorelative attitudes are able to minimise culture shock in contact with other cultures. Culture shock is a kind of discomfort someone may experience in a new cultural environment. Learners may encounter culture shock when their cultural values are found to conflict with those of the target culture. Many students in the ST class were shocked by the treatment of pets like children in Britain as they used their cultural perspectives to judge the values of another culture. The students in the IC class, on the contrary, were able to avoid culture shock and became more tolerant with respect to the different treatment of pets in the target culture. They were also able to minimise culture shock about unfamiliar gestures or different norms of socialising in the target culture such as in the situation of the American friend who only paid for his own meal. The movement away from culture shock resulted in the students' positive intercultural attitudes towards the target culture.

Students with ethnorelative attitudes are also able to judge another culture from the others' perspective and develop empathy towards members of the target culture. Davison (2000) defines empathy as a "feeling with others" that "implies a sense of we-ness and togetherness" (p.5). Davison emphasises the relativity of this concept. He argues, "being empathetic is not just about trying to put myself in another's shoes. It is also about trying to understand how the world from my shoes frames how I can even hope to see the world from you. The relational aspect of empathy requires that I know myself as much as I know you" (Davison, 2000, p.14). The demonstration of empathy in the IC class reflects these ideas of Davison with evidence of students' empathy towards the lives of aged Americans in nursing homes from their understanding about the life of an old Vietnamese man living in a nursing home in California. When the students were able to judge another culture from the others' perspective, they developed an intercultural perspective that enabled them to become interculturally competent.

\subsection{Summary}

This chapter has presented the results and discussion about the effect of adopting an intercultural stance on the development of the learners' intercultural competence. The results included those from the pre- and post-tests, evidence of learning from journals, self-evaluation questionnaire, interviews, and four case studies. The results showed that the intercultural competence of the learners in the intercultural class increased 
significantly more than that of those in the standard class. The students in the intercultural class developed a better understanding of the target culture and their selves. They became ethnographers who engaged in discovering and exploring the target language culture. Some students were even able to mediate between cultures by negotiating their own cultural identities. Students were also able to overcome ethnocentric attitudes and move towards ethnorelativism with which they judged another culture from the others' perspectives and developed an intercultural perspective that valued other cultures and people. The results also showed that the reflective journal was an effective tool for culture teaching and learning, particularly in cultivating learners' affective capacities as the nurturing of these capacities has been overlooked in the EFL classroom. This positive effect of the reflective journal echoes Elola's (2008) study which showed that personal journals had a positive impact on the development of learners' intercultural competence. In brief, this study has provided evidence for the feasibility and benefits of intercultural language learning within an Asian context.

In the next chapter, I will draw conclusions from the findings of the study and suggest implications for EFL teaching and learning in Vietnam. 


\section{Chapter IX \\ CONCLUSIONS AND IMPLICATIONS}

\subsection{Introduction}

Intercultural competence has become an important goal of foreign language education in response to the need for learners to function effectively in an increasingly multicultural world. This study investigated intercultural teaching and learning in tertiary EFL classrooms in Vietnam, a context in which intercultural approaches to language teaching and learning have not been widely considered.

This study consisted of three phases. The first phase involved a curriculum review that examined the nature and the extent of the elaboration of culture and culture learning in the curriculum frameworks for tertiary EFL programmes and in the national education policy on foreign language education in Vietnam in order to identify the potential for developing intercultural language learning. The second phase was an analytical study of the perceptions of Vietnamese EFL teachers and students on culture in language teaching and learning. The third phase involved an empirical study that investigated the effect of adopting an intercultural stance in English speaking lessons on the development of the learners' intercultural competence in the EFL classroom. More broadly, this phase aimed to examine the feasibility of intercultural teaching and learning in the Vietnamese EFL context.

This chapter first summarises the findings of the study, then suggests implications for curriculum designers, education policy makers, and intercultural language teaching and learning in the EFL classroom. Limitations of the study are also discussed. Finally, possible areas for further research are proposed and conclusions are given.

\subsection{Summary of findings}

This section summarises the main findings of the three phases of this study and the contribution these findings make to the development of more comprehensive models of intercultural awareness and intercultural attitudes. 


\subsubsection{Curriculum review}

The first phase of the study, a curriculum review, revealed the limited view of culture and culture learning in the curriculum frameworks for the Vietnamese tertiary EFL programmes and in the national education policy on foreign language education.

First, the curricular documents do not emphasise the importance of culture and culture learning in language learning, but offer an instrumental orientation to EFL that aims to equip learners with knowledge of the English language and communication skills for future jobs. Communicative goals are prioritised in the training objectives without dealing with intercultural dimensions in communication practice to achieve intercultural outcomes. Communicative competence is emphasised as a standard of native-speaker competence instead of intercultural communicative competence, which is also supported by the national education policy on foreign language education.

Secondly, there is little explicit recognition of the relationship between language and culture in language learning. The designation of culture to separate culture courses establishes a separate status, construct and treatment of culture and culture learning rather than integrating it into language learning. Explicit comparisons and connections are stated between learners' home culture and the target culture in culture courses rather than between languages and cultures.

Thirdly, the separate culture strand overall constructs culture as knowledge about a particular culture, i.e., British and American culture as the predominant cultures in EFL learning. Only one single objective in the culture courses reflects an exploratory and reflective approach to culture.

In spite of the limited view of culture and culture learning in the curricular documents, some potential areas for developing intercultural language learning are identified. These include the explicit mention of culture and culture learning in the training objectives, a focus on learners' first language and culture at the beginning of language learning and an objective in the language skills courses in the national curriculum which states that learners should be able to "communicate effectively and appropriately with native English speakers and English-speaking foreigners". 


\subsubsection{Teachers' and students' perceptions and classroom practices}

The findings of the second phase of the study are concerned with the teachers' and students' perceptions of culture in language teaching and learning and their culture teaching and learning practices.

\subsubsection{Teachers' perceptions and culture teaching practices}

The teachers defined culture in EFL teaching and learning in a broad range of ways from culture as seen in social structures to culture in instantiation of particular speech acts. Only six out of the twelve interviewed teachers demonstrated awareness of the relationship between language and learning. The teachers' beliefs about culture teaching revealed a predictable priority for teaching language. They expressed concern about teaching culture according to topics, about the need to focus on language rather than on culture, and about inadequate exposure to culture in language courses. The teachers were most concerned about various constraints that restricted their opportunities for culture teaching.

Classroom observations showed that the teachers prioritised teaching language over teaching culture with a focus on grammatical functions and tenses. Observations of the ten language classes and the two culture classes revealed that the facts-oriented approach to culture teaching was the teachers' most common classroom practice. The teaching of cultural connotations of vocabulary and expressions and the teaching of cultural awareness were much less frequent, while other reported ways of culture teaching tended to depend on each teacher's personal experience. The teachers believed that their approaches to culture teaching were appropriate in their language teaching.

The findings also identified some potential areas for adopting intercultural language learning in Vietnamese EFL classes. These include the awareness of the students' own culture and the real-life situations in the lessons which can provide many opportunities for learners to engage in intercultural language learning. 


\subsubsection{Students' priorities in EFL learning and perceptions of culture learning}

The students treated culture as a subordinate priority in language learning. Their ultimate purpose for learning English was entirely congruent with their reason for study at university which was to get a good job after graduation. The students did not consider culture learning as a valued end in itself and therefore gave it a low value in language learning. They also prioritised the linguistic content over the cultural content and showed greater preferences for language-related topics over those related to culture.

The students defined culture in terms of social structures rather than in relation to differences in language and communication. Like the teachers, their beliefs about culture and language learning also revealed a predictable priority for learning language rather than culture. They expressed concern about the native-speaker standard of language proficiency as the goal of language learning, about cultural background knowledge as a prerequisite for culture learning and about inadequate exposure to culture in language courses. The students also identified a number of constraints that restricted their opportunities for culture learning and therefore influenced their motivation to engage in culture learning.

The students were aware of the importance of understanding their own culture in culture learning, but only a minority demonstrated awareness of the relationship between language and culture. Their most important reason for culture learning was the acquisition of behavioural capacities while affective capacities were less valued. The students also considered culture learning beneficial in terms of facilitating language learning, developing communication skills with speakers of the target language and increasing cultural knowledge and understanding. Overall, they supported the teachability of language and culture in EFL classes.

Regarding the students' experience of culture learning, the learning of cultural facts was the most popular culture learning activity in the classroom. This corresponds to the teachers' facts-oriented approach to culture teaching. The students considered this approach to culture learning both advantageous and disadvantageous, but they expected to achieve effectiveness through other ways of culture learning that involved more intercultural skills. Due to the lack of social interaction with native English speakers, the students mainly learned about the target culture through the 
media. Consequently, they experienced a linguistic barrier to communication with speakers of the target language rather than a cultural barrier.

The findings also reveal some potential areas for the uptake of intercultural language learning in Vietnamese EFL classes. These include the students' high ranking of communication with foreigners, the acquisition of behavioural capacities as the most important purpose for culture learning, strong awareness of the importance of their own culture in culture learning, and the perceived benefits of culture learning.

\subsubsection{Intercultural language teaching and learning}

The findings of the third phase of the study are concerned with intercultural language teaching and learning in the Vietnamese EFL classes.

\subsubsection{Development of the learners' intercultural competence in EFL learning}

A comparison of the intercultural development of students in the IC class, in which an intercultural stance was taken, and students in the ST class, with traditionally taught lessons, showed statistically significant intercultural gains in the former as compared to the latter. In terms of intercultural awareness, the IC students developed better insight into different aspects of the target culture and became more aware of their own culture and of the impact of their own perspectives on understanding of other cultures. They also better articulated communicative awareness of how to act in a culturally appropriate manner in interaction with people from other cultural backgrounds. Some IC students even demonstrated an awareness of how to mediate between cultures while maintaining their cultural identities. In terms of intercultural attitudes, the IC students demonstrated a lower level of ethnocentrism, and developed openness, respect and tolerance towards the target culture. Ethnorelativism was also enhanced as reflected in their understanding of different cultural values in relation to one another and the value they placed on understanding other cultures and seeing behaviours from the others' perspective.

The statistics results and descriptive data from the learners' reflective journals (sections 8.2 and 8.3, chapter VIII) showed that the students engaged more or less in intercultural language learning dependent on certain topics. Therefore, the results did 
not show linear development across time. Some topics allowed learners to engage more deeply with intercultural issues than others. For example, the topics such as 'interpersonal communication', 'pets', 'the elderly', 'men and women', 'festivals and holidays', 'kindergarten education', generated divergent cultural values and behaviours, and consequently the students engaged more actively in intercultural language learning. Other topics, such as 'shopping', 'advertising', 'exceptional people', 'fear and phobia', 'science and technology', did not generate diverse cultural values, and thus the students engaged less in intercultural language learning. This suggests that intercultural topics which are more likely to raise disagreement or conflict with learners' cultural values should be encouraged for discussion in the classroom so as to actively engage them in exploring cultural differences and mediating between different cultural values.

In brief, there was a positive effect of adopting an intercultural stance in EFL learning on the development of the learners' intercultural competence. This intercultural development was more likely to depend on the nature of different topics that the students engaged in.

\subsubsection{Assessing learners' intercultural competence through language learning}

The study adopted Deardorff's (2006) argument that intercultural competence can most easily be measured in its separate components rather than holistically. Thus, the study focused on assessing the learners' intercultural awareness and attitudes. Each of these components was operationalised into constructs and subconstructs and presented in linear models of intercultural awareness and attitudes (see sections 8.5.1 and 8.5.2, chapter VIII). The development of intercultural competence can be mapped using these models of intercultural awareness and attitudes which distinguished different levels of intercultural competence that language learners progress through during the process of acquiring intercultural competence in language learning.

In addition, the study showed that each component of intercultural competence could be measured both quantitatively and qualitatively. The results of the pre-test and post-test with the use of the Intercultural Competence Inventory and the quantitative content of the learners' reflective journals provided evidence for a possible quantitative measurement of the two components of intercultural competence, i.e., intercultural awareness and attitudes. The combination of 
quantitative and qualitative measures provided a fuller picture of the whole process of the learners' intercultural competence acquisition in the EFL classroom.

In short, intercultural competence can most usefully be assessed in terms of its separate components which are operationalised into constructs and subconstructs. A combination of both quantitative and qualitative measures provides a more comprehensive assessment of the whole process of learners' intercultural development.

\subsubsection{Experience of intercultural language learning}

The results of the self-evaluation questionnaire in both classes showed that the students in the IC class had a better experience of intercultural language learning than those in the ST class. The IC students reported that they had a positive experience of intercultural language learning. The intercultural lessons developed their insights into the target culture as well as their own culture with critical thinking about various aspects in each culture. They became more aware of the influence of their own

cultural perspectives on understanding other cultures and the relationship between language and culture. The students also reported that learning language and culture together was an effective approach to language learning as they were able to improve their speaking skills, as well as enhance their intercultural awareness and attitudes towards other cultures. They also felt more confident to interact with people from other cultural backgrounds and more motivated to learn about other cultures. Reflective journal writing was considered an effective method for culture teaching and learning.

In brief, the students had a positive experience of intercultural language learning. This confirms the positive effect of the intercultural intervention on the development of the learners' intercultural competence.

\subsubsection{Interrelatedness of the findings}

The results obtained from the three phases of the study showed some interesting interconnections.

First, the separate treatment of culture in the curriculum frameworks and the emphasis of the national education policy on the native-speaker standard of language 
proficiency were instantiated in the teachers' perceptions about the separate treatment of culture teaching in language teaching. Similarly, the absence of an exploratory and reflective approach to culture was evident in both the curriculum frameworks and in the teachers' tendency to teach cultural facts.

Second, the results showed that the teachers and students had similar perceptions of culture and of preferred classroom practices. Both gave priority for teaching and learning the linguistic content rather than the cultural dimension. Both also had similar concerns about a number of constraints on culture teaching and learning such as students' level of language proficiency, students' cultural background knowledge or students' degree of receptiveness to culture learning.

Third, despite the emphasis on learned factual knowledge in the curriculum frameworks and in the teacher and student views of culture, the intercultural intervention in the empirical study showed that, when given opportunities to engage in more interculturally informed language learning, the students reacted positively and were receptive to the values of intercultural language learning. They were able to gain a better insight into and a better understanding of both their own culture and the target culture through their explorations and reflections on cultural differences.

\subsection{Implications}

This section suggests implications for intercultural language teaching and learning in Vietnamese EFL settings based on the findings of the study. These implications may also be useful in other contexts where English is taught as a foreign language.

\subsubsection{Implications for curriculum designers}

The curriculum review highlighted a number of implications for Vietnamese curriculum designers. First, the importance of culture and culture learning is not emphasised in the Vietnamese National Curriculum and the two English majors which place a strong emphasis on language. As the goals of modern EFL teaching and learning aim to meet the need for language learners to function effectively in English in a globalised world, curriculum designers may need to adopt more interculturallyinformed curriculum platforms. If the importance of culture in language teaching and 
learning is emphasised in the curriculum frameworks, then teachers are more likely to consider planning their lessons with both linguistic and intercultural objectives.

Second, native-speaker competence is identified as the goal for teaching and learning and assessment in the curricular documents for Vietnamese tertiary EFL programmes. As the goal of intercultural language learning is to achieve intercultural competence rather than native-speaker competence, it is not necessary to base the norms for instruction or assessment on the latter. Communicative practices with intercultural dimensions should be encouraged in language learning in order to develop intercultural competence in learners. Also, if learners' intercultural competence is treated as an important part of language testing, it would encourage teachers to set up the goals of their lessons towards developing both linguistic competence and intercultural competence for language learners.

Third, the curriculum review shows that an exploratory and reflective approach to culture is stated in one objective of culture courses. Such an approach could be beneficial if it is developed in language courses so as to engage learners in cultural exploration in language learning. For such an approach to culture learning to be adopted in the curriculum, a dynamic view of culture and an integrated approach to culture teaching and learning are needed. A dynamic view of culture would enable students to critically evaluate cultural facts they learn from the textbook. An integrated approach to culture teaching and learning would help teachers and students become more aware of the relationship between language and culture in language teaching and learning.

\subsubsection{Implications for education policy makers}

The Vietnamese national education policy on foreign language education (section 3.5.4, chapter III) shows that Vietnamese EFL learners are supposed to study and work in "an integrated, multilingual and multicultural environment" after graduation. Such a goal requires learners to be both linguistically and interculturally competent, while only linguistic competence is emphasised in the national education policy. In order that students can achieve this goal, education policy makers may consider integrating interculturality into the education policy.

Education policy makers should also be aware of teachers' beliefs and their current culture teaching practices on which new policies on intercultural language 
teaching can be built to develop both intercultural competence and linguistic competence for language learners. These education policies should be applied not only on a large scale that deals with the whole system of education but also on a smaller scale within each EFL programme. As no teacher participants in this study were aware of any education policy that highlighted the importance of culture teaching and learning, it is important that they be fully informed about new trends in intercultural language teaching and learning for their classroom practices. In addition, Vietnamese EFL teachers should also be provided with opportunities to take part in seminars, workshops, conferences or teacher development programmes on intercultural language teaching so that they can become familiar with international trends in foreign language education and make efforts to develop an intercultural perspective in their language teaching.

\subsubsection{Implications for intercultural language teaching and learning}

In this section, I suggest a number of implications for intercultural language teaching and learning in the Vietnamese EFL classroom.

\subsubsection{Adopting an intercultural stance in the existing EFL programme}

The study introduced an intercultural stance into the English speaking lessons in an existing EFL programme. The aim was to integrate language and culture in language learning, rather than having a separate course on intercultural language learning, which facilitated language classes with a fixed curriculum. A variety of factors need to be taken into account, including the lesson goals, the input of intercultural knowledge, the teacher's role, the student's role, the classroom settings and the intercultural activities. The intercultural activities can be built on the five principles of intercultural language learning proposed by Liddicoat et al. (2003). Students should be encouraged to actively construct their intercultural knowledge, make connections between their own culture and the target culture, participate in social interaction, critically reflect on intercultural topics and take responsibility for developing an intercultural perspective towards other people and cultures. 


\subsubsection{Developing teacher and student awareness of the relationship between language and culture}

The study showed that the teachers' beliefs about culture in language teaching were aligned with the way they addressed culture in the EFL classroom. A change of teachers' beliefs, therefore, may lead to a change in their classroom practices. This means that an increase in teachers' awareness of the cultural dimension in language teaching may encourage them to pay more attention to intercultural language teaching. As only half of the teacher participants in the study were aware of the relationship between language and culture, it is important that Vietnamese EFL teachers develop this awareness for culture teaching. In addition, as there were similarities between the teachers' and the students' beliefs about culture teaching and learning, a change in teachers' beliefs may lead to a change in students' beliefs. In other words, teachers may work to become agents of change for students to develop their cultural awareness. If teachers consider the importance of culture in language teaching, this may contribute to increasing students' awareness about the relationship between language and culture and the importance of culture in language learning.

In addition, the majority of the student participants in the second phase of this study were not aware of the relationship between language and culture. Consequently, they underestimated the role of culture in language learning and treated culture learning as a subordinate goal rather than an inseparable component of language learning. Learners should be then given opportunities to enhance their awareness of the relationship between language and culture, which will be beneficial for their language learning.

\subsubsection{Enhancing teachers' intercultural experience}

The teacher's intercultural experience contributed to the development of learners' intercultural competence in the present study. According to Byram (1991), teachers' intercultural experience is the main precondition for successful intercultural language teaching. $\mathrm{Gu}$ (2005) finds that intercultural experience had a significant impact on professional development of Chinese teachers and British trainers. Göbel and Helmke (2010) report a substantial connection between teachers' intercultural experience and students' intercultural outcomes. They argue that the more highly interculturally 
experienced teachers are, the more likely they are to put cultural awareness and discussions about culture into practice in the classroom. The findings of the present study echo these studies in that it confirmed the positive impact of the teacher's intercultural experience on students' intercultural outcomes. As teachers' intercultural experience makes a difference in students' learning outcomes, it is important to increase opportunities for teachers to engage in more intense intercultural contacts with people from English-speaking cultures across various contexts. School exchanges or even virtual school contacts (ibid) with English-speaking countries can be a good chance for teachers to enhance their intercultural experience. However, the significant implication of intercultural experience for teacher education is to help them build up “a teacher's sense of plausibility about teaching” (Prabhu, 1990, p.172) that transcends intercultural contexts $(\mathrm{Gu}, 2005)$.

\subsubsection{Using critical incidents as a platform for discourse}

The present study used culture assimilators as critical incidents in the intercultural lessons to engage the students in the IC class in intercultural language learning. These critical incidents aimed to develop learners' critical thinking in different cultural situations. By actively participating in the critical incidents, the students became critical cultural informants to one another in the classroom. Henderson (2004) suggests that critical incidents can be used as a platform for discourse to develop learners' cultural awareness and promote discussions about the target culture. Kumaravadivelu (2008) also states that "a critical mind can help the individual develop the knowledge, skills and disposition necessary to deal with the challenges of contemporary realities" (p.164). Critical incidents should, therefore, be promoted to develop learners' intercultural competence in the classroom. As students need to have some cultural knowledge to deal with critical incidents (Cushner and Brislin, 1996), it is necessary that they construct their intercultural knowledge through cultural exploration.

Critical incidents can result in learners' discomfort, embarrassment or conflict as they are exposed to different cultural values. Corbett (2010) argues that language learners need to mediate between different sides in uncomfortable situations in order to develop strategies to deal with conflict. The cultural situations used in the present study involved different cultural problems that contrasted different cultural values of 
the target culture and the learners' own culture. To solve cultural problems in such situations, learners can engage in four problem-solving phases of Description, Analysis, Plan Action and Experience (Miller, 2009) to mediate between cultures and develop their intercultural competence. The OSEE Tool (Deardorff and Deardorff, 2000, cited in Deardorff, 2008, p.44) can also be used to engage students in critical incidents. This tool involves students in four steps:

(i) $\mathrm{O}$ - Observe what is happening

(ii) $\mathrm{S}$ - State objectively what is happening

(iii) $\mathrm{E}$ - Explore different explanations for what is happening

(iv) $\mathrm{E}$ - Evaluate which explanation is the most likely one

Deardorff (2008) states that exposing students to the OSEE Tool can help them understand the rationales behind the behaviours they encounter in intercultural situations and therefore enhance their intercultural competence.

\subsubsection{Treating the classroom as a community}

The present study used the classroom to engage the students in role-plays and discussions about different cultural issues for culture learning. They also had a chance to conduct an ethnographic interview with a native English speaker invited to the classroom. The classroom is a cultural context in which teachers' and learners' linguistic and cultural backgrounds shape their experiences and expectations (Liddicoat, 2008). Although discussing culturally sensitive issues may lead to heated arguments (Baldano and Holm, 1997), students can gain a global perspective and intrinsically learn about cultural differences (Henderson, 2004). The present study showed that the classroom is a place where the students were enabled to voice their opinions freely, which facilitated exchanges of different opinions and fostered language learning (Henderson, 2004). The classroom should, therefore, be treated as a community for students to develop intercultural competence as it can be seen both as a preparation for experience and an experience itself (Göbel and Helmke, 2010). Teachers can take advantage of the 'safe place' of the classroom to engage students "with differences in belief and ideology...in order to promote genuine understanding and respect" (Corbett, 2010, p.5). 


\subsubsection{Fostering learners' social interaction with native speakers of the target language and other cultural informants}

The students' ethnographic interview with the native English speaker in the present study contributed to the development of their intercultural understanding and intercultural attitudes towards the target culture. Opportunities to conduct ethnographic interviews with native speakers of the target language to seek their perspectives on their own culture, therefore, can provide learners with a better understanding of different aspects of the target culture. Native English speakers can be invited to the classroom for students to carry out interviews. In addition, students are also encouraged to seek opportunities to interview or exchange emails with other cultural informants beyond the classroom and bring the information for discussion in the classroom. This allows them to make comparisons between different sources to triangulate the information about the target culture and consequently develop a better insight and understanding about the target culture rather than depending on one individual source of data. A rich exploration about the target culture with various cultural informants would help them avoid generalising any individual interpretation as a representative description of the whole target culture. As cross-cultural contact does not automatically lead to intercultural competence, careful guidance, critical analysis and educational support are needed (Guo, Arthur and Lund, 2009).

In order to conduct successful ethnographic interviews with cultural informants, students may engage in the following stages to develop good skills for ethnographic interviews (Corbett, 2010, pp.113-129):

(i) Developing interview questions: learners devise appropriate and polite questions for different kinds of interviewees from different cultural groups.

(ii) Following up interview questions: learners elicit further information in their interviews on any unclear and unelaborated answers of the interviewees by asking follow-up questions.

(iii) Exploring assumptions: learners interpret and reflect on their interviewees' unspoken assumptions by asking questions and requesting clarification.

(iv) The interviewers from another planet: learners 'defamiliarise' their daily routines radically by imagining they come from a different planet. They can reflect on the way questions relate to their particular interests and concerns. 
(v) Preparing for an online interview: learners may conduct an interview online, by e-mail or through a chat room whenever they cannot get the chance for direct contact with people from another culture.

\subsubsection{Encouraging learners' participation in online intercultural exchanges}

The students in this study mainly learned about the target language culture through the media outside the classroom due to lack of contact with speakers of the target language. To compensate for this shortcoming in Vietnamese EFL classes, an efficient way to develop learners' in-depth understanding of the target culture is to provide them with opportunities to participate in an online intercultural exchange. In this kind of online intercultural learning, Corbett (2010) suggests that learners can be connected with e-partners in another country to learn about different cultures through the website the Global Gateway managed by the British Council ${ }^{12}$. Corbett adds that learners need to observe, describe and discuss local linguistic and cultural practices in everyday settings in their own culture first and then share their insights online with their e-partners. This online intercultural exchange can engage learners in a dynamic and interactive process in which they are able to construct their intercultural knowledge and understanding of the other culture with their foreign partners (Furstenberg, 2010). By participating in such enriched forums, learners become "the real actors of their own learning" who can decipher and interpret the meaning of their foreign peers' messages (Furstenberg, 2010, p.331). Such opportunities as the online intercultural exchange will largely contribute to enhancing not only learners' willingness to communicate with people from other cultural backgrounds but also their intercultural skills necessary for effective intercultural communication.

\subsubsection{Encouraging learners' reflective journals for culture learning}

Reflection as a classroom process is considered a core element of developing interculturality (Kohonen, 2000). It is a process of interpretation of experience in which the learner makes personal sense of experiences (Liddicoat, 2008). The present study showed that the reflective journal was an efficient tool for intercultural language

\footnotetext{
${ }^{12} \mathrm{http}: / /$ schoolsonline.britishcouncil.org/home
} 
learning. It enabled the students to develop their cognitive and affective capacities for intercultural language learning. In addition, the learners were also empowered in the reflective journals. The power of the teacher was transferred to them and there was less imposition of the teacher's ideas on their thinking. They also had their own voice to negotiate cultural identities. Due to these benefits, Vietnamese EFL learners should be encouraged to keep a regular reflective journal for culture learning. Language courses or programs should include a significant reflection component in order to foster student awareness and the process of intercultural development (Deardorff, 2008). Ideally, reflective journals could be developed into a component of a culture portfolio and used as a compulsory component assessment so that students treat it more seriously to assist their acquisition of intercultural competence in language learning.

\subsection{Areas for further research}

There are some areas in the present study that merit further research.

First, a larger sample of teacher participants could be considered with a questionnaire that is sent to many EFL teachers in different universities in Vietnam. The questionnaire could be completed online so that more teachers are able to participate in it. Generalisations could be then drawn from a large sample of participants. Classroom observations may be also extended to various types of language courses so that a closer link can be built between the teachers' actual culture teaching practices in the classroom and the status, construct and treatment of culture and culture learning in the curricular documents.

Second, the correlation between learners' linguistic competence and intercultural competence needs further investigation. For the sake of the present study, the learners' first language was used in all the data collection methods. Future investigation may look into how students use the target language to develop their intercultural competence. This aims to examine whether the use of the target language would produce a better connection between their linguistic competence and intercultural competence.

Third, as language and culture should be integrated from the beginning of language learning, it is worth investigating how to introduce an intercultural stance in beginning language courses. This would contribute to enhancing learners' awareness 
of language and culture right from the beginning of language learning so as to provide a foundation for them to engage more effectively in culture learning at higher levels of language proficiency in their studies.

Fourth, in order to compensate for the lack of interaction with native speakers of the target language in Vietnamese EFL classes, further research can be conducted with students' participation in online intercultural exchanges with people from other cultural backgrounds. Such a study would contribute to enhancing Vietnamese EFL learners' interculturality for more effectiveness in intercultural language learning in the classroom.

Finally, a longitudinal study is needed to provide deeper insight into how language learners' intercultural competence evolves over a longer period. For example, future research may investigate how first-year or second-year students develop their intercultural competence over a period of one year. Such a longitudinal study may consider examining the development of learners' intercultural competence over time, which may help teachers work out a suitable level of intercultural competence that students are required to acquire at different levels of language proficiency.

\subsection{Conclusions}

Overall, the study provided useful insight into culture in language teaching and learning in the context of tertiary EFL education in Vietnam. The importance of culture and culture learning is not emphasised in the current curriculum frameworks and in the national education policy. The designation of culture to separate culture courses establishes a separate status, construct and treatment of culture and culture learning in the curriculum frameworks. The teachers' culture teaching practices were greatly influenced by their perceptions and beliefs about culture in language teaching. The learners' priorities in EFL learning and their perceptions of culture in language learning also strongly influenced the outcomes of their culture learning. Both the teachers and students believed that a variety of constraints restricted their opportunities for culture teaching and learning and therefore influenced their motivation to engage in culture teaching and learning. The study also showed a positive effect of adopting an intercultural stance in an existing EFL programme on 
the development of the learners' intercultural competence in the classroom. Therefore, intercultural teaching and learning was made feasible in the Vietnamese EFL context. Given the inseparable relationship between language and culture and the importance of intercultural understanding in communication with people from other cultural backgrounds, if Vietnamese EFL classes are to effectively equip students with the ability to become both linguistically and interculturally competent, then it may be necessary for Vietnamese EFL teachers to put more emphasis on cultural objectives in EFL teaching and learning. In addition, as the acquisition of intercultural competence is a life-long task, English language learners then may need to put more efforts into developing their intercultural competence in the classroom and beyond in order to be effective and successful in their intercultural encounters in life. 


\section{REFERENCES}

Asia Education Foundation. (2004). Asian Languages Professional Learning Project. Retrieved from http://www.asiaeducation.edu.au/for_teachers/professional_ learning/languages/getting_started/the_asian_languages_professional_learning _project.html.

Agar, M. (1994). Language shock: Understanding the culture of conversation. New York: William Morrow and Company.

Allen, L. Q. (2000). Culture and the ethnographic interview in foreign language teacher development. Foreign Language Annals, 33(1), 51-57.

Allen, L. Q. (2004). Implementing a culture portfolio project within a constructivist paradigm. Foreign Language Annals, 37(2), 232-239.

Allen, W. W. (1985). Toward cultural proficiency. In A. C. Omaggio (Ed.), Proficiency, Curriculum, Articulation: The Ties That Bind. Reports of the Northeast conference on the Teaching of Foreign Languages. Middlebury, VT: Northeast Conference.

Alptekin, C. (2002). Towards intercultural communicative competence in ELT. ELT Journal, 56(1), 57-64.

Alvarez Valencia, J. A., and Bonilla Medina, X. (2009). Addressing culture in the EFL classroom: A dialogic proposal. Profile, 11(2), 151-170.

Anton, M., Dicamilla, E., and Lantolf, J. (2003). Sociocultural theory and the acquisition of Spanish as a second language. In B. Lafford and R. Salaberry (Eds.), Spanish second language acquisition: The state of the science (pp. 262284). Washington, DC: Georgetown University Press.

Arthur, N., and Collins, S. (2005). Culture-infused counselling: Celebrating the Canadian mosaic. Calgary, AB: Counselling Concepts.

Atkinson, D. (1999). TESOL and Culture. TESOL Quarterly, 33, 625-654.

Aubrey, S. (2009). Creating a Global Cultural Consciousness in a Japanese EFL Classroom. English Language Teaching, 2(2), 119-131.

Baker, W. (2008). A critical examination of ELT in Thailand: The role of cultural awareness. RELC Journal, 39, 131-146.

Baker, W. (2009). Intercultural awareness and intercultural communication through English: An investigation of Thai English language users in higher education Unpublished $\mathrm{PhD}$, University of Southampton. 
Baldonado, A. A., and Holm. (1997). Cultural/ ethnicity issues in the classroom. Hoitotiede, 9(5), 231-236.

Barro, A., Jordan, S., and Roberts, C. (1998). Cultural practice in everyday life: the language learner as ethnographer. In M. Byram and M. Flemming (Eds.), Language Learning in Intercultural Perspective. Cambridge: Cambridge University Press.

Bateman, B. E. (2004). Achieving affective and behavioural outcomes in culture learning: the case for ethnographic interviews. Foreign Language Annals, $37(2), 240-253$.

Bauer, B., deBenedette, L., Furstenberg, G., Levet, S., and Waryn, S. (2006). The Cultura Project. In J. A. Belz and S. L. Thorne (Eds.), Internet-mediated intercultural foreign language education (pp. 31-62). Boston: Heinle.

Bennett, J., Bennett, M., and Allen, W. (2003). Developing intercultural competence in the language classroom. In D. L. Lange and R. M. Paige (Eds.), Culture as the Core: Perspectives in Second Land Learning. USA: Information Age Publishing.

Bennett, J. M., and Bennett, M. J. (2004). Developing intercultural sensitivity: An integrative approach to global and domestic diversity In D. Landis, J. M. Bennett and M. J. Bennett (Eds.), Handbook of intercultural training (pp. 147165). Thousand Oaks, CA: SAGE.

Bennett, M. J. (1993). Towards ethnorelativism: A developmental model of intercultural sensitivity. In R. M. Paige (Ed.), Education for Intercultural Experience (2nd) (pp. 21-72). Yarmouth, ME: Intercultural Press.

Bennett, M. J. (2009). Defining, measuring, and facilitating intercultural learning: a conceptual introduction to the Intercultural Education double supplement. Intercultural Education, 20(4), S1 - S13.

Berg, B. (2009). Qualitative Research Methods for the Social Sciences (7th ed.). Boston: Allyn and Bacon.

Berg, B. L. (2007). Qualitative Research Methods for the Social Sciences (sixth ed.). Boston: Pearson Education, Inc.

Berry, J. W., and Kalin, R. (1995). Multicultural and ethnic attitudes in Canada: An overview of the 1991 national survey. Canadian Journal of Behavioural Science, 27, 301-320. 
Berry, J. W., Kim, U., Power, S., Young, M., and Bujaki, M. (1989). Acculturation attitudes in plural societies. Applied Psychology, 38, 185-206.

Bhabha, H. K. (1992). Post-colonial authority and post-modern guilt. In L. Grossber, P. Nelson and P. Treichler (Eds.), Cultural Studies (pp. 56-66). London: Routledge.

Bhabha, H.K. (1994). The Location of Culture. London, Routledge.

Bhawuk, D. P. S., and Brislin, R. (1992). The measurement of intercultural sensitivity using the concepts of individualism and collectivism. International Journal of Intercultural Relations, 16, 413-436.

Boud, D. (2001). Using journal writing to enhance reflective practice. New Directions for Adult and Continuing Education 90.

Breach, D. (2004). What makes a good teacher? Teacher's Edition, 16, 30-37.

Brislin, R. W. (1990). Applied Cross-Cultural Psychology. London: SAGE.

Brown, A. (1994). The advancement of learning. Educational Researcher, 23(8), 4-12.

Brown, J. D. (2001). Using surveys in language programs. New York: Cambridge University Press.

Byram, M. (1989). Cultural Studies in Foreign Language Education. Philadelphia: Multilingual Matters.

Byram, M. (1991). Teaching culture and language: towards an integrated model. In D. Buttjes and M. Byram (Eds.), Mediating languages and cultures: Towards an intercultural theory of foreign language education (pp. 17-30). Clevedon: Multilingual Matters.

Byram, M., Morgan, C. et al. (1994). Teaching-and-Learning Language-and-Culture. Clevedon: Multilingual Matters.

Byram, M. (1997). Teaching and Assessing Intercultural Communicative Competence. Clevedon: Multilingual Matters.

Byram, M. (2000). Assessing Intercultural Competence in Language Teaching. Sprogforum, 6(18), 8-13.

Byram, M. (2003). On being 'bicultural an intercultural'. In G. Alred, M. Byram and M. Fleming (Eds.), Intercultural experience and education (pp.50-66). Clevedon: Multilingual Matters.

Byram, M. (2006). Language Teaching for Intercultural Citizenship: the European Situation. Paper presented at the NZALT conference, University of Auckland. 
Byram, M., and Feng, A. (2004). Culture and language learning: teaching, research and scholarship. Language Teaching, 37, 149-168.

Byram, M., and Fleming, M. (1998). Language Learning in Intercultural Perspective: Approaches through Drama and Ethnography. Cambridge: Cambridge University Press.

Byram, M., Gribkova, B., and Starkey, H. (2002). Developing the intercultural dimension in language teaching: A practical introduction for teachers. Retrieved from http://www.lrc.cornell.edu/director/intercultural.pdf

Byram, M., and Risager, K. (1999). Language Teachers, Politics and Cultures. Clevedon: Multilingual Matters.

Byram, M., and Zarate, G. (1997). Defining and assessing intercultural competence: Some principles and proposals for the European context. Language Teaching, 29, 239-243.

Cadd, M. (1994). An attempt to reduce ethnocentrism in the foreign language classroom. Foreign Language Annals, 27(2), 143-160.

Canale, M., and Swain, M. (1980). Theoretical bases of communicative approaches to second language teaching and learning. Applied Linguistics, 1(1), 1-47.

Carr, J. (2007). A critical literacy approach to intercultural language teaching and learning. . ILTLP: Self-Access Module 1. Retrieved from http://www.iltlp.unisa.edu.au/doclibmodules/iltlp_module_self_access01.doc

Castro, P., Sercu, L., and Mendez García, M. C. (2004). Integrating language-andculture teaching: an investigation of Spanish teachers' perceptions of the objectives of foreign language education. Intercultural Education, 15(1), 91104.

Celce-Murcia, M. (2007). Toward more context and discourse in grammar instruction. TESL-EJ, 11(2).

Chambers, A. (2004). Changing concepts in culture and language learning. In M. Smith (Ed.), Readings in the Teaching of Culture. Dublin: ITE.

Chavez, M. (2002). We say "Culture" and students ask "What?": University students' definitions of foreign language culture. Teaching German, 35(2), 129-140.

Chomsky, N. (1965). Aspects of the theory of syntax. Cambridge, MA: The MIT Press.

Cohen, L., Manion, L., and Morrison, K. (2007). Research Methods in Education. New York: Routledge. 
Cooper, D. R., and Schindler, P. S. (2001). Business research method. New York: McGraw-Hill.

Coperias Aguilar, M. J. (2009). Intercultural communicative competence in the context of the European higher education area. Language and Intercultural Communication, 9(4), 242-255.

Corbett, J. (2003). An intercultural approach to English language teaching. Clevedon: Multilingual Matters Ltd.

Corbett, J. (2010). Intercultural language activities. Cambridge: Cambridge University Press.

Cortazzi, M., and Jin, L. (1999). Cultural mirrors: Materials and methods in the EFL classroom. In E. Hinkel (Ed.), Culture in Second Language Teaching and Learning (pp. 196-219). Cambridge: Cambridge University Press.

Council of Europe (2001). Common European Framework of Reference for Languages: Learning, Teaching, Assessment, Council of Europe, Modern Languages Division. Strasbourg and Cambridge: Cambridge University Press.

Crawford, L. M., and McLaren, P. (2003). A critical perspective on culture in the second language classroom. In D. L. Lange and R. M. Paige (Eds.), Perspectives on Culture in Second Language Learning (pp. 127-157). Greenwich, Connecticut: Information Age Publishing

Creswell, J. W. (2002). Educational research: Planning, conducting, and evaluating quantitative and qualitative approaches to research. Upper Saddle River, NJ: Merrill/Pearson Education.

Creswell, J. W. (2005). Educational research: Planning, conducting, and evaluating quantitative and qualitative research (2nd ed.). Upper Saddle River, N.J.: Merrill.

Crichton, J., Papademetre, L., and Scarino, A. (2004). Integrated Resources for Intercultural Teaching and Learning in the Context of Internationalisation of Higher Education. Research Centre for Languages and Culture Education in the School of International Studies at the University of South Australia.

Crozet, C., and Liddicoat, A. J. (1999). The challenge of intercultural language teaching: Engaging with culture in the classroom. In J. Lo Bianco, A. J. Liddicoat and C. Crozet (Eds.), Striving for the Third Place: Intercultural Competence through Language Education (pp. 113-123). Melbourne: Language Australia. 
Crozet, C., and Liddicoat, A. J. (2000). Teaching culture as an integrated part of language: implications for the aims, approaches and pedagogies of language teaching. In A. J. Liddicoat and C. Crozet (Eds.), Teaching Languages, Teaching Cultures (pp. 1-18). Melbourne: Applied Linguistics Association of Australia.

Crozet, C., Liddicoat, A. J., and Lo Bianco, J. (1999). Intercultural competence: from language policy to language education. In J. Lo Bianco, A. J. Liddicoat and C. Crozet (Eds.), Striving for the Third Place: Intercultural Competence through Language Education (pp. 1-20). Melbourne: Language Australia.

Culhane, S. (2004). An Intercultural Interaction Model: Acculturation Attitudes in Second Language Acquisition. Electronic Journal of Foreign Language Teaching, 1(1), 50-61.

Cunningham, S., and Moor, P. (2005). New Cutting Edge (Intermediate). Singapore: Longman.

Cushner, K., and Brislin, R. W. (1996). Intercultural Interactions: A Practical Guide. Thousand Oaks: SAGE Publications.

Cushner, K., McClelland, M., and Safford, P. (1996). Human Diversity in Education: An Integrative Approach. New York: McGraw-Hill.

Dahl, O. and Habert, K. (1986). Mote Mellom Kulturer. Oslo.

Davison, T. (2000). Empathy: A paradoxical key to successful human learning futures. Proceedings of the Technological Education and National Development Conference, "Crossroads of the New Millennium" (2 ${ }^{\text {nd }}$, April, 8-10, Abu Dhabi, United Arab Emirates).

De Wever, B., Schellens, T., Valcke, M., and Van Keer, H. (2006). Content analysis schemes to analyze transcripts of online asynchronous discussion groups: A review. Computers and Education, 46, 6-28.

Deardorff, D., and Deardorff, D. (2000). Crossing cultures course material. Unpublished manuscript. Duke University.

Deardorff, D. K. (2004). The identification and assessment of intercultural competence as a student outcome of international education at institutions of higher education in the United States. Unpublished dissertation, North Carolina State University, Raleigh. 
Deardorff, D. K. (2006). Identification and assessment of intercultural competence as a student outcome of internationalization. Journal of Studies in International Education 10(3), 241-266.

Deardorff, D. K. (2008). Intercultural competence: A definition, model and implications for education abroad. In V. Savicki (Ed.), Developing Intercultural Competence and Transformation (pp. 32-52). Sterling, Virginia: Stylus Publishing, LLC.

Diaz-Greenberg, R., and Nevin, A. (2003). Listen to the voices of foreign language student teachers: Implications for foreign language educators. Language and Intercultural Communication, 3(3 ), 213-226.

Dinh, H. V. (2005). Vị trí của văn hóa trong dạy học ngoại ngữ [The place of culture in foreign language teaching and learning]. Ngôn ngũ và Đời sống [Linguistics and Life ], 3(113), 36-42.

Dornyei, Z. (2007). Research Methods in Applied Linguistics. Spain: Oxford University Press.

Doyé, P. (1999). The Intercultural Dimension. Foreign Language Education in the Primary School. Berlin: Cornelsen Verlag.

Elola, I., and Oskoz, A. (2008). Blogging: Fostering intercultural development in foreign language and study abroad contexts. Foreign Language Annals, 41(3), 454-477.

Ezzy, D. (2002). Qualitative Analysis. Malaysia: Allen and Unwin.

Fantini, A. (2000). A central concern: Developing intercultural competence, in SIT Occasional Papers Series. Retrieved from www.sit.edu/publications.

Fantini, A. (2005). Exploring Intercultural Communicative Competence: A Construct, in SIT Occasional Papers Series. Retrieved from www.sit.edu/publications.

Fantini, A. (2006). Exploring and assessing intercultural competence. Retrieved from http://www.sit.edu/publications/docs/feil_research_report.pdf.

Fantini, A. (2009). Assessment of Intercultural Competence Form [A Developmental Educational Tool in a YOGA Format]. Retrieved from www.sit.edu/publications.

Finkbeiner, C. (2007). Criteria-based review of the draft final report on intercultural language learning: Implications for pedagogy. Ministry of Education, New Zealand. 
Finkbeiner, C. (2008). Culture and good language learners. In C. Griffiths (Ed.), Lessons from Good Language Learners (pp. 131-141). Cambridge: Cambridge University Press. .

Finkbeiner, C. (2009). Using 'Human Global Positioning System' as a navigation tool to the hidden dimension of culture In A. Feng, M. Byram and M. Fleming (Eds.), Becoming Interculturally Competent through Education and Training (pp. 151-173). Bristol: Multilingual Matters.

Fleming, M. (2003). Intercultural Experience and Drama. In G. Alred, M. Byram and M. Fleming (Eds.), Intercultural experience and education (pp. 87-100). Clevedon: Multilingual Matters.

Forsman, L. (2010). EFL Education in the New Millennium: Focus on the Promotion of Awareness of Difference and Diversity. Scandinavian Journal of Educational Research, 54(5), 501 - 517.

Foster, P., Tonkyn, A., and Wigglesworth, G. (2000). Measuring spoken language: a unit for all reasons. Applied Linguistics, 21(3), 354-375.

Friedrich, P. (1989). Language, ideology and political economy. American Anthropologist, 91, 295-305.

Furstenberg, G. (2010). Making culture the core of the language class: Can it be done? The Modern Language Journal, 94(2), 329-332.

Gall, M. D., Borg, W. R., and Gall, J. P. (1996). Education research: An introduction ( $6^{\text {th }}$ ed. $)$. New York: Longman.

Gall, J. P., Gall, M. D., and Borg, W. R. (2005). Applying Educational Research: A Practical Guide (5th ed.). Boston: Pearson.

Gee, J. (1990). Social Linguistics and Literacies. Ideology in Discourses. New York: The Falmer Press.

Gee, J. (1999). An Introduction to Discourse Analysis: Theory and Method. London and New York: Routledge.

Geertz, C. (1973). The Interpretation of Cultures. New York: Basic Books.

Geertz, C. (1983). Local Knowledge. New York: Basic Books.

Göbel, K., and Helmke, A. (2010). Intercultural learning in English as foreign language instruction: The importance of teachers' intercultural experience and the usefulness of precise instructional directives. Teaching and Teacher Education, 26, 1571-1582. 
Goetz, J. O., and LeCompte, M. D. (1984). Ethnography and Qualitative Design in Educational Research. New York: Academic Press. .

Gohard-Radenkovic, A., Lussier, D., and Penz, H., and Zarate, G. (2004). Reference fields and methodologies. In G. Zarate, A. Gohard-Radenkovic, D. Lussier and H. Penz (Eds.), Cultural mediation and the teaching and learning of languages (pp. 27-58). Strasbourg Cedex: Council of Europe Publishing.

Government of the Socialist Republic of Vietnam (2008). Quyết định số 1400/QĐTTg của Thủ tướng chính phủ về việc phê duyệt đề án "Dạy và học ngoại ngũu trong hệ thống giáo dục quốc dân giai đoạn 2008-2020"[Resolution 1400/QĐTTg by the Prime Minister on the approval of the project "Teaching and learning foreign languages in the national education system in the period of 2008-2020"]. Retrieved from http://www.chinhphu.vn/portal/page? pageid=578,33345598and_dad=portaland_schema=PORTALanddocid=78437 .

Graddol, D. (2006). English Next. Plymouth: British Council.

Gray, J. (2000). The ELT coursebook as cultural artefact: how teachers censor and adapt. ELT Journal, 54(3), 274-283.

$\mathrm{Gu}$, Q. (2005). Intercultural Experience and Teacher Professional Development. RELC Journal, 36(5), 5-22.

Gunterman, G., Hendrickson, S., and de Urioste, C. (1996). Basic assumptions revisited: Today's French and Spanish students at a large metropolitan university. In J. E and Liskin-Gasparro (Eds.), Patterns and Policies: The Changing Demographics of Foreign Language Instruction (pp. 3-34). Boston: Heinle.

Guo, Y., Arthur, N., and Lund, D. (2009). Intercultural inquiry with pre-service teachers. Intercultural Education, 20(6), 565 - 577.

Hadley, O. A. (2001). Teaching Language in Context (3rd ed.). Boston, MA: Heinle and Heinle.

Hamilton, H., Gurak, E., Findlater, L., and Olive, W. (2003). The confusion matrix. Retrieved from http://www2.cs.uregina.ca/ hamilton/courses/831/notes/ confusion matrix/confusion matrix.html.

Hammer, M. R., Bennett, M. J., and Wiseman, R. (2003). Measuring intercultural sensitivity: The intercultural development inventory. International Journal of Intercultural Relations, 27, 421-443. 
Hanley, J. (1999). Beyond the tip of the iceberg: Five stages toward cultural competence. Reaching today's youth, 3(2), 9-12.

Harlow, L., and Muykens, J. (1994). Priorities for intermediate-level language instruction. Modern Language Journal, 78, 141-154.

Harvey, S., Conway, C., Richards, H. and Roskvist, A. (2010). Evaluation of Teacher Professional Development Languages (TPDL) in Years 7-10 and the Impact on Language Learning Opportunities and Outcomes for Students. A report to the Ministry of Education.

Helm, F. (2009). Language and culture in an online context: what can learner diaries tell us about intercultural competence? Language and Intercultural Communication, 9(2), 91-104.

Henderson, S. (2004). Strengthening cultural awareness in the classroom: A case in point. In Seeking Educational Excellence. Proceedings of the 13th Annual Teaching Learning Forum, 9-10 February 2004. Perth: Murdoch University. Retrieved from http://lsn.curtin.edu.au/tlf/tlf2004/henderson.html.

Hew, K. F., and Cheung, W. S. (2003). Models to evaluate online learning communities of asynchronous discussion forums. Australian Journal of Educational Technology, 19(2), 241-259.

Heyl, B. S. (2001). Ethnographic interviews. In P. Atkinson, A. Coffey, S. Delamont, J. Lofland, and L. Lofland (Eds), Handbook of ethnography (pp. 369-383). London: Sage.

Hiller, G. G. (2010). Innovative methods for promoting and assessing intercultural competence in higher education. Paper presented at the Proceedings of Intercultural Competence Conference.

Hofstede, G. (1997). Cultures and Organisations: Software of the Mind. Intercultural Cooperation and its Importance for Survival. New York: McGraw-Hill. .

Hofstede, G., and Hofstede, G. J. (2005). Cultures and organizations: software of the mind. New York: McGraw-Hill Professional.

Holliday, A. (1999). 'Small cultures'. Applied Linguistics, 20(2), 237-264.

Hongladarom, S. (1998). Asian philosophy and critical thinking: divergence or convergence? Paper presented at the Second AAPEND conference.

Ho, S.T.K. (2011). An intercultural perspective on teaching and learning in the Vietnamese EFL classroom. University of Sydney Papers in TESOL, 6, 43-69. 
House, J. (2007). What is an 'Intercultural Speaker'? In E. Alco and M. P. Safont (Eds.), Intercultural language use and language learning (pp. 7-21). Dordrecht, the Netherlands: Springer.

Hsieh, H.F., and Shannon, S. (2007). Three approaches to qualitative content analysis. In A. Bryman (Ed.), Qualitative Research 2. London: SAGE Publications.

Hu, W. Z., and Gao, Y. H. (1997). Waiyu Jiaoxиe yи Wenhua [Foreign Language Teaching and Culture]. Changsha: Hunan Education Press.

Imahori, T. T., and Lanigan, M. L. (1989). Relational model of intercultural communication competence. International Journal of Intercultural Relations, 26(5), 473-491.

Ingram, D., and O'Neil, S. (2001). The enigma of cross-cultural attitudes in language teaching - Part 1. Babel, 36(2), 12-38.

Itakura, H. (2004). Changing cultural stereotypes through e-mail assisted foreign language learning. System, 32, 37-51.

Jacobson, W., Schleicher, D., and Maureen, B. (1999). Portfolio assessment of intercultural competence. International Journal of Intercultural Relations, 23(3), 467-492.

Johnson, B. R. (1997). Examining the validity structure of qualitative research. Education, 118(3), 282-292.

Jon, J-E. (2009). 'Interculturality' in higher education as student intercultural learning and development: a case study in South Korea. Intercultural Education, 20(5), 439-449.

Jones, B. (1995). Exploring otherness - An approach to cultural awareness. London: CILT.

Jones, L. (2002). Let's Talk. Cambridge: Cambridge University Press.

Kaikkonen, P. (1997). Learning a culture and a foreign language at school -aspects of intercultural learning. Language Learning Journal, 15, 47-51.

Kaikkonen, P. (2001). Intercultural learning through foreign language education. In V. Kohonen, R. Jaatinen, P. Kaikkonen and J. Lehtovaara (Eds.), Experiential Learning in Foreign Language Education (pp.61-105). Malaysia: Pearson Education.

Kelley, C., and Meyers, J. (1995). The Cross-Cultural Adaptability Inventory. Minneapolis, MN: National Computer Systems.

Kim, Y. Y. (2001). Becoming Intercultural. London: SAGE. 
Kim, Y. Y. (2009). The identity factor in intercultural competence. In D. K. Deardorff (Ed.), The SAGE Handbook of Intercultural Competence. Thousand Oaks, CA: SAGE.

Kim, M.S. (2010). Intercultural communication in Asia: current state and future prospects. Asian Journal of Communication, 20(2), 166-180.

Kim, Y. Y., and Gudykunst, W. B. (1999). Teaching intercultural communication. In A. L. Vangelisti, J. A. Daly and G. W. Friedrich (Eds.), Teaching communication: Theory, research, and methods (pp. 171-180). Mahwah, New Jersey: Lawrence Erlbaum Associates.

Klein, F. M.-V. (2004). Culture in the foreign language classroom: Teachers' beliefs, opportunities and practice. Unpublished $\mathrm{PhD}$ Thesis, University of Minnesota.

Koester, J., and Olebe, M. (1988). The behavioural assessment scale for intercultural communication effectiveness. International Journal of Intercultural Relations, 12, 233-246.

Kohonen, V. (2000). Student reflection in portfolio assessment: Making language learning more visible. Babylonia, 1, 13-16.

Kramsch, C. (1991). Culture in language learning: A view from the United States. In K. DeBot, K. R. Ginsberg and C. Kramsch (Eds.), Foreign Language Research in Cross-Cultural Perspective (pp. 177-180). Amsterdam, the Netherlands: John Benjamins Publishing Company.

Kramsch, C. (1993). Context and Culture in Language Teaching. Oxford: Oxford University Press.

Kramsch, C. (1995). The cultural component of language teaching. Language, Culture and Curriculum, 8(2), 83-92.

Kramsch, C. (1998). Language and Culture. Oxford: Oxford University Press.

Kramsch, C. (2003). The privilege of the non-native speaker. In C. Blythe (Ed.), The Sociolinguistics of Foreign-Language Classroom: Contributions of the Native, the Near-Native and the Non-Native speaker (pp. 251-262). Boston: Heinle.

Kramsch, C. (2004). The language teacher as go-between. Utbildning and Demokrati, 13(3), 37-60.

Kramsch, C. (2006). Culture in language teaching. In H. L. Anderson, K. Land and K. Risager (Eds.), Culture in Language Learning (pp. 11-25). Denmark: Aarhus University Press. 
Kramsch, C., and Sullivan, P. (1996). Appropriate pedagogy. ELT Journal, 50(3), 199-212.

Krippendorff, K. (1980). Content Analysis. An Introduction to its Methodology. London: Sage Publications Ltd.

Krippendorff, K. (2004). Content Analysis: An Introduction to Its Methodology (2nd ed.). Thousand Oaks, CA: SAGE Publications.

Kroeber, A. L. and Kluckhohn, C. (1952). Culture: A Critical Review of Concepts and Definitions. Cambridge, MA: Peabody Museum.

Kroll, B. (1977). Combining ideas in written and spoken English: a look at subordination and coordination. In E. Oschs and T. Bennett (Eds.), Discourse across Time and Space. SCOPIL (Southern California Occasional Papers in Linguistics).

Kumaravadivelu, B. (2008). Cultural globalization and language education. New Haven, CT: Yale University Press.

Kvale, S. (1996). Interviews: An Introduction to Qualitative Research Interviewing. London: Sage Publications.

Labov, W. (1972). Sociolinguistic patterns. Philadelphia, PA: University of Pennsylvania Press.

Lange, D. L. (1998). The Teaching of Culture in Foreign Language Courses. Centre for International Education. International Research and Studies Program. US Department of Education.

Lange, D. L., and Paige, M. (2003). Introduction. In R. M. Paige and D. L. Lange (Eds.), Culture as the core: Perspectives on culture in second language learning (pp. ix-xvii). Greenwich: Connecticut: Information Age Publishing.

Larzén, E. (2005). In Pursuit of an Intercultural Dimension in EFL-teaching : Exploring Cognitions among Finland-Swedish Comprehensive School Teachers. Åbo: Åbo Akademi University Press.

Larzén-Östermark, E. (2009). Language teacher education in Finland and the cultural dimension of foreign language teaching - a student teacher perspective. European Journal of Teacher Education, 32(4), 401-421.

LeCompte, M., and Goetz, J. (1982). Problems of reliability and validity in ethnographic research. Review of Educational Research, 52(1), pp.30-60. 
Lessard-Clouston, M. (1997). Towards an understanding of culture in L2/FL education. The Internet TESL Journal, III(5). Retrieved from http://iteslj.org/Articles/Lessard-Clouston-Culture.html

Liaw, M. (2006). E-learning and the development of intercultural competence. Language Learning and Technology, 10(3), 49-64.

Liddicoat, A. J. (2002). Static and dynamic views of culture and intercultural language acquisition. Babel, 36(3), 4-11, 37.

Liddicoat, A. J. (2004). Intercultural language teaching: Principles for practice. The New Zealand Language Teacher, 30, 17-23.

Liddicoat, A. J. (2006). Intercultural language teaching: Paper presented at the ILTLP, Adelaide. 29-30 August.

Liddicoat, A. J. (2008). Pedagogical practice for integrating the intercultural in language teaching and learning. Japanese Studies, 28(3), 277-290.

Liddicoat, A. J., Papademetre, L., Scarino, A., and Kohler, M. (2003). Report on Intercultural Language Learning. Canberra, ACT: Commonwealth of Australia.

Littlewood, W. (2001). Students' attitudes to classroom English learning: A crosscultural study. Language Teaching Research, 5(1), 3-28.

Lofland, J., and Lofland, L. H. (1995). Analyzing Social Settings: A Guide to Qualitative Observations and Analysis. Belmont, CA: Wadsworth.

Mackey, A., and Gass, S. M. (2005). Second Language Research: Methodology and Design. New Jersey: Laurence Erlbaum Associates.

Marques, J. F., and McCall, C. (2005). The application of interrater reliability as a solidification instrument in a phenomenological study. The Qualitative Report, $10(3), 439-462$.

McDonough, J., and McDonough, S. (1997). Research Methods for English Language Teachers. India: Arnold.

Miller, J. (2009). Beyond Competence: Processes and Strategies for Effective Intercultural Communication. Proceedings of the Digital Stream Conference. California State University, Monterey Bay. ISSN 1946-1526.

Mitchell, R., and Myles, F. (2004). Second Language Learning Theories (2nd ed.). London: Arnold.

Ministry of Education. (2007). The New Zealand Curriculum. Wellington: Learning Media. 
Ministry of Education and Training (2004). Quyết định số 36/2004/QD-BGDandDT về việc ban hành bộ chưong trình khung giáo dục đại học khối ngành tiếng Anh trình độ đại hoc [Resolution 36/2004/QD-BGDandDT on the approval of the Higher Education National Curriculum Frameworks of English]. Hanoi: MOET.

Moon, J. (1999). Reflection in Learning and Professional Development. London: Kogan Page.

Neuendorf, K. A. (2002). The Content Analysis Guidebook. Thousand Oaks, CA: Sage Publications.

Neuliep, J. W., and McCroskey, J. C. (1997). The development of a US and generalized ethnocentrism scale. Communication Research Reports, 14, 385398.

Newton, J., Yates, E., Shearn, S. and Nowitzki, W. (2010). Intercultural Communicative Language Teaching: Implications for Effective Teaching and Learning. Report to the Ministry of Education.

Newton, J., and Shearn, S. (2010a). Intercultural language learning and teaching: A literature review. In J. Newton, E. Yates, S. Shearn and W. Nowitzki (Eds.), Intercultural Communicative Language Teaching: Implications for Effective Teaching and Learning (pp. 3-51). Report to the Ministry of Education.

Newton, J., and Shearn, S. (2010b). An Evidence-based framework of principles for effective intercultural teaching and learning. In J. Newton, E. Yates, S. Shearn and W. Nowitzki (Eds.), Intercultural Communicative Language Teaching: Implications for Effective Teaching and Learning (pp. 53-76). Report to the Ministry of Education.

Nguyen, T. H. A. (2002). Cultural effects on learning and teaching English in Vietnam. The Language Teacher, 26(1), 6-10.

Nguyen, T. M. P., and Le, T. G. C. (2007). Speaking 3. Danang: Department of English, College of Foreign Languages, the University of Danang.

Standards for Foreign Language Learning: Preparing for the 21st Century. (1996). Yonkers, NY: National Standards in Foreign Language Education Project.

Nunan, D. (1989). Designing Tasks for the Communicative Classroom. Cambridge: Cambridge University Press. .

Nunan, D. (1992). Research methods in language learning. New York Cambridge University Press. 
O'Dowd, R. (2003). Understanding the "other side": Intercultural learning in a Spanish-English e-mail exchange. Language Learning and Technology, 7(2), 118-144.

Ogbu, J. U. (1988). Cultural diversity and human development. In D. T. Slaughter (Ed.), Black children and poverty: A developmental perspective (pp. 11-28). San Francisco: Jossey Bass.

Paige, R. M. (2004). The intercultural in teaching and learning: a developmental perspective. In J. Crichton, M. Paige, L. Papademetre and A. Scarino (Eds.), Integrated Resources for Intercultural Teaching and Learning in the Context of Internationalisation in Higher Education. Research Centre for Languages and Culture Education in the School of International Studies at the University of South Australia.

Paige, R. M., Jorstad, H. L., Siaya, L., Klein, F., and Colby, J. (2003). Culture learning in language education: A review of the literature. In D. L. Lange and R. M. Paige (Eds.), Culture as the Core: Perspectives on Culture in Second Language Learning (pp. 173-236). USA: Information Age Publishing.

Papademetre, L., and Scarino, A. (2006). Teaching and learning for intercultural communication: A multi-perspective conceptual and applied journey for teachers of world culture languages (2nd ed.). Adelaide: UniSA.

Peltokorpi, V., and Schneider, S. C. (2009). Communicating across cultures: The interaction of cultural and language proficiency. Paper presented at the International Workshop on Intercultural Collaboration 2009, Palo Alto, California, USA.

Peterson, R. (1994). A meta-analysis of Cronbach's Coefficient Alpha. Journal of Consumer Research, 21(2), 38-91.

Pham, D. B. (2001). Vai trò của nhân tố văn hóa trong quá trình giao tiếp bằng tiếng nước ngoài [The role of the cultural factor in communication by a foreign language]. Ngôn Ngũu [Linguistics], 4, 70-76.

Pham, H. H. (2005). Readers respond: University English classrooms in Vietnam. ELT Journal, 59(4), 336-338.

Phan, L. H. (2004). University classrooms in Vietnam: contesting the stereotypes. ELT Journal, 58(1), 50-57.

Phan, L.H. (2008). Teaching English as an International Language: Identity, Resistance and Negotiation. Clevedon: Multilingual Matters Ltd. 
Phillips, J. K. (2003). National standards for foreign language learning. In D. L. Lange and R. M. Paige (Eds.), Culture as the core: Perspectives on culture in second language learning (pp. 161-171). Greenwich, Connecticut: Information Age Publishing.

Prabhu, N. S. (1990). There is no best method-why? TESOL Quarterly, 24(2), 161176.

Prosser, M., and Trigwell, K. (1999). Understanding learning and teaching. Buckingham: SRHE and Open University Press.

Putnam, L. L., and Conrad, C. R. (1999). Teaching organizational communication. In A. L. Vangelisti, J. A. Daly and G. W. Friedrich (Eds.), Teaching communication: Theory, research, and methods (2nd ed., pp. 141-156). Mahwah, New Jersey: Lawrence Erlbaum Associates, Publishers.

Rantz, F., and Horan, P. (2005). Exploring intercultural awareness in the primary modern language classroom: The potential of the new model of European Language Portfolio developed by the Irish Modern Languages in Primary Schools Initiative (MLPSI). Language and Intercultural Communication, 5(3and4), 209-221.

Richards, J. C., Platt, J., and Platt, H. (1992). Longman dictionary of language teaching and applied linguistics (2nd ed.). Malaysia: Longman.

Risager, K. (1996). Sprog, kultur og internationalisering i sprogundervisningen, "Sprog, kultur, intersprog". ROLIG Papir.

Risager, K. (1998). Language teaching and the process of European integration. In M. B. M. Fleming (Ed.), Language Learning in Intercultural Perspective. Approaches Through Drama and Ethnography. Cambridge: Cambridge University Press.

Risager, K. (2005). Languaculture as a key concept in language and culture teaching. In A. Preisler, H. Haberland, S. Kjaerbeck and K. Risager (Ed.), The Consequences of Mobility (pp. 185-196). Roskilde: Roskilde University.

Risager, K. (2007). Language and Culture Pedagogy. Clevedon: Multilingual Matters. Rourke, L., Anderson, T., Garrison, D. R., and Archer, W. (1999). Assessing social presence in asynchronous text-based computer conferencing. Journal of Distance Education, 14(2). Retrieved from http://cade.icaap.org'/vo114.2/rourke.eral.html 
Ryan, P. M. (1995). Foreign Language Teachers' Perceptions of Culture and the Classroom: A Case Study. Reports-Research/Technical.

Saville-Troike, M. (1989). The Ethnography of Communication. Oxford: Blackwell.

Scarino, A. (2009). Assessing intercultural capacity in learning languages: Some issues and considerations. Language Teaching, 42(1), 67-80.

Scarino, A. (2010). Assessing intercultural capacity in learning languages: A renewed understanding of language, culture, learning and the nature of assessment. The Modern Language Journal, 94(ii), 324-329.

Scarino, A., and Crichton, J. (2007). Why the intercultural matters to language teaching and learning: an orientation to the ILTLP programme Intercultural Language Teaching and Learning in Practice: Professional Learning Programme Resource for Participants (ILTLP). Research Centre for Languages and Cultures Education (RCLCE), University of South Australia: Commonwealth of Australia.

Schulz, R. A. (2007). The challenge of assessing cultural understanding in the context of foreign language instruction. Foreign Language Annals, 40(1), 9-26.

Sercu, L. (2001). La dimension interculturelle dans la vision pédagogique en langue éntrangère. Analyse comparative des conceptions professionnelles des enseignants d'anglais, de français et d'allemand. In G. Zarate (Ed.), Langues, Xénophobie, Xénophilie dans une Europe Multiculturelle (pp. 169-180): CRDP de Basse-Normandie.

Sercu, L. (2002). Autonomous learning and the acquisition of intercultural communicative competence: Some implications for course development. Language, Culture and Curriculum, 15(1), 61-74.

Sercu, L. (2005). The future of intercultural competence in foreign language education: Recommendations for professional development, educational policy and research. In L. Sercu (Ed.), Foreign Language Teachers and Intercultural Competence: An international Investigation (pp. 160-181). Clevedon: Multilingual Matters.

Sercu, L., Bandura, E., Castro, P., Davcheva, L., Laskaridou, C., Lundgren, U., et al. (2005). Foreign Language Teachers and Intercultural Competence: An International Investigation. Clevedon: Multilingual Matters. 
Sercu, L., Méndez García, M., and Castro, P. (2005). Culture learning from a constructivist perspective. An investigation of Spanish foreign language teachers' views. Language and Education, 19(6), 483-495.

Shaules, J. (2007). Deep Culture: The Hidden Challenges of Global Living. Clevedon: Multilingual Matters Ltd.

Sinicrope, C., Norris, J., and Watanabe, Y. (2007). Understanding and assessing intercultural competence: a summary of theory, research, and practice (technical report for the foreign language program evaluation project). Second Language Studies, 26(1), pp. 1-58.

Skopinskaja, L. (2003). The role of culture in foreign language teaching materials: An evaluation from an intercultural perspective. In I. Lázár (Ed.), Incorporating Intercultural Communicative Competence in Language Teacher Education (pp. 39-68). European Centre for Modern Languages: Council of Europe Publishing.

Skopinskaja, L. (2009). Assessing intercultural communicative competence: test construction issues. Synergies Pays Riverains de la Baltique, 6, 135-144.

Slater, S. (1995). Issues in conducting marketing strategy research. Journal of Strategic Marketing, 3(4), 257-270.

Sowden, C. (2007). Culture and the 'good teacher' in the English Language classroom. ELT Journal, 61(4), 304-310.

Sparrow, L. M. (2000). Beyond multicultural man: Complexities of identity. International Journal of Intercultural Relations, 24(2), 173-201.

Stake, R. (2005). Qualitative case studies. In N. K. Denzin and Y. S. Lincoln (Eds.), The Sage handbook of qualitative research (3rd ed.). Thousand Oaks, CA: Sage.

Stevens, D. (2003). English for the English: An intercultural approach. In G. Alred, M. Byram and M. Fleming (Eds.), Intercultural experience and education (pp. 179-195). Clevedon: Multilingual Matters.

Stewart, D. W., and Shamdasani, P. N. (1990). Focus Groups: Theory and Practice. Newbury Park, California: Sage Publications.

Straffon, D. A. (2003). Assessing the intercultural sensitivity of high student students attending an intercultural school. International Journal of Intercultural Relations, 27, 487-501. 
Straub, J. (2007). Kompetenz. In J. Straub, A. Weidemann and D. Weidemann (Eds.), Handbuch interkulturelle Kommunikation und Kompetenz. Stuttgart, Germany: Metzler.

Tang, Y. (2006). Beyond behaviours: goals of cultural learning in the second language classroom. The Modern Language Journal, 90(i), 86-99.

Taylor, E. W. (1994). Intercultural competency: A transformative learning process. Adult Education Quarterly, 44(3), 154-174.

Ting-Toomey, S. (1999). Communication Across Cultures. New York: The Guilford Press.

Tomalin, B., and Stempleski, S. (1993). Cultural Awareness. Hong Kong: Oxford University Press.

Tomlinson, B. (2001). The inner voice: A critical factor in language learning. Journal of the Imagination in L2 Learning, 6, 26-33. Retrieved from http://www.njcu.edu/cill/vol6/tomlinson.html.

Tomlinson, B., and Masuhara, H. (2004). Developing cultural awareness. MET, 13(1), $1-7$.

Tornberg, U. (2000). Om språkundervisning i mellanrummet - och talet om 'kultur' och 'kommunikation' i kursplaner och läromedel från 1962 till 2000 [On foreign language teaching and learning in a discursive space - and conceptions of 'culture' and 'communication' in curricular texts and teaching materials from 1962 to 2000]. Acta Universitatis Upsaliensis.

Tornberg, U. (2004). The multicultural foreign language classroom: An arena for democratic experiences. Utbildning and Demokrati, 13(3), 5-9.

Trompenaars, F., and Hampden-Turner, C. (1998). Riding the waves of culture. New York,: McGraw-Hill.

Tseng, Y. (2002). A lesson in culture. ELT Journal, 56(1), 11-21.

Tsou, W. (2005). The effects of cultural instruction on foreign language learning. RELC Journal, 36(1), 39-57.

Tsui, A. B. M. (2003). Understanding Expertise in Teaching. Cambridge: Cambridge University Press.

University of South Australia. (2007). Intercultural Language Teaching and Learning Project. Retrieved from http://www.iltlp.unisa.edu.au/.

van Ek, J. A. (1986). Objectives for foreign language learning. Strasbourg: Council of Europe. 
Vogt, K. (2006). Can you measure attitudinal factors in intercultural communication? Tracing the development of attitudes in e-mail projects. ReCALL, 18(2), 153173.

Wang, L. and Coleman, J. (2009). A survey of Internet-mediated intercultural foreign language education in China. ReCALL, 21(1), 113-129.

Weaver, G. (1993). Understanding and coping with cross-cultural adjustment stress. In R. M. Paige (Ed.), Education for the Intercultural Experience (pp. 137-168). Yarmouth, Maine: Intercultural Press.

Weber, R. P. (1990). Basic Content Analysis. Newbury Park, CA: Sage Publications.

Williams, T. R. (2005). Exploring the impact of study abroad on students' intercultural communication skills: Adaptability and sensitivity. Journal of Studies in International Education, 9(4), 356-371.

Williams, M., and Burden, R. L. (1997). Psychology for Language Teachers: A Social Constructivist Approach. Cambridge: Cambridge University Press.

Wiseman, R. (2002). Intercultural communication competence In W. Gudykunst and B. Mody (Eds.), Handbook of international and intercultural communication (pp. 207-224). Thousand Oaks: Sage Publications Ltd.

Wolf, W., and Riordan, K. (1991). Foreign language teachers' demographic characteristics, in-service training needs, and attitudes towards teaching. Foreign Language Annals, 24, 471-478.

Wood, D. (1996). Teacher Cognition in Language Teaching. Cambridge: Cambridge University Press.

Wright, D. A. (2000). Culture as information and culture as affective process: a comparative study. Foreign Language Annals, 33, 330-341.

Yu, W. and Chang, X-M. (2009). An investigation into learners' intercultural communicative competence, US-China Foreign Language, 7(8), 22-27.

Zhang, F., and You, H. (2009). Motives of indirectness in daily communication - An Asian perspective. Asian Culture and History, 1(2), 99-102.

Zhu, H. (2010). College English Teaching Viewed from the Perspective of Intercultural Communication. English Language Teaching, 3(3), 107-110. 


\section{APPENDICES}

All appendices are enclosed in a CD attached to this thesis. 